UNIVERSIDAD NACIONAL DE LA PLATA

FACULTAD DE HUMANIDADES Y CIENCIAS DE LA EDUCACIÓN

SECRETARÍA DE POSGRADO

\title{
INVERSIONES HIDROELÉCTRICAS DEL DESARROLLO E IMPACTOS SOCIO-TERRITORIALES
}

\author{
Historia y memorias del caso \\ de la Presa Potrerillos de Mendoza
}

\author{
Mariana Raffani
}

Tesis para optar por el grado de Magíster en Historia y Memoria

Director/a: Dra. Mercedes Lentini, Universidad Nacional de Cuyo.

Co/director/a: Dra. María Rosa Catullo, Universidad Nacional de La Plata.

La Plata, 31 de marzo de 2016 
A Marta y Tito, mi mamá y mi papá, por estar siempre.

\begin{abstract}
A Berta Cáceres.
Ambientalista indígena hondureña, asesinada el 3 de marzo de 2016 por su lucha contra la represa de Agua Zanca y defensa de la naturaleza.
\end{abstract}

\title{
Agradecimientos
}

A las Dra. Mercedes Lentini y Dra. María Rosa Catullo, por su dedicación, motivación y generosidad durante la investigación; a los pobladores de Cacheuta y Potrerillos, y funcionarios del IPV, Municipalidad de Luján de Cuyo y de la DOADU entrevistados, por su amabilidad al destinar parte de su tiempo en conversar conmigo y aportar su experiencia. A la ayuda económica de CONICET y a mis amigas Jenny Duque, que me ayudó a esbozar en sus comienzos el proyecto y Lorena Scala, que me acompañó en varios momentos a realizar el trabajo de campo. 


\section{RESUMEN}

En el contexto de la globalización, a causa del cumplimiento de políticas nacionales o internacionales de desarrollo, millones de personas en todo el planeta son desplazadas y relocalizadas, siendo este fenómeno más frecuente en los denominados países del "Tercer Mundo". Este constituye el tema de la presenta investigación. El propósito del trabajo es contribuir, a partir del estudio de un caso, a la reflexión sobre los efectos de tales políticas que se emplazan en lugares concretos habitados generando efectos multidimensionales para las poblaciones afectadas.

Como objetivo general se plantea reconstruir el proceso de ordenamiento territorial que en nombre del desarrollo se realiza vinculado a la Presa Potrerillos desde 1998 en los lugares de Cacheuta y Potrerillos, y sus efectos sobre la situación habitacional, la economía de subsistencia y las redes de integración socio-comunitarias, así como sobre lugares de memoria de los pobladores, sin dejar de considerar las estrategias adaptativas y/o de resistencia de los mismos al nuevo ambiente físico y social, así como el contexto en que se evocan las memorias.

En este sentido, se plantean como objetivos específicos: 1) Ahondar en los fundamentos del desarrollo planteado en el proyecto de la Presa Potrerillos, así como en el orden territorial planificado en torno al perilago; 2) Recrear el proceso de desalojo y relocalización de la población, e indagar en las implicancias habitacionales y sobre la tenencia de la tierra para la población no relocalizada; 3) Indagar en los efectos y estrategias adaptativas en relación a las actividades económicas de subsistencia; en las redes de integración socio-comunitarias de los pobladores -por ellas entendemos las redes de relaciones de vecindad, parentesco, amistad, relaciones laborales y organizaciones sociales (formales e informales)-; así como sobre los espacios públicos comunes, dentro de los que se incluyen los lugares de memoria; 4) Analizar el contexto de evocación de las memorias, en relación al desarrollo socio-territorial de las localidades y su integración al desarrollo local mayor.

Si bien son numerosos los actores colectivos involucrados en estos procesos de carácter político, se pone énfasis, por un lado, en la población afectada relocalizada y no relocalizada; y por otro lado, en el actor responsable del proyecto que en nuestro caso es el gobierno provincial, específicamente el sector vinculado al reordenamiento territorial del perilago y al proceso de desalojo y relocalización.

Se postula como hipótesis que los proyectos de inversión y desarrollo, en el marco de la globalización neoliberal son productores de desplazamiento de poblaciones, y como producciones sectoriales, generan ordenamientos socio-territoriales no democráticos y excluyentes para algunos sectores. En el caso de estudio, el desarrollo promovido por el Estado provincial para el área circundante a la obra, a partir de la definición de los usos del suelo, propicia la concentración económica y genera desalojos y relocalizaciones, así como la desatención de los sectores afectados.

El diseño metodológico adoptado, para dar alcance a los objetivos de investigación, se enmarca en el paradigma dialógico e interpretativo dada la pretensión de captar las perspectivas y significaciones de los sujetos involucrados en el caso de estudio. Considerando que se trata de la reconstrucción de un proceso que tuvo inicio hace más de 10 años, se apela a las memorias de los actores del proceso, como a documentos oficiales y periodísticos para la elaboración del conocimiento histórico y social del mismo, en tanto pasado reciente y proceso no concluido al momento de esta investigación.

Palabras claves: proyectos de inversión y desarrollo, lugar, población afectada, efectos multidimensionales, memorias. 


\section{INDICE}

INTRODUCCIÓN

CAPITULO I

CONTENIDOS TEÓRICOS

1. Acerca del desarrollo, el lugar y los registros del pasado 11

1.1"El" desarrollo y "la" historia en América Latina 11

$1.2 \mathrm{El}$ "lugar" como espacio inventado, aportes conceptuales para su abordaje 13

2. Desalojos y relocalización a causa del desarrollo 15

2.1 Los proyectos de inversión y desarrollo: las presas hidroeléctricas $\quad 15$

2.2La relocalización de población $\quad 18$

2.2.1 Proceso de actores y efectos colectivos 18

$\begin{array}{lll}2.2 .1 & \text { Los contenidos y costos sociales } & 21\end{array}$

2.3Los desalojos en los principios y directrices internacionales 23

2.2.2 En nombre del "bien común" 23

2.2.3 Antes y durante los desalojos del desarrollo: los ideales $\quad 25$

$\begin{array}{ll}2.2 .4 & \text { Las mínimas reconocidas }\end{array}$

CAPITULO II

ASPECTOS METODOLÓGICOS

CAPITULO III

CACHEUTA Y POTRERILLOS

$\begin{array}{ll}\text { 1. Ubicación geográfica } & 32\end{array}$

2. Un poco de historia $\quad 33$

2.1En la Mendoza del siglo XIX $\quad 33$

2.1.1 La conquista de las aguas termales de Cacheuta 33

2.1.2 Intercambios mercantiles y la participación de "Potrerillos" 34

2.2El siglo XX en Los Andes mendocinos $\quad 36$

2.2.1El Trasandino y los comienzos del turismo de montaña 37

2.2.2El aluvión de 1934: rupturas y reacomodos 39

2.2.3Nuevos impulsos: carreteras e integración cordillerana $\quad 41$

2.2.4 Potrerillos, a partir de los 40' y hasta la llegada de la presa 43

2.2.5 La necesidad de embalsar el agua del Río Mendoza 46

CAPITULO IV

EN EL CONTEXTO DE LOS AÑOS $90 \quad 49$

1. La reconfiguración neoliberal del orden mundial 49

$\begin{array}{ll}1.1 \mathrm{En} \text { torno a las ciudades latinoamericanas } & 50\end{array}$

2. En Argentina y Mendoza $\quad 52$

2.1 Y ¿Qué fue de las aguas del Río Mendoza? $\quad 57$

CAPITULO V

EL PROYECTO DE LA PRESA POTRERILLOS Y EL LUGAR PLANEADO Y AFECTADO

EN TORNO AL PERILAGO

1. Los fundamentos de la obra $\quad 61$

2. El ordenamiento del perilago $\quad 63$

3. El lugar afectado por el llenado del embalse 68

4. Los promotores del "futuro" y hacedores de "la historia" 69

\section{CAPITULO VI}

LOS EFECTOS EN POTRERILLOS Y SUS POBLADORES

$\begin{array}{ll}\text { 1. Sobre la tierra y la vivienda } & 73\end{array}$

$\begin{array}{ll}1.1 \text { El proceso de desalojo y relocalización } & 73\end{array}$ 
$\begin{array}{lll}\text { 1.1.1 } & \text { Antes del traslado } & 73\end{array}$

$\begin{array}{ll}\text { 1.1.1.1 Datos y promesas oficiales } & 73\end{array}$

1.1.1.2 Del primer contacto entre funcionaros y pobladores: dudas, propuestas y temores 76

1.1.1.3 Los estudios definitorios y la solución habitacional 78

1.1.1.3.1 La gestión de las viviendas y la metodología de compensación económica 78

1.1.1.3.2 Las familias afectadas

1.1.1.3.3 “con un mínimo de participación” en "un fenómeno "externo” y "ajeno" 84

1.1.1.3.4 El emprendimiento habitacional 86

1.1.1.4 Demoras e ¿imprevistos? Los efectos de la crisis del 200191

1.1.1.5 El antes del traslado desde la memoria de los pobladores 93

1.1.1.6 Cuando llegó la noticia "no se la creía", "pero ya estaba firmado" 93

1.1.1.7 "Empezaron a avanzar" y "sistemáticamente nos fueron separando" 94

1.1.1.8 "todos queríamos cosas distintas". Acuerdos y desacuerdos 96

$\begin{array}{ll}\text { 1.1.1.8.1 Los terrenos y el tipo de viviendas } & 97\end{array}$

1.1.1.8.2 El reconocimiento económico y social 99

1.1.2 El momento bisagra: "sí o sí te cambiás y listo" 101

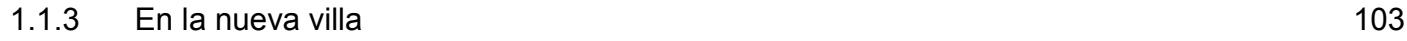

$\begin{array}{ll}\text { 1.1.3.1 Las casas nuevas desde adentro } & 104\end{array}$

1.1.3.1.1 "Nos quedamos todos con deuda". El costo de la urbanización 104

$\begin{array}{ll}\text { 1.1.3.1.2 Los espacios de la cotidianidad } & 106\end{array}$

$\begin{array}{lll}\text { 1.1.3.1.3 Se sintió la muerte } & 108\end{array}$

1.1.3.2 Quienes eligieron irse de Potrerillos 111

1.1.3.2.1 Como alternativa a la relocalización 111

1.1.3.2.2 La emigración de pobladores después de relocalizados 113

\begin{tabular}{ll}
1.2 & De Avenida Los Cóndores: de colonos a propietarios \\
\hline
\end{tabular}

2. Sobre las economías de subsistencia 117

2.1 "estábamos fuera del circuito" 117

2.2 "muchos cambiaron sus oficios" 119

$\begin{array}{ll}2.3 \text { "Queremos una participación activa" } & 124\end{array}$

2.4 "Detrás del perilago" 129

2.5 "fue un proyecto que quedó truncado". Por los funcionarios 132

3. Sobre los espacios colectivos de integración 136

CAPITULO VII

LOS EFECTOS EN CACHEUTA Y SUS POBLADORES 139

1. Sobre el lugar de antes: “era más tranquilo (...) había turismo de paso” 139

2. El impacto del corte y desvío de la ruta 7

2.1 "estamos marginados" y "esperando desde hace años" 142

$\begin{array}{lr}2.2 \text { Promesas } & 144\end{array}$

3. El crecimiento de la población y la ocupación del territorio 145

3.1 Alrededor de los rieles: tierra, techo y trabajo 145

$\begin{array}{ll}3.2 \text { Sobre los espacios públicos de la localidad } & 148\end{array}$

$\begin{array}{lr}3.2 .1 \mathrm{La} \text { in-comunicación } & 148\end{array}$

3.2.2 La escuela y el cementerio: ex - espacios públicos $\quad 148$

3.2.3 Por acción de los vecinos: la posta de salud, la plaza y el playón 150

$\begin{array}{ll}3.2 .4 \text { Inexistentes } & 152\end{array}$

3.3 "Cacheuta prácticamente ha tenido todo el impacto negativo" 153

REFLEXIÓN FINAL: PARA NO CONCLUIR 155

$\begin{array}{lr}\text { BIBLIOGRAFÍA } & 163\end{array}$

$\begin{array}{lr}\text { ANEXOS } & 170\end{array}$ 


\section{Nómina de Abreviaturas}

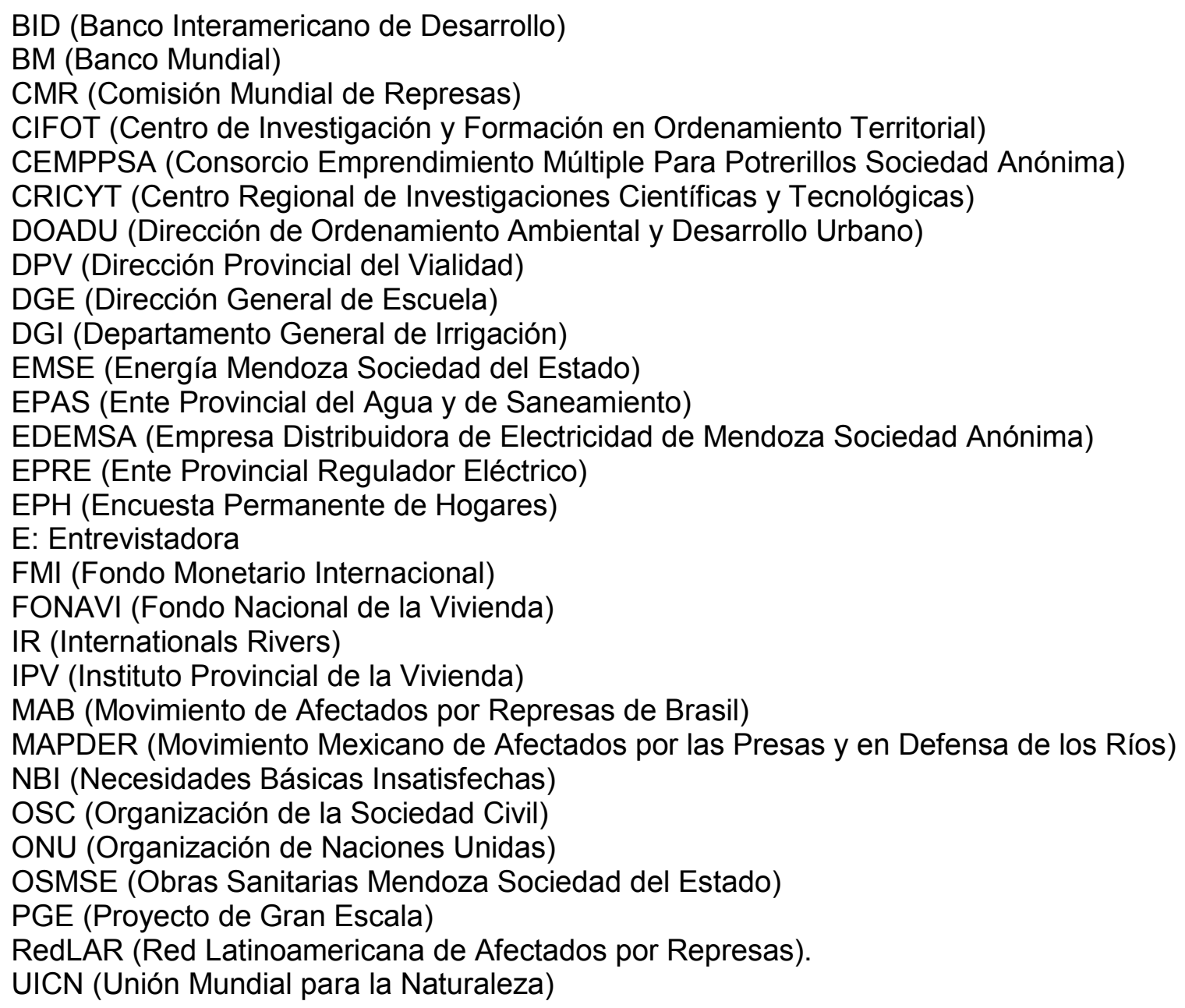




\section{INTRODUCCIÓN}

En el contexto de la globalización, millones de personas en todo el planeta son desplazadas y reasentadas, siendo este fenómeno más frecuente en los denominados países del "Tercer Mundo". Entre los motivos que generan los desplazamientos se pueden mencionar las catástrofes naturales, los conflictos étnicos, políticos o religiosos, así como el cumplimiento de políticas nacionales o internacionales de desarrollo, que llevan a cabo grandes emprendimientos como gasoductos, autopistas, presas hidroeléctricas, ferrocarriles, entre otros (Catullo, 2006). De estos motivos, el último y sus efectos sobre quienes deben obligatoriamente mudarse constituye el tema de la presente investigación.

El propósito de la tesis es contribuir, a partir del estudio de un caso, a la reflexión sobre los efectos de tales políticas que persiguiendo modelos/diseños globales se emplazan en lugares concretos habitados, generando efectos multidimensionales para las poblaciones afectadas. De este modo, se pretende aportar a la producción de conocimiento históricosocial sobre el desarrollo, consideramos "el lugar" como espacio de proyecciones e intervenciones materiales y simbólicas, construidas desde agentes externos al mismo, así también, como espacio de pertenencia, prácticas y experiencias vividas y significadas por quienes lo habitan o habitaban, en nuestros casos, los afectados por el proyecto de desarrollo.

En ese marco, desde una perspectiva crítica, territorial y temporalmente situada, en esta tesis se construye el objeto de estudio en torno al proyecto de inversión y desarrollo de la Presa Potrerillos, emprendimiento vinculado al uso y consumo del agua que fue ejecutado en el contexto del capitalismo neoliberal entre los años 1998 y 2001 en la Provincia de Mendoza, Argentina. Esta obra se emplaza sobre el Río Mendoza aproximadamente a 3,5 km. de la localidad de Cacheuta, a una altura aproximada de 1.200 m.s.n.m., tiene un paredón de $116 \mathrm{~m}$ de altura y su lago artificial cubre una superficie de 1.300 hectáreas que puede almacenar un volumen total de $420 \mathrm{hm} 3$ (Gobierno de Mendoza. Ministerio de Ambiente y Obras Públicas. 2000). Este proyecto implica también un plan de ordenamiento y gestión territorial de los alrededores del embalse, lo cual, desde los inicios de la obra, ha generado un gran impacto en las localidades de Cacheuta y Potrerillos del Departamento de Luján de Cuyo y en la vida de sus pobladores, quienes en algunos casos fueron desalojados y relocalizados.

A más de diez años de la inauguración de la obra, que constituye un hito en la historia del territorio provincial, los interrogantes que dan origen a este trabajo son: primero ¿cómo 
aconteció el proceso de ordenamiento territorial en torno a la construcción de la Presa Potrerillos y cuáles fueron los efectos sobre los pobladores de Cacheuta y Potrerillos?; segundo ¿cómo se conciben el proceso y sus resultados por parte de los pobladores afectados, así como de los funcionarios intervinientes? y tercero ¿en qué contexto socioterritorial del proceso en estudio se evocan las memorias de los afectados y funcionarios? En base a estos interrogantes, el objetivo del trabajo es reconstruir el proceso de ordenamiento territorial que en nombre del desarrollo se realiza vinculado al proyecto de la Presa Potrerillos desde 1998 en los lugares de Cacheuta y Potrerillos, y sus efectos sobre la situación habitacional, la economía de subsistencia y las redes de integración socio-comunitarias, así como sobre los lugares de memoria de los pobladores, sin dejar de considerar las estrategias adaptativas y/o de resistencia de los mismos al nuevo ambiente físico y social, así como el contexto en que se evocan las memorias. En este sentido, se plantean como objetivos específicos:

1) Ahondar en los fundamentos del desarrollo planteado en el proyecto de la Presa Potrerillos, así como en el orden territorial planificado en torno al perilago;

2) Recrear el proceso de desalojo y relocalización de la población, e indagar en las implicancias habitacionales y sobre la tenencia de la tierra para la población no relocalizada;

3) Indagar en los efectos y estrategias adaptativas en relación a las actividades económicas de subsistencia; en las redes de integración socio-comunitarias de los pobladores -por ellas entendemos las redes de relaciones de vecindad, parentesco, amistad, relaciones laborales y organizaciones sociales (formales e informales)-; así como sobre los espacios públicos comunes, dentro de los que se incluyen los lugares de memoria.

4) Analizar el contexto de evocación de las memorias, en relación al desarrollo socioterritorial de las localidades y su integración al desarrollo local mayor.

Si bien son numerosos los actores colectivos involucrados en estos procesos de carácter político, se pone énfasis, por un lado, en la población afectada relocalizada y no relocalizada; y por otro lado, en el actor responsable del proyecto que en nuestro caso es el gobierno provincial, específicamente el sector vinculado al reordenamiento territorial del perilago y al proceso de desalojo y relocalización. No obstante, no se deja de considerar actores que de algún modo fueron partícipes del proceso aún en curso.

En este trabajo se postula como hipótesis que los proyectos de inversión y desarrollo, en el marco de la globalización neoliberal son productores de desplazamiento de 
poblaciones, y como producciones sectoriales, generan ordenamientos socio-territoriales no democráticos y excluyentes para algunos sectores. En el caso de estudio, el desarrollo promovido por el Estado provincial para el área circundante a la obra, siguiendo el modelo global, a partir de la definición de los usos del suelo, propicia la concentración económica y genera desalojos y relocalizaciones, así como la desatención de los sectores afectados. En este sentido, como hipótesis derivadas se postula que: a) el Estado provincial a la vez que promueve la integración de una red de capitales privados en las zonas de mayor impacto de la obra, desintegra las redes locales de integración social y económica de los pobladores; b) la relocalización arbitraria propicia un contexto vulnerable a la manifestación de posteriores migraciones de los afectados; c) los grupos de escasos recursos socio-económicos son los más expuestos a los efectos negativos del proyecto; y d) la participación de los afectados en la co-creación de la perspectiva del desarrollo y en su planificación disminuye los efectos negativos evitables de las obras.

El diseño metodológico adoptado, para dar alcance a los objetivos de investigación, se enmarca en el paradigma dialógico e interpretativo dada la pretensión de captar las perspectivas y significaciones de los sujetos involucrados en el caso de estudio. Considerando que se trata de la reconstrucción de un proceso que tuvo inicio hace más de 10 años, se apela a las memorias de los actores del proceso, como a documentos oficiales y periodísticos para la elaboración del conocimiento histórico y social del mismo, en tanto pasado reciente y proceso no concluido al momento de esta investigación.

Los resultados alcanzados han sido organizados en siete capítulos. En el primer capítulo se exponen los elementos conceptuales que guiaron la elaboración del estudio. Se inicia con una reflexión sobre la relación entre desarrollo e historia desde un pensamiento situado en América Latina, en el que se posiciona este trabajo; luego nos centramos en la noción de proyectos de inversión y desarrollo para adentrarnos posteriormente en la caracterización de los efectos sobre las poblaciones afectadas que estos emprendimientos conllevan. Finalmente, abordamos la noción de lugar como espacio social multidimensional, aportes conceptuales que nos servirán de referencia para el abordaje del caso de estudio.

En el segundo capítulo, se describe el diseño metodológico adoptado y se mencionan los diferentes procedimientos y técnicas puestos en práctica para dar alcance a los objetivos de investigación.

En el tercero se realiza una breve reseña de la historia de las áreas de Cacheuta y Potrerillos hasta la instalación de la Presa Potrerillos, en relación a las dinámicas 
económicas y sociales; y en el cuarto capítulo, se caracteriza el contexto social, político y económico neoliberal mundial y su impacto en la realidad nacional y de la Provincia de Mendoza, donde comenzó a desarrollarse el proyecto en estudio.

Posteriormente, en el quinto, sexto y séptimo capítulo se centra la mirada en los procesos acontecidos en los lugares de Cacheuta y Potrerillos desde el emplazamiento de la obra. En el quinto capítulo se exponen y analizan los fundamentos que sustentan el proyecto de la Presa Potrerillos, así como el Plan de ordenamiento territorial y desarrollo turístico del perilago, área circundante al emprendimiento. En el sexto, se aborda el proceso acontecido en el lugar de Potrerillos y los efectos sobre sus habitantes; y en el séptimo se reconstruye el proceso vivido como consecuencia de la obra en la localidad de Cacheuta. Por último, se esbozan reflexiones finales sobre el estudio, organizadas en función de los supuestos planteados al inicio del proceso investigativo. 


\section{CAPITULO I \\ CONTENIDOS TEÓRICOS}

\section{Acerca del desarrollo, el lugar y los registros del pasado}

\section{1 "El" desarrollo y "la" historia en América Latina}

Al indagar sobre el origen local y la construcción que da forma y dirección al denominado desarrollo que se presenta actualmente y en América Latina -desde su colonizacióncomo modelo único, imperante y exclusivo, encontramos que las políticas globales en que se enmarcan los denominados "proyectos de inversión y desarrollo" constituyen, desde el segundo milenio del calendario cristiano, un diseño histórico-cultural fabricado en Europa primero y luego también en Estados Unidos e impuesto en América Latina, Asia y África. Este fue, aludiendo a De Sousa Santos (2009) el milenio de los "descubrimientos imperiales" de Occidente, que en el marco de una relación de poder vinculada al saber, se declara descubridor y declara descubierto a "Oriente, el salvaje y la naturaleza" (p. 213). El mismo arguye que dos dimensiones caracterizan a estos descubrimientos: una de ellas es empírica, que es el acto de descubrir; y la otra es conceptual, que es la idea de lo que se descubre. Esta segunda dimensión gobierna a la primera declarando al descubierto como inferior. Esta ubicación es la que para el autor justifica la relación de dominación entre descubridor y descubierto, y permiten la expansión del imperio-sistema mundial capitalista centrado en Europa hacia lo lejano, lo de abajo y las márgenes, mediantes la implementación de estrategias de imposición económica, política y cultural ${ }^{1}$. Esto nos muestra que quien clasifica lo realiza de manera arbitraria declarando legítima la clasificación a quienes considera subalternos en relación al modelo privilegiado.

En este marco, la historia contada desde lo espacial, llamada también historia de la geopolítica, emerge como consecuencia de una doble operación que crea las condiciones y explica la constitución de Europa como punto de referencia planetario. Ellas son, aludiendo a Mignolo (2001), primero la colonización del tiempo con la invención de la Edad Media y de la Antigüedad como antecesores del renacimiento y la invención de una historia lineal y universal, creada desde el oriente del Mediterráneo (Jerusalén como origen religioso y Atenas como origen filosófico); y luego la colonización del espacio de la cual surgieron en referencia a la centralidad de la $E$ (Europa) las tres AAAs (Asia, África y

$1 \quad$ En términos del autor: "Si el salvaje es, el lugar de la inferioridad, la naturaleza lo es de la exterioridad. Pero, como lo que es exterior no pertenece y lo que no pertenece no es reconocido como igual, el lugar de la exterioridad es también el de la inferioridad. Al igual que el salvaje, la naturaleza es simultáneamente una amenaza y un recurso" (De Sousa Santos, 2009: p.221). 
América). Como se puede ver, en coincidencia con el autor, es una operación de ordenación espacial más que temporal en la que se evidencia "la complicidad entre epistemología, control social y organización del poder" (p.29).

En América Latina, en palabras de Arturo Roig (2000):

"La mundialización, tuvo sus inicios con la conquista europea de las tierras americanas. Fácil es, pues, definir este vasto fenómeno como un proceso de ocupación del globo terrestre justificado por sucesivas ideologías de diversa inmensidad y amplitud, pero todas organizadas sobre relaciones asimétricas entre los imperios de turno y las colonias o neocolonias, según los casos, como uno de los hechos más notables de repercusión hasta nuestros días. En el siglo XVI y XVII se habló de Evangelización; en el XVIII y XIX, de Civilización; en el XIX y parte del XX, de Progreso; más tarde se invocó al desarrollo, prolongado a su modo por lo que ahora llaman globalización" (citado en Arpini, 2005, p.32).

De esta manera, como diseño global proyectado, el desarrollo se sustenta en principios y discursos que constituyen metarrelatos de carácter pretendidamente universal, generando efectos de poder como mecanismo para ejercer el control. En este sentido, el conocimiento sobre el desarrollo se traduce en objetos, teorías y conceptos, así como en las formas de producirlo, o sea, en prácticas reguladas y en subjetividades creadas que hacen que la gente se reconozca desde parámetros externos en base a lo que se define como normal o anormal (Escobar, 1996). Esto nos lleva a comprender las nociones de mercado y economía como contingencias históricas y producciones culturales que producen un determinado orden social, donde los beneficios del desarrollo son excluyentes y lleva a vastos sectores de la población al empobrecimiento y a la desprotección.

Este escenario injusto, dentro de la tradición historiográfica occidental ha sido presentado según periodizaciones que significan continuidad histórica. Aludiendo a Roig (2008), esta "continuidad", es planteada como una exigencia y se muestra como "necesidad racional". En este esquema, los sectores de poder, con sus intelectuales, crean su propia imagen histórica continua y aseguran su permanencia, ignorando, deformando o disminuyendo los "hechos" o procesos conflictivos que "por no ingresar en las líneas de significado sobre las que se monta la "continuidad" resultan no ser "hechos históricos" (Ibidem, p.137). De esto se desprende "la anulación de la variabilidad histórica y del sentido circunstanciado, o sea históricamente radicado, de la experiencia humana" (Ferrarotti, 1990, p.14) y por tanto la existencia de historias y memorias negadas, no historiadas, no valoradas, como constituyen las de quienes son afectados por las decisiones y prácticas económicas, jurídicas y simbólicas en aras de la modernidad, del progreso o el desarrollo. 
Considerando que nuestro tema de estudio remite a un proceso de rupturas, resistencias y readaptaciones vinculadas al proyecto de la Presa Potrerillos, el cual afectó las cotidianidades -en sus aspectos habitacionales, economías de subsistencia, y redes de integración social, por nombrar algunos- de los pobladores de Cacheuta y Potrerillos, efectos éstos que trascienden los tiempos de los calendarios de las institucionales oficiales interventoras, en este trabajo se entiende a las "periodizaciones históricas" no como orden cronológico o mera sucesión según fechas, sino como "agrupamiento de hechos, dentro de ciertas fechas, que reciben una unidad desde una valoración que marca o señala una etapa (Roig, 2008, p.132).

Esta forma de pensar las periodizaciones nos invita a considerar los sentidos posibles por los cuales las historias/memorias se hacen comunicables, evocando cotidianidades que son afectadas justa o injustamente. De esta forma, entendemos que la valoración de las discontinuidades significativas de lo cotidiano es lo que posibilita la variabilidad de la historia y de los sentidos de las experiencias humanas localizadas (Ferrarotti, 1990).

De acuerdo a este marco de interpretación sobre el desarrollo impuesto a lo largo del planeta y sobre los registros y periodizaciones de esa historia, con vista a la realización de los objetivos planteados en este trabajo, resulta también necesario especificar cómo entendemos el "lugar" o los lugares habitados sobre los que se ejecutan los proyectos de desarrollo. En ello ahondamos a continuación.

\subsection{El "lugar" como espacio inventado, aportes conceptuales para su abordaje}

Para el abordaje de los lugares habitados y sometidos a las manifestaciones del capital global como constituyen nuestros lugares de estudio a partir de la instalación de la Presa Potrerillos, resultan pertinentes los aportes conceptuales de Henri Lefebvre (1971, [1974]), quien comprende al espacio social como producto de lógicas, prácticas y representaciones diversas, esto es, a partir de su producción material y simbólica.

El autor, en consideración, propone las categorías analíticas de espacios dominados y espacios apropiados (Ibidem, 1971). Los espacios apropiados serían aquellos utilizados para servir las necesidades y las posibilidades de un grupo o colectividad. Así, estos posibilitarían además de una "apropiación" funcional una "apropiación" simbólica y de identidad que se origina en lo que se considera "el lugar" de cada individuo. Es el espacio habitado, vivido y enraizado.

Por otro lado, los espacios dominados, serían aquellos que desde una racionalidad técnica e instrumental son utilitarios y funcionalmente transformados con la finalidad de 
controlar los procesos naturales y sociales, sometiéndolos al interés del modelo de producción capitalista. Este es vuelto por planificadores y políticos un espacio abstracto de propiedad y acumulación, a la vez que fragmentado por numerosas estrategias que se entremezclan y superponen: ellas son las de organismos internacionales, de los Estados, de empresas transnacionales, etc.

Estas prácticas de apropiación y/o dominación del espacio revelan, siguiendo al mismo autor, el proceso social de producción del espacio que es construido a partir de relaciones de poder. De esta forma, como producto social, el espacio puede explicarse a partir de tres dimensiones (Lefebvre 1991-[1974]) que son coexistentes y simultáneas a la vez que cada una mantiene cierta autonomía. Ellas son:

1) La práctica espacial que refieren a la forma en que se genera, utiliza y percibe el espacio. Está asociada a la experiencia de la vida cotidiana que lo produce lentamente como dueño y lo apropia;

2) Las representaciones del espacio que se refieren a su conceptualización, a los espacios concebidos desde una lógica particular y desde saberes técnicos y racionales vinculados con las instituciones normalizadas del poder dominante presentes en las estructuras estatales, en la economía y en la sociedad civil, las cuales se expresan a través de signos verbales o materiales (discursos, mapas, etc.); y

3) Los espacios de representación, que es el espacio vivido en estrecha correlación con la práctica social, sus signos e imágenes asociadas. Este sería el espacio de los "habitantes", de los "usuarios", como de escritores que no aspiran más que a describirlos. En esta última dimensión se ubican a los "lugares de memoria", de una comunidad, que entendemos, aludiendo a Pierre Nora (1984), son sitios que tienen su raíz en lo concreto, en el espacio, el gesto, la imagen y el objeto, donde se instala el recuerdo en lo sagrados, se une el pasado y el presente, y subsiste una consciencia conmemorativa. Es decir, es un lugar de restos, signos de reconocimiento y de pertenencia de grupo. Son espacios de rituales, ofrecidos a la experiencia más sensible, como de elaboración de la experiencia más abstracta; en efecto, son: material, simbólico y funcional de manera simultánea.

Cada una de estas dimensiones inventa de manera diferente el espacio social y entre las mismas mantienen una relación dialéctica entre lo percibido, lo concebido y lo vivido.

Entendiendo de esta forma el lugar, y considerando que el objeto de la tesis es un proceso conflictivo y de resistencias surgidas como respuesta de los afectados al Estado promotor del proyecto global de desarrollo, la reconstrucción de la historia reciente vinculada a la instalación de la Presa Potrerillos nos lleva a considerar distintas fuentes 
provenientes de los actores que habitan y/o habitaban Cacheuta y Potrerillos, así como de los sectores dependiente del Estado que los intervinieron. Esto implica reconocer la conformación, coexistencia y pronunciación de memorias plurales -orales e impresascomplementarias y/o contradictorias en torno al caso.

En este sentido, como dimensión de la vida social históricamente construida e influenciada por el orden hegemónico, así como también por instancias críticas, entendemos que la memoria configura representaciones a partir de las cuales los individuos y grupos sociales se perciben y reconocen desde consensos y disensos en relación a identidades y proyectos políticos (Cuevas Marín, 2005, p.11), en nuestro caso, en relación a la obra y sus efectos. De este modo, concebimos que los recuerdos son siempre colectivos, ya que "llevamos siempre con nosotros y en nosotros una determinada cantidad de personas" (Hallbwachs 2004, p.26), y que los mismos se construyen en dialogo con las instituciones de la sociedad, ya que se recuerda en los denominados "marcos sociales de la memoria" que refieren aludiendo a Halbwachs (1994) a nociones, actos y recuerdos de actos que se busca mantener para organizar de determinada manera la vida social.

Seguidamente se profundiza en las características de los proyectos de inversión y desarrollo y en sus efectos sobre las cotidianidades de las poblaciones que habitan en los lugares elegidos para la instalación de las grandes obras.

\section{Desalojos y relocalización a causa del desarrollo}

\subsection{Los proyectos de inversión y desarrollo: las presas hidroeléctricas}

Asociado a la integración y expansión del capitalismo y más acrecentadamente al proyecto neoliberal, en las últimas décadas del siglo $\mathrm{XX}$ y primera del siglo $\mathrm{XXI}$, en torno a ciudades y regiones, promovidos por organismos nacionales e internacionales ${ }^{2}$ se llevan a cabo los denominados "proyectos de inversión y desarrollo", que implican la construcción de grandes obras de infraestructura como las de represa y canales, ferrocarriles, autopistas, gasoductos, oleoductos, etc. Ellos constituyen grandes obras públicas que implican grandes inversiones de capital y a lo largo de la historia mundial se presentan como fundamentales para el surgimiento y desarrollo de los Estados.

2 Algunas instituciones involucradas en estos proyectos son distintas agencias de gobierno, el Banco Mundial (BM), y otras instituciones financieras internacionales como el Banco Interamericano de Desarrollo (BID), el Banco Asiático de Desarrollo y el Banco Africano de Desarrollo. 
En el marco de una matriz de desarrollo de base económica, este tipo de proyectos es definido como "emprendimiento productivo-financiero que se identifica, se formula, se justifica y se desarrolla vinculado con su contexto como un sistema abierto de relaciones de 'entrada y salida de bienes' correlacionados con 'salidas y entradas de fondos'” (Ginestar, 2001, p.52). Constituyen en términos de Lins Ribeiro (1987) "una forma de producción vinculada a la expansión de sistemas económicos" que el mismo denomina Proyectos de Gran Escala (PGE).

Considerando la construcción de la ciudad de Brasilia y la megarepresa hidroeléctrica binacional de Yacyretá, Lins Ribeiro conceptualiza que los PGE pueden ser analizados a partir de tres dimensiones interrelacionadas que se presentan de forma simultánea: 1) el gigantismo, 2) el aislamiento y 3) el carácter temporario de estos emprendimientos. Atendiendo al autor, el "gigantismo" hace referencia a la escala de los proyectos que requieren grandes flujos de capital y trabajo planeado que son accionados por una corporación. Así también, porque se emplazan en extensas áreas territoriales y administran bienes naturales respondiendo a necesidades económicas existentes regionales, nacionales e internacionales, lo cual genera nuevos ejes económicos de consideración. Atendiendo al alcance de los cambios de estos emprendimientos, es que los mismos se incluyen en los considerados asuntos geopolíticos.

El "aislamiento" refiere a que la localización de estos proyectos implica una logística específica y la creación de una organización social ajustada a las necesidades del proceso productivo. Este aislamiento, para el autor es relativo y refiere a aspectos socioeconómicos como la carencia de infraestructura, la dificultad para contratar mano de obra calificada, etc., más que geográficos. Por último, respecto a la "temporariedad" señala que los PGE son identificables en el tiempo, poseen un comienzo y una estimación de finalización, por lo cual es una forma de producción que se activa y se desactiva existiendo momentos de gran carga simbólica, tales como la fecha de inicio del proyecto, así como la ceremonia de inauguración de la obra (Lins Ribeiro, 1987, p.8-9).

En cuanto a las presas hidroeléctricas, el "boom" de estas construcciones comienza con el mejoramiento del diseño de las turbinas durante la década de 1930, aumentando considerablemente la construcción de las mismas hacia 1950 (Balazote, 2001). Atendiendo a la base de datos de la Comisión Mundial de Represas (CMR) publicada en el año 2000, como mínimo 45.000 represas han sido construidas para satisfacer demandas de agua o energía. Para esa fecha -anuncia- la mitad de los ríos del mundo tiene al menos una represa y a inicios del siglo XXI un tercio de los países del mundo 
depende de la energía hidráulica para satisfacer más de la mitad de su suministro eléctrico. Algunas cifras indican que las grandes represas generan el $19 \%$ de la electricidad mundial total y en cuanto al objetivo de irrigación, cerca del $30-40 \%$ de los 271 millones de hectáreas que se irrigan en el mundo dependen de represas (p.6).

Radovich (2005) manifiesta que en procura de lograr consenso sobre la necesidad de las mismas son comúnmente denominadas "emprendimientos de propósitos múltiples". Al respecto, la $\operatorname{CMR}(2000$, p.6) indica que a nivel mundial son promocionadas además de como medio para satisfacer las necesidades de agua y energía, como inversiones estratégicas a largo plazo capaces de producir beneficios adicionales, entre los que enumera el desarrollo regional, la creación de empleo, la promoción de una base industrial con potencial exportador, la generación de ingresos mediante la exportación directa de electricidad, o de productos agrícolas o de productos procesados por industrias intensivas en electricidad, así como la refinación de aluminio. De esta forma, estos grandes proyectos se legitiman políticamente mediante lo que Lins Ribeiro denomina ideología de la redención, que responde a la ideología del progreso, y defienden "la suposición de que los proyectos de gran escala son positivos porque desarrollarán una región, suministrando bienestar a todo el mundo" (Lins Ribeiro, 1987, p.11).

Estas son, en palabras de Radovich "expresiones concretas de una ideología de la era tecnológico, verdaderos íconos del desarrollo económico y del progreso científico" (Radovich, 2005, p.99) ligadas a la concentración de poder y no constituyen, siguiendo al autor, un rasgo exclusivo de la sociedad capitalista, dado que esta manifestación ideológica también se encuentra en las políticas energéticas llevadas a cabo en países donde tuvo vigencia el socialismo como Rusia, China, India y Egipto.

De esta manera, entendemos a los mega-proyectos como la combinación de intereses materiales y prácticas ideológicas que ocupan un lugar fundamental en la orientación de los procesos económicos y en la reproducción de sus resultados, los cuales en general son desigualmente distribuidos y se expresan en los costos sociales que conllevan estos emprendimientos.

A continuación nos introducimos en las características de los procesos relocalizatorios, en los actores que le dan forma, en sus efectos y costos sociales. 


\subsection{La relocalización de población}

\subsubsection{Proceso de actores y efectos colectivos}

Como parte de procesos de ordenamientos territoriales originados por la construcción de presas hidroeléctricas u otros emprendimientos, las relocalizaciones constituyen procesos políticos en los cuales se hallan involucrados actores colectivos que poseen diferentes grados de poder que se ejerce a lo largo de las intervenciones. En este sentido, las mismas implican "objetivos y actividades públicas en las que los planificadores de los programas poseen un poder diferencial que utilizan sobre las poblaciones a relocalizar generando en mayor o menor grado, conflictos y resistencias y consecuentes negociaciones entre los actores del proceso" (Catullo, 2006, p.46). De este modo, entendemos que los procesos relocalizatorios se llevan a cabo en medio de luchas de poder en las que se juegan intereses de sectores heterogéneos.

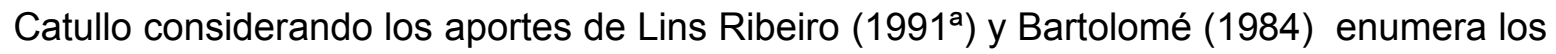
actores colectivos que integran estos procesos, tanto del PGE como del programa de relocalización. Ellos son:

“1) las agencias multilaterales que financian el PGE; 2) el "propietario", responsable de la ejecución del PGE y, sobre todo, el sector relacionado con los reasentamientos poblacionales; 3) las empresas contratistas (nacionales e internacionales) también ligadas a los procesos de relocalización; 4) las estructuras de gobierno (nacionales, regionales y locales) relacionadas con el PGE y el programa de relocalización; 5) la población en general y, específicamente los sectores "receptores" de los grupos desplazados; 6) las instituciones y las organizaciones externas de actuación local y regional relacionadas con el proceso de relocalización (por ejemplo, Iglesia Católica, partidos políticos, ONG); 7) la población a relocalizar, y 8) las asociaciones y grupos corporativos de orden local o regional" (2006, p.37).

La interacción de este conjunto de actores nos lleva a entender que los procesos de relocalización son también procesos de comunicación en los que se generan codificaciones y decodificaciones en múltiples direcciones.

A partir de la especificación de los actores colectivos involucrados en estos procesos, en nuestro caso de estudio se pone énfasis, por un lado, en el actor responsable o promotor del proyecto que es el gobierno provincial, específicamente el sector vinculado al ordenamiento territorial del perilago, así como también en el encargado del proceso de desalojo y relocalización; y por otro lado, en la población afectada relocalizada así como en la no relocalizada habitante de lo que hoy constituyen las márgenes de la presa que también se vio afectada. En relación a estos últimos, acordamos con Balazote y Radovich 
(2003) quienes reconsideran el criterio "afectado" superando la mera clasificación de afectados "directos" e "indirectos" que suelen aplicar las empresas públicas o privadas encargadas de las obras, sin considerar que los perjuicios superan las orillas de los lagos y exceden los niveles de las cotas de inundación (p.105).

En cuanto a los efectos de las relocalizaciones sobre quienes deben trasladarse, paradójicamente aún cuando las mismas, para ser diferenciadas de las de refugiados, fueron denominadas "relocalizaciones para el desarrollo" (Scudder y Colson, 1982, p.267), salvo en contados casos no tienen como objetivo principal el beneficio de los relocalizados, por el contrario, lo frecuente, es que sean concebidas "como un componente periférico, un costo adicional y de alguna manera "ilegítimo" del proyecto global" (Bartolomé, 1984, p.118).

Aludiendo a Bartolomé (1984), las relocalizaciones asociadas a la construcción de represas -tal como es nuestro caso de estudio- se caracterizan por: a) la marcada concentración temporal de los impactos del proyecto global sobre las estrategias vitales de la población a reasentar; b) la interdependencia y retroalimentación de esos impactos con el contexto del PGE, y c) la naturaleza compulsiva y temporalmente acotada del desplazamiento de la población (p.118). El término compulsiva hace referencia al carácter arbitrario, obligatorio y apremiante de la medida, que como consecuencia inmediata implica la pérdida del contexto físico y social habitual de la vida de los relocalizados (Ibidem, p.119).

Bartolomé describe este desarraigo del entorno y modo de vida familiar como situación de "drama social", considerando que este evento actúa con características de "catástrofe natural", debido a que es irreversible y ajeno de la decisión de los afectados. Ésta se manifiesta en la inseguridad de los mecanismos tradicionales de supervivencia, en la desorientación, incertidumbre, impotencia y miedo que genera efectos traumáticos a nivel individual y colectivo en la población, perturbando aquello que otorgaba cierta regularidad y predictibilidad a sus vidas (Ibidem, p.120-121).

Buscando describir estos efectos, Scudder y Colson (1982) elaboran el concepto de stress multidimensional de relocalización considerando dos componentes: uno de carácter fisiológico y otro de carácter socio-cultural. El primero alude a las tasas de morbilidad y mortalidad, que se ven afectadas durante los períodos anterior y posterior a la relocalización, lo cual se acompaña de las condiciones de la infraestructura sanitaria, así como de la atención médica pre-existente, el nivel nutricional previo, la existencia de enfermedades infecciosas, etc. Por su parte, componente socio-cultural refiere al impacto 
sobre: a) la estructura de liderazgo local, b) la red de relaciones sociales en que se inserta cada individuo y cada unidad familiar -basadas en la vecindad, parentesco, amistad instrumental, relaciones laborales-, c) las pautas de conducta más directamente relacionadas con la adaptación al medio ambiente físico y social y d) la "persona" (el individuo en tanto sumatoria de atributos sociales) del relocalizado.

En relación a este segundo componente, Bartolomé (1984, p.124) agrega que intracomunitariamente estos procesos provocan que los mecanismos de control se debiliten y pierdan capacidad para canalizar las tensiones, lo cual puede traducirse en conflictos interpersonales, intrafamiliares y sociales con los encargados de la relocalización, situación que puede variar según la existencia previa o no de cohesión comunitaria y bases organizacionales que puedan ejercer resistencia.

Por su parte Catullo (1987, p.128), incorpora a su explicación el elemento territorial así como los aspectos de la historia y la memoria de las poblaciones a relocalizar. Hace alusión a las implicancias de estas obras sobre la historia común, la memoria colectiva, el patrimonio socio-cultural que les es propio a los sectores relocalizados, así como a las redes sociales primarias y secundarias cotidianas de pertenencia, en fin, a los efectos sobre las identidades generadas espacialmente a partir de interacciones intracomunitarias -establecidas en instituciones formales e informales-, así como locales y regionales.

Para finalizar, considerando que estos procesos tienen su inicio mucho antes del traslado físico de la población, cuando surgen los primeros rumores sobre la obra y continúan luego de la finalización de esta (Scudder y Colson, 1982), coincidimos con Catullo (2006) en que trascienden los calendarios programados por las instituciones responsables de la intervención, así como también, en que las estrategias adaptativas de los afectados difieren según sean relocalizaciones rurales o urbanas.

Al respecto Bartolomé (1984, p.133) plantea diferencias en torno a los procesos de relocalización rural y urbana, entre ellas menciona:

“1) las relocalizaciones urbanas operan sobre un contexto socioeconómico con mayor diferenciación y especialización de funciones que el rural; 2) esta diferenciación y especialización se manifiesta, entre otras cosas, en el frecuente divorcio entre funciones habitacionales y funciones productivas; 3 ) de lo anterior se deduce que las relocalizaciones parciales presentan mayor complejidad que las totales; 4) el núcleo de afectación recae sobre los esquemas vitales de supervivencia antes que sobre la vivienda, aunque ésta tenga un papel clave dentro del esquema; 5) es de prever, sin embargo, una más alta capacidad de respuesta por parte de la población urbana que en la rural, fundamentalmente porque la primera está más habituada a hacer frente a situaciones de fluidez en la estructura de oportunidades y a emplear estrategias adaptativas más flexibles; y 6) 
la relevancia del tema en la marginalidad urbana, tanto por el patrón de ubicación espacial de los marginados como por la severidad del impacto que tiene el trabajo sobre éstos".

En nuestro caso de estudio se trata de una relocalización rural en medio de un proceso de urbanización del lugar, por ello los aspectos afectados en los que centraremos la investigación son los efectos sobre la situación habitacional, bienes y servicios, como sobre los lugares de memoria, las fuentes de trabajo o de recursos, así como las redes de integración socio-comunitarias de los pobladores, sin dejar de considerar las estrategias adaptativas de los mismos al nuevo ambiente físico y social.

A continuación se ahonda en los vacíos de contenidos y los costos sociales recurrentes que a nuestro entender constituyen las faltas éticas y políticas de este tipo de proyectos.

\subsubsection{Los contenidos y costos sociales}

Mientras que, por un lado, los promotores de estos proyectos recalcan las demandas de desarrollo económico y social que las presas intentan satisfacer -irrigación, electricidad, control de inundaciones y suministro de agua-, por otro lado, sus opositores denuncian los impactos adversos como el desplazamiento y empobrecimiento de personas, la inequitativa distribución de costos y beneficios, la destrucción de ecosistemas y recursos pesqueros, el endeudamiento y sobrecostos de las obras que requieren de grandes inversiones, etc. ${ }^{3}$ En cuanto a estas implicancias desfavorables, la CMR (2000, p.6) afirma que en término de impactos sociales, a nivel mundial los efectos negativos de las represas no son valorados y considerados adecuadamente, y exterioriza que entre 40 y 80 millones de personas han sido desplazadas en todo el mundo a causa de las mismas impactando en los medios de subsistencia y en la salud de las comunidades que dependen de los ambientes ribereños afectados.

De los desplazados a causa de este tipo de proyectos, muchos no fueron reconocidos (o registrados como tales) y por lo tanto ni siquiera reasentados o indemnizados. En otros casos, en los que se entregó una indemnización, ésta fue insuficiente, y entre los desplazados reconocidos como tales, muchos no fueron incluidos en programas de reasentamiento. Así también, quienes fueron reasentados, rara vez se les restituyó sus medios de subsistencia, ya que los programas de reasentamiento se han centrado en el

3 En cuanto a la relación entre desarrollo capitalista, desplazamiento y empobrecimiento, encontramos denuncias de esta tríada en los documentos de Marx, K. (1946) El Capital. Crítica de la Economía Política. Tomo I.; Arendt, H. (2006) Los Orígenes del Totalitarismo; y Polanyi, K. (1992) La Gran transformación. Los orígenes políticos y económicos de nuestro tiempo. 
traslado físico, y no en el desarrollo económico y social de los afectados, como tampoco en el impacto sobre el patrimonio cultural de las comunidades locales - sumergimiento y degradación de monumentos arqueológicos y cementerios- (Ibidem, p.19).

Aludiendo a Barone y Fernández (2006) respecto de los contenidos sociales de este tipo de proyectos, hay debilidades comúnmente halladas desde el momento del diseño de los mismos. Siguiendo a los autores, a éstas las podemos agrupar en tres grupos:

1. La inexistencia de una política de reasentamiento nacional adoptada por los gobiernos que defina reglas en materia de responsabilidades institucionales, derecho de los afectados, financiación, adquisición de tierras, compensaciones, indemnizaciones, titulación, etc.; 2. La falta de definición técnica de los proyectos en base a su factibilidad social en el área de la zona a intervenir, y/o falta de diseños básicos para una adecuada preparación de los planes de reasentamientos como programas de acción específicos y el presupuesto en recursos humanos, económicos y los tiempos necesarios para la ejecución de los planes; y 3. La supremacía -en las instituciones responsables de los proyectos- de la perspectiva de la ingeniería sobre las perspectivas de las ciencias sociales, lo cual relega un conjunto de componentes como las acciones correlativas al reasentamiento, que tienen que ver con la consulta y participación de los afectados, y el acompañamiento social antes, durante y después del traslado que cuanto mucho se encuentran débilmente contemplados.

Estos aspectos olvidados o no contemplados de los procesos de relocalización, confirman que los mismos constituyen un fin subordinado a los objetivos del PGE o "componentes marginales" (Bartolomé, 1984) en la planificación de estos grandes proyectos.

A razón de lo expuesto, la construcción de grandes represas en materia de desarrollo sustentable viene siendo cuestionada en muchos países del mundo. Como forma de resistencia a este tipo de proyectos y a sus consecuencias, en Brasil se formó en la década del 80 un movimiento de oposición popular al desarrollo hídrico surgiendo la Comisión Regional de Afectados por Represas (CRAB) y luego el Movimiento de Afectados por Represas de Brasil (MAB) integrados por diversas organizaciones de afectados. Este movimiento adquirió una fuerza tal que hasta proclamaron en 1988 el 14 de marzo el Día de conmemoración de la Lucha contra las represas, sumando a este evento y posteriores a representantes afectados de la Presa binacional Yaciretá.

Más tarde, organizado por el MAB, se celebró en 1997 en Curitiba, Brasil el "Primer Encuentro Mundial de Afectados por las Grandes Represas" con representantes de organizaciones de derechos ambientales y humanos de 20 países. En esta oportunidad 
los participantes dieron a conocer la Declaración de Curitiba que denuncia el abismo existente entre los beneficios económicos y sociales prometidos por los constructores de represas y los resultados que arroja la realidad una vez terminada la obra; y aboga por una moratoria a la construcción de grandes represas. Así también, en esta oportunidad se estableció el 14 de marzo "Día Internacional de Acción contra las Represas y por los Ríos, el Agua y la Vida". Este encuentro ayudó a afianzar el movimiento mundial, las acciones colectivas e impactó en la gestión de organismos internacionales y de varios gobiernos que consideraron el documento.

En 2003 se realizó la segunda reunión en Tailandia, esta vez asistieron alrededor de 300 personas procedentes de 62 países. La reunión brindó la oportunidad de discutir los resultados de la CMR (2000), conformada por iniciativa de la UICN (Unión Mundial para la Naturaleza) y el BM, luego del encuentro de Curitiba. Posteriormente el Tercer Encuentro Mundial de Afectados por las Grandes Represas "Ríos para la vida 3" se llevó a cabo del 1 al 7 de octubre de 2010 en la ciudad de Temacapulín, en el estado mexicano de Jalisco. Esta vez en su organización participaron la organización Internationals Rivers (IR), el Movimiento Mexicano de Afectados por las Presas y en Defensa de los Ríos (MAPDER) y de la Red Latinoamericana de Afectados por Represas (RedLAR) (http://www.proteger.org.ar/tema/encuentro-afectados-por-represas/).

Como vemos, en los primeros años del siglo XXI los efectos del desarrollo global son reconocidos por organismos internacionales. A partir de ello, los mismos elaboran instrumentos discursivos -conceptuales y legales- dando legitimidad a la continuidad de estos proyectos. Entre estos dispositivos se encuentran las "órdenes" de desalojo y relocalización de población que les permiten a los Estados, en el marco del modelo hegemónico, la liberación de las áreas elegidas para el emplazamiento de las obras. Sobre esto ahondamos a continuación.

2.3 Los desalojos en los principios y directrices internacionales

\subsubsection{En nombre del "bien común"}

En este apartado, se realiza un análisis del discurso de un documento elaborado por Naciones Unidas (2007) donde se define y justifican los desalojos y los reasentamientos cuando estos son causados por los proyectos "del desarrollo" y en función de esta "razón" conceptualmente se los diferencia de los "desalojos forzosos". 
Aludiendo a los Principios básicos y directrices sobre los desalojos y el desplazamiento generados por el desarrollo, expuestos en el Informe elaborado por el Relator Especial Sr. Miloon Kothari sobre una vivienda adecuada ( $p .15)$, se reconoce que en el marco de los instrumentos jurídicos internacionales que protegen los derechos humanos, los Estados deben abstenerse de realizar desalojos forzosos y proteger a la población contra los desalojos de los hogares y de la tierra ${ }^{4}$. El término "desalojo forzoso" entiende que:

"se aplican a acciones y/u omisiones relacionadas con desplazamientos coaccionados o involuntarios de personas, grupos y comunidades de sus hogares y/o tierras y los recursos comunes de propiedad que estaban ocupando y de los que éstos dependían, eliminando o limitando con ello la capacidad de una persona, un grupo o una comunidad de residir o trabajar en una vivienda, residencia o lugar particulares sin que se haya ofrecido o no se tenga acceso a formas apropiadas de protección jurídica o de otro tipo" (punto 4, p.15).

Es decir, los "desalojos forzosos" refieren a traslados físicos de población de manera arbitraria, donde los afectados no tienen acceso a protección jurídica, social, etc., o sea, no tienen acceso a la garantía de los derechos humanos y por tanto se ven expuestos a la pobreza y marginación, desigualdad, conflictos sociales, segregación, etc. Ahora, habiendo expuesto el alcance de este término, el mismo informe al finalizar esta definición, al pie de página manifiesta:

"La prohibición de los desalojos forzosos no se aplica a los desalojos que se llevan a cabo de conformidad con la legislación ni conforme a las disposiciones de los tratados internacionales de derechos humanos" (p.16).

De este modo, con esta aclaración se considera que los desalojos son "no forzosos" cuando los Estados promotores del desarrollo y creadores de las leyes y reglamentos jurídicos los justifiquen y "negocien" en estos marcos la liberación y dominación de los espacios requeridos por tales proyectos. Es decir, los mismos son avalados o tienen "plena justificación" cuando se realicen en "el marco de la ley" y bajo lo que en el informe citado se denomina "circunstancias excepcionales". Estas son aquellas que se cometan por causa de proyectos de desarrollo o sea que:

\footnotetext{
${ }^{4}$ Entre estos instrumentos se encuentra la Declaración Universal de Derechos Humanos, el Pacto Internacional de Derechos Económicos, Sociales y Culturales (párr. 1, art.11), la Convención sobre los Derechos del Niño (párr. 3, art. 27), las disposiciones sobre la no discriminación que figuran en el párrafo $2 \mathrm{~h}$ ) del artículo 14 de la Convención sobre la eliminación de todas las formas de discriminación contra la mujer y el artículo 5 e) de la Convención sobre la Eliminación de la Discriminación Racial. Así también el artículo 17 del Pacto Internacional de Derechos Civiles y Políticos, el artículo 21 de la Convención sobre el Estatuto de los Refugiados, de 1951, el artículo 16 del Convenio $N^{\circ} 169$ de la Organización Internacional del Trabajo (OIT) sobre pueblos indígenas y tribales independientes (1989); y el artículo 49 del Convenio de Ginebra relativo a la protección debida a las personas civiles en tiempo de guerra, del 12 de agosto de 1949 (Naciones Unidas, 2007)
} 
"se planifican y se llevan a cabo so pretexto de servir al "bien común", como, por ejemplo los desalojos vinculados a los proyectos de desarrollo e infraestructuras (en particular, grandes presas, proyectos industriales y energéticos a gran escala, industrias mineras $u$ otras industrias extractivas); medidas de compra del suelo relacionadas con la renovación urbana, la rehabilitación de los tugurios, la renovación de las viviendas, la restauración de las ciudades y otros programas de utilización de la tierra (también para fines agrícolas); litigios sobre bienes, propiedad inmobiliaria o el sueldo; especulación descontrolada del suelo; importantes negocios internacionales o actos deportivos; y, aparentemente fines ambientales. Entre estas actividades figuran también las que cuentan con el apoyo de la asistencia internacional para el desarrollo" (p.16).

Como se puede visualizar, en estos casos, los desalojos quedarían argumentados por las políticas de desarrollo global y por la universalizante definición de "bien común" que implica la no aceptación y respeto de la diversidad, particularidad y autodeterminación de lo que para cada pueblo, comunidad, grupo o persona significa "su bien". Este marco conceptual de Naciones Unidas no hace más que confirmar la ambigüedad jurídica que caracteriza a este tipo de proyectos de desarrollo (Balazote y Radovich, 2003).

A partir de lo expuesto, entendemos que los denominados "proyectos del desarrollo" son reflejo de proyectos sociales y territoriales más amplios que dan continuidad a los fundamentos y prácticas institucionales que se vienen imponiendo desde su colonización en América Latina, Asia y África. En este sentido, las conceptualizadas por Naciones Unidas "circunstancias excepcionales" constituyen una política global que nada tiene de circunstancial como tampoco de excepcional.

Esto nos lleva a comprender que la política jurídica como la económica es construida desde la subjetividad como "universales abstractos" (Dussel, 2005) y desde los denominados centros, siguiendo el ritmo de la expansión de los mercados y la acumulación de riquezas, proyecto acompañado de un no reconocimiento de sujetos y culturas localizadas, corporeizadas y organizadas en torno a valoraciones y formas diferentes de racionalidad.

\subsubsection{Antes y durante los desalojos del desarrollo: los ideales}

Aludiendo al documento de Naciones Unidas (2007), antes de producirse los desalojos, todas las personas que pudieran verse afectadas deberían participar en los procesos de planificación y desarrollos urbanos y rurales y los Estados responsables de los proyectos deberían considerar los siguientes elementos:

"a) un aviso apropiado a todas las personas que podrían verse afectadas de que se está considerando el desalojo y que habrá audiencias públicas sobre los planes y alternativas propuestos; 
b)difusión eficaz por las autoridades de la información correspondiente por adelantado, en particular los registros de las tierras y los planes amplios de reasentamiento propuestos, con medidas dirigidas especialmente a proteger a los grupos vulnerables;

c) un plazo razonable para el examen público, la formulación de comentarios y/o objeciones sobre el plan propuesto;

d) oportunidades y medidas para facilitar la prestación de asesoramiento jurídico, técnico y de otro tipo a las personas afectadas sobre sus derechos y opciones; y

e) celebración de audiencias públicas que den la oportunidad a las personas afectadas y a sus defensores a impugnar la decisión de desalojo y/o presentar propuestas alternativas y formular sus exigencias y prioridades de desarrollo".

Estas medidas que expone el informe se tendrán en cuenta como ejes orientadores a la hora de la reconstrucción de nuestro caso de estudio, así como también los siguientes requisitos que, manifiesta el documento, los Estados deberían considerar durante los desalojos (p.23):

"a. La presencia obligatoria de funcionarios gubernamentales o sus representantes en el lugar, quienes deben identificarse a las personas que van a ser desalojadas y presentar una autorización oficial para el desalojo.

b. Para garantizar la transparencia y el cumplimiento de los principios internacionales de derechos humanos durante la ejecución de cualquier desalojo, debería permitirse el acceso de observadores neutrales, en particular observadores nacionales e internacionales, a petición del Estado.

c. Los desalojos no deberían realizarse de una forma que viole la dignidad y los derechos humanos a la vida y a la seguridad de las personas afectadas.

d. Los Estados también deben adoptar medidas para garantizar que las mujeres no sean objeto de violencia ni discriminación de género durante los desalojos, y que se protegen los derechos humanos de los niños.

e. Cualquier uso legal de la fuerza debe respetar los principios de la necesidad y la proporcionalidad, así como los Principios básicos sobre el empleo de la fuerza y de armas de fuego por los funcionarios encargados de hacer cumplir la ley y el código de conducta nacional o local que corresponda a las normas internacionales de aplicación de la ley y de los derechos humanos.

f. Los desalojos no deben realizarse con tiempo inclemente, por la noche, durante los festivales o las fiestas religiosas, antes de las elecciones o durante o justo antes de los exámenes en las escuelas.

g. Los Estados y sus agentes deben adoptar medidas para garantizar que nadie sea objeto de ataques directos o indiscriminados $u$ otros actos de violencia, especialmente dirigidos contra las mujeres y los niños, o privado arbitrariamente de sus bienes o posesiones a consecuencia de la demolición, el incendio intencionado y otras formas de destrucción deliberada, negligencia o cualquier forma de castigo colectivo.

h. Los bienes y las posesiones abandonados involuntariamente deben protegerse contra la destrucción y la apropiación, la ocupación o el uso arbitrarios e ilegales.

i. Las autoridades y sus agentes nunca deben exigir u obligar a las personas desalojadas a que destruyan sus propias viviendas $u$ otras construcciones. Sin embargo, la posibilidad de hacerlo debe ofrecerse a las personas afectadas, ya que podría facilitar la conservación de posesiones y de materiales de construcción". 
Una vez realizados los desalojos, los Estados también deben garantizar el cumplimiento de ciertos estándares mínimos compensatorios de los perjuicios provocados. Sobre estos ahondamos a continuación.

\subsubsection{Las mínimas reconocidas}

Asumiendo el daño causado a millones de personas a las que se les ha violado derechos a causa del "desarrollo", como modo de reparar el incumplimiento cometido por los Estados, Naciones Unidas (2007) elabora nuevos derecho para los afectados. Se trata del "derecho al reasentamiento" que se aplica en estas circunstancias a toda persona, grupo o comunidad. El mismo incluye:

"el derecho a una tierra distinta mejor o de igual calidad, y una vivienda que debe satisfacer los siguientes criterios de adecuación: facilidad de acceso, asequibilidad, habitabilidad, seguridad de la tenencia, adecuación cultural, adecuación del lugar y acceso a los servicios esenciales, tales como la salud y la educación" (p.18)

Excepto para los casos que considera de fuerza mayor, el documento plantea que el reasentamiento de la población desalojada se debe efectuar inmediatamente después del desalojo y que como mínimo las autoridades competentes deben garantizar que las personas o los grupos desalojados, especialmente los que no pueden ganarse el sustento, tengan acceso seguro a:

"a) alimentos esenciales, agua potable y saneamiento; b) alojamiento básico y vivienda; c) vestimenta apropiada; d) servicios médicos esenciales; e) fuentes de sustento; f) pienso para los animales y acceso a la recursos comunes de propiedad de los que dependían anteriormente; y g) educación para los niños e instalaciones para el cuidado de los niños. Los Estados también deberían asegurar que los miembros de la misma familia ampliada o comunidad no se separen a consecuencia de los desalojos" (p.24).

Estas mínimas contemplan la existencia previa de una política establecida por parte de los Estados que incorpore los derechos humanos de las mujeres, niños, pueblos indígenas y otros grupos vulnerables, en particular su derecho a poseer bienes y a tener acceso a los recursos, el pago por parte del agente promotor del reasentamiento de todos los gastos del mismo, y la garantía del derecho de las personas, grupos y comunidades afectados al consentimiento previo con pleno conocimiento de causa en lo que respecta a la reinstalación, donde el Estado deberá proporcionar todas las comodidades, servicios y oportunidades económicas necesarias y al alcance de la población.

Así también, debe contemplar que los lugares de reinstalación no se encuentren situados en tierras contaminadas o en la cercanía inmediata a fuentes de contaminación, 
asegurando el derecho al nivel más alto posible de salud física y mental de los habitantes; que las personas, grupos y comunidades afectadas reciban la información suficiente sobre los proyectos y procesos de planificación y ejecución del Estado relativos al reasentamiento de que se trate, en particular información sobre el supuesto uso de las viviendas o lugares desalojados y sus beneficiarios propuestos; y contemplar la plena participación de los afectados en todo el proceso de reasentamiento, teniendo en cuenta los planes alternativos propuestos por ellos (Ibidem, p. 25). Manifiesta así mismo, que si después de una audiencia pública completa e imparcial se estima que todavía existe la necesidad de proceder con el reasentamiento, se debe dar a los afectados al menos 90 días antes del reasentamiento (Ibidem, p.26).

De esta forma, en el marco de estos principios y directrices, las personas afectadas, de ser "afectados justificados" pasan a ser "afectados compensados" por los Estados promotores de los proyectos del desarrollo. Sin embargo, como leímos antes y veremos también a continuación, los contenidos sociales en general no son tenidos en cuenta por los grandes proyectos y los desalojos, aún cuando se realicen ofreciendo protección jurídica y social, son vividos igualmente como forzosos en función de que no han sido elegidos e implican para los afectados intervenciones impuestas, "cocinadas" o "empaquetadas" por quienes detentan y concentran el poder.

En otras palabras, en el marco de este tipo de proyectos, los desalojos son considerados externalidades a ser remediadas en defensa de los intereses del capital acumulado y de los Estados que sustentan la bandera de la ideología del progreso y la modernidad. 


\section{CAPITULO II ASPECTOS METODOLOGICOS}

La indagación en la historia y memorias del desarrollo y sus efectos, al asumir una postura crítica con respecto a los procesos de globalización, en particular aquellos que fortalecen las dinámicas históricas de diferenciación y exclusión, implica la práctica de hacer de la producción y enunciación del mismo el reconocimiento de voces y pensamientos en términos de pluralidad.

Considerando, además, que lo social involucra una historicidad y viceversa, es decir, que el hombre es en sí mismo cotidianamente un proceso, y actúa a la vez en procesos estructurales, con motivo de recuperar y recrear la historia y las memorias en torno al proceso socio-territorial en estudio, se incorpora en este trabajo como referente epistemológico el paradigma dialógico e interpretativo.

En este marco, entendemos la producción de conocimientos en torno a memorias como una labor colectiva entre "sujetos" que dialécticamente elaboran conceptualizaciones a partir de las propias prácticas y experiencias. Esto implica la generación de espacios de "construcción cooperativa del conocimiento", entendidos como procesos de "interacción cognitiva" (Vasilachis de Gialdino, 2008, p.213), donde "Seres humanos (...) 'trabajan" sobre y con las memorias del pasado" (Jelin, 2002, p.14).

De esto deriva que, ubicarlas temporalmente significa aludir en palabras de Jelin (Ibidem) al "espacio de la experiencia en el presente" (p.13), a los contextos grupales y sociales específicos en que las mismas son evocadas. De esta forma, la memoria yace como mediación que permite la reconstrucción de la historia y su interpretación desde la comprensión y significados que los sujetos de los procesos les otorgan.

Es decir, sin dejar de considerar que la historia de los "hechos" se convierte en material indispensable en la reconstrucción de procesos históricos, éste no es suficiente para comprender las maneras en que los sujetos sociales interpretan los acontecimientos y construyen su memoria. Desde esta perspectiva, ni la historia se diluye en la memoria ni la memoria es descartada por falta de objetividad, así como ambas son pensadas como campos atravesados por disputas de poder (Hallbwachs, 2004).

En el marco de lo expuesto, la estrategia metodológica recorrida asume como diseño de investigación el estudio de caso, el cual se aboca a la reconstrucción del proceso de intervención socio-territorial vinculado al perilago de la Presa Potrerillos, o sea, a los lugares de Cacheuta y Potrerillos y a los efectos sobre sus pobladores, que en algunos casos fueron desalojados y relocalizados. Como fenómeno delimitado en un contexto 
(Lentini, 2009), este proceso se aborda históricamente considerando el contexto sociopolítico y económico así como geográfico en el que se desenvuelven los diversos actores y sus interrelaciones.

La estrategia metodológica involucra la triangulación de estrategias propias de la investigación cualitativa que nos posibilitan acceder a datos primarios y secundarios, apelando a tres fuentes históricas: documentación escrita, grafica y audiovisual, la cultura material -la arquitectura y el paisaje- y la producción oral: la palabra hablada (narrada) que en este trabajo quedará registrada. Es decir, la estrategia se nutre de tres ingredientes de la investigación social: documentación, observación y conversación.

En primer lugar, en relación al tema de estudio se realiza análisis de contenido documental. Esta técnica se aplica al Informe elaborado por el Relator Especial Sr. Miloon Kothari sobre una vivienda adecuada de Naciones Unidas (2007) donde se exponen los "Principios básicos y directrices sobre los desalojos y el desplazamiento generados por el desarrollo", el cual constituye un referente del derecho internacionalmente reconocido. Esta técnica también se emplea en el análisis de documentos oficiales vinculados al proyecto de inversión y desarrollo de la Presa Potrerillos y al plan de gestión y ordenamiento del perilago, donde se incluye la relocalización de parte de la población afectada. Estos corresponden a la Dirección de Ordenamiento Ambiental y Desarrollo Urbano (DOADU), del Ministerio de Medio Ambiente y Obras Públicas del Gobierno de Mendoza, al Instituto Provincial de la Vivienda (IPV) de Mendoza, a la Municipalidad de Luján de Cuyo, y al Centro de Investigación y Formación en Ordenamiento Territorial (CIFOT) de la Facultad de Filosofía y Letras de la Universidad Nacional de Cuyo.

Otros documentos escritos que se consideran son: la bibliografía académica existente sobre el caso o el lugar, material grafico y fotográfico del Archivo Histórico de la Provincia de Mendoza y de la Dirección de Planificación del Ministerio de Turismo así como los artículos periodísticos de los diarios "Los Andes" y "UNO" de Mendoza, los cuales nos permite realizar una aproximación histórica a los lugares en estudio, como al contexto en que se planeó y ejecutó el proyecto de la presa y la relocalización. Estos registros nos posibilitan, además, observar cómo se relacionan entre sí los actores involucrados en el proceso y conocer cómo eran vividos los efectos inmediatos del reordenamiento territorial en torno al perilago.

Dentro del material documental, otro recurso técnico utilizado que nos permite recrear cómo era vivido este proceso por los pobladores de los lugares "en aquel momento" es el 
audiovisual denominado "el cuarto oscuro: 6mm3" (2005) dirigido por Tomás Ochoa que incluye testimonios de los pobladores sobre el desalojo y la relocalización.

Para ahondar en la narrativa oral o memoria de este proceso y sus implicancias para los pobladores afectados de Cacheuta y Potrerillos, así como en las estrategias colectivas de resistencia surgidas como respuesta al Estado se realiza un total de 20 entrevistas a pobladores relocalizados y no relocalizados afectados, así como a técnicos y directivos profesionales y políticos intervinientes.

En ambos casos se realizan entrevistas semi estructuradas. En el caso de los afectados, estas guardan relación con relatos o historias de vida desde las cuales emergen problemáticas sociales a partir de las percepciones de los participantes en el momento de realización de las entrevistas; es decir, trabajamos con percepciones, recuerdos, sensaciones, valores, deseos y saberes sobre un pasado reciente que mantiene continuidades y discontinuidades con el contexto presente de evocación de la memoria, momento en el cual a partir de indagar en las vivencias del pasado, se recrean las perspectivas de los sujetos. En el caso de los técnicos y profesionales intervinientes, se abordan temas vinculados a la intervención realizada sobre la zona afectada por la obra, así como a la evaluación que los mismos realizan del proceso años después.

En uno y otro caso los ejes temáticos que guían las entrevistas refieren a los efectos habitacionales y sobre la tenencia de la tierra, sobre las economías de subsistencias como sobre las redes de integración de los pobladores, así como a los efectos sobre los espacios públicos y/o comunes, causados por el proyecto de desarrollo de la Presa Potrerillos y el Plan de ordenamiento territorial y desarrollo turístico del perilago elaborado por el Gobierno de Mendoza.

En el marco de esta investigación, la incorporación de la historia oral, apelando a la memoria como fuente para recabar una serie de datos que no han quedado registrados en los documentos oficiales, nos aporta una forma más completa de comprensión del proceso en estudio y entendemos que, a la vez, constituye un medio de autoescucha de la cotidianidad, modo privilegiado de crítica y desmistificación de la macrohistoria.

Para finalizar, los testimonios se acompañan con material fotográfico sobre la cultura material, lo que nos muestra en imágenes los cambios materiales acontecidos en los lugares, las marcas en la arquitectura y en la configuración del paisaje. 


\section{CAPITULO III \\ CACHEUTA Y POTRERILLOS}

\section{Ubicación geográfica}

Las localidades de Cacheuta y Potrerillos se encuentran en el Departamento de Luján de Cuyo. La primera se localiza a $45 \mathrm{~km}$ de la Ciudad de Mendoza, a 1.245 m.s.n.m, y la segunda a $69 \mathrm{~km}$ y a 1.380 m.s.n.m. Ambas se emplazan en valles ubicados en la precordillera de la Provincia de Mendoza, localizada en el centro oeste de la República Argentina y constituían parte de un sistema de asentamientos ubicados a lo largo del denominado Corredor Andino junto a Blanco Encalada, Álvarez Condarco y Uspallata, todos situados en las proximidades del río Mendoza.

Estos parajes, previo a la obra, se conectaban urbanística y funcionalmente a través de la Ruta Nacional $\mathrm{N}^{\circ} 7$, eje de vinculación Este-Oeste que a escala regional vincula la ciudad de Mendoza con Chile, uniendo las ciudades de Santiago y Valparaíso con Buenos Aires y las brasileras de Sao Pablo y Río de Janeiro.

\section{Mapa del Departamento de Luján de Cuyo}

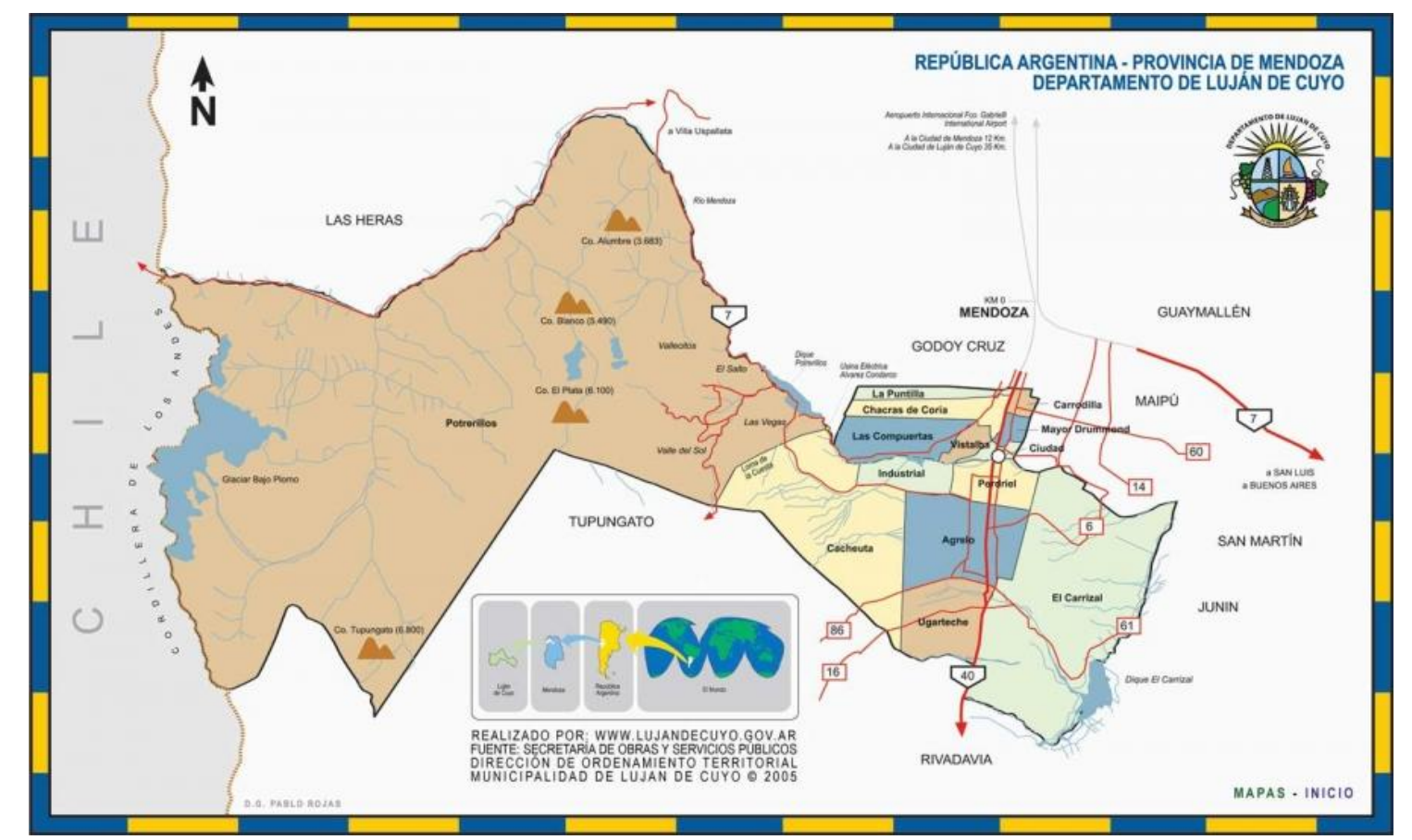

Fuente: Secretaría de Obras y Servicios Públicos. Dirección de Ordenamiento Territorial. Municipalidad de Luján de Cuyo. Disponible en: www.lujandecuyo.gov.ar 


\section{Un poco de historia}

\subsection{En la Mendoza del siglo XIX}

\subsubsection{La conquista de las aguas termales de Cacheuta}

El manantial de aguas termales que surge entre las rocas del lugar denominado Cacheuta no pasó desapercibido por los conquistadores y fue llamado en aquel entonces "Baño de la Punta del Río" y más tarde "Boca del Río". Conforme al sistema de encomiendas por el que los conquistadores se distribuían las tierras y sus habitantes, las tierras donde vivía el cacique huarpe Cacheuta y su comunidad -hoy actual lugar de Cacheuta- fueron adjudicadas al capitán Juan Ortiz de Urbina (Acordinaro, 2009). Yendo más atrás en la línea del tiempo, se afirma que:

"Siglo y medio antes de la entrada de Pizarro en los dominios de Atahualpa, en 1598, estas termas fueron incorporadas al dominio de los incas por los seguidores de Yupanqui, octavo emperador de la dinastía del Sol. Se inició por ese entonces una peregrinación de enfermos desde el Perú para aprovechar los vapores y las aguas de la fuente termal de los "Baños de la Punta del Río", como los denominó luego el conquistador" (Los Andes, 26/08/84).

Estas tierras, antes de 1822 eran disputadas con la intención de descubrir metales preciosos, sin embargo el descubrimiento de las aguas templadas hicieron de este lugar un sitio conocido por la explotación de las mismas. Aludiendo a Acordinaro (2009), las disposiciones del Cabildo de 1822 eran allanar el camino y construir un puente para llegar al lugar, fabricar cuartos y habitaciones y cubrir los baños de la intemperie como condiciones mínimas para la explotación de las aguas (p. 280).

La visita de turistas se fue fortaleciendo a lo largo de ese siglo y en 1893 se construyó un hotel y las primeras piletas balnearias en el lugar. Luego, el gobierno, por medio de la Ley 381, el 20 de junio de 1907 expropió una superficie de 35 has con destino a la construcción de un hotel de mayor escala y obras complementarias, como también celebró convenios para el uso y conservación de las termas. También convino destinar parte de lo recaudado a pasajes y pensión de los carenciados que por prescripción médica debían hacer uso de las aguas termales. El 11 de febrero de 1910, el ejecutivo, a través de la Ley 515 llamó a concurso para la explotación de las termas de Cacheuta por parte de empresas concesionarias -que generalmente fueron extranjeras o de extranjeros asociados a capitales privados (Ibidem, 2009).

Es importante destacar que en aquella primera época de la actividad turística de Cacheuta, los visitantes llegaban a través del ferrocarril, que había sido habilitado hasta 
Uspallata en 1891. Estos constituyen los antecedentes de lo que luego fue el gran Hotel Termas de Cacheuta, de relevancia nacional e internacional.

\subsubsection{Intercambios mercantiles y la participación de "Potrerillos"}

Aludiendo a Brachetta et. al (2012), después de 1820, el perfil económico de Mendoza se organizó como espacio económico intermedio entre los mercados vinculados al comercio internacional de Buenos Aires y Valparaíso. Se ligaba a los mercados de algunas áreas de Buenos Aires y Santa Fe, y la región chilena del Valle de Aconcagua. Siguiendo a las autoras, Buenos Aires era la principal compradora de vinos, frutas secas, trigo y harinas producidas localmente. Chile, por su parte, importaba de Mendoza hacienda en pie y productos derivados de la ganadería, como cueros, jabón y sebo. De Santa Fe provenía yerba originaria de Paraguay como también arroz y azúcar para consumo; y de las ciudades portuarias provenían productos importados como algodones ingleses, papel y elementos de ferretería que no se producían en la región. Sin embargo, este flujo comercial no se tradujo en beneficios relevantes para la provincia.

Luego de 1825, debido a las distancias geográficas, los costos del sistema de carga y transporte que se realizaban en carretas y recuas de mulas, los impuestos que cobraban las provincias y la disminución del consumo de vinos cuyanos por la preferencia en Buenos Aires de licores importados -en su mayoría de origen español- el intercambio se tornó desfavorable para la economía local. Ante esta situación, el entonces gobernador Pedro Molina, gestionó ante el gobierno de Rosas medidas proteccionistas para la economía local y firmó en 1835 junto al gobierno de San Juan un convenio con el país de Chile para fomentar el intercambio comercial entre lugares vecinos (Ibidem, p. 83).

Pero esta vez, arguyen las autoras, Mendoza no participó del intercambio por su perfil vitivinícola, lo hizo por la actividad ganadera (ganado en pie) y la producción de trigo y alfalfa. El mercado mendocino se acoplaba a la tradicional reexportación de ganado de Buenos Aires, del sur de Santa Fe y Córdoba hacia Chile, rubro este que por décadas se constituyó en el principal exportable del país junto al de las frutas secas, el sebo y el jabón -en menor medida-.

Vinculado a la exportación de ganado hacia Chile, Mendoza emprendió el negocio de engorde del ganado en tránsito; para ello, las tierras cultivadas de la provincia se cubrieron de alfalfares, así como de plantaciones de trigo, que hicieron relevante la producción de harina local. Debido a la extensión que adquirió el negocio de engorde de ganado, la provincia de Mendoza fue denominada el potrero de la Confederación 
Argentina (Ibidem, p.84), calificativo referido a la gran presencia de animales que se utilizó también para denominar a uno de nuestros lugares de estudio como Potrerillos en el que se desarrollaba esta actividad.

Volviendo a considerar los estudio de Brachetta et. al (2012), las relaciones comerciales trasandinas crecieron notablemente entre los años 1860 y 1872 . Mientras se importaban lienzos, tejidos, arroz, licores, cigarros, aceite, medicamentos, café, máquinas, elementos de mercería y ferretería, muebles, té, yerba, pieles, papel, indumentarias, sombreros y calzados, se continuaba exportando en primer lugar ganado, a lo que se incorporó minerales de plata, cueros y jabón.

Si bien esta ruta de intercambio obtuvo resultados beneficiosos para los empresarios mendocinos, siguiendo a las autoras citadas, la provincia no logró amortiguar los desequilibrios comerciales que mantenía en el intercambio con la región del Litoral, lo cual se debía al hecho de que el trigo y las harinas de la provincia competían en precio y calidad con los producidos en el sur de Santa Fe. Ante este panorama, los políticos y empresarios provinciales comenzaron a revalorar la actividad vitivinícola como estrategia alternativa para reconvertir la economía de la provincia. Actividad que en el tiempo se vio asociada a nuevas prácticas económicas, como por ejemplo al turismo, así como a nuevas rutas comerciales que con el correr de las décadas fueron consolidadas por la intervención estatal con obras de infraestructura que favorecieron y aceleraron el intercambio mercantil, lo cual se facilitó aún más con la llegada en 1885 del ferrocarril a la capital de Mendoza.

La adopción de la vitivinicultura como motor de crecimiento provincial en las últimas décadas del siglo XIX implicó la ampliación de las áreas cultivadas para la producción agrícola. Para ello se realizaron obras hidráulicas por parte de los empresarios vitivinícolas, así como desde el estado con sus expertos contratados - entre los que se destacó el Ing. Cipoletti-. Esta opción fue acompañada por la Ley de Tierras y la legislación de aguas para administrar el riego (1884); así también un papel primordial en este desarrollo lo tuvo la mano de obra proveniente de Italia, España y Francia en su mayoría la que ingresó al país hacia fines de siglo que incidió en la conformación sociocultural de la provincia (Ibidem, p.108).

El dominio de estos negocios en los que se basaba la economía mendocina era liderado por una élite de empresarios regionales que mantenían el control de establecimientos productivos (chacras, haciendas y estancias) dispersos a lo largo de la ruta comercial -de la época colonial- que conectaba a Mendoza con el litoral y a Mendoza con Chile. Estos 
establecimientos eran organizados de acuerdo al ciclo de producción como en relación con el acceso al agua (Ibidem, p.86).

En el distrito de Potrerillos, en la época colonial, el capitán Juan Luis de Guevara, constituyó una de sus estancias de haciendas, con distintos potreros (Maza, 1990). Allí se localizaron la estancia El Plata, de propiedad de Genaro Segura y Frankil Guevara, que luego pasó a ser propiedad de Gaetano Larroca; la estancia San Ignacio, de propiedad del Dr. Juan Agustín Maza, la cual pasó a su descendencia; y la estancia El Salto, que fue adquirida en propiedad por el Ing. Luis Fourcade y hoy pertenece a sus sucesores. Estas grandes extensiones se proveían de las aguas del río Blanco y de los arroyos Salto de las vacas y Las mulas, los cuales han sido fundamentales para los asentamientos humanos.

\subsection{El siglo XX en Los Andes mendocinos}

Una serie de hechos y acontecimientos vinculados a las políticas nacionales económicas y sociales, así como a los ciclos y belleza de la naturaleza se articulan para dar forma a los parajes de Cacheuta y Potrerillos. Entre los sucesos más relevantes se encuentra el emplazamiento en las zonas del proyecto de inversión y desarrollo del Ferrocarril Trasandino (1872-1984) y sus estaciones, que conllevó obras de infraestructura asociadas al servicio de transporte como la construcción de grandes hoteles cordilleranos, la apertura del corredor andino -posterior Ruta Internacional N7-, así como también, vinculado al crecimiento de la población, la construcción de obras de equipamientos como escuelas, centros de salud y destacamentos policiales. Intercalado con estas obras podemos citar también otros hitos productos de los ciclos de la naturaleza como los aluviones de los años 1934 y 1965 que como consecuencia generaron destrozos materiales y pérdidas humanas, lo cual afectó la vida económica y social de los lugares. Asociado a estas transformaciones, estos valles se fueron poblando así como parcelando sus largas estancias agrícolas y ganaderas formadas desde la colonia (Estancia El Plata, Estancia El Salto y Estancia San Ignacio), dando lugar en estos parajes a la proliferación de viviendas de residencia permanentes para quienes trabajaban la tierra, con los animales, en servicios turísticos, en las instituciones públicas, etc., así como también de casas y diversos alojamientos de fin de semana de quienes residen en la ciudad.

Así mismo, a lo largo del siglo XX y como antecedentes del proyecto de inversión y desarrollo de la Presa Potrerillos, que comenzó a ser construida en el último año del siglo, se realizaron sucesivos estudios sobre la conveniencia de embalsar el agua del Río Mendoza. A continuación se profundizará en los acontecimientos expuestos. 


\subsubsection{El Trasandino y los comienzos del turismo de montaña}

Desde los primeros años del siglo XX, se extienden a lo ancho de Mendoza las vías del Ferrocarril Transandino, que unía en sus extremos a las capitales de las ciudades de Buenos Aires y Santiago de Chile. Si bien la construcción de la traza comienza en 1872, la obra atravesó los lugares de Cacheuta y Potrerillos y llegó a Puente del Inca en el año 1902 (Lacoste, 2000). Este emprendimiento de capitales británicos, administrado por el F.C. Pacífico ofrecía el servicio de traslado de personas y cargas.

Asociado a su actividad principal, la empresa impulsó otros servicios como el de facilitar la circulación de información a través de la Revista Mensual BAP ${ }^{5}$, y el Boletín Informativo sobre la actividad agrícola y frutícola que se realizaba aledaña a las estaciones de la República Argentina. A través de estas publicaciones periódicas también se promocionaba turísticamente a algunos lugares de lo largo de la traza, como por ejemplo a Puente del Inca, Cacheuta y Uspallata en el caso de Mendoza. De este modo el F.C. Pacífico ocupo un papel importante en el fomento del intercambio y mejoramiento de la productividad del agro como de la promoción turística dentro del país (Ibidem, p. 148149). Así, alrededor de esta obra de transporte y comunicaciones se potenció el intercambio entre las ciudades y pueblos existentes así como se dio inicio a la conformación de nuevos asentamientos humanos.

En Cacheuta y Potrerillos, nuestros lugares de estudio, vinculado a las estaciones del ferrocarril se realizaron emprendimientos turísticos y comerciales que dieron inicio al turismo de montaña como actividad económica, lo cual fomentó a estos valles como destinos de residencia y trabajo para algunos y de visita para otros, en su mayoría argentinos y chilenos.

Aledaño a la Estación Cacheuta se construyó el Hotel Termas de Cacheuta (1913-1934), que junto al Hotel de Puente del Inca (1903-1965), fueron promovidos turísticamente por la Compañía de Hoteles Sudamericanos -empresa subsidiaria del F.C. Pacífico- que los administraba (Ibidem). Estas instalaciones, atendiendo a la historia del turismo en Argentina o a la incorporación de las vacaciones como práctica social (Pastoriza, 2011), son dos de los tantos hoteles que a lo largo del siglo $\mathrm{XX}$ se construyeron para brindar servicios para el ocio a las distintas clases sociales -primero a las altas y aristocráticas, luego a las clases medias y por último a los trabajadores- en los centros turísticos que se fueron consolidando en Argentina ${ }^{6}$.

\footnotetext{
${ }^{5}$ Esta revista impulsada por Editorial Atlántida se editó entre 1917 y 1947 (Lacoste, 2000, p.148).

${ }^{6} \mathrm{Al}$ respecto, Pastoriza (2011) profundiza en las concepciones y prácticas culturales relacionadas con el turismo y el ocio que fueron configurando desde fines del siglo $\mathrm{XIX}$, pequeñas ciudades
} 
El Hotel Termas de Cacheuta, y sus lujosas instalaciones y servicios ${ }^{7}$ hicieron de Cacheuta un centro turístico sobresaliente de Mendoza y del país, que contaba con actividades todo el año, siendo visitado por científicos de muchas nacionalidades en tiempo en que la medicina proponía los baños termales como forma de cura de dolencias de los huesos, piel, ciática y otras, así como por personalidades de la política y las artes, llegando a registrar entre 1913 y 1919 la visita de más de 30.000 personas (Los Andes, $26 / 08 / 84)^{8}$.

A continuación del complejo hotelero, otra obra de relevancia fue la construcción de la Usina hidroeléctrica de Cacheuta por parte de la Empresa Luz y Fuerza en 1926 en el denominado Cajón de Cacheuta. Esta obra, entre sus instalaciones comprendía un dique derivador, un túnel de conducción y la línea de transmisión de transporte de energía, como también la construcción de viviendas para el personal, así como una escuela y un cementerio (Acordinaro, 2009). Estas residencias localizadas en distintos desniveles y los servicios de hotelería primero, sumado luego a la instalación de hosterías y casas de té, son las que dan cuerpo al pueblo de Cacheuta, al que en 1928 llegaba desde la ciudad un camino de tierra.

turísticas ribereñas entre las que sobresalió Mar del Plata, con la presencia de numerosos balnearios. Estímulo este que luego se extendió -asociado a las instalaciones del ferrocarril primero y de las carreteras automovilísticas después- a los lugares serranos y termales, como Córdoba y Mendoza. Así es, que en materia turística, en la primer mitad del siglo XX, los sitios que se tornaron más conocidos fueron los hoteles: Bristol Hotel de Mar del Plata (1886), el Plaza Hotel (1909) y el Club Hotel de la Ventana (1911) en Buenos Aires; en Córdoba el Sierras Hotel (Alta Gracia), Hotel Yacanto (Villa Dolores) y el Edén Hotel (La Falda); y en Mendoza: el Termas Hotel Puente del Inca y el Hotel Termas de Cacheuta.

${ }^{7}$ Este hotel de dos plantas disponía de 147 habitaciones, dos comedores, sala de lectura, sala de música, sala de juego, cinematógrafo y teatro, una terraza con vista al río adornada con obras de arte, un mirador y jardines en distintos niveles entre las escalinatas. Una cocina y carnicería, panadería, pastelería, verdulería y fiambrería, así como tambo, criaderos de aves y conejos, una sección para la fabricación de hielo y aguas gaseosas -el agua utilizada provenía del Río Blanco-. Su estructura edilicia también contemplaba habitaciones para el personal del hotel, un pabellón para los enfermos carenciados que utilizaban los servicios por prescripción médica, una farmacia y consultorio médico, una capilla y una caballeriza (Acordinaro, 2009). En cuanto a los baños termales, contaba con 19 piezas con bañeras y dos grutas destinadas a vapor de agua y emanaciones radiactivas, locales para masajes, otros para descanso, y baños de lluvia, una peluquería y un depósito de ropa (Los Andes, 26-08-84).

${ }^{8}$ Aludiendo a Acordinaro (2009) la explosión turística en Cacheuta fue favorecida por dos motivos de índole internacional: por un lado, la inauguración de este Hotel Internacional sucedió en una época en que los baños termales eran el turismo de moda de las élites. Por otro lado, el hecho de que la primera guerra mundial impedía en Europa las actividades turísticas de las reconocidas termales italianas de Veneto, Montecatini y Capri, lo cual llevó a esta clase social a explorar termas sudamericanas. 

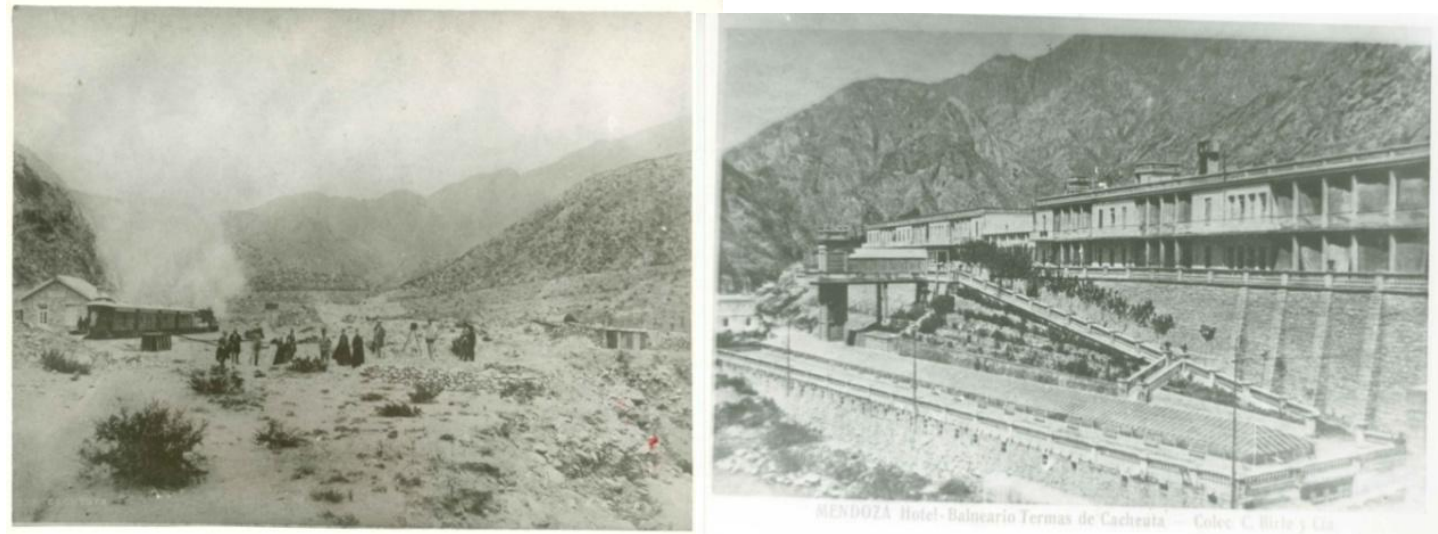

Imagen 1: Estación Ferrocarril de Cacheuta. Foto del Archivo General de la Provincia de Mendoza. Imagen 2: Hotel Balneario Termas de Cacheuta. Colec. C. Birle y Cía. Foto del Archivo General de la Provincia de Mendoza.
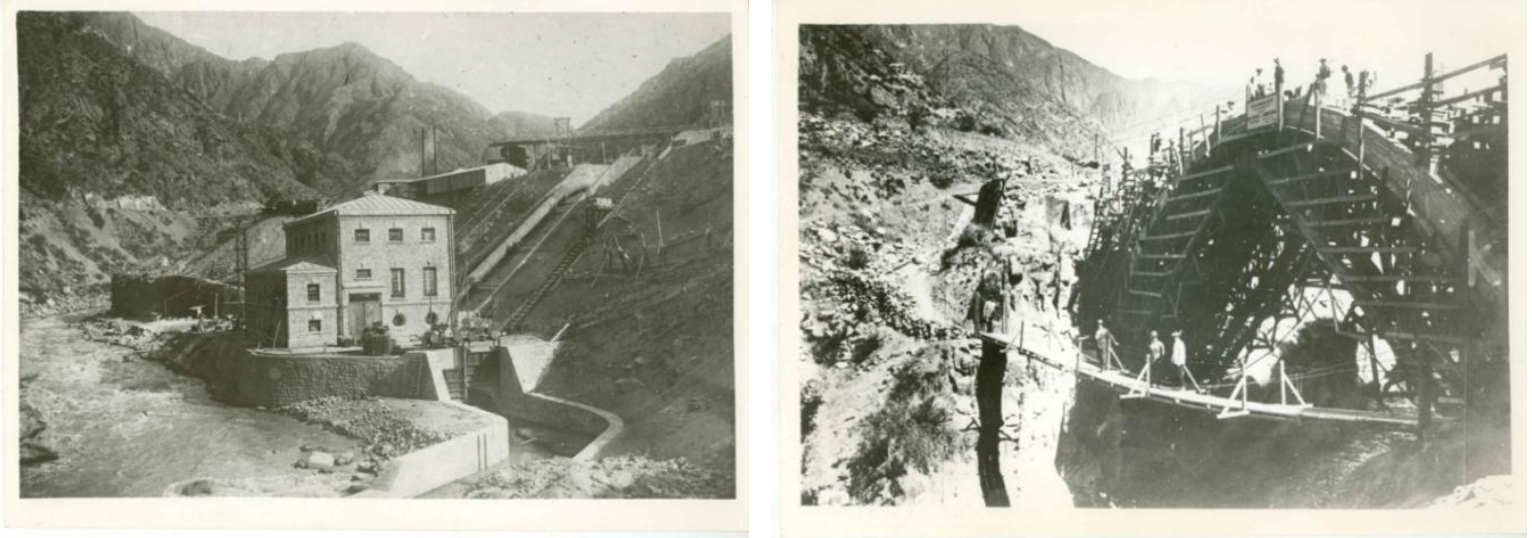

Imagen 3: Usina eléctrica Cacheuta inaugurada en 1926. Foto del Archivo General de la Nación y del Archivo General de la Provincia de Mendoza.

Imagen 4: Puente en construcción camino a Cacheuta 1928. Foto del Archivo General de la Nación y del Archivo General de la Provincia de Mendoza.

\subsubsection{El aluvión de 1934: rupturas y reacomodos}

En enero de 1934 un aluvión ${ }^{9}$ interrumpió y luego dio un nuevo impulso al proceso económico turístico iniciado en la zona de montaña. El derrumbe del Glaciar del Río

\footnotetext{
${ }^{9}$ Aclara Villegas de Lillo (2002):

"Cuando el Glaciar grande del Nevado avanza precipitadamente por su valle en dirección oeste-este, cruza el cauce del río Plomo y se suelda con las estibaciones occidentales del Cordón de los Chorrillos. Impide entonces que el río Plomo siga su curso y forma una laguna con importantes volúmenes de agua. Generalmente un vertedero natural desagua la laguna, pero cuando cede y se rompe una gran masa de agua llega repentinamente al Río Mendoza, aumenta su caudal instantáneamente y corre a toda velocidad aguas abajo, arrasando todo a su paso.

Este fenómeno cíclico (1786...., 1933-1934..., 1984-1985...) siempre ocasionó pérdida de vidas humanas y daños materiales. Puede llegar a cobrar tal nivel de catástrofe que ha
} 
Plomo y la vulnerabilidad del cajón del Río Mendoza destruyeron parte del Hotel Termas de Cacheuta, -el cual dejó de funcionar hasta 1937-, de la Usina hidroeléctrica de Cacheuta, como también las vías del Trasandino desde Punta de Vaca a la ciudad de Mendoza.

Este acontecimiento afectó no solo a las personas residentes y las actividades promovidas hasta el momento en los lugares, sino que también se vieron comprometidos los distintos sectores económicos, sociales y culturales que se conectaba a través de este servicio de transporte, como los trabajadores ferroviarios que quedaron cesantes sin leyes de protección laboral, y las relaciones entre los países de Argentina y Chile que se vieron empañadas de modo considerable. Aún cuando el servicio de este medio de transporte se continúo prestando desde Punta de Vaca hasta Los Andes, trayecto en el que las vías no habían sido afectadas, este hecho, siguiendo los estudios de Lacoste (2000), significó el final definitivo de los servicios del trasandino de capitales británicos (pp. 245-253).

A partir de este momento intervenciones del Estado se suceden en función de dar respuesta en materia de transporte. El Estado diseño un sistema alternativo mixto de camiones y buses para cubrir el trayecto de Punta de Vaca a Mendoza, pero esta vez utilizando el camino de tierra que pasa por Uspallata y Villavicencio. Este sistema, más caro, lento y seguro fue el que se utilizó aludiendo al mismo por el lapso de 10 años.

Esta interrupción generó, por otro lado, un fuerte impulso al desarrollo vial sobre el nuevo corredor andino como la pavimentación de la carretera que une Mendoza-Villavicencio, el arreglo de los caracoles de Villavicencio (que une Villavicencio-Cruz de Paramillo), y mejoras en los tramos de Uspallata y Punta de Vaca. Estas inversiones públicas en obras viales para la circulación de autos, camiones y micros fueron acompañadas con inversiones en más hoteles de montaña, como los Hoteles de Uspallata (1936) y Villavicencio (1940) (Ibidem, 2000).

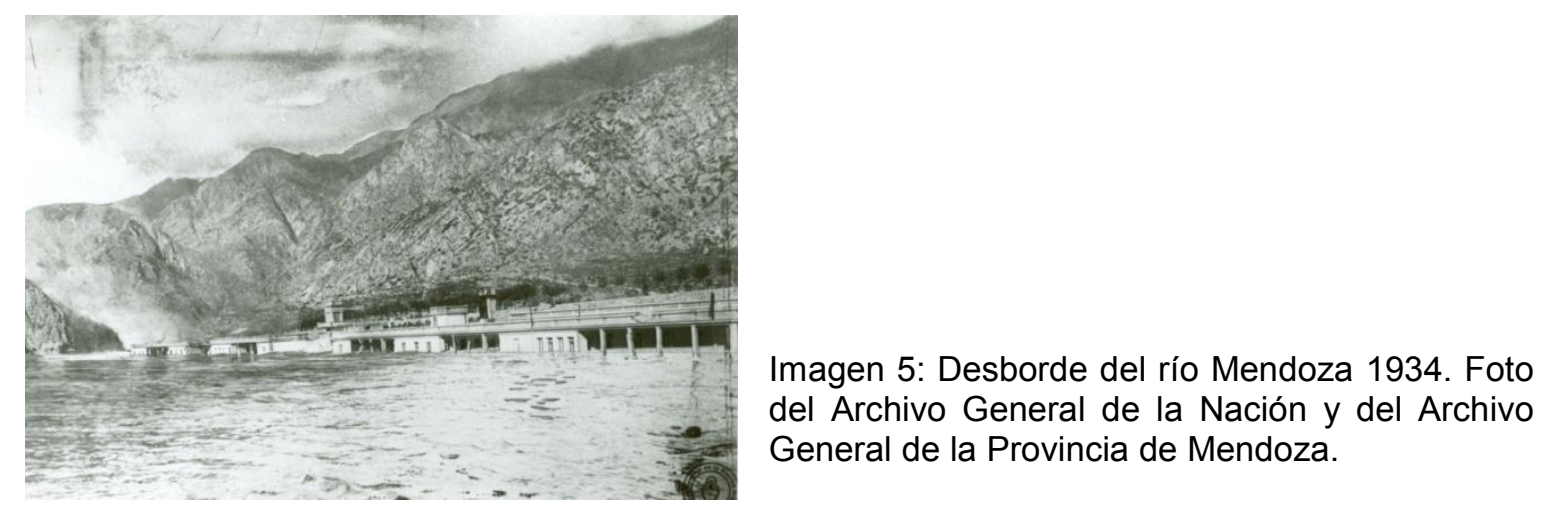

sido considerado como premisa para el cálculo de la cota máxima de elevación del nivel del agua, en el embalse de la Presa Potrerillos" (p.113). 


\subsubsection{Nuevos impulsos: carreteras e integración cordillerana}

Sumado al desarrollo turístico expuesto, con el objetivo de promover la integración turística de los valles de la zona cordillerana, el destino a Potrerillos como excursión de recreo comenzó a ser ofrecido por la empresa de transporte y comunicación que trasladaba desde la capital de Mendoza pasajeros al Hotel Termas de Cacheuta. Esta apuesta al turismo, fue favorecida por el entonces gobernador Guillermo Cano (19351938) que como objetivo de gobierno se propuso el fomento y promoción de Cacheuta, Potrerillos y Puente del Inca como lugares de atracción turística, para lo cual invirtió en obras viales y puentes como por ejemplo el realizado sobre el río Mendoza en el camino a Cacheuta. Estas obras se realizaron en el marco de la ley $\mathrm{N}^{\circ} 1216$ que Cano propuso y propició ante la $\mathrm{H}$. Legislatura con la finalidad de crear el turismo como la nueva industria de la provincia. Al respecto, en el discurso elevado ante este órgano, dando cuenta de la labor cumplida en el período de su mandato el mismo expresaba:

“...cuenta Mendoza con un conjunto de condiciones no igualadas por otra región del país: clima benigno y saludable con noches frescas en verano y espléndido sol en los días de invierno; bellezas panorámicas de todo orden; una espléndida red de caminos; productos regionales de alta calidad, con sus vinos y sus frutas; fuentes termales en abundancia, cuyas aguas tienen cualidades curativas ya probadas; y numerosos lugares históricos llenos de evocación para el viajero.

Movilizar ese conjunto de condiciones, coordinar la acción de los distintos organismos del Estado para el fomento del turismo y crear las comodidades necesarias de alojamiento, esa es la finalidad de la Ley 1216" (Gob. Cano, 1938, p.253).

Esta labor de promoción se realizó desde la Dirección Provincial de Turismo a través de todos los medios de comunicación: guías, folletos, diarios, revistas, afiches, carteles murales y en tranvías, postales, estampillas, estaciones radiodifusoras y las columnas de la prensa nacional con información necesaria para el visitante ${ }^{10}$.

Como parte de los servicios ofrecidos se fomentó la organización de excursiones a Mendoza desde Buenos Aires y el litoral argentino; para ello la firma PC Pacífico incorporó el servicio ferroviario del tren "El cuyano" que reducían el tiempo de traslado de Buenos Aires a Mendoza a 15 horas, lo que aumentó el movimiento de pasajeros. Como

\footnotetext{
${ }^{10}$ Entre las ofertas publicadas se encontraban: 1) Una lista de hoteles con sus direcciones y precios; 2) Campamento histórico del Plumerillo; 3) Iglesia y Calvario de La Carrodilla; 4) Trenes rápidos a Mendoza; 5) Guía General para una estadía económica; 6) Fiesta de la Vendimia de 1937; 7) El Parque de Mendoza; 8) "Camping" en Mendoza; 9) Provisión y desinfección de agua del Balneario "Playas Serranas"; 10) Curas uvo-termales; 11) Platos Mendocinos y 12) La Virgen de la Carrodilla Patrona de los Viñedos (Cano, 1938:256). A esta promoción se añadió luego la de la Fiesta de la Vendimia, evento propio de los trabajadores de las viñas, que fue apropiada por el Estado haciendo de ella un evento oficial en el mandato del mismo gobernador.
} 
parte de este plan también se promovió la habilitación de comodidades de alojamiento en casas de familia, la ampliación y mejoramiento de hoteles por parte de sus dueños, como la construcción de hoteles y hosterías nuevos (Cano, 1938). Referido a Potrerillos, textualmente el gobernador en el documento citado exponía:

"En la propiedad fiscal de Potrerillos se ha organizado un servicio de "camping", que constituye el primer ensayo orgánico que sobre la materia se hace en el país.

Se ha instalado allí un campamento dividido en dos secciones, con capacidad para ciento cincuenta personas.

Se recibe al turista en una carpa armada que cuenta con un catre, colchoneta, mesa, banco, farol y tacho para agua.

El campamento tiene comodidades instaladas para servicios sanitarios, ducha higiénica y agua caliente para cada sección. Hay también pileta para natación.

Además, hay una pista central para baile y reuniones, con servicio de restaurant y cantina anexos, siendo los precios controlados por la Dirección Provincial de Turismo.

El costo del transporte desde Buenos Aires al campamento, ida y vuelta con una estadía en éste de 15 días, es de \$155.-para mayores.

Hasta ahora el campamento que comenzó a funcionar en los primeros días de Enero, ha recibido 470 personas, siendo unánime la satisfacción por la comodidad de las instalaciones, la buena alimentación y la vida natural, sana y con atractivos, que se hace en el "Camping" de Potrerillos (p. 259).

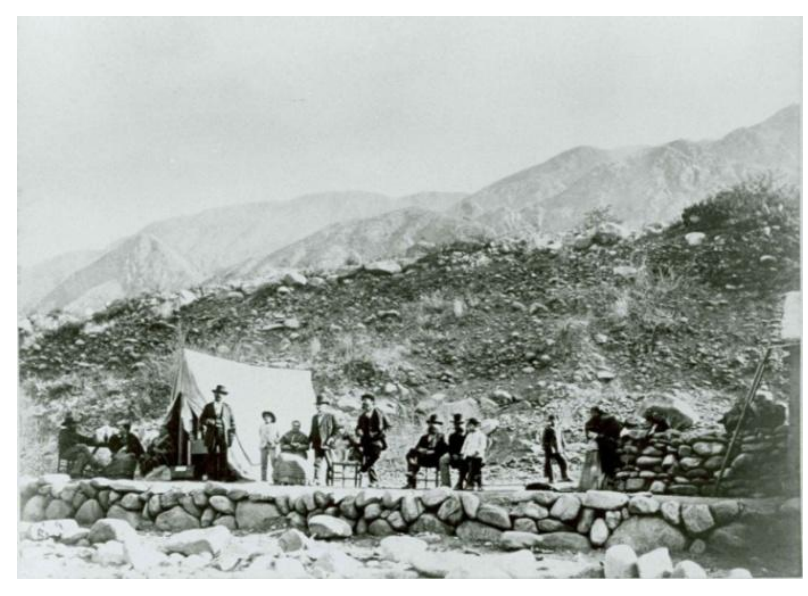

Imagen 6: Provincia de Mendoza. Garganta del Río Mendoza. Álbum de Alberto Rodríguez. Foto del Archivo General de la Provincia de Mendoza.

Esta política de integración turística de los valles cordilleranos se vio fortalecida por parte del Estado con la inversión en carreteras viales. Así en 1935 se habilitó el tramo desde Cacheuta a Potrerillos y en 1941 se inició el asfalto de ese tramo. Esta carretera constituiría posteriormente y hasta la construcción del Dique Potrerillos la ruta Internacional $\mathrm{N}^{\circ} 7$.

Aludiendo a Pastoriza (2011) con la emergencia del automotor, en los primeros años del SXX surgieron asociaciones de deportistas como el Automóvil Club Argentino (ACA) y el Touring Club Argentino (TCA), las cuales a través de mapas y revistas se dedicaron a promocionar recorridos turísticos urbanos y rurales -entre los que se encontraban los 
destinos de Cacheuta y Potrerillos-; a la vez, que les exigían al Estado la construcción de caminos y la difusión de educación vial (p.85). Esta vinculación entre el Estado y asociaciones privadas creció en los años 30, de tal modo que en 1936 el ACA estrechó lazos con el Estado, logrando un convenio con Yacimiento Petrolíferos Fiscales (YPF), por el cual a lo largo del país se construyeron la red nacional de Estaciones de Servicios, como también edificios del ACA en las ciudades cabeceras, "con la triple función de ser sedes sociales, garajes y estaciones de servicios" (Ibidem, p.113).

La instalación de Estación de Servicios YPF y de los servicios de ACA -en este caso camping- llegaron también a Potrerillos. Estos, junto a los servicios que detallaremos a continuación, forman parte de las condiciones ofrecidas por el lugar para la atracción de turistas y parada obligada de quienes circulaban desde y hacia el país de Chile.

La integración de los valles cordilleranos se vio completada en 1961 cuando se construyó un puente sobre el río Mendoza uniendo a las poblaciones de Potrerillos y Uspallata, que desde el cese del servicio ferroviario estuvieron separadas. Este tramo de $50 \mathrm{~km}$ quedó pavimentado en 1971, desde entonces Potrerillos se constituyó en parada obligada para quienes circulaban con destino al país trasandino o arribaban a Mendoza desde el mismo por la Ruta Internacional $\mathrm{N}^{\circ} 7$.

\subsubsection{Potrerillos, a partir de los 40' y hasta la llegada de la presa}

En la intersección de los ríos Blanco y Mendoza, alrededor de la Estación de Potrerillos, el 25 de enero de 1942 se inauguraba el Gran Hotel Potrerillos construido por el Estado provincial $^{11}$. Siguiendo el mismo estilo arquitectónico del hotel, aledaño se construyó el Centro Cívico que fue oficialmente inaugurado en 1945. De esta manera, "Villa Potrerillos" se constituía en el paraje cabecera del Distrito de Potrerillos que incluía en aquellos años a las estancias mencionadas.

La pavimentación del corredor andino y luego la apertura de caminos por parte de la Dirección Provincial de Vialidad (DPV) hacia los valles de Potrerillos, posibilitó a lo largo de los años cuarenta la instalación de emprendimientos públicos y privados que contribuyeron al crecimiento de la población como al desarrollo de nuevas actividades económicas en estos parajes. A las actividades agrícolas y ganaderas realizadas en las

\footnotetext{
${ }^{11} \mathrm{El}$ mismo contaba con equipamiento de jerarquía, por lo que se le otorga categoría de hotel cinco estrellas (Villegas de Lillo, 2002).
} 
estancias El Salto, El Plata y San Ignacio, así como minera ${ }^{12}$, se sumó la actividad turística y la de los empleados públicos que prestaban servicios en el lugar.

Al Hotel Potrerillos se sumaron emprendimientos turísticos de índole privada como la Residencia "Cariño Botao", los hoteles "Los Pinos" y "El Carmelo" y las hosterías "Mi Montaña" y "San Antonio". Así también, en esta década en el valle de Vallecitos, donde se acumulaba nieve sobre las quebradas del Cordón del Plata, se creó un centro de ski, el cual debido a los inadecuados caminos dejó de funcionar hasta 1962 cuando se realizó el 7 y 8 de julio el "Primer Festival de la Nieve en la Provincia". Además de lugar de referencia para la realización de deportes invernales, este valle se fue constituyendo en lugar de aclimatación de andinistas que se preparan para ascender al Cerro Aconcagua.

Esta gran actividad hotelera considerando los estudios de Villegas de Lillo (2002) se mantiene activa hasta la década del 60, en que deviene un proceso de decadencia a lo largo del circuito turístico de montaña. Esto se debe, en parte al alud que en 1965 destruyó el Hotel Termas de Puente del Inca, dejándolo definitivamente fuera de servicio, así como a las roturas que sufrió el Hotel Termas de Cacheuta que en 1970 es cerrado, abandonado y saqueado. La misma suerte corre el Gran Hotel Potrerillos, que deja de prestar sus servicios en 1967, este es luego reabierto y mantiene su funcionamiento hasta comienzos de la obra de la Presa Potrerillos (p. 113). Siguiendo a la autora, de los hoteles de montaña, el único que continuó funcionando en forma ininterrumpida hasta la fecha es el Hotel Uspallata. Otras causas de este decaimiento a las que hace referencia son la escasa oferta de actividades ofrecida por estos hoteles, lo que hace a sus servicios poco rentables y en ningún caso autosustentables; y el hecho de que en este último tercio del SXX se evidencia en los turistas -de elite- la preferencia por visitar el exterior.

Mientras tanto, a partir de los años sesenta se comienza el fraccionamiento de las estancias, siendo la primera la tierra de Cornejo Lecina. Esto dio lugar a un Potrerillos compuesto de nuevas localidades como Las Vegas, El Salto, Villa Fourcade, El Carmelo, Piedras Blancas, Los Zorzales, Refugio Don Bosco, Valle del Sol, Alto Manantiales, Chacritas, Las Carditas, El Refugio, Vallecitos, etc. A partir del loteo, en estos parajes se fue incrementando la construcción de casas de fin de semana, cabañas, casas de té, restaurantes, hosterías, etc. Según dato de Villegas de Lillo (2002), las casas de fin de

\footnotetext{
${ }^{12}$ Las minas más importantes son las de bentonita, ubicadas en la Estancia El Salto y Cacheuta Sur, al norte del Cerro Cocodrilo y en la Estancia San Ignacio. Le sigue en importancia la arcilla, la que se explota sobre la Ruta Provincial $\mathrm{N}^{\circ} 89$ antes de llegar a la planta potabilizadora y alrededor del puesto Agua de Las Avispas. Existen además extracciones de áridos en la margen derecha del río Mendoza a la altura del desvío al Gran Hotel Potrerillos y en la zona próxima al Camping "Don Domingo", que quedó bajo el agua (Gudiño de Muñoz, 2002).
} 
semana en 1998 llegaron a sumar 1800, número que desde entonces a la actualidad continúa creciendo.

En este marco, la actividad de la construcción, comienza a surgir en la zona como fuente laboral y atrae población en busca de trabajo, de esta manera contribuye al crecimiento de la población de residencia permanente y de residencia temporaria. La proliferación de casas de fin de semana lleva también al surgimiento de los servicios de jardinería, vigilancia, reparaciones, comercios y proveedurías como fuentes de sustento económico. Estas actividades llevan a Potrerillos a posicionarse como uno de los centros turísticos para el descanso y la recreación más importante del circuito de alta montaña.

En cuanto a la situación de tenencia de las tierras, fuera de las estancias, las tierras ocupadas son en su mayoría consideradas fiscales, o han sido cedidas para la explotación minera. En este contexto, en la zona existen familias colonas instaladas desde hace más de 100 años, otras constituyen la segunda generación de las primeras y otras han sido atraídas por las posibilidades de trabajo que ofrece la zona desde la década del 40 (Gudiño de Muñoz, 2002, p.97).

En relación a las funciones y equipamientos con que llegó a contar Villa Potrerillos a fines de siglo, aludiendo a Villegas de Lillo, este lugar fue categorizado como Centro Polifuncional Secundario, es decir, contaba con los siguientes servicios:

"- de administración: representaciones del Gobierno Nacional y Provincial como Registro Civil y agencias de Obras Sanitarias Mendoza S.A., Empresa Distribuidora de Energía Mendoza S.A., Dirección Provincial de Vialidad, Departamento General de Irrigación.

- a la comunidad: instituciones públicas y privadas como escuelas primaria y secundaria, centro de salud, policía, patrulla fija de gendarmería nacional, delegación de bomberos, hogar de Ancianos de la Dirección de Ancianidad.

- de protección ambiental como Dirección de Bosques y Recursos Naturales, forestación y vivero.

- sociales: tales como organizaciones comunales (uniones vecinales, sindicatos, mutuales), centros de culto (templos evangélicos, parroquias o capillas), centro artesanal, cultural y biblioteca (en la antigua Estación del Ferrocarril), Centro Tradicionalista, Club Juvenil de Potrerillos, cancha de fútbol.

- de comunicaciones: correo, teléfonos públicos y más de 40 líneas privadas, CTI, antena satelital (TDH), repetidoras de televisión abierta y por cable.

- recreativos turísticos: infraestructura para la atención del turismo (hoteles u hosterías, restaurantes, cabañas para alquiler, campings) y empresas para turismo aventura (rafting, cabalgatas, trekking y expediciones.

- comercios: despensas y sandwicherías, minimarket, proveedurías generales, panaderías, kioscos, viveros, corralón, centros dedicados a la producción exhibición y venta de artesanías para abastecer a mendocinos y turistas.

-relacionadas con el transporte: estaciones de servicio, talleres mecánicos y gomerías, transporte colectivo de pasajeros con frecuencia diaria y a diversos horarios de líneas privadas" (Ibidem, pp.111-112). 
Con respecto a la localidad de Cacheuta, esta es considerada antes de la realización de la obra centro unifuncional en cuanto que su actividad principal es la producción de energía eléctrica (DOADU, 2000, p.57). Estas actividades, equipamiento e infraestructura de los lugar, a fines de la década del 90 y principio del nuevo siglo sufren cambios asociados con la construcción de la Presa Potrerillos, sobre ello ampliaremos más abajo.

\subsubsection{La necesidad de embalsar el agua del río Mendoza}

En un contexto de escasez hídrica y fragmentación territorial, Mendoza no es ajena a los escenarios de aridez hídrica que se agudizan en las tierras secas del mundo. Se localiza en la zona templada y en la denominada "Diagonal Árida Sudamericana" por lo que posee un clima árido a semiárido con un promedio de precipitaciones de $200 \mathrm{~mm}$ anuales. De esta forma, los aportes hídricos que se utilizan en las tierras secas irrigadas, es decir, en los oasis, provienen casi en su totalidad de la fusión de las nieves y glaciares ubicados en la Cordillera de los Andes. Estos ríos de régimen nivo-glacial han definido importantes cuencas con grandes centros urbanos y superficies bajo riego.

En este marco, el manejo del agua en Mendoza produce un territorio fragmentado en el que los oasis artificiales de riego ocupan sólo un $3 \%$ de la superficie de Mendoza (Therburg et al. 2004, p. 1). En las tierras secas irrigadas (oasis), el 98,5\% de un total de 1.741.610 habitantes que viven en la provincia (INDEC, 2010) practica sus actividades conformando núcleos agrourbano-industriales. El resto del territorio, las tierras secas no irrigadas, que representan el $97 \%$ de la superficie, constituyen una zona de planicies y cordones montañosos donde habita el 1,5\% de la población (Therburg et al. 2004, p. 10).

Si bien el Departamento General de Irrigación (DGI), destaca que la provincia se encuentra en "alerta hídrico", o sea, que el agua es escasa en cantidad y que su calidad se está viendo comprometida, la mentada escasez hídrica en la provincia no es vivida por todos de la misma forma. Esta situación se vislumbra en el gran contraste entre tierras irrigadas y tierras no irrigadas, fragmentación que se explica en palabras de Montaña et al (2005) "en la apropiación y manejo de los caudales de los ríos mendocinos y de los acuíferos por parte de determinados grupos sociales" (p. 28).

Este panorama de escasez se agudiza en el oasis Norte y, en particular en la cuenca del río Mendoza, ya que es la más comprometida debido a su concentración demográfica y económica. Posee el mayor aglomerado urbano y constituye la primera metrópolis regional del oeste argentino denominada Área Metropolitana de Mendoza. Esta concentra más del $60 \%$ del total de la población mendocina y la mayor actividad agroindustrial, 
comercial y de servicios de la provincia; pero también es una cuenca que en su recorrido posee marcadas contradicciones territoriales entre las poblaciones ubicadas en su tramo superior y los poblados sitos aguas abajo (Grosso y Raffani, 2013).

En el marco de lo expuesto, hacia fines del siglo XIX surge la idea de embalsar las aguas del Río Mendoza a fin de incrementar la dotación de este bien para el oasis norte de la provincia. La necesidad de tal intervención, llevó a los gobiernos que se sucedieron a los largo del siglo XX a realizar estudios sobre su factibilidad, sin embargo la construcción de la presa, después de numerosos intentos se concretó en los últimos años del siglo.

Un punteo sobre la historia de este proyecto se remonta a 1898, cuando el Ing. Cipolletti manifestaba la necesidad de aprovechar las aguas del Río Mendoza. Esta necesidad también fue expresada posteriormente por el Ing. Fush -uno de los descubridores del petróleo en Mendoza-, el Ing. Casaffoush, quien esbozó un primer proyecto en 1909, y el Ing. Ivaniservich quien en 1916 le introdujo algunas modificaciones al anterior. Luego, el Gobernador Lencinas con la idea de realizar la obra en el Distrito de Uspallata del Departamento de Las Heras contrató al Ing. Ward de Inglaterra para que estudiara las centrales hidraúlicas y los embalses de los ríos Tunuyán, Diamante y Atuel, así como la regulación del Río Mendoza. Este último, en 1923 desestimó la idea de construir la presa en Uspallata por la de realizarla en Potrerillos (Lafalla, 2010, p.287).

Durante las décadas siguientes continuaron los estudios sobre el aprovechamiento del río Mendoza. En los años 30, ingenieros de la entonces empresa petrolera estatal YPF realizaron estudios geológicos, estos fueron continuados en los años 41 y 43 por el Ing. Brandmay, quien indicó que sus resultados eran favorables para la construcción de la obra. En 1948, Agua y Energía Eléctrica contrató a la Sociedad Argentina de Ingenieros Proyectistas (SADIP) nuevamente para la ejecución de estudios en relación a los Proyectos Potrerillos, Uspallata y Salto de Potrerillos. Entre 1962 y 1964 esta tarea fue realizada por estudiosos japoneses y en 1967 se realizaron perforaciones en la zona del posible emplazamiento de la presa, a lo que se sucedieron contrataciones de consultoras internacionales, como la de un consorcio español que en 1969 advirtió las conveniencias de la realización de la obra. A partir de estos resultados, en 1975 la Consultora Bolognesi Morletto, propuso la construcción de una presa de $800 \mathrm{hm}^{3}$ en Uspallata. Debido a la inestabilidad institucional de la época y al golpe de Estado en 1976 una vez más no se comenzó con la obra (Lacoste, 1998).

El gobierno de facto cívico-militar, en diciembre de 1979, también anunció que se realizaría la presa y la ampliación de las centrales hidráulicas de Cacheuta y Álvarez 
Condarco bajo el proyecto que denominó Aprovechamiento Múltiple Potrerillos (Diario Los Andes, 26-12-79); y en marzo de 1980 llamó a concurso para la precalificación de las empresas. Sin embargo en marzo de ese mismo año, fecha en que el gobierno había prometido que iba a comenzar las obras, no sucedió nada.

Luego, en marzo del 82, bajo el régimen del gobierno de facto de Cejuela, se llamó a licitación para la construcción de la obra y a la misma se presentaron cuatro consorcios oferentes. Lacoste (1998) arguye que "tras el estudio técnico de las propuestas, el Gobierno resolvió declarar desierta la licitación, por incapacidad gubernamental de financiamiento" (p.130). Así es, que los dictadores tampoco ejecutaron el proyecto.

Con el retorno de la democracia, el Gobernador Llaver (1983-1987) también anunció que se realizaría el dique Potrerillos. Si bien en el año 87 el proyecto fue aprobado en la Legislatura, el gobierno no contaba con los fondos necesarios para la construcción del emprendimiento. La idea de realizar la obra fue retomada por el Gobernador Gabrielli (1991-1995), quien en el marco de avanzar en una política de Estado, creó una comisión pluripartidista y multidisciplinaria para el estudio del proyecto, la cual propuso llamar a licitación para elaborar nuevos estudios. Aludiendo a Lacoste (Ibidem, p.131) se solicitaba a las empresas cotizar el proyecto conocido elaborado en 1979 que proponía realizar una presa de $750 \mathrm{hm}^{3}$ y el realizado por esta nueva comisión de $420 \mathrm{hm}^{3}$, -que la comisión consideraba menos costosa y más rentable-. En 1995 al concurso lo ganó el Consorcio de empresas mendocinas para Potrerillos Sociedad Anónima (CEMPPSA), formado por las empresas José Cartellone CCSA e IMPSA, quien analizó más conveniente la segunda de las propuestas evaluadas. Este resultado fue inspeccionado asimismo por una evaluación externa que procuró el Estado. Para ello contrató a la consultora Harza Grimat, la cual ratificó en 1997 la conveniencia de realizar la presa de $420 \mathrm{hm}^{3}$ que finalmente se ejecutó. 


\section{CAPITULO IV \\ EN EL CONTEXTO DE LOS AÑOS 90}

El proceso de desalojo y relocalización a causa de la instalación de la Presa Potrerillos, luego de numerosos intentos como vimos anteriormente, tuvo su inicio en los últimos años de la década del 90; por ello, en este apartado, nos abocamos al contexto global que caracteriza a este período. Se describen en primer lugar, las particularidades de la fase neoliberal del capitalismo que constituye el marco estructural de entonces, así como su impacto en las transformaciones económicas, institucionales y urbanas en torno a las ciudades latinoamericanas, metropolitanas e intermedias. Luego se profundiza en el impacto de este modelo en Argentina y en Mendoza, lo cual da cuenta de los importantes cambios sociales, políticos y económicos acontecidos que hacían parte del período en el que transcurría nuestro caso de estudio.

\section{La reconfiguración neoliberal del orden mundial}

Variadas y heterogéneas son las teorías o explicaciones acerca de la globalización. En este trabajo la entenderemos "como la manifestación intensificada de un viejo proceso de comercio transcontinental, de expansión capitalista, colonización, migraciones mundiales e intercambios transculturales" (Coronil, 2005, p.88). Este fenómeno, sin embargo, presenta características peculiares en su fase neoliberal, que desde la década del 70 exhibe un cambio en la concentración y en el carácter de los flujos financieros, lo cual ha generado nuevas formas de integración global que se ven acompañadas de una incrementada polarización de las diferencias sociales entre y dentro de las naciones, proceso promovido por las fuerzas del mercado no reguladas y móviles en crecimiento.

Aludiendo a Coronil, a esta fase de la globalización, sus críticos la consideran "implosiva en vez de expansiva", esto significa, que la misma fragmenta construyendo analogías en base a asimetrías mediante nuevas formas de dominación que polarizan, excluyen y diferencian. Esto sugiere en términos del autor "una reconfiguración del orden mundial capitalista y una reorganización concomitante de la cartografía geopolítica y cultural de la modernidad" (Ibidem, p. 89).

Este contexto, gobernado por la racionalidad del mercado global, se caracteriza por la privatización de la economía y los servicios públicos, la creciente "privatización de la naturaleza" -que lleva a los organismos internacionales a hablar de recursos naturales, patrimonio producido y recursos humanos directamente como capital-, el aumento de la productividad y la competitividad, la expatriación del capital, la desnacionalización de las 
industrias y los servicios, la fuga de cerebros y la intensificación de los flujos migratorio. Así también se caracteriza por la desaparición de los proyectos de integración nacional y la redefinición de los vínculos colectivos. En resumen, la globalización neoliberal se caracteriza no solamente porque la riqueza se concentra en cada vez menos manos -en gran medida libre del control público-, sino también porque esta riqueza se transforma a través de un proceso de homogeneización y abstracción que se extiende a través del "ciberespacio", generando redes trasnacionales financieras y políticas que integran a las élites metropolitanas y periféricas (Ibidem, p.97-103).

Esta fase neoliberal del capitalismo que reconfigura el orden mundial se estructura aludiendo a Castell (2006) en torno a redes globales de flujos de capital, gestión e información. Es decir, que el acceso al conocimiento tecnológico, constituye la base de la productividad y la competencia de la nueva economía mundial. Se trata en términos del autor de una "economía de interconexiones electrónicas" (p.509). Este proceso, genera transformaciones en las representaciones y relaciones entre poblaciones, culturas, mercados y naciones, en las que a la vez que se abren al flujo de capital, se cierran al movimiento de los pobres profundizando la fragmentación del tejido social localizado en un territorio residencial segregado en el que diferencialmente se materializa la concentración del capital.

De este modo, este modelo refiere a relaciones asimétricas en las que se somete población, pero en esta fase de la globalización es por efecto del mercado. Evocando la igualdad potencial y la uniformidad de todas las gentes y culturas, así como el desdibujamiento de las fronteras geográficas, el mercado se presenta como estructura de posibilidades, y la pobreza, la marginación y el desempleo es explicada como consecuencia de acciones humanas individuales o colectivas, ocultando de este modo el carácter violento estructural de dominación que se expresa en un discurso actualizado de progreso (Coronil, 2005).

\subsection{En torno a las ciudades latinoamericanas}

En el marco de un capitalismo desregulado y sin fronteras geográficas, donde la planeación de las ciudades es un proyecto internacional, orientado hacia afuera, liderado por el sector privado y legitimado en el mercado, la importancia de las ciudades como nodos de la nueva economía global (Sassen, 2007) da lugar desde los años 90 a un proceso de adaptación de las ciudades latinoamericanas a la lógica urbanística de la competitividad global como doctrina del desarrollo urbano dominante (Brand, 2009). 
En este sentido, muchas ciudades se transforman mediante la reconstrucción de imágenes culturales y arquitectónicas, la renovación de equipamiento e infraestructura y la reestructuración de economías locales, acompañado por ciclos intensivos de construcción. Así también, las ciudades denominadas atrasadas por el proceso de modernización empiezan a ser reconocidas como lugares competentes para el mercado. Siguiendo este rumbo, ciertos temas adquieren importancia en torno de las ciudades. Ellos son: las políticas de control de recursos estratégicos como el agua, las políticas de abastecimiento alimentario, el control de poblaciones dentro como fuera de la ciudad, los mega-proyectos y el papel del capital en las reconfiguraciones del espacio urbano, así como las políticas de seguridad, los cambios en los regímenes políticos y económicos, las representaciones y discursos sobre el gobierno urbano, entre otros.

Es decir, más allá de las características de cada una de las ciudades de América Latina que tienen que ver con las historias y culturas de sus pobladores, desde fines del siglo $X X$, se identifican tendencias que dominan su transformación constituyendo una nueva etapa de la urbanización en la región. Esta evolución que se dirige a la formación de un nuevo patrón de urbanización se relacionan con: i) la configuración y continua expansión de un espacio mundial de acumulación; ii) la financierización prácticamente total de la economía mundial; iii) la estructuración de una nueva arquitectura productiva organizada en red desplegada por el planeta entero; iv) la imposición de nuevas condiciones para la competitividad, la desregulación, flexibilización y segmentación de los mercados de trabajo; y v) la explosiva intensificación de la movilidad y la consecuente comprensión de la relación espacio-tiempo en las ciudades (De Mattos, 2009, p.77).

Estas condiciones estructurales en el contexto de este nuevo paradigma, significan diferencias cualitativas y cuantitativas para las economías emergentes de la región que se ven impactadas de manera drástica, instaurando una economía altamente informal y una ciudad predatoria. Aludiendo a Betancur (2009) desde los años 70 cuando agentes del capital Central liderado por grupos como la Comisión Trilateral e instituciones como el Banco Mundial (BM) y el Fondo Monetario Internacional (FMI) impusieron lo que se conoce como régimen flexible de acumulación a la región, se colocó a su economía prácticamente en manos de las entidades bancarias más poderosas del mundo y abrió la puerta para que los denominados países desarrollados le impusieran su agenda. Este "segundo saqueo moderno" de la historia de América Latina -como lo denomina el autorhizo que las economía de la región adquiriesen una triple tarea: la de servir a la deuda externa, operar como eslabón inferior de la cadena de transferencia de riqueza hacia 
arriba y hacia abajo, y sostener las élites locales cada vez más reducidas pero a la vez más ricas y globalizadas.

De esta manera, gran parte de la plusvalía producida en América Latina y demás países del Sur es succionada por los mercados del Norte a través del pago de intereses a la deuda externa. Otro mecanismo de extracción de valor lo constituye la desregulación, la financialización, las transferencias forzadas de patrimonio público al sector privado global por medio de mecanismos como la privatización, la sobreexplotación de los recursos naturales, la penetración no restringida de las multinacionales, la desindustrialización, y la reorganización de las economías de la región en formas que garantizan la transferencia ininterrumpida de capital hacia el Centro (Ibidem, 2009).

De esta manera, la globalización neoliberal ha impulsado el proceso de urbanización de las ciudades de la región acentuando y dando nuevas dimensiones a sus características preexistentes: elites ahora desterritorializadas, segregación socio espacial, urbanización de la pobreza, desplazamientos poblacionales y cercenamientos del acceso a la tierra urbana y a la ciudad de crecientes sectores de la población, degradación del trabajo, crisis de legitimidad de los gobiernos locales, informalidad e inhabitabilidad de los asentamientos populares, economías ilegales, etc. Paralelo a estas acentuaciones, este proceso genera nuevas modalidades de ocupación del espacio urbano como las "urbanizaciones cerradas" -condominios, barrios privados, countries, chacras, ciudades privadas-, emprendimientos inmobiliarios que son considerados espacios estratégicos para la inversión de capitales y que encuentran expresión en la proliferación de formas privatizadas de la seguridad y la integración social (Svampa, 2004).

De este modo, el proceso de neoliberalización no es sólo un asunto ideológico o de teoría económica, sino también de transformación de las relaciones sociales y las experiencias cotidianas -con el trabajo, la vivienda, los servicios públicos, la educación y la salud-; como creador de actitudes y valores que transforman las subjetividades individuales y colectivas, así como de identidades (Brand, 2009).

En este contexto estructural y paradigma urbanístico dominante se sitúa el proceso socioterritorial ligado al proyecto de la Presa Potrerillos en estudio. A continuación se ahonda en las características que adquirió este modelo en Argentina y en Mendoza.

\section{En Argentina y Mendoza}

La globalización neoliberal que en Argentina tuvo lugar desde 1976 y se consolidó en la década del 90, produjo una gran transformación del mercado que reestructuró las 
relaciones Estado-sociedad, Estado-capital y capital-trabajo. Estas transformaciones estructurales en articulación con los cambios centrales del Estado argentino consolidaron un nuevo patrón de acumulación basado en la valorización financiera, alrededor del cual los sectores dominantes -con la coacción de los sectores subalternos desde la dictadura militar- constituyeron un sistema de dominación con graves consecuencias políticas, económicas, sociales y del funcionamiento democrático (Basualdo, 2001).

En un contexto de presiones de los acreedores externos, así como de vinculación a los intereses de los grupos económicos locales, el gobierno nacional reformó la estructura del sector público y la orientación de la transferencia de los recursos estatales. En este sentido el marco regulatorio que posibilitó la implementación de este modelo se formó por la creación de la Ley Nacional N²3.696 de Reforma del Estado, que dispuso la intervención de las empresas estatales para la transferencia de los activos públicos al sector privado; la Ley de Emergencia Económica destinada a eliminar subsidios, reintegros impositivos y transferencias implementadas por el sector público y el Decreto 23.697 de Necesidad y Urgencia; así mismo el Decreto de Ley $N^{\circ} 2.284$ de 1991 de Desregulación Económica; y conjuntamente la Ley $\mathrm{N}^{\circ} 23.928$ de Convertibilidad. En consideración, el ajuste macroeconómico se orientó al ajuste del presupuesto del gasto social. Esta serie de medidas realizadas por el Estado, fueron condicionadas por las recomendaciones del FMI y del BM, que alimentaban la idea de que la solución necesaria era tomar como ejemplo a los "exitosos", ganadores en las pujas distributivas y la colonización del Estado..." (Novaro, 2006, p.223), pensamiento este que fue reforzado con la promoción del privatismo por parte de los formadores de opinión promercado ${ }^{13}$.

\footnotetext{
${ }^{13}$ En este marco, la reforma del mercado puede entenderse aludiendo a Etchemendy (2001) como un proceso en el cual la asignación negociada de rentas del Estado a ciertos actores económicos sectoriales tradicionales constituye un componente esencial. Considerando que la naturaleza de las compensaciones en el caso argentino, asociadas con los patrones de desregulación parcial y las asignaciones directas de rentas, están dirigidas no a los desocupados o a los perdedores individuales del mercado sino a los actores colectivos poderosos arraigados en el viejo sistema Estado-céntrico; se entiende que el Estado era poseedor de algo de autonomía y coordinador del proceso de transformación de mercado que controlaba los tiempos y alcance de reformas específicas con el objetivo de forjar coaliciones que puedan alcanzar algún grado de gobernabilidad y satisfacer los intereses de algunos sectores que tienen grandes posibilidades de perder con la apertura de la economía, tales como la burguesía local protegida, los sindicatos tradicionalmente corporativistas, el partido oficial en el Congreso o los apoyos clientelistas en las provincias periféricas. De esta manera, se entiende que la liberalización económica, como fenómeno multidimensional y el carácter de las compensaciones en el caso argentino no implican un cambio abrupto y unidireccional, sino que está lleno de posiciones intermedias, reformas parciales y privilegios económicos otorgados políticamente (Etchemendy, 2001).
} 
Junto a la reestructuración económica y la Convertibilidad se implementó la reforma de la Corte Suprema (ampliación de la cantidad de miembros), lo cual le resultó clave al gobierno para garantizar la vigencia del denominado por Basualdo (2001) transformismo argentino, en tanto que centró la suma del poder público en el ejecutivo. En este sentido, siguiendo al autor, se aseguraba la mayoría de los votos y se legislaba en base a los decretos de necesidad y urgencia. La continuidad de este modelo quedó asegurada a fines del primer mandato de Menem, cuando los dos partidos centrales del sistema político firman el denominado Pacto de Olivos, que permitirá la reelección del presidente, consolidando de esta manera la dinámica del sistema político.

Este viraje en el curso de la democracia se explica aludiendo a Novaro (2006), por la gestación de un "consenso menemista" como estrategia desarrollada por el mismo gobierno desde fines de los 80 que consistió en una transformación simultánea de sus bases de apoyo como del escenario político en el que hasta entonces se desempeñaba. Se trataba, en palabras del autor, de un "consenso antiestatista" en el que los grandes grupos económicos vieron la oportunidad de maximizar en lo inmediato sus beneficios avalados por un gobierno que excusado en la necesidad de regular la hiperinflación de comienzo de su mandato, se encargó de anular la deliberación y confrontación de alternativas, fortificando socialmente la idea de "asociar la eficacia con el gobierno de uno, y el pluralismo, los partidos, el Congreso y demás ámbitos de deliberación y negociación con la dilaciones y la palabrería" (p. 217).

En el marco de estas políticas, el período comprendido entre 1992 y fines de 1994 registraba un considerable crecimiento económico en el que se conjugaban dos cuestiones complementarias y decisivas que institucionalizan este proceso. Por un lado, la presencia de los grupos económicos, las empresas extranjeras y la banca transnacional que se asocian constituyendo una 'comunidad de negocios' sobre las empresas estatales privatizadas; y por otro lado, la generación de un ciclo expansivo del consumo interno que incorpora a vastos sectores sociales, dando lugar al consenso social sobre el nuevo modelo de acumulación (Basualdo, 2001, p.66).

En este contexto, siguiendo a Basualdo, la apertura comercial adquiere una importancia decisiva porque se conjugó con un creciente deterioro del tipo de cambio real, donde los instrumentos que controlaban las prácticas comerciales desleales acentuaron las asimetrías derivadas de la propia apertura comercial. Esto quedó reflejado en la estructura de precios y rentabilidades relativas que impulsaron una inédita destrucción industrial con expulsión de mano de obra e inequitativa distribución del ingreso. Desde 
1994 en adelante, iniciada la fase declinante del proceso privatizador, se produce una oleada de transferencias de propiedad que reavivan la salida del capital local al exterior, basándose en la elevada rentabilidad de las grandes empresas, a la cual se agregan posteriormente, las ventas de empresas y/o participaciones accionarias por parte de la fracción local del capital concentrado. Estas transferencias dieron lugar al crecimiento de las ganancias de las empresas transnacionales y los conglomerados extranjeros, en detrimento de los demás tipos de propiedad, especialmente de los grupos económicos que se habían consolidado durante los años anteriores (p. 78).

Como resultado, en el transcurso de los dos mandatos de este gobierno, bajo el signo del neoliberalismo se consolidó un proceso de segregación cada vez más marcado entre incluidos y excluidos, entre zonas prósperas y postergadas, así como la tendencia a la concentración económica, que fue colocando en una situación cada vez más precaria a empresas pequeñas y medianas. Situación que se agravaría desde mediado de 1994 con la consecuente quiebra de numerosas empresas y tasas muy elevadas de desocupación y pobreza, a lo que el gobierno nacional respondió con planes de asistencia.

En relación a la aceptación/resistencia por parte de los sectores sociales afectados por las políticas económicas y sus efectos, Basualdo (2001) expone que la inmovilización de los sectores subalternos para generar una alternativa política y social que cuestione las bases de sustentación del nuevo patrón de acumulación, se explica por el accionar de la dictadura militar previa que contribuye con los sectores dominantes con la destrucción de parte de los cuadros políticos, dirigentes sindicales, etc. que hacían posible la organización y movilización de los sectores populares. Tarea de desmovilización, desestructuración y disciplinamiento de los sectores dominantes que prosiguió con la llegada de los gobiernos constitucionales y del nuevo patrón de acumulación con la cooptación de quienes representaban a los sectores menos favorecidos. En este sentido, la década de los 90 se trata -aludiendo al mismo- de un proceso en el cual los partidos políticos se vacían política y socialmente y se incorporan como sistema bipartidista homogéneo a la órbita de los sectores dominantes, cortando vínculos con los intereses de su base social y su pasado histórico; en su lugar estos partidos adquieren un formato empresario con una organización vertical regida por relaciones contractuales, desaparece así la discusión político-ideológica, e incluso la diferenciación de las líneas internas partidarias, quedando disuelta la figura de la militancia.

Al respecto, Novaro (2006) sostiene que parte de la estrategia para generar "consenso menemista y antiestatista", fue el control del peronismo y la seducción de la opinión 
pública, componentes necesarios para que Menem ganara las elecciones manteniendo unido al peronismo, atendiendo las demandas de sus dirigentes y de parte de sus votantes. Este autor hace hincapié en el nuevo sentido de la opinión pública sobre la política no encuadrada por identidades políticas, sino enmarcada bajo el lema de una 'Nueva política' preocupada en apariencia por el interés general, lo que le permitió al gobierno ignorar los reclamos en términos de derechos adquiridos, desprendiéndose de empresas y empleados públicos, de la prestación de servicios básicos y demás obligaciones con lo que deterioró los vínculos de pertenencia ideológica del electorado.

Estas políticas de apertura, ajuste y desregulación de la economía nacional, así como la presencia de capital externo y de lobbies locales en las actividades competitivas también tuvieron lugar en la Provincia de Mendoza. Este contexto facilitó privatizaciones en múltiples sectores de su economía, entre ellos las empresas estatales productoras de servicios públicos: Banco Mendoza, Banco de Previsión Social y servicios previsionales (AFJP), que pasaron a ser gestionadas por entidades privadas. En el sector agroindustrial, la empresa estatal líder en el mercado vitivinícola Bodegas y Viñedos Giol (dueña de las marcas "Toro" y "Canciller", entre otras), así como La Colina, empresa frutícola de importancia de la región también pasaron a manos privadas. Otro sector fuertemente impactado fue el del petróleo y la minería con la privatización de Yacimientos Petrolíferos Fiscales (YPF) (Gago, 1999).

Aludiendo a Gago (1999), estas privatizaciones hicieron visible los nuevos actores líderes de la región, que generaron un elevado nivel de modernización y competitividad a lo largo de esta década -y siguientes-, y posicionaron a sus empresas inter-ramas (agroindustria, construcción, servicios, bancas) en el ámbito del Mercosur, provocando la desvalorización de las otras fracciones del capital productivo (Pymes).

Si bien el sector agroindustrial constituye la fortaleza de la economía regional, siguiendo la tendencia del neoliberalismo, a partir de los años 90 se observa en Mendoza el crecimiento del sector servicios: comercio -súper e hipermercados-, restaurantes y hoteles; transporte y comunicaciones; establecimientos financieros; servicios sociales, comunales y personales, -creación de parques tecnológicos e instituciones de salud de alta complejidad, multimedios-, etc. (Red de Observatorios de Cuyo, 2011). Acompañando este proceso, el Estado provincial invierte en infraestructura para el comercio, las comunicaciones y el transporte, ejes de desarrollo para la integración a la economía global. De esta forma, consolida la vinculación comercial interoceánica del Mercosur con la restauración del corredor andino (Ruta internacional $N^{\circ} 7$ ) y el túnel internacional Cristo 
Redentor con destino a la ciudad de Santiago de Chile, así como con los pasos fronterizos del sur de la provincia, El Pehuenche y Las Aucas. En esta década se concreta también la construcción de la Presa Potrerillos, que se propone múltiples objetivos de desarrollo económico, emprendimiento que constituye nuestro caso de investigación.

En fin, en este período, en sintonía con la realidad nacional la economía de Mendoza muestra dos caras a considerar: mientras por un lado registra un crecimiento sostenido en las actividades productivas (Red de Observatorios de Cuyo, 2011); por otro lado, con la incorporación de altas tecnologías en los procesos productivos, así como debido a las leyes de flexibilización se precariza la relación laboral-salarial generando altos índices de desocupación, subocupación y "trabajo en negro" o informal, lo cual induce procesos migratorios hacia los centros urbanos y la radicación de asentamientos precarios (Gago, 1995). Esta desigualdad, considerando la investigación realizada por Trapé, et. al (2011:3) según datos de la Encuesta Permanente de Hogares (EPH), se ve acrecentada entre los años 1984 y 2002, y comienza a disminuir desde el 2003 al 2009, a partir de las nuevas políticas del Estado nacional.

2.1 Y ¿Qué fue de las aguas del río Mendoza?

La administración y gestión del agua no fue ajena a estas transformaciones, dentro del combo de reformas realizadas en la provincia podemos mencionar tres vinculadas al agua del Río Mendoza: la privatización de las empresas estatales distribuidoras de agua y luz, Obras Sanitarias Mendoza Sociedad del Estado (OSMSE) y Energía Mendoza Sociedad del Estado (EMSE), así como la construcción del proyecto de inversión y desarrollo de la Presa Potrerillos y concesión de la explotación de las usinas hidroeléctricas de Cacheuta, Álvarez Condarco y El Carrizal.

En cuanto a la primera, desde su provincialización en 1880 -período histórico signado por la descentralización del Estado nacional-, la empresa prestadora de los servicios de agua potable y saneamiento adoptó la forma jurídica de Sociedad Estatal provincial; más tarde, en el marco del contexto privatista de la década del 90 esta fue traspasada a manos privadas constituyéndose en una Sociedad Anónima. Este proceso se realizó por medio de la Ley Provincial 6044/93 por la cual el gobierno cambio la personería jurídica de la institución estatal por la de Sociedad Anónima y estableció un marco regulatorio sobre cómo se debía prestar el servicio de agua y cloacas sobre la totalidad del territorio fijado como servido al que debía someterse el prestador; y en materia de organización administrativa creó por Ley en el ámbito del Ministerio de Medio Ambiente, Urbanismo y Vivienda, el Ente Provincial del Agua y de Saneamiento (EPAS) como ente autárquico del 
Estado provincial, encargado del ejercicio de regulación, control y policía de los servicios mencionados, el cual comenzó a funcionar en julio de 1996. De esta manera "tras la solapada pretensión de reordenar las instituciones de prestación de los servicios de provisión de agua potable y saneamiento, se ocultaba este primer paso, que sería el necesario para la efectiva privatización que se realizaría 5 años después" (Jofré, s/f), en 1998 cuando mediante licitación pública internacional vendió el 70\% de las acciones, incluyendo también las acciones de capital. En adelante, la sociedad anónima prestadora de servicios de agua potable y saneamiento pasó a llamarse Aguas Mendocinas.

Paralelamente a este proceso se ejecutó de igual modo la privatización de la empresa del Estado Provincial EMSE que pasó a llamarse Empresa Distribuidora de Electricidad de Mendoza Sociedad Anónima (EDEMSA). Se dictó por ley un marco regulatorio sobre la prestación del servicio y se creó el Ente Provincial Regulador Eléctrico (EPRE), ente estatal destinado a fiscalizar que el concesionario cumpla con la ley y el contrato fijado.

Estas privatizaciones guardan estrecha relación con el proyecto de inversión y desarrollo de la Presa Potrerillos, la otra gran obra vinculada al agua iniciada en esta década. Al respecto, la prensa local, aludiendo a los anuncios del Gobernador Lafalla de retomar el proyecto de Potrerillos y llamar a licitación, redactaba:

"Para construir Potrerillos, el gobernador parte de lo que consideró "una condición que doy por hecha y es que la Legislatura apruebe la venta, el proceso licitatorio de EMSE y constituya el fideicomiso para que con el producido de la venta, afrontar la financiación de la obra. Una cosa condiciona la otra". Y ratificó el concepto señalado que si no se privatiza EMSE "absolutamente no hay plata" para la construcción de Potrerillos” (Los Andes, 06/04/1997).

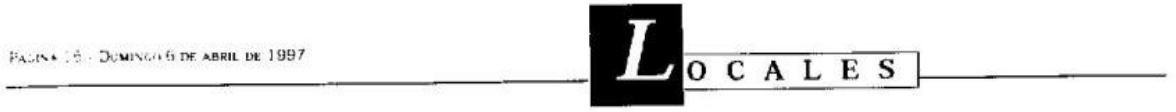

Lafalla resolvió retomar el proyecto, pero...

\section{Sin la venta de EMSE no hay construcción de Potrerillos}

Fi gobernador anunció que se retoma of proceso licitatorio del proyerto Potrerillos, aunque a expensas de la privatización de FMSE. Funcionarios de las distintas ireas tendrán a su cargo un dictamen para la pas
terior adjudicación de la obra, la elaboración de un terior adjudicación de la obra, la elaboracion de
ulan hidrico v el andisis del impacto ambiental.
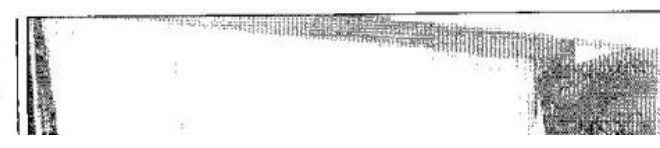

Fuente: Los Andes, 06/04/1997. 
Este discurso, dentro del proceso histórico vinculado al proyecto de Potrerillos nos permite imaginar el contexto de vaciamiento estatal en que finalmente se llevaba a cabo la concreción de la obra.

Luego de los muchos intentos por concretar la construcción de la presa, el 16 de enero de 1995 salieron a la venta los pliegos para la licitación y en mayo de ese año habían tres interesados para quedarse con la construcción de la presa: el grupo formado por las empresas mendocinas IMPSA (Pescarmona) y Cartellone Construcciones Civiles SA, la firma Benito Roggio e Hijos, y las constructoras españolas Consorcio Dragados y Construcciones SA, representados en Argentina por DYCASA. De estos oferentes, el primer grupo finalmente se encargó de la construcción de la obra (Lacoste, 1998).

El 5 de diciembre de 1997 el gobierno de Lafalla firmó el contrato por el que constituyó la sociedad anónima denominada Consorcio Emprendimiento Múltiple Potrerillos Sociedad Anónima (CEMPSA) a la que le adjudicaba la obra que duraría tres años. En palabras del entonces gobernador:

“...el precio se pactó en 300 Millones, 170 ponía la Provincia y 130 los empresarios privados. ...este era un precio "llave en mano", es decir, no podía haber mayores costos de ninguna naturaleza porque el proyecto en definitiva había sido confeccionado por las empresas, y si surgían modificaciones corrían por su cuenta y riesgo" (Lafalla, 2010, p.293).

Con este grupo se acordó no sólo la construcción de la obra, sino también se le entregó en concesión la explotación de las centrales hidroeléctricas de Cacheuta, Álvarez Condarco y El Carrizal por un plazo de 25 años; privatización que el 29 de diciembre de 1997 tuvo aprobación por parte de la Legislatura (Los Andes, 30/12/1997).

A modo de cierre de este capítulo, aludiendo a Marre et. Al (2007), en el contexto de la globalización neoliberal, las políticas privatizadoras de los servicios públicos de los años 90, dependiendo del país del que se trate, presentaron diferencias en relación a los beneficios que se percibieron por la concesión. Las mismas se destinaron en su mayor parte al pago de ganancias o rentabilidad de los accionistas, y en segundo lugar a satisfacer las necesidades de los usuarios o al mejoramiento del servicio. De este modo, la demanda de agua dentro del sector energético, se presenta como "estratégica" en cuanto a las economías de escala que pueden generar, consideración que no ocurre en relación a la demanda de agua potable y saneamiento -también insumos de baja sustituibilidad-, donde la misma crece en relación a la escala de la población localizada en zonas urbanizadas (Müller, 2012). 


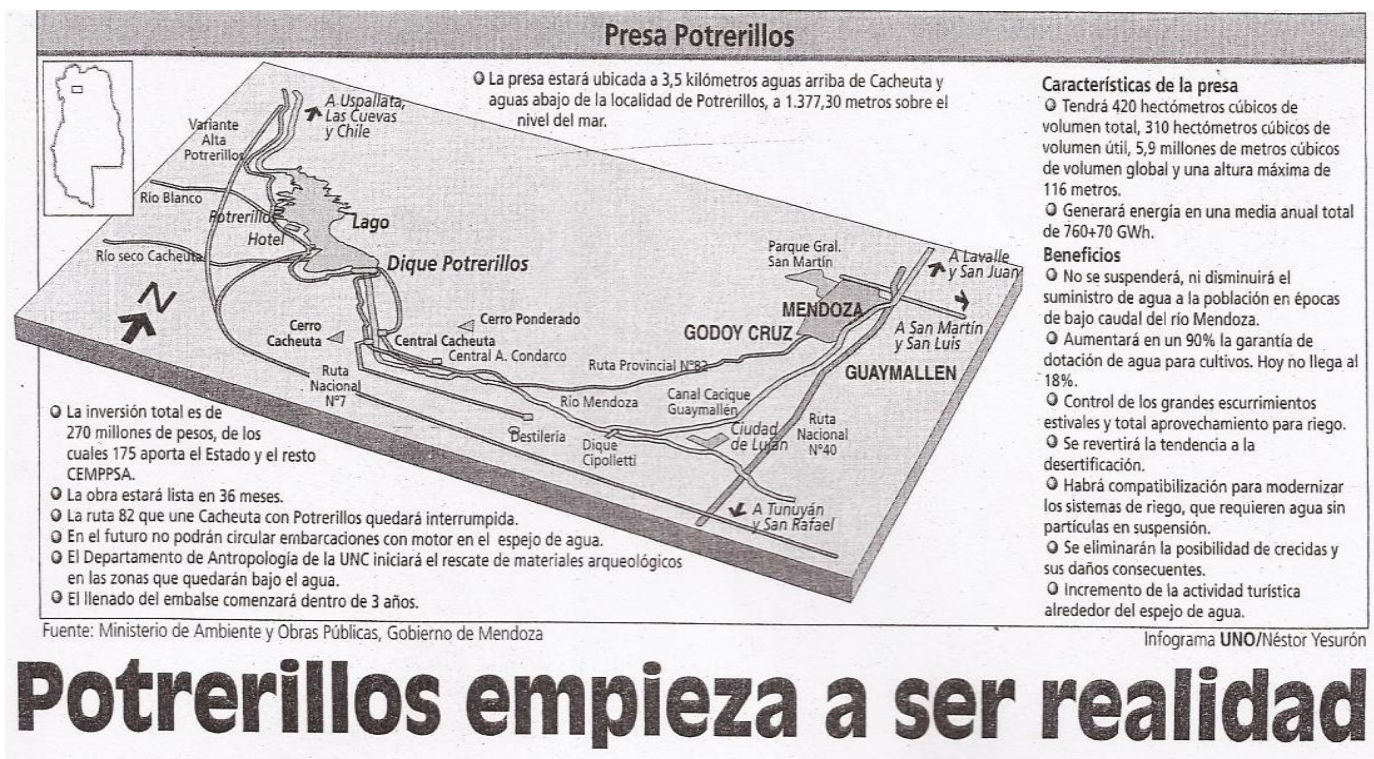

Por VALERIA MENDEZ De la redacción de UNO

Después de años de discusión y polémica, ayer quedó firmada el acta entre el Gobiemo y CEMPPSA (Consorcio de Empresas Mendocinas Para Potrerillos SA), que habilita la construcción de la presa, las nuevas instalaciones de la centra hidroeléctrica Cacheuta y la amplia ción de Alvarez Condarco. Las obras se iniciarán los primeros dís de enero, es decir la semana entrantte y culminaŕn según aseguró en 36 semanas.

En la sede del Banco Río, quedaron depositados también los $175 \mathrm{mi}$ ron depositados tam los lits milones de pesos que le corresponde aportar al Estado. La suma, en maconsorcio que integran las empresas Cartellone y Pescarmona, el compromiso de pago. También, mediante un fideicomiso, los mendocino tienen asegurado que Cemppsa n tienen asegurado que Cemppsa no en las obras. Estos 175 millones y han sido destinados a Potrerillos

El Gobierno firmó con el consorcio de Pescarmona y Cartellone el acta para iniciar la construcción de la presa

2.000 puestos de trabajos, durante tres años. Tanto el presidente de Cemppsa, Jorge Adra como el ingeniero Enrique Pescarmo coincidieron en que el emprendimiento de Potrerillos traerá no solamente más rabio, energa y terts regas a La ion, siogeso y futuro. La inverion total es de $270 \mathrm{mi}$ llones de pesos, de los cuales -como se dijo- 175 aporta el Estado el resto Cemppsa. Enrique Pescarmona no dudo en señalar que esta inversion "va a mejorar la zona y a incrementar la actividad económica". Respecto a a la situación económica de la Provincia con miras al 99, el empresario dijo que "los primeros tres meses van a ser muv du-

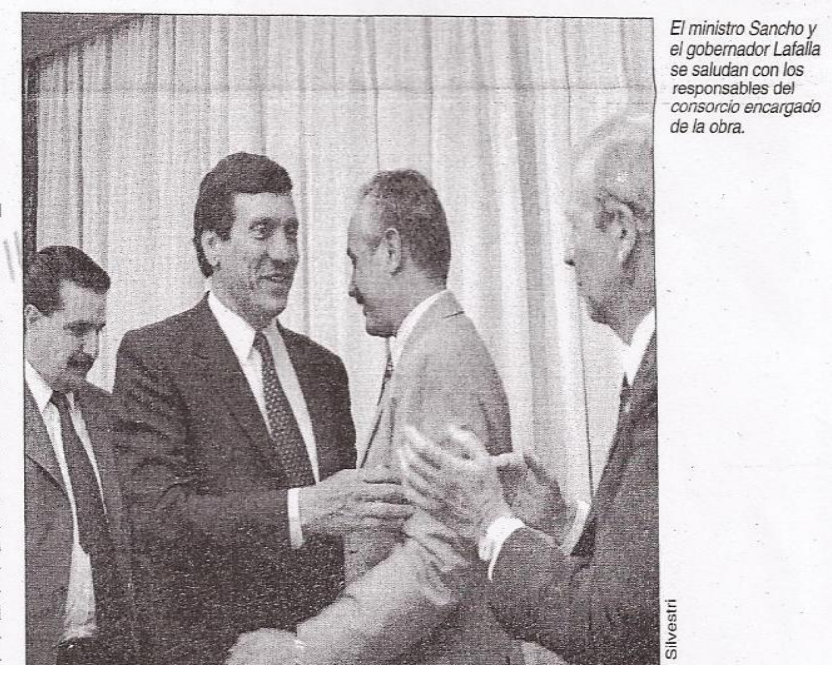

Fuente: Diario UNO, 29/12/1998

Seguidamente nos adentramos en la reconstrucción del caso de estudio. Abordamos en primer lugar el proyecto de la Presa Potrerillos, sus alcances e implicancias esperadas para el perilago. 


\section{CAPITULO V \\ EL PROYECTO DE LA PRESA POTRERILLOS Y EL LUGAR PLANEADO Y AFECTADO EN TORNO AL PERILAGO}

Considerando el concepto de "espacios dominados" explicitado en el marco teórico, que se entiende, son aquellos que desde una racionalidad técnica e instrumental son transformados con el fin de controlar los procesos naturales y sociales para someterlos al interés del modelo de producción capitalista; con el propósito de describir y analizar el nuevo orden-lugar proyectado vinculado a la construcción de la Presa Potrerillos, en este capítulo, se abordan las representaciones del espacio, es decir, el modo en cómo el Estado provincial conceptualiza, grafica y justifica la lógica e intervenciones que producen el espacio en torno al perilago, lo cual incluye los efectos físicos y materiales esperados por los promotores del proyecto en los lugares de Cacheuta y Potrerillos y sus habitantes. Así también, se consideran dos momentos que poseen gran carga simbólica como el día de la firma e inauguración de la obra, en que se imparten discursos verbales alusivos exclusivamente al emprendimiento.

\section{Los fundamentos de la obra}

Referido a los discursos que fundamentan la construcción de este tipo de obras de infraestructura de gran escala, Radovich (2005) manifiesta que es una práctica frecuente en procura de lograr consenso sobre la realización de las mismas el denominarlas "emprendimientos de propósitos múltiples", nombre utilizado en la etapa de los estudios de factibilidad para obtener la legitimidad del proyecto, lo cual encubren el principal objetivo que generalmente consiste en desarrollar la producción de energía. En el caso de la Presa Potrerillos, cuyo proyecto se denomina "Aprovechamiento Integral del Río Mendoza - Proyecto Potrerillos", la producción de energía así como los beneficios del riego -que aportan la mayor parte de los beneficios económicos- se presentan como objetivos importantes, pero adquiere fundamental relevancia el objetivo planteado en relación al uso del suelo del perilago, el cual implica un plan de ordenamiento urbano por parte del Estado provincial que conlleva múltiples efectos para la población residente permanente del lugar, así como para los intereses económicos del mercado inmobiliario, turístico y recreativo de la zona a partir de la explotación de las márgenes del embalse.

A continuación se exponen los objetivos publicados por el Ministerio de Ambiente y Obras Públicas en la Síntesis de la Manifestación General de Impacto Ambiental, en 
cumplimiento de la Ley 5.961 Art.33; Decreto 2.109/94 Art. 19º del Sistema de Información Pública, que dan justificación a la construcción de la gran obra:

Proveer los requerimientos de la demanda de consumo de agua potable en el Gran Mendoza y su zona de influencia, con alrededor de un millón de habitantes, dentro del denominado Oasis Norte, asegurando el abastecimiento normal ante el crecimiento de las demandas en las próximas cinco décadas como mínimo.

Regular los caudales instantáneos del río que impiden un máximo aprovechamiento de las aguas, para distintos usos y sobre todo garantizar las dotaciones de los terrenos cultivados con derechos de riego que presentan déficit estacionales por la variabilidad de la oferta del régimen hídrico existente.

Incrementar la producción de energía eléctrica en la provincia a través de la puesta en servicio de las dos centrales hidroeléctricas existentes, Cacheuta y Álvarez Condarco.

- Contribuir a minimizar el riesgo que causan las crecidas periódicas del Río Mendoza y en particular las que se pueden originar como consecuencia de la ruptura del embalse natural sobre el alto Río Plomo.

- Posibilitar un desarrollo sustancial al turismo nacional e internacional por medio de un espejo de agua permanente que permitirá potenciar actividades turísticas y recreativas.

- Crear directa e indirectamente puestos de trabajo, tanto durante la construcción como una vez que el espejo esté en funcionamiento. Durante la construcción, a lo largo de 5 años, se crearán nuevos puestos de trabajo con un pico de hasta 1.500 personas, estimándose en una cifra mayor, la ocupación derivada de servicios vinculados a las obras y el incremento en la actividad económica. (Gobierno de Mendoza. Ministerio de Ambiente y Obras Públicas. Los Andes, 13/12/1998). (Las negritas me pertenecen).

Estos párrafos en los que se percibe la exaltación de los beneficios de la gran obra dado que la Presa Potrerillos multiplicará el "consumo de agua potable", los "derechos de riego", "la producción de energía eléctrica", el "turismo nacional e internacional" y los "puestos de trabajo" representan las razones que se considera dan sentido y justifican la gran inversión de capital que demanda este tipo de proyectos, como también minimizan los costos sociales, ambientales y culturales que ocasiona a los sectores perjudicados.

La ideología que subyace a la realización de la obra, no se manifiesta solamente en el discurso oficial, que en términos de Geertz (1995) busca "crear conciencia colectiva" de la magnificencia de la obra, sino que también se evidencia en el tratamiento que ciertos medios le dan a la misma. A continuación se expone un fragmento de una nota publicada sobre la presa en un periódico de la Provincia de Mendoza:

"la regulación de un caudaloso río de montaña supone una obra de ingeniería de gran envergadura. Y ello demanda un esfuerzo que sólo pueden llevar a cabo las sociedades fuertes y con visión de futuro.

Los pueblos en decadencia son inaptos para este tipo de propósitos. Están aferrados a la coyuntura, malgastan buena parte de sus energías y tiempo en 
luchas intestinas por el poder, y no pueden mirar más allá de sus narices". (UNO, 31/12/1997) (Las negritas me pertenecen).

Es notorio el énfasis puesto en el carácter reproductivo de la obra que multiplica "obras", "esfuerzos", "sociedades fuertes" y "futuro" y no en la reproducción del capital, cuya lógica es la que justifica este tipo de proyectos que en consonancia con los valores del modelo neoliberal expanden el mercado del agua y sus alrededores y son razón de disputas por la apropiación del territorio. Es importante señalar el último párrafo de la cita donde se diferencia a los pueblos en consideración a su visión de futuro o a su actuación coyuntural sin aludir a la historia y cosmovisión de los mismos así como a los contextos políticos, económicos y sociales de quien se trata.

Habiendo mencionado los argumentos que justifican la construcción de la Presa Potrerillos, en el siguiente apartado, volviendo a nuestras áreas de estudios -Cacheuta y Potrerillos-, ahondamos en el plan de ordenamiento y desarrollo del perilago y en sus implicancias para quienes habitan estos lugares.

\section{El ordenamiento del perilago}

En relación al área comprometida por la instalación de la obra, desde la cota de máximo embalse $-1381,70$ msnm-, el Estado Provincial establece un área de hasta $1.200 \mathrm{~m}$ alrededor del lago artificial para su ordenamiento, esto implica la planificación del uso y gestión del territorio y el ambiente de los valles y zonas ribereñas. En este sentido, a fin de evitar que el orden se origine de forma espontánea, por Resolución 619 de junio de 2000, el Ministro de Ambiente y Obras Públicas faculta a la Dirección de Ordenamiento Ambiental y Desarrollo Urbano (DOADU) a llevar a cabo el plan de "Ordenamiento y Gestión Territorial del Emprendimiento Potrerillos - Desarrollo Turístico y Recreativo (Perilago)" bajo la Dirección de la Dra. Nelly Gray de Cerdán y la Supervisión del Sr. Jefe de Asesores del Ministerio, Ing. Francisco Morandini.

Desde este sector institucional, imaginando un polo de desarrollo económico en los alrededores del perilago, se expresa que el gobierno provincial asume la responsabilidad de planificar el área con los propósitos de:

1. “asegurar la preservación del ecosistema existente, la calidad del agua del futuro reservorio y el uso racional de las tierras del perilago, como una condición necesaria para definir escenarios de desarrollo sustentable.

2. garantizar la organización estratégica de un espacio integrado a un contexto mayor, como es el del Corredor Bioceánico Central del Mercosur, en el tramo andino, con inversiones orientadas a captar los flujos comerciales y 
turísticos y las posibilidades de desarrollo que derivan de las nuevas funciones que asume el oasis norte y el Gran Mendoza en el Bloque como nodo de transferencia de cargas internacionales y cabeza del corredor comercial hacia los mercados del Pacífico" (Gobierno de Mendoza. DOADU, 2000, p.7). (Las negritas me pertenecen).

De este modo, el orden pensado para el área, se plantea un propósito hacia adentro del lugar, así como otro hacia la integración del mismo al contexto mayor de la economía. En relación al primero de los propósitos, para garantizar la sustentabilidad de este modelo de desarrollo, Pujol (DOADU, 2000) expone que el Estado provincial debería garantizar la calidad del agua para consumo humano, la protección de la cuenca, reglamentar los usos del agua del embalse y los riesgos ambientales más relevantes ${ }^{14}$, así como considerar la participación comunitaria de los pobladores que han sido desplazados de sus lugares habituales para su inclusión laboral y habitacional en el nuevo lugar, brindando capacitación para la generación de emprendimientos turísticos u artesanales, empleo de mano de obra lugareña en la construcción del dique y obras de infraestructuras aledañas del entorno, etc.; y para quienes quieren irse de la zona, brindar posibilidades para que puedan hacerlo. Así también manifiesta, que para que el desarrollo sea sustentable, se requiere la participación de los afectados en el órgano de administración del perilago y su área de influencia, esto es en el Comité de Participación Comunitaria que debe integrar el Ente Administrador de la Presa Embalse Potrerillos (p.156-162).

El segundo propósito, considera estratégica la ubicación de la zona sobre la Ruta N7, una de las arterias de circulación del Mercosur, por ello se plantea la integración del área al sector turístico de la economía, así como el aprovechamiento de la circulación de cargas internacionales hacia los mercados del Pacífico ${ }^{15}$. En el marco de estos propósitos, el perfil del desarrollo buscado por los planificadores, aludiendo a Reina, Avanzini y Videla (Ibidem, p.20), se determinan usos del suelo para los alrededores del embalse en base a las siguientes definiciones:

- "Emprendimientos turísticos autosuficientes: se trata de grandes emprendimientos hoteleros -resort- o residenciales -cerrados- con servicios y equipamientos propios. Están dirigidos a satisfacer las demandas de un turismo internacional. Se trata de hoteles cuatro o cinco estrellas o condominios privados, donde además de

\footnotetext{
141. Aceleración de la sedimentación, 2. Disminución del nivel del agua, 3. Contaminación por tóxicos, 4.Eutroficación, 5.Acidificación, 6.Colapso del ecosistema acuático y 7. Calentamiento global de lagos y reservorios (DOADU, 2000, p. 162-164).

${ }^{15}$ Ver en Anexo cartografía que grafica este objetivo, registrando el recorrido de la ruta y su paso por los lugares comprometidos por la obra.
} 
servicios de alojamiento y comidas, cuentan con campos de deportes varios, casino, comercios, restaurantes, piscinas, entre otros.

- Centro de servicio turístico: Los mismos constituyen enclaves donde se concentran servicios al turismo. Consistirán en pequeños centros comerciales, correos, policía, oficina de información, centro de artesanías, centros de interpretación, centro de operaciones de actividades turísticas, entre otros. Asimismo formaran parte de estos Centros, cabañas de alquiler, hoteles y equipamientos y servicios afines.

- Camping, clubes náuticos, balnearios: Estas categorías de emprendimientos constituyen los usos más frecuentes en el área de perilago.

- Apoyo a la ruta: Se define como tal a los emprendimientos relacionados con los servicios a la Ruta Nacional $N^{\circ} 7$ (estaciones de servicios, paradores, restaurantes, playas de estacionamiento).

- Emprendimientos turísticos complementarios: Se trata de emprendimientos turísticos no incluidos en el resto de la clasificación detallada -compatibles con los objetivos del área-.

- Conservación: serán recomendados para aquellos espacios naturales que no presentan aptitud para desarrollar emprendimientos turísticos y por sus condiciones naturales constituyen ambientes frágiles, con interés paisajístico o valor ecológico.

- Investigación: serán recomendados terrenos que presentan yacimientos paleontológicos, localizados en los afloramientos triásicos".

El desarrollo imaginado para el área afectada se trata en otras palabras, de un escenario diferente al que existía previo a la instalación de la presa y que los habitantes experimentaban a diario. Este desarrollo que busca el nuevo orden socio-territorial es planeado desde la DOADU a través de un conjunto de estrategias, programas y proyectos entre los que podemos mencionar a los denominados: 1. "Dinámica del medio natural en la ribera norte del río Mendoza”, 2. "Gestión del riesgo en el área del embalse", 3. "Estrategias de Ordenamiento Urbano-Regional. Planificación participativa (Relocalización de la Villa Potrerillos y plan de usos del suelo)" -proyecto sobre el cual profundizaremos en el próximo capítulo-, 4. "Programa de Ordenamiento Integral del Corredor Bioceánico Tramo montañoso", 5. "Marco legal administrativo para el desarrollo del área. Normas e instituciones", y 6. "Balance hídrico del agua. Oferta del agua para el desarrollo", que fueron planeados para una primera etapa, contemplada de abril a diciembre del 2000.

Planeados para una segunda etapa -de enero a diciembre del 2001- podemos mencionar los siguientes: 7. "Mercado turístico para el área. Marketing", 8. "Propuesta de tratamiento y manejo de áreas protegidas", 9. "Infraestructura básica de uso público para el desarrollo", 10. "P.O.T Plan de Manejo y Gestión", y 11. "Plan de Desarrollo Turístico" (Ibidem, p.11-12) los cuales involucrarían a actores estatales y privados. 
Considerando la existencia de diversas poblaciones que se esperaba fueran parte de la producción del espacio en estudio: la población residente, la población flotante de los fines de semana, así como la población atraída como clientela de las nuevas instalaciones turísticas, la DOADU propone un estilo de desarrollo mixto. En este sentido, la propuesta general de ordenamiento, aludiendo a Gray de Cerdán (Ibidem, 2000, p125-128) consiste en una zona compuesta por cuatro áreas:

1) Centro cívico e histórico, ubicado sobre el borde del Embalse, el cual contiene la mayor cantidad de edificios públicos, equipamientos y servicios instalados. Es el área donde se realizó la relocalización, que contiene yacimientos arqueológicos y constituye el nodo principal.

2) Nodos de servicios poli-funcionales: considera a los parajes de Las Chacritas, El Salto y Las Vegas para la instalación de servicios orientados a la población con residencia estable y flotante, que cumplen con las modalidades de abastecimiento, compra y satisfacción de las necesidades de la población.

3) Servicios recreativos y turísticos: se trata de armonizar los servicios turísticos y recreativos ya existentes en la zona, e identificar espacios con potencialidad para el desarrollo de hotelería y equipamientos en el borde costero del lago; y

4) Complementos residenciales: ocupan los terrenos mejor posicionados para el ocio, el descanso, la observación de la naturaleza. En este sentido se potencian los terrenos ya utilizados por los residentes, los que se han previsto para la relocalización de la población del embalse, los proyectos inmobiliarios y las áreas para la extensión del tejido urbano.

Como vemos, es extensa y variada la zona de impacto del proyecto. En la cartografía expuesta al final de este apartado se diferencia circundante a la presa: la zona de mayor impacto para la población local, la zona de menor impacto para la población local y la zona que comprende áreas sin ningún desarrollo actual destinado al turismo y sin servicios. En esta delimitación podemos ver que los lugares de Potrerillos y Cacheuta se localizan en el área de mayor impacto de la obra para la población local, sin embargo el plan de ordenamiento territorial y desarrollo turístico del perilago se piensa y aplica solo para el primero de los lugares.

De este modo, la creación del nuevo lugar implicó como primer paso la elaboración de un marco jurídico-administrativo, o "representaciones normalizadas" en términos de Lefebvre, para que los planificadores y ejecutores del orden en torno a la presa operen dentro de la legalidad y así justifiquen sus intervenciones como el desalojo y relocalización de la población, la declaración de una zona "protegida" en relación a otras que no lo son, la inversión en obras de infraestructura, la realización del marketing del sector turístico, la atracción de inversiones de capitales privados, etc. 
Mapa de zonificación de impacto de la Presa Potrerillos

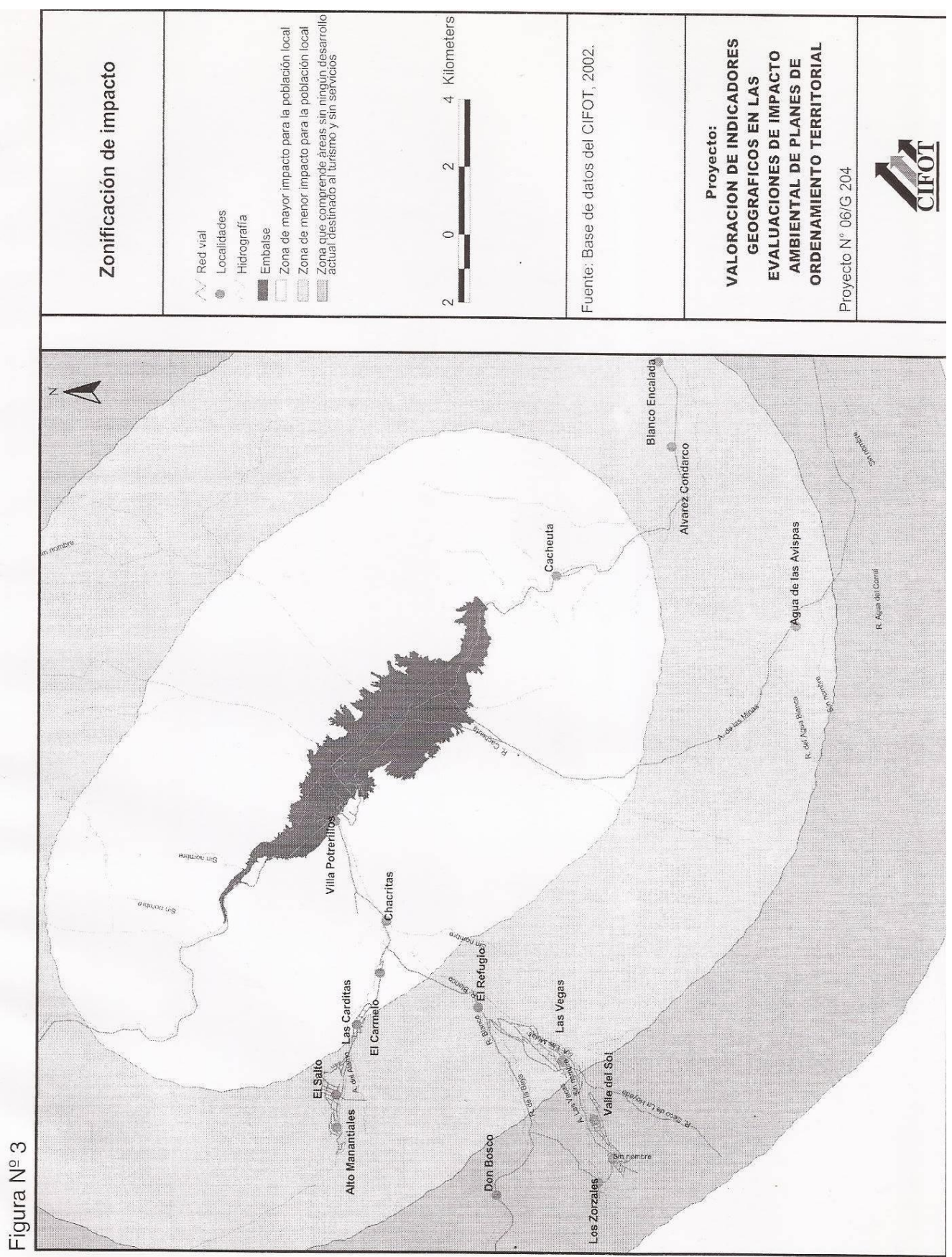

Fuente: Cartografías elaboradas por el CIFOT. En Proyección N2 - 2002.

Más allá o más acá de los argumentos expuestos en el plan de ordenamiento en vistas al futuro desarrollo, la realización de la obra conllevó efectos negativos sobre la zona de su emplazamiento, en particular en la que se utilizó como vaso del embalse, y por tanto sobre la población que en este lugar residía. Sobre esto nos centramos a continuación. 


\section{El lugar afectado por el llenado del embalse}

La zona que quedó sumergida de 1300 hectáreas de superficie aproximadamente, significó para los lugares de Cacheuta y Potrerillos la pérdida de una serie de instalaciones existentes que cumplían funciones de servicios, alojamiento y turismo, así como de las redes de riego, drenaje y distribución de energía eléctrica, las vías de circulación de automotores y ferroviarias e importantes áreas forestadas. A estas desinstalaciones del lugar se suma el desalojo de la población que allí residía, como de las actividades económicas que se desarrollan en las márgenes del Río Mendoza en camping, cabañas, comercios, prestación de servicios, entre otras (DOADU, 2000, p.7).

Aludiendo a datos elaborados por el CIFOT, organismo a quien el Ministerio de Ambiente y Obras Públicas de la provincia encomienda la tarea de diagnosticar la realidad socioeconómica de Potrerillos previo a la instalación de la presa, las familias que vivían en el área del embalse y que debían ser relocalizadas en un primer momento eran 107 luego este número bajó- y las construcciones edilicias comprometidas eran 172, de diferente calidad y tipo de construcción, destinados a viviendas, comercios, actividades artesanales, escuela, iglesia, centro de salud, seguridad, etc.

Asociado a las redes que atraviesan la zona, se desinstaló la vieja estación del ferrocarril trasandino, $26.000 \mathrm{~m}$ de rieles y los durmientes con sus respectivos tornillos y clavos, así como la fibra óptica, dos acueductos, puentes, cables de teléfonos, cables de luz, postes de diversos materiales y metros de camino pavimentado incluyendo la Ruta Nacional $\mathrm{N}^{\circ} 7$. En relación a los procesos ecológicos de la zona -rica en biodiversidad animal como vegetal-, se determina una disminución en las posibilidades de hábitat de fauna terrestre y acuática como de insectos e invertebrados. De los árboles existentes, 16.000 fueron erradicados con la promesa de reforestar luego el perilago con la misma cantidad.

La presa compromete también el patrimonio arqueológico, paleontológico y patrimonial de Potrerillos, estos son los yacimientos y sitios de interés histórico como: los Cerros Cocodrilo, Bayo y Cabra, con vestigios paleontológicos y el yacimiento de San Ignacio, lugar de actividad agroalfarera del siglo VII d.C. Así también las construcciones y espacios que tienen valor cultural como la Estación de FFCC Trasandino, la calle Los Álamos, con su arbolado especial y el casco de la antigua Estancia San Ignacio (DOADU, 2000, p.78). En cuanto a la vía de circulación que conectaba a las localidades en estudio, la Síntesis de la Manifestación General de Impacto Ambiental anunciaba que las mismas durante el desarrollo de las obras se encontrarían afectadas: 
"por el tránsito de materiales e insumos necesarios para la construcción de la obra con afectación de la calidad del aire, ruidos, vibraciones y fundamentalmente problemas de accesibilidad por el corte de la ruta (...). Se trata de impactos negativos de alcance local y temporarios que deberán tratarse con Planes de Mitigación y Control a lo largo de la construcción de la obra previéndose obras alternativas para no afectar la comunicación entre Cacheuta y Potrerillos" (Gobierno de Mendoza. Los Andes, 13/12/1998). (Las negritas me pertenecen).

De esta forma, como podemos ver a partir de lo expuesto, el proyecto de la Presa Potrerillos y del ordenamiento del perilago implican la afectación de un conjunto de aspectos que involucran la vida de los pobladores y demás especies del área utilizada o en palabras de Lefebvre del "espacio dominado".

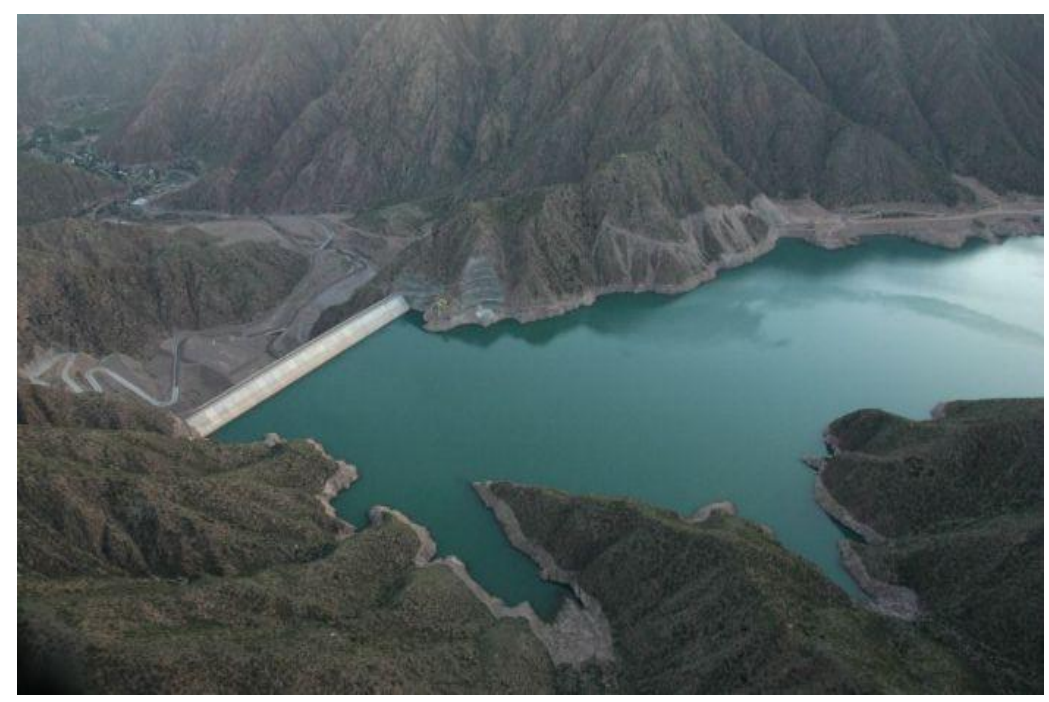

Imagen 7. Presa Potrerillos. Diario Los Andes on-line 29/09/2011. En esta fotografía podemos ver a la localidad de Cacheuta, aguas abajo de la presa.

Seguidamente, para finalizar este capítulo sobre los argumentos que dan fundamento al proyecto de inversión y desarrollo de la Presa Potrerillos así como al nuevo lugar-orden afectado, se exponen fragmentos de los discursos realizados el día de la firma y de la inauguración de la presa, los cuales nos permiten visualizar la importancia que ésta conllevó para quienes ejercían el poder político y económico en ese momento.

\section{Los promotores del "futuro" y hacedores de "la historia"}

Debido a que la Presa Potrerillos es producto de incontables discusiones, declaraciones e incluso anteriores intentos fracasados, el acto del día de la firma del contrato para iniciar la obra, así como el día de la inauguración, son fechas que portan una considerable carga simbólica para los actores responsables de la misma. Esto se hace evidente en los 
discursos impartidos en tales acontecimientos por parte del Estado y los empresarios a cargo de la construcción.

En el momento de la firma del acta en diciembre de 1998, que da inicio al emprendimiento por parte del Gobierno de Mendoza y de CEMPPSA (Consorcio de Empresas Mendocinas Para Potrerillos S. A.), encargado de la construcción de la presa, las nuevas instalaciones de la Central Hidroeléctrica Cacheuta y la ampliación de la Central Hidroeléctrica Álvarez Condarco, en la prensa local se leía:

"Lafalla señaló que muchos gobernadores de la Provincia hubiesen deseado estar en su lugar en este momento" (UNO, 29/12/1998).

Haciendo mención al tiempo transcurrido desde el primer boceto del proyecto de la presa al momento del acuerdo definitivo, el entonces gobernador exponía:

"Me pesa el descreimiento de la gente, muchas veces justificado. Pero ahora no hay porqué desconfiar, la obra estará lista en 36 meses porque hay un contrato firmado, voluntad, decisión y recursos (...) logramos quebrar esta inercia de 80 años, durante los cuales hemos hablado tanto de Potrerillos" (Gobernador Arturo Lafalla. UNO, 29/12/1998).

En cuanto a la inversión realizada, la visión empresarial se manifestaba en el siguiente fragmento:

"Tanto el presidente de Cemmpsa, Jorge Adra como el ingeniero Enrique Pescarmona, coincidieron en que el emprendimiento de Potrerillos traerá no solamente más trabajo, energía y tierras regadas para Mendoza, sino progreso y futuro" (UNO, 29/12/1998).

En sintonía con estas primeras palabras, el día de la inauguración, luego de años de trabajo en la zona, en un contexto de crisis económica y política, y de estallido social del país, el Gobernador Roberto Iglesias y el Presidente Fernando De La Rúa, el 10 de diciembre del año 2001, inauguraban la obra del paredón significando el comienzo del llenado del embalse. En ese acto, el discurso oficial en boca de los mandatarios, que levantaban la bandera del nacionalismo -útil componente de la ideología redentora planteada por Lins Ribeiro (1987)-, expresaban:

"la obra es una epopeya del pueblo mendocino y de los argentinos" (Presidente Fernando De La Rúa. Los Andes, 11/12/2001).

"Los mendocinos estamos dando el ejemplo. Aún en uno de los momentos más difíciles hacemos la obra más importante del país. Yo les digo a los argentinos que miren a Mendoza" (Gobernador Roberto Iglesias. Los Andes, 11/12/2001).

Por su parte, el representante de la empresa constructora exponía: 
"Hemos cumplido con la historia. Mostramos que cuando se comprometen voluntades, a pesar de los problemas los objetivos se consiguen" (Los Andes, 11/12/2001).

Acompañando esta inauguración, en el mismo medio periodístico se anunciaba que obras relacionadas con la presa aún no se encontraban terminadas, que la fecha estimada para ello era en diciembre del 2003, de ello se deduce que probablemente el acto inaugural fue adelantado a causa del contexto de crisis política, económica y social que vivía el país, que detonó en la renuncia del Presidente Fernando De La Rúa días después de su viaje a Mendoza para participar del acto inaugural. En la misma nota, también se comunicaba que las tareas pendientes eran entre otras: la terminación del trazado de la variante alta de la Ruta 7, y la entrega de las nuevas casas (Los Andes, 11/12/2001), ambos aspectos que incumbían en la vida de los pobladores afectados.

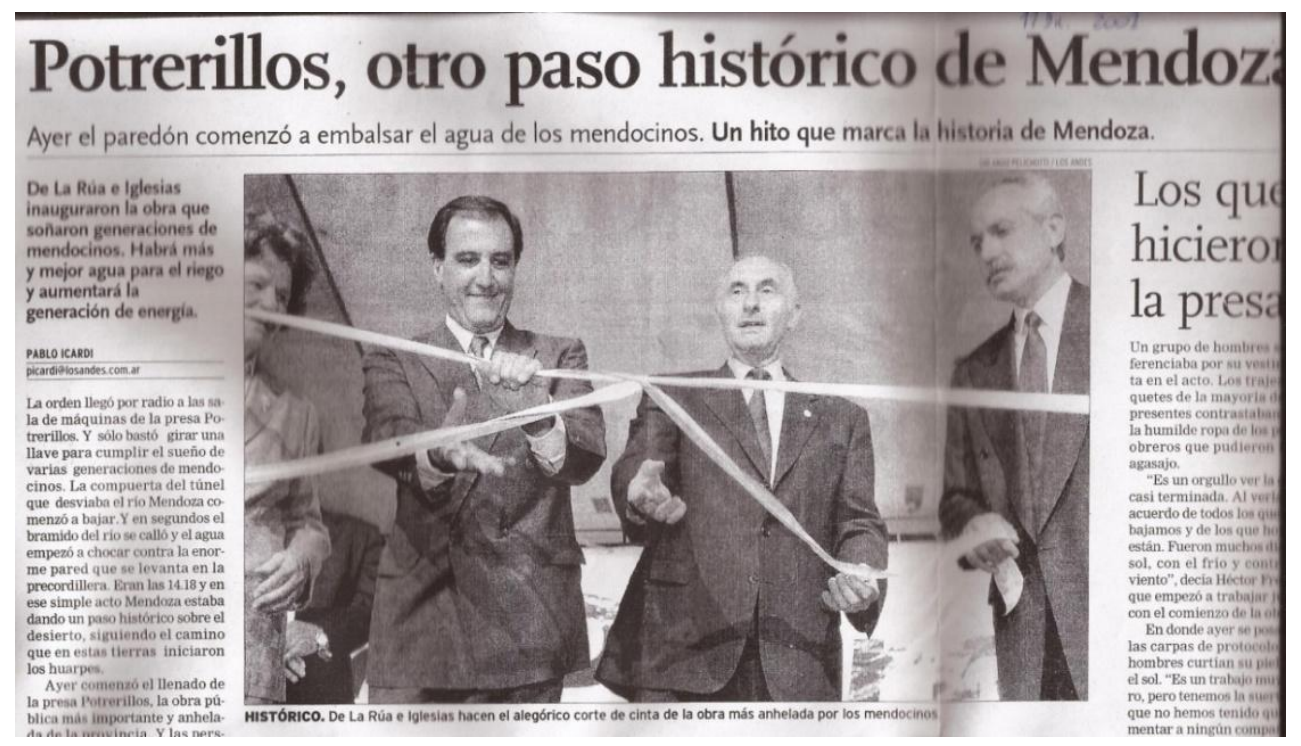

Fuente: Los Andes, 11/12/2001.

De este modo, presentada como producto de la obediencia a una tendencia histórica, la denominada "obra del siglo XX de Mendoza" se constituía en un hito de la historia de las grandes obras de la provincia; la misma se mostraba como la imagen que de sí el Estado deseaba trasmitir e imponer. En este sentido, en coincidencia con Lins Ribeiro (1987), las ceremonias del momento de la firma y de la inauguración de este tipo de obra constituyen escenarios privilegiados para la demostración de poder político; en ellas, a través de los discursos se vende, justifica y evita, al tiempo que vehiculizan las ideologías subyacentes a las prácticas y/o políticas territoriales. 
De esta forma, el proyecto se relaciona con el imaginario de un determinado futuro, que tiene que ver en palabras de Quijano (2002) con un "imaginario histórico" que lejos se encuentra del conocimiento de las "experiencias históricas concretas" particulares, acontecida en cada espacio/tiempo -que refieren a usos y significados, códigos de pertenencia, representaciones, clasificaciones, y aprehensiones cognitivas- como constituyen las de quienes son afectados por este tipo de decisiones y prácticas políticas, económicas, jurídicas y simbólicas en aras del desarrollo.

A continuación, se reconstruye el proceso de desalojo y relocalización de la población que residía en el sector ocupado por el embalse. Para ello, se contempla la intervención realizada por el Estado así como las manifestaciones realizadas por los pobladores afectados a través de los medios públicos de comunicación. 


\section{CAPITULO VI \\ LOS EFECTOS EN POTRERILLOS Y SUS POBLADORES}

Considerando que el modelo de desarrollo que persigue el proyecto en estudio significa un juego de intereses y poder, que implica situaciones de conflicto, negociación, aceptación y resistencias por parte de los actores partícipes del mismo, el abordaje de los efectos socio-territoriales generados por la obra hidroeléctrica de la Presa Potrerillos sobre la población de Potrerillos, se realiza considerando en primer lugar la sucesión de hechos, anuncios y denuncias públicas que quedaron registrados en documentos oficiales y periodísticos, para pasar luego a considerar la memoria de los sujetos del proceso, que a partir de relatos orales fueron registrados en el transcurso de esta investigación. De esta manera, el relato de la historia y las memorias se complementan en la comprensión de un proceso que incluye actores diversos como sujetos afectados y funcionarios intervinientes, quienes mantienen disimiles posiciones y representaciones en relación al acontecimiento. En este sentido, en este apartado aludimos al impacto de la obra sobre los espacios habitados, vividos y enraizados por los afectados, que Lefebvre (1974/2000) define como los espacios utilizados por el grupo o comunidad para servir sus necesidades y posibilidades de "apropiación" funcional como simbólica e identitaria originada en lo que se considera "el lugar" de cada persona. Estos espacio aludiendo al autor se gestan a partir de prácticas espaciales asociadas a las experiencias de la vida cotidiana domésticas, laborales, educativas, recreativas, etc.- así como a formas de política que se expresan en los espacios de representación, que son los espacios vividos por los habitantes en estrecha correlación con la práctica social, sus signos e imágenes asociadas, refieren en otros términos a "gestos, recorridos, cuerpos y memoria, símbolos y sentidos, contradicciones y conflictos, deseos y necesidades, etc. Es tiempo cercado en un espacio" (Lefebvre, 1972:187 cit en Nuñez, 2009).

En este marco, en este capítulo abordamos los efectos sobre la población de Potrerillos relocalizada así como de quienes no siendo relocalizados igualmente se vieron afectados por encontrarse en el área de impacto del proyecto sobre la localidad.

\section{Sobre la tierra y la vivienda}

1.1 El proceso de desalojo y relocalización

1.1.1 Antes del traslado

1.1.1.1 Datos y promesas oficiales 
Radovich (2005) manifiesta que resulta una práctica común en los procesos de instalación de grandes proyectos de inversión y desarrollo, partir del presupuesto de la existencia de "vacío demográfico" del área afectada por el emprendimiento, lo cual no solo sirve para minimizar los costos sociales de tales proyectos, sino también brindar legitimidad a que la obra beneficie casi exclusivamente a sectores sociales localizados lejos del área de su emplazamiento. Si bien en nuestro caso de estudio se reconoce la existencia de la población residente en Potrerillos, las implicancias del proyecto sobre el lugar y la vida cotidiana de las personas que lo habitan se ven minimizados por los promotores del desarrollo en relación a los múltiples efectos que manifiestan traerá la Presa Potrerillos para las tierras y habitantes del Oasis Norte de la provincia.

En relación a los afectados por la obra, en el año 1998 el CIFOT comenzó con una primera etapa de estudios socio-económicos sobre la población que residía en el área de emplazamiento del proyecto, entrevistó a 107 familias y 440 personas dando a conocer los siguientes datos:

En cuanto a la tenencia de la tierra, muchos de los habitantes que deben trasladarse se encuentran asentados en terrenos fiscales, pero existen familias "colonas" que acreditan habitar en el lugar desde hace más de cien años, o constituyen la segunda generación en el lugar, ya que sus padres y ahora ellos han sido y son empleados de las instituciones del Estado localizadas en Potrerillos. En otros casos se han instalado atraídas por las posibilidades de trabajo que ofrecía el desarrollo de la actividad turística-recreativa en la década del '40. Existen también casos en que los terrenos se encuentran ocupados por hogares en comodato, como inquilinos o cuidadores ad-honorem (Gudiño, 2002).

Referido a la cantidad de personas por hogares encuestados, ésta oscila entre 3 y 5 miembros. Se registran familias con ingresos bajos debido a empleos inestables o dependiente de pensiones o jubilaciones, y familias con ingresos más altos procedentes de empleos públicos y comerciantes. Sumada a estas actividades, predominan las actividades rurales asociadas a huertas familiares, la crianza de animales de granja y caballos que se alquila a turistas mayormente los fines de semana. Así mismo se realizan actividades complementarias vinculadas a las casas de fin de semana, venta de pan, tortas, empanadas, dulces, artesanías, etc. Según los resultados arrojados por este relevamiento, de las familias que se localizan próximas al centro cívico, el $80,6 \%$ cuenta con ingresos por debajo de la línea de pobreza (Ibidem, 2002).

En base a los datos de este primer diagnóstico, respecto de las familias que debían trasladarse, en la Síntesis de la Declaración de Impacto Ambiental se publicaba: 
"El análisis de la población local que deberá ser relocalizada indica que un alto porcentaje se encuentra con necesidades básicas insatisfechas y con ingresos por debajo de la línea de pobreza, aunque la localidad cuenta con buena prestación de servicios de educación, salud, seguridad, etc. (Gobierno de Mendoza. Los Andes, 13/12/1998). (Las negritas me pertenecen).

Para mitigar estos efectos anunciados sobre la población del lugar, el Estado promotor del proyecto en el mismo documento prometía:

"soluciones habitacionales, regularización de la tenencia de la tierra y Programas de reinserción social y económica con Proyectos de Capacitación y Desarrollo para reinserción en procesos productivos en la zona".

Así también, referido al período de trabajo en la construcción de las obras exponía:

"se trata de un impacto positivo alto, temporario y zonal, que debe ir acompañado de Programas de Inserción y Capacitación Laboral, sobre todo para la población local" (Ibidem. Los Andes, 13/12/1998). (Las negritas me pertenecen).

De esta manera, en base a indicadores estatales de medición de las condiciones socioeconómicas de la población, así como a las promesas de viviendas y tenencia de la tierra, trabajo, capacitación, reinserción social y económica se argumenta el desalojo y relocalización de las familias afectadas.

En relación a este pronóstico positivo para los pobladores del lugar, cabe mencionar que las necesidades básicas insatisfechas $(\mathrm{NBI})^{16}$ presentadas por la población no habían resultado de interés por parte del Estado hasta el momento de la construcción de la presa; así como también el hecho de que si bien una parte de la población presentaba NBI e ingresos por debajo de la línea de pobreza, el documento expresa contradictoriamente que estos indicadores no tienen relación con las prestaciones estatales brindadas en la zona para garantizar los derechos de salud, educación, vivienda, etc. De esta forma, la presentación de la obra, como un espacio de concentración de la actividad económica, cuyo efecto multiplicador beneficiaría no solo a los relocalizados a quienes se les promete revertir su situación de pobreza, sino también a toda el área de influencia de la obra, se vincula con lo que Lins Ribeiro denomina "ideología de la redención", que legitima un desarrollo planteado por unos pocos y subestima los efectos sobre las poblaciones.

\footnotetext{
${ }^{16}$ Los indicadores de NBI (Necesidades Básicas Insatisfechas) se miden por hogar y considera: 1 . El hacinamiento, 2. La precariedad de la vivienda, 3. Las condiciones sanitarias -sin retrete con descarga de agua-, 4. La asistencia escolar de personas en edad escolar, y 5. La capacidad de subsistencia -hogares con 4 o más personas por miembro ocupado-.
} 
1.1.1.2 Del primer contacto entre funcionarios y pobladores: dudas, propuestas y temores Una vez anunciada públicamente la construcción de la presa, los responsables del proyecto de ordenamiento territorial del perilago comienzan a mantener reuniones con los pobladores a relocalizar en la Escuela Cap. De Frag. Carlos A. Negri. En ellas se tratan temas alusivos a la relocalización, al funcionamiento de la Unión Vecinal, planes de vivienda del IPV, tarea de las sicólogas que envía el Estado en el lugar, búsqueda de terrenos fiscales en la zona de Perilago, búsqueda de terrenos para reubicación individual, apoyo al funcionamiento de la Entidad Intermedia, etc. (Gray de Cerdán, 2003). Como reacción a esto, en este período (1998-2000) comienza la resistencia de la población al plan de relocalización forzosa. La respuesta defensiva de los pobladores que al parecer era "no esperada" por parte del Estado, es descripta por Gray de Cerdán, directora del plan de ordenamiento en términos de que acontecía "una fuerte problemática social que es comandada por la Unión Vecina de Potrerillos" (Ibidem, p.350).

Para los pobladores, en esta etapa de impacto del proyecto, cuando todavía no habían sido trasladados, las dudas, el desconcierto y el temor a las pérdidas y al desarraigo eran una constante. La incertidumbre rondaba sobre si la construcción de la presa les cambiaría la vida y perjudicaría sus fuentes de trabajo, si se tenían que ir o podrían quedarse, si el pueblo se refundaría en el mismo lugar o en otro. Se comenzaban a presentar, en otras palabras, los efectos del "stress multidimensional de relocalización" (Scudder y Colson, 1982).

En mayo de 1999, en una nota realizada por Diario Los Andes, expresaban que ante la "nada en concreto" que presenta el gobierno "proponemos que se refunde el pueblo aquí mismo" y "se mantengan el mayor número de propiedades que sea posible" junto a los ríos y montañas; así como, que "les permitan participar con sus diferentes actividades y aprovechar el progreso que la obra hidráulica traerá a la zona" (07/05/1999). En esta nota manifiestan también que hay vecinos desconsolados y desconfiados de la actitud de los representantes del gobierno que ni siquiera quieren asistir a las reuniones porque consideran que:

"el poder de decisión lo tienen los del Gobierno y creo que no hace falta que nos quieran convencer de que nos tenemos que ir a otro lado. Si nos tenemos que ir nos iremos. Lo que sí creemos, es que ellos quieren explotar el perilago y dejarnos al margen" (Los Andes, 07/05/1999).

Sobre la idea oficial de que los pobladores del pueblo sean trasladados a un barrio, la gran mayoría se opone, ya que los mismos tienen un estilo de vida consolidado a través 
de los años, vinculado al medio natural así como al tránsito vehicular de la Ruta 7 y arribo de población visitantes. En sus propios términos:

"Cada uno de nosotros tiene su actividad, está acostumbrado a vivir en casas que no están una al lado de la otra, sino bien distantes, como en toda zona rural. ¿Qué vamos a hacer en un mismo caserío, por ejemplo cinco panaderos juntos? ¿Nos vamos a vender el pan entre nosotros?" (Los Andes, 07/05/1999).

Respecto de la expropiación, los afectados postulan que será una tarea complicada y dolorosa para ellos, debido a que, aludiendo a la población estable:

"hay gente que vive en el lugar hace más de 30 años y no ha gestionado su título de propiedad, pero (...) tienen derechos adquiridos sobre los terrenos porque se sienten, ellos mismos, el pueblo. Son los que lo sostiene y lo hicieron crecer" (Ibidem, 07/05/1999).

En otra nota realizada meses después, en relación a los terrenos del perilago, se exponía ante los medios que gran parte de la población piensa que:

"estos terrenos no se van a expropiar para que estos espacios tengan utilidad pública, sino que el verdadero motivo es para hacer negocios inmobiliarios privados" (Los Andes, 08/07/1999).

Con esta desconfianza vivían los pobladores la manifestada intención del gobierno de hacer participar a los afectados en el destino del pueblo. Los siguientes titulares dan cuenta de lo forzado que resultaba para los mismos la idea de tener que trasladarse en pos de un desarrollo por ellos no buscado, ni anhelado.

Ante un posible desarraigo por las obras del dique

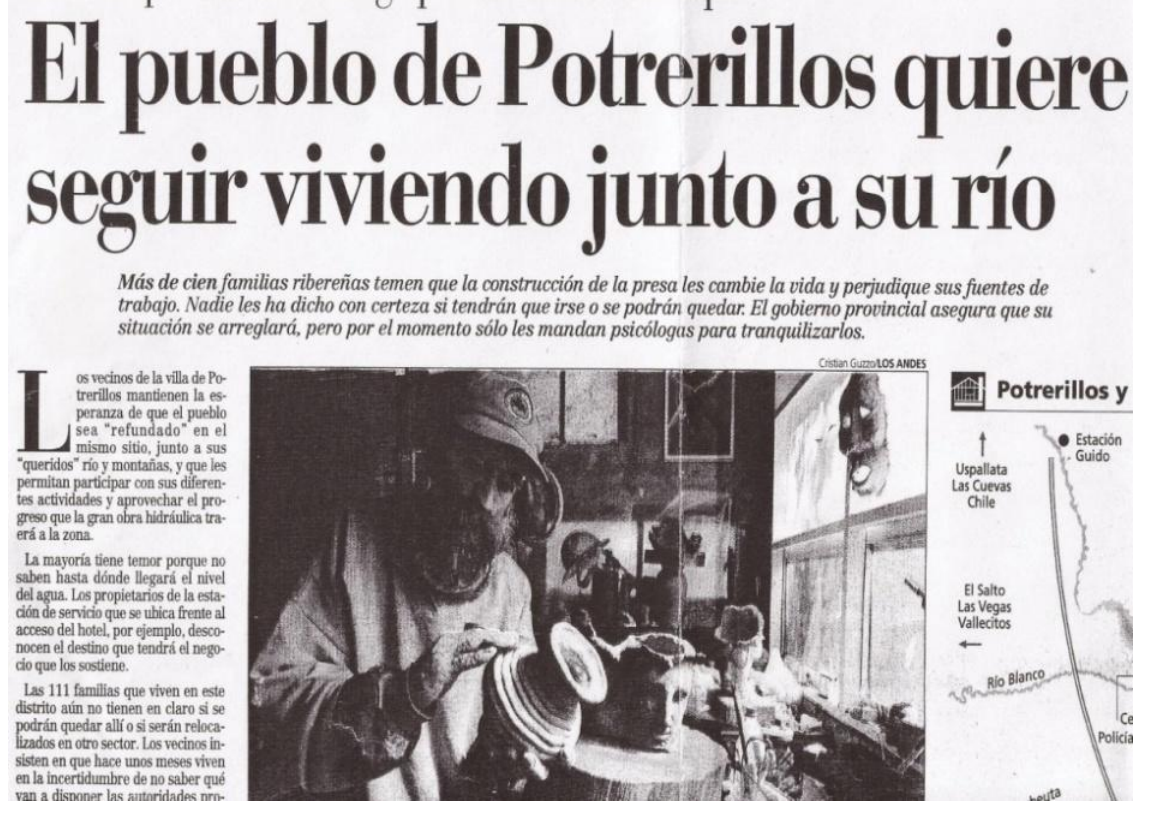

Fuente: Los Andes, 07/05/1999. 


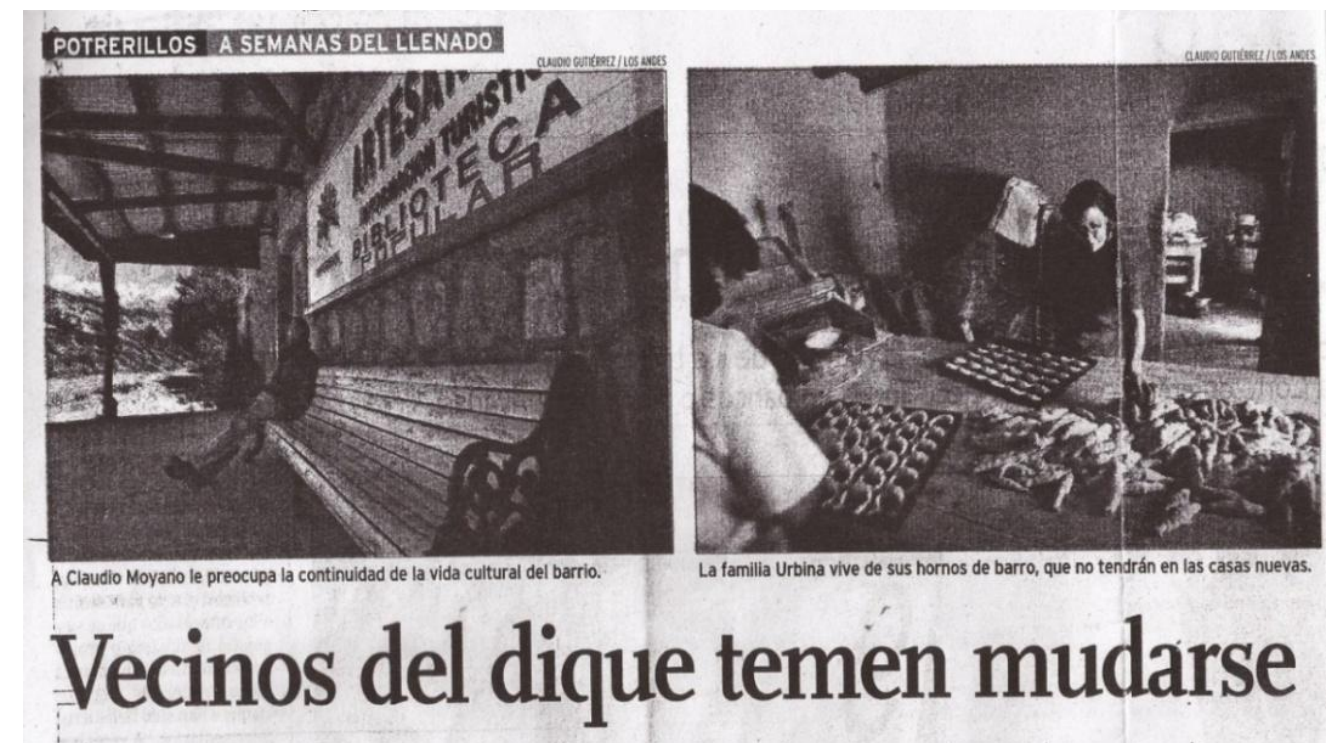

Viven en el perilago y tendrán que irse. El barrio nuevo está, pero se quejan por las cuotas altas.

Fuente: Los Andes, 25/11/2001.

\subsubsection{Los estudios definitorios y la solución habitacional}

Entre los primeros estudios, reuniones y declaraciones públicas iniciadas en 1998, y el momento de las acciones concretas transcurrió un período de dos años. Debido a esto, en el año 2000 el IPV, la Municipalidad de Luján de Cuyo y la DOADU, dependencias del Estado involucradas en la tarea de la relocalización realizaron nuevos estudios sobre los pobladores afectados por la construcción de la presa para actualizar la información y ampliar aspectos no contemplados en el relevamiento anteriormente. Así también, realizaron intervenciones legales, técnicas y sociales a fin de ejecutar la solución habitacional prometida a quienes debían mudarse.

A continuación se describe en que consistió la solución habitacional brindada por el Estado, la gestión de las viviendas y la metodología de compensación económica, así como los resultados del último diagnóstico socio-económico de la población a partir del cual el Estado diseña el emprendimiento.

\subsection{La gestión de las viviendas y la metodología de compensación económica}

El 22 de agosto de 2000, por medio de Ley Provincial $\mathrm{N}^{\circ} 6.811$, promulgada por Decreto del Poder Ejecutivo №1.887 de fecha 06 de setiembre de 2000, la Provincia dona al IPV dos fracciones de terreno ubicadas en el Distrito de Potrerillos para implementar el emprendimiento habitacional para los residentes permanentes de la Villa de Potrerillos afectados por la presa. Así también, el día 31 del mismo mes, por Decreto 1825, el 
Ministerio de Ambiente y Obras Públicas del Gobierno de la Provincia autoriza al IPV a instrumentar la operatoria de vivienda para los habitantes permanentes de la Villa Potrerillos que decidan quedarse en la zona, así como también para aquellos que opten por dejar la localidad.

Para quienes decidan quedarse, la operatoria consistió en: 1) realizar la licitación pública, 2) establecer la financiación para la ejecución de las viviendas, equipamiento y urbanización, 3) estipular el precio de las viviendas, y 4) proceder con las escrituras. En relación al primer paso de tal directiva, por Resolución 947, el IPV resuelve llamar a Licitación pública para la construcción de la "Villa Potrerillos" los días 03 y 06 de setiembre del año 2000. En anexos se expone el folleto publicado en los medios de comunicación locales en el que constan los acotados plazos en que debía realizarse la obra y el presupuesto oficial destinado para la construcción de 70 viviendas, la urbanización y trabajos complementarios.

De esta licitación pública, las empresas ganadoras fueron Antares S.A y Laugero Construcciones S.A. las cuales constituyeron una Unión transitoria de empresas.

Aludiendo al mismo decreto, la financiación de las obras, se realizó con fondos provenientes del Fondo Provincial de la Vivienda que administra el IPV, y con fondos del Ministerio de Ambiente y Obras Públicas. Respecto del precio de las viviendas lo que debían reintegrar los adjudicatarios eran los costos de vivienda y equipamiento, en los casos que correspondía, no así el costo de la infraestructura, la urbanización ni del lote. A este precio se le descontaba el valor que resultaba de la metodología de compensación, y el monto resultante debía ser pagado por el adjudicatario en 360 cuotas mensuales con una tasa de interés $0 \%$, después de dos años de la entrega de las viviendas.

En relación a las escrituras, el gobierno determina que previo a la entrega de las viviendas, se formalice la escritura traslativa del dominio a favor del adjudicatario y se constituyera una hipoteca en primer grado de privilegio a favor del IPV para garantizar la devolución del precio de la unidad.

Para quienes eligiesen trasladarse residencialmente de Potrerillos la solución habitacional propuesta por el Estado era otorgar a los mismos un préstamo para compra de vivienda, compra de terreno y construcción de hasta la suma de veintinueve mil pesos $(\$ 29.000)-$ de aquel tiempo-, que debería ser reintegrado en 360 cuotas con un interés del $0 \%$, no ante de los 6 meses de la relocalización del beneficiario a otra localidad.

Para ofrecer una compensación o resarcimiento económico a los habitantes por las molestias o perjuicios causados por el desalojo y la relocalización involuntaria, el equipo 
técnico social del IPV y la Municipalidad de Luján de Cuyo idearon una metodología de evaluación de las viviendas que ocupaban los afectados al momento del relevamiento. La misma contemplaba las mejoras realizadas en el lugar por parte de los pobladores así como las características socioeconómicas de los grupos familiares.

Las variables sociales consideradas eran: año de residencia en la zona / ocupación efectiva de la vivienda / afectación de la actividad laboral / situación de salud del grupo familiar / cantidad de menores a cargo / ingresos del grupo familiar, etc.; y las variables técnicas: año de construcción de la vivienda / metros cubiertos / materiales de construcción utilizados / estado de conservación de la vivienda / mejoras / forestación / etc. Cada uno de estas variables tenía una numeración de ponderación y al sumar los valores de las variables se obtenía un valor económico. Este valor resultante de las evaluaciones finalmente se descontaba del valor de los créditos de las nuevas viviendas o del préstamo otorgado por el IPV a quienes decidieron dejar la localidad (Decreto N¹825 del Ministerio de Ambiente y Obras Públicas).

Para aquellos casos en que el reconocimiento económico resultase mayor que el crédito otorgado por el IPV a los habitantes permanentes de la Villa Potrerillos para adquisición de viviendas, por Resolución N 499 del 16 de julio de 2002, el Directorio del IPV resuelve que el mismo no pagará suma alguna, dándose por canceladas las viviendas adquiridas y constituyéndose la correspondiente Escritura Traslativa de Dominio a favor de quienes están en la lista. Para los casos en que el reconocimiento económico resulte menor que el crédito otorgado por el IPV a los habitantes para adquisición de viviendas, el Instituto constituirá a su favor, Hipoteca en Primer Grado de Privilegio por la diferencia que surja por Resolución 1046/01. Cuando las diferencias económicas de los créditos otorgados a los habitantes permanentes de la Villa Potrerillos resulten a favor del IPV, serán reembolsados por este en el marco de las condiciones establecidas en la Resolución.

A partir de esta metodología, el IPV evaluaba las condiciones socio-económicas de las familias y diseñaba la solución habitacional. Sobre la misma, quienes la aplicaron y fueron entrevistados en el marco de la elaboración de esta tesis exponían:

"fue un sistema súper novedoso porque no había antecedentes para buscar como valorar el desarraigo (...) entonces se empezaron a escuchar a las personas bueno a ver qué es lo que más valora Ud.- eso quedó registrado y se le empezaron a dar valor económico a todas esas cosas, a los árboles, al alambrado, a la construcción, a los años que llevaban viviendo ahí, se fueron como desarrollando ítems en donde cada uno tenía un coeficiente para sacar un valor. Si tuviera la posibilidad de hacerlo hoy hago mi autocrítica en el sentido de que se pudiera haber trabajado el tema de que la gente tiene sus derechos y a esto hay que valorizarlo. Se hizo en ese momento mucho esfuerzo para que se 
reconocieran los derechos adquiridos que ellos tenían por estar ahí a pesar de que legalmente te decían no les corresponde nada, hay que sacarlos, esa era la visión de los abogados del Estado, del Ministerio, por el tema de que no tenían papeles. (...) fue una experiencia bastante traumática para la gente pero podría haber sido mucho peor si no se hubieran hecho esos trabajos previos de reconocimiento de lo que ellos tenían" (Trabajadora Social. Miembro del equipo social del Área Vivienda de la Municipalidad de Luján de Cuyo, 10/12/2014).

Según manifiesta la entrevistada, la metodología elaborada por el equipo encargado de la relocalización fue una propuesta innovadora vinculada a los efectos sobre la población que genera la construcción de represas. Sin embargo, aún cuando la misma constituye ahora un antecedente en materia de desalojo y relocalización a causa de los proyectos de desarrollo, en el proceso en estudio su aplicación no se plantea en un marco de derecho de los afectados en la co-creación y participación del desarrollo del nuevo lugar a habitar, sino que es planeada en términos del mal menor que el Estado les pudo haber causado a los habitantes afectados por la obra. Los resultados que surgen de la implementación de esta metodología sobre la población afectada los exponemos en el siguiente apartado.

\subsection{Las familias afectadas}

Del nuevo diagnóstico realizado sobre las familias afectadas, en base a las variables utilizadas en la metodología de compensación, aludiendo a documentos de la DOADU (2000, p.58 y 132) surge que los grupos familiares se componen en un $30 \%$ por familias constituidas por 5 o más personas, y en un $53 \%$ por 2 a 4 miembros. De los mismos, el $76 \%$ de los hogares tiene jefatura con figura masculina.

La mayoría de las familias son oriundas de la zona, algunas por más de tres generaciones de pertenencia. Al momento del estudio, el $94 \%$ vivía en la zona desde hacía más de 5 años. De ese porcentaje, el 37\% tenía una antigüedad de más de 20 años.

La salud del grupo estudiado era buena y en cuanto a la escolaridad, el $77 \%$ de la población contaba con escolaridad primaria completa.

Se trata en su mayoría de familias dedicadas a las actividades primarias: crianza de animales; y terciarias: comercio, artesanías o gastronomía, en función de la actividad turística- recreativa de la zona. De esta población el $42 \%$ contaba con ingresos inestables. Entre los mismos se registran casos de contratados y gente que vivía de changas. En general los grupos familiares contaban como ingreso principal con el del jefe de familia. El $30 \%$ de la población percibía ingresos menores a $\$ 300$ (pesos trescientos).

Debido a que en gran medida la población concentraba su actividad económica de subsistencia en la Ruta 7 y en la Avenida Los Cóndores, ambas arterias comprometidas 
por la construcción de las obras, este diagnóstico anticipaba que casi el $50 \%$ de la población se vería afectada laboralmente.

Respecto de las viviendas que poseían, estas eran en su mayoría autoconstruidas por sus habitantes, de materiales como ladrillo y adobe, y muchas poseían servicios básicos no legalizados. En cuanto a la tenencia de la misma, el 55\% de la población era propietaria de la vivienda, no así del terreno, que eran de propiedad fiscal.

En cuanto a las condiciones de habitabilidad se presentan diferentes situaciones por lote: la existencia de una vivienda en donde conviven dos grupos familiares, la existencia de una vivienda con un solo grupo familiar, más de una vivienda con dos grupos familiares distintos, dos o más viviendas y en una de ella conviven dos grupos familiares, y también familias que si bien residen permanentemente desde hace 5 años y realizan actividades artesanales, ocupan casas pertenecientes al ex Ferrocarril Trasandino.

En cuanto a la aspiración de quedarse o no en la zona y al lugar de residencia, el $85 \%$ de la población manifestó el deseo de permanecer en Potrerillos y el resto optó por trasladarse a zonas urbanas del Gran Mendoza como Luján de Cuyo, Guaymallén, Las Heras, etc. De las primeras, el 60\% manifestaron el deseo de conservar las condiciones de vida que poseían al momento del relevamiento, además de optar por viviendas individuales para la relocalización.

Parte de la información relevada por el equipo interdisciplinario de técnicos y profesionales quedó documentada en fotografías. A continuación exponemos algunas fotos de las casas que se localizaban por debajo de la cota máxima de la presa y fueron en algunos casos demolidas, en otros, desarmadas y trasladadas por sus dueños. Si bien estas fotos no representan la totalidad de las viviendas de la población, se ha realizado una selección buscando mostrar la variedad de materiales usados en las construcciones, así como sus tamaños y formas. Como podemos ver se trata en muchos casos de viviendas de adobe, ladrillo y cemento, madera, chapas y mixtas; autoconstruidas en algunos casos, pre-fabricadas en otros, con baño adentro y afuera de la vivienda. Así mismo observamos, en la parte exterior de las viviendas, la presencia de hornos y que los espacios utilizados para la instalación de las mismas son amplios y rodeados de vegetación. Las viviendas se encuentran distanciadas entre sí. 

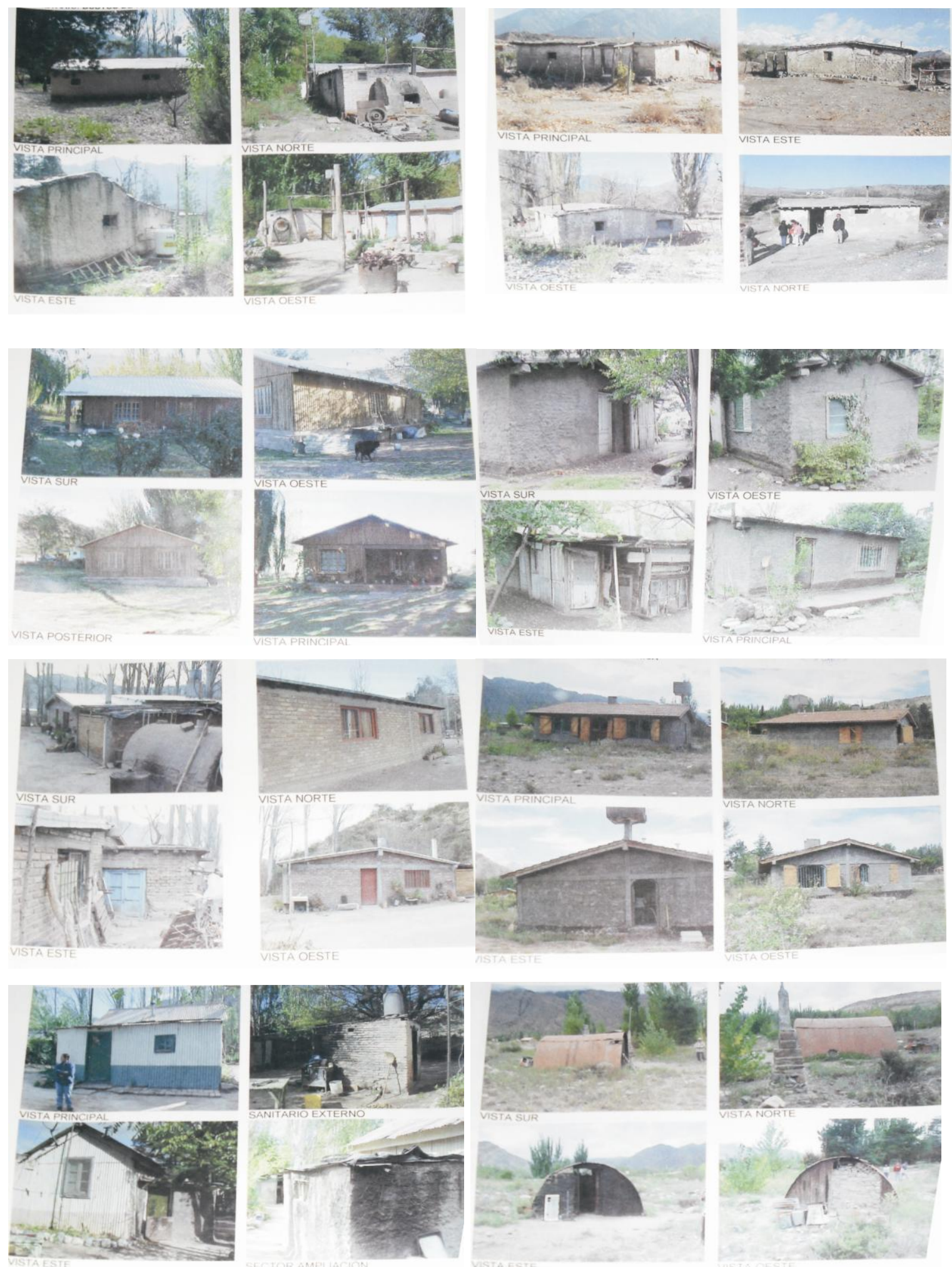

Imagen 8, 9, 10, 11, 12, 13, 14, 15: Archivo del Instituto Provincial de la Vivienda. Asunto: Entrega Villa Potrerillos. Relocalización Villa Potrerillos. Relevamiento y tasación de viviendas existentes. Gerencia de Evaluación de Créditos. Tomo I, II y III. Gobierno de Mendoza. 


\subsubsection{3 "con un mínimo de participación" en "un fenómeno "externo" y "ajeno"}

En paralelo al relevamiento domiciliario realizado por los técnicos y profesionales responsables de la relocalización, el mismo equipo convoca a reuniones a los pobladores con el objetivo de hacerlos partícipes de los cambios no elegidos que los involucraban. En estas instancias, en palabras de Gray de Cerdán, Directora del Plan de ordenamiento territorial del perilago:

"se buscó restablecer vínculos con las organizaciones de la comunidad, rever los proyectos de relocalización previos que habían sido fuertemente resistidos por la Comunidad en años anteriores y avanzar para poder cumplir con los plazos previstos en la obra" (DOADU, 2000, p.123).

De este modo, a contra reloj, siguiendo los plazos establecidos por los empresarios para el llenado del embalse, en una primera etapa, aludiendo a la funcionaria, la DOADU ofreció a la comunidad, considerando las demandas de los pobladores, realizar el estudio de las posibilidades de localización, evaluando los aspectos ambientales, económicos, sociales así como las posibilidades concretas de previsión de servicios e infraestructura. Sin embargo, de las alternativas evaluadas a partir de variables como superficie del terreno, topografía, posibilidades de expansión, integración con los sitios históricos a conservar, sitios arqueológicos, equipamiento existente, aptitud forestal, capacidad portante del suelo y ubicación estratégicas de los terrenos para la instalación de las viviendas, en base a la propuesta urbana general -expuesta en el capítulo anterior- la relocalización finalmente tuvo lugar al norte del cauce del río Blanco, en el área del Centro cívico e histórico, donde se concentran los principales equipamientos (Ibidem p. 129).

La idea central en el diseño, argumenta Gray de Cerdán fue localizar a la población y sus instalaciones en la zona alta con un triple propósito: aprovechar las visuales sobre el lago y el río; utilizar las zonas menos vulnerables a los fenómenos aluvionales y; separar la población de los flujos de circulación del corredor vial y ferroviario (Ibidem p. 126).

Luego de las reuniones con motivo de la elección del terreno, se sucedieron otras para la elección de las viviendas. En este caso el IPV presentaba opciones a la población entre las que podía elegir la localización de la parcela que más le convenía dentro del predio de la relocalización, el diseño de la vivienda (distribución interna, construcciones complementarias según la actividad económica), el plan de financiamiento a tomar en relación al reconocimiento de las inversiones realizadas en infraestructura de la vivienda anterior, la relocalización de las actividades económicas afectadas, etc. (Ibidem, p.128). Como podemos ver en los documentos citados, la tarea de planificación y ejecución de la relocalización por parte del Estado constituyó un trabajo minucioso que consideró la 
situación particular de cada grupo familiar afectado. Sin embargo, la participación que se buscaba, vale aclarar, era dentro de las opciones presentadas por los planificadores del nuevo orden-lugar para cumplir con los plazos establecidos por los empresarios encargados de la presa, es decir, lejos se encontraba de la intención de incluir a los afectados en la construcción de la idea y planificación del desarrollo del nuevo lugar. Esta lectura sobre la participación de los pobladores en el proyecto también se puso de manifiesto en el documento de la DOADU (Gray de Cerdán, 2000, p.132):

"el Proyecto se presenta ante la comunidad como un fenómeno "externo" y "ajeno" a ellos, al que deben adaptarse en la medida en que se presentan los hechos".

Sobre este momento de intervención sobre la población previo al traslado las funcionarias encargadas de las áreas sociales del IPV como de la Municipalidad de Luján de Cuyo involucradas en la relocalización años después relataban:

"nosotros - alude al IPV- recibimos el proyecto de relocalización que comenzamos a coordinar con la DOADU, tuvimos un año para todo el proceso, proceso más que apretado, no hubo posibilidad de trabajar mucho con la gente con el tema de concientización, de que se vayan apropiando, eso agrega nivel de conflicto que ya existe porque no quieren moverse de los lugares que ocupan desde hace 20,30, 40 años, aparte del operativo, los técnicos y demás. E: ¿Por qué fue tan corto el plazo? LT: Porque no estaba planeado, (...) en el proyecto de Potrerillos el tema de la relocalización era un tópico, el tema es que no se abordó desde el momento en que se comenzó a ejecutar la obra del dique, ya estaba listo el paredón para empezar a llenar el embalse cuando empezamos, se trabajó con ellos en el proyecto de viviendas, eso mereció muchísimas reuniones de conflictos, pero bueno, se trató de trabajar en el corto plazo con un mínimo de participación de parte de la gente" (Coordinadora del equipo social del IPV, 26/09/2011).

"Yo me acuerdo haber estado en reuniones informativas donde la gente lo primero que preguntaba era bueno, cual es la cota máxima y nosotros no se la podíamos confirmar porque oficialmente no la teníamos confirmada, pero sabíamos efectivamente que el agua iba a cubrir toda esa zona, que de hecho lo ha hecho." (Coordinadora del equipo social de la Dirección de Vivienda de la Municipalidad de Luján de Cuyo, 03/12/2014).

De esta manera la participación de la gente en el desarrollo no era el objetivo de la intervención del Estado, el objetivo era la desocupación del lugar para el llenado del embalse. En este marco se fundamenta el escaso y acelerado tiempo en que se desarrolló el proceso de relocalización que aludiendo a los testimonios expuestos se efectuó de manera desarticulada del proyecto de construcción de la gran obra. Esta situación estimuló la adecuación de los tiempos de los planificadores e interventores de la relocalización a la realidad de los empresarios y no al proceso de desapego y readaptación obligada que tenían que vivir abruptamente quienes habitaban por años en 
el lugar, y tenían que pensar en trasladarse aún cuando el Estado no confirmaba el perímetro del área que requería la obra. Esto da cuenta del papel secundario o circunstancial que ocupó la relocalización en el proyecto de la Presa Potrerillos.

En resumen, el proceso de relocalización fue conflictivo y motivó en varios casos la solicitud de un abogado por parte de los pobladores para hacer juicio al Estado en reclamo de la propiedad veinteñal o por daños y perjuicios. Sobre esto una entrevistada agregaba:

"ha sido conflictivo, hasta el día de hoy tenemos una partecita de todo ese barrio con una situación legal (Coordinadora del equipo social de la Dirección de Vivienda de la Municipalidad de Luján de Cuyo, 03/12/2014).

La misma alude a las familias que se rehusaron a pagar el crédito otorgado por el IPV y le hicieron juicio al Estado provincial, y por tanto aunque ocupan la vivienda no se les ha dado de alta como adjudicatarios de la vivienda. Sobre los efectos de estas reuniones, y la participación de los afectados en el proceso, más abajo consideraremos la memoria de los pobladores, lo cual nos posibilita conocer cómo era vivida por ellos la intervención del Estado y cuáles son sus representaciones del proceso en estudio.

\subsection{El emprendimiento habitacional}

Aludiendo a los datos finales de los estudios y definiciones institucionales, el IPV en un terreno de aproximadamente 40 hectáreas de superficie, distribuidas en 120 lotes de 1000 $\mathrm{m}^{2}$ y de $2500 \mathrm{~m}^{2}$, localizados junto a la margen sur del Río Blanco y al oeste del predio ocupado por el Hotel Potrerillos -propiedad del IPV-, construyó 70 (setenta) viviendas de cuatro tipologías distintas con posibilidades de ampliación que varían de uno a cuatro dormitorios, según el tamaño del grupo familiar: 18 viviendas de un dormitorio, 16 de dos dormitorios, 20 de tres y 16 de cuatro dormitorios, más la casa de cisternas; y para aquellas familias cuya actividad económica era comercial construyó locales comerciales 14 en total- (Informe técnico del IPV, 2000).

La localización de las viviendas se emplazan en tres zonas de acuerdo con las actividades laborales desarrolladas por los pobladores: la zona urbana residencial en lotes de $1000 \mathrm{~m}^{2}$; la zona urbana comercial en lotes de $1000 \mathrm{~m}^{2}$, que en algunos casos cuenta con locales comerciales; y la zona semi-rural y la rural con lotes de $2.500 \mathrm{~m}^{2}$, para los pobladores que poseían animales (Gray de Cerdán, 2003).

Las obras de urbanización comprendieron cunetas empedradas, badenes de hormigón, calles enripiadas y forestación. El conjunto de la calles se han previsto con anchos de 20 
y 16 metros. El área destinada a espacios libres y de ubicación de algunos equipamientos coincide con una formación geológica de interés paisajístico y con la ubicación del cementerio de la Villa (Consejo Nacional de la Vivienda, 2002).

En lo referente al equipamiento se conectaron los servicios mediante una red de agua distribuida por una cisterna elevada, el riego del arbolado público se prevé por cunetas; la red cloacal con sus estaciones de bombeo y planta de tratamiento de efluentes está ubicada en la parte más elevada del emprendimiento y a más de $500 \mathrm{~m}$ de las viviendas; y la red eléctrica con distribución subterránea e iluminación para el alumbrado público. Así también se plantaron 4000 forestales y 1000 especies arbustivas en terrenos de los pobladores y en áreas destinadas a espacios comunitarios (Ibidem, 2002) ${ }^{17}$.

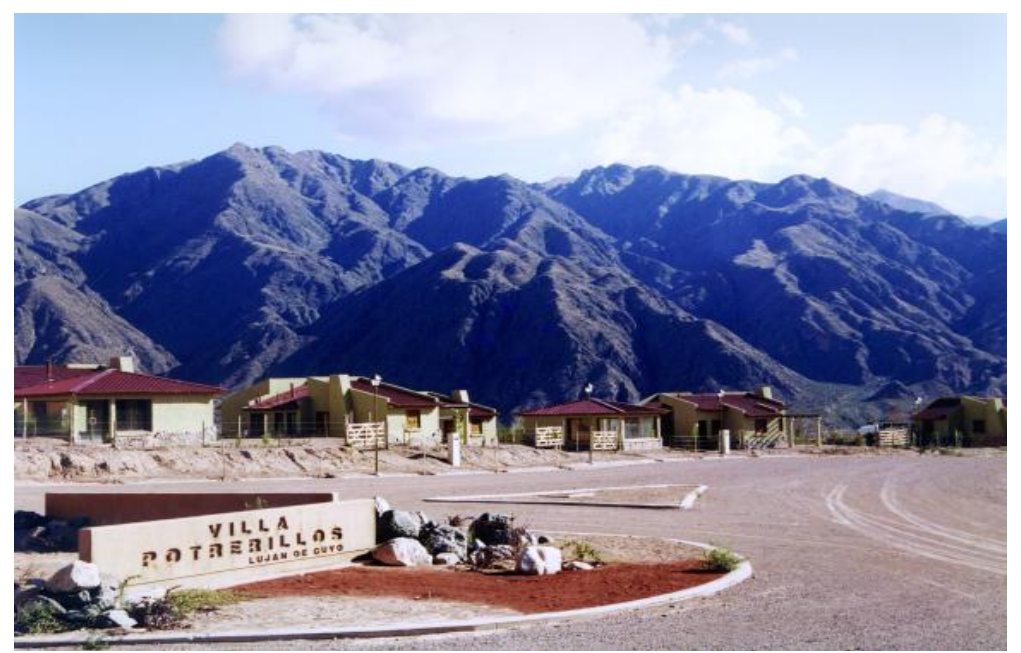

Imagen 16. Revista del Consejo Nacional de la Vivienda. №6. Abril 2002

Años después, al momento de realización de esta investigación, quienes se encargaron de la construcción del emprendimiento habitacional, evalúan de la siguiente manera el resultado de la gestión de las viviendas y la intervención sobre la población:

"en mi directorio había 2 personas que se oponían a que a la gente de Potrerillos le diéramos más que a otras personas inscriptas, de cooperativas, y el Ministro Cobos y Morandini me presionaban terriblemente porque a la gente había que darles algo muy bueno porque la gente iba a hacer problema, iba a hacer manifestación, y ellos ya lo sabían, le tenían miedo a la gente porque las asistentes sociales de la Casa de Gobierno ya le habían advertido que no quería moverse de su lugar, pensaban que ir allí arriba era irse al desierto, y no veían nada, había un terreno totalmente árido y con una topografía muy diferenciada, un relieve medio montañoso tipo serranía con grandes movimientos de suelo a realizarse, (...) nosotros estábamos haciendo una vivienda dos veces y media más cara que una vivienda común del IPV, más o menos.

\footnotetext{
${ }^{17}$ Ver en anexo el plano del barrio construido para la relocalización de los pobladores.
} 
Yo estoy muy satisfecho por el resultado final, constructivamente yo digo que es el mejor barrio de la historia del FONAVI; ahora a lo mejor hay alguno mejor pero en esa época el FONAVI nunca había hecho un barrio tan hermoso, para colmo nosotros teníamos que convencer a la gente para que le gustara la casa y no se fuera. Llegó el día que había que pintarla entonces al grupo de F se le ocurrió usar los colores del entorno, de la naturaleza para incluso diferenciar al barrio para que no haya uniformidad, dijimos vamos a hacer algo diverso, las viviendas eran diseminadas medio irregularmente, el barrio se pintó con 4 colores distintos.

Nunca el IPV había hecho un estudio tan exhaustivo social y económico, fue extraordinario, fue un ejemplo de gestión lo que hicimos con esta gente, respetar la topografía, que no hubiera cables, las acequias empedraditas, bueno todo como un barrio privado, hay barrios privados hoy que son mucho peor que ese, de hecho había políticos que me pedían vivienda en ese barrio, yo le digo ¿pero vos sos tonto?, gente allegada al gobernador me decía - ¿Che, no tenés una vivienda?" (Presidente del directorio del IPV encargado de la ejecución del emprendimiento habitacional, 19/12/2014).

Como podemos ver, desde el equipo técnico y social de los sectores encargados de la relocalización se realizó un trabajo bajo presión del Gobernador Iglesias y sus ministros con la intención de seducir y convencer a los afectados con una nueva vivienda y evitar que los mismos manifestaran públicamente el rechazo a la decisión de tener que trasladarse por la instalación de la presa.

En relación a la gestión, se aduce que significó un trabajo paradigmático desde el punto de vista social, en cuanto a la metodología de relevamiento y compensación económica que propició la puesta en valor económico de lo tangible como de lo intangible de las familias afectadas, para luego descontarlo del valor de la casa adjudicada; y desde el punto de vista técnico, que la obra significó un emblema en la historia del IPV, ya que implicó una construcción sobre un terreno irregular, de viviendas con características adecuadas a la zona de montaña y de un costo económico superior a las casas construidas por el IPV para la población en general.

Así mismo, se manifiesta la importancia del trabajo en equipo de quienes hicieron el proyecto de la villa así como la articulación con otras reparticiones del Estado para ejecutar la decisión política del gobierno. Sobre esto se narraba:

"había mucho peso en las decisiones por parte del Ministerio que influía sobre el resto de las reparticiones para movilizarlas y destacar algunos profesionales de cada una para armar una mesa de trabajo para que se llevara a cabo, se tomara la decisión y se impulsara" (Diseñador del proyecto urbanístico de la villa y de las viviendas. Coordinador de la Dirección de Obra. IPV, 11/12/2014).

El tiempo de ejecución de la obra, el cual es un condimento crucial en el proceso en estudio, es otro aspecto que se considera no común en las obras que habitualmente realiza el IPV y que se destaca por parte de los funcionarios entrevistados: 
"el plazo de obra en que se trabajó era muy limitado, era en 4 meses (...) después se extendió en 105 días el barrio, llegó a terminarse en 7 meses y días, eso era algo atípico (...). Esa obra se proyecto en el 2000, y se construyó todo el 2001 prácticamente" (Ibidem, 11/12/2014).

En este período de tiempo acotado en que se ejecutó la obra, indagamos sobre la participación de los afectados en el diseño de las viviendas. En este sentido el encargado del diseño del proyecto manifestaba:

"a gente se le dio participación a través de un censo que se hizo en que se tomaban las necesidades de la gente, se hicieron 4 prototipos de viviendas y cada uno variaban de 1 a 4 dormitorios y ellos fueron eligiendo el modelo que más les gustaba con la cantidad de dormitorios que se daban por el núcleo familiar que cubrían con eso todas las necesidades que tenían" (Ibidem, 11/12/2014).

De esta forma, en el proceso de relocalización en estudio, la participación de los pobladores se asocia por parte de los funcionarios al relevamiento de las condiciones socioeconómicas de la población afectada y luego a la adecuación de las viviendas nuevas a la cantidad de miembros por hogar, así como a la elección de detalles como el color de la vivienda o variaciones dentro de los criterio establecido por los técnicos y/o profesionales del IPV.

Otro tema que surgió en las entrevistas realizadas a los funcionarios intervinientes sobre el emprendimiento habitacional refiere a la especulación sobre las viviendas del nuevo barrio que comenzó a partir de su construcción por parte de población no residente del lugar. En algunos casos esta especulación se sustentaba en la necesidad de obtener una vivienda propia por parte de quienes no la tenían; en otros casos, la especulación se basaba en la oportunidad económica que generaba una vivienda de la nueva villa en términos de mercado inmobiliario. Estas situaciones llevaron a establecer ordenanzas legales a fin de delimitar la solución habitacional para quienes residían en lo que después constituyó el vaso de embalse, así como también para limitar el accionar de los especuladores inmobiliarios. Sobre el primer caso expuesto se expresaba:

"Cuando llegamos se estableció el número de familias y se dictó una ordenanza municipal de congelamiento, como se venía una gran inversión que era una obra pública algunas personas veían la posibilidad de obtener una vivienda. En enero del 2000 se hizo el relevamiento, aquel que se extiende fuera de este tiempo en el lugar no tendría una respuesta, sino era como algo que nunca se iba a poder terminar, es más se pusieron carteles en la zona. Había siempre como ese temor de que te encontrabas una carpita al costado de la ruta y un nuevo poblador que te decía yo vivo acá me van a dar vivienda, pero bueno, había como un marco legal por la ordenanza que de alguna manera nos daba la seguridad de quienes eran las familias con nombre y apellido que estaban desde hace tiempo y que había que 
darles una respuesta" (Trabajadora Social. Municipalidad de Luján de Cuyo, 10/12/2014).

Sobre el segundo caso expuesto, el entonces Presidente del directorio del IPV, hacía mención a la intensión manifiesta que le había sido expresada de comprar viviendas a los pobladores una vez que estas se les hayan entregado. En términos del funcionario:

"Mucha gente decía que la gente iba a vender las vivienda inmediatamente porque las viviendas eran tan lindas, entonces puse una clausula que decía que se adjudicaba con la condición de que por 5 años no podían hacer ninguna operación, tenía razón viene suponete el político que te dije y me dice te doy 70.000 dólares, porque la casa a mi me había costado 90.000, quiere decir que comprarla por 70.000 dólares es un buen negocio para un tipo que lo único que hacía era vender pan los domingos, te imaginas se iba a Lujan y se compraba tres casas" (Presidente del directorio del IPV, 19/12/2014).

De esta manera, la relocalización de la Nueva Villa que significaba una gran inversión en viviendas y obras de urbanización, equipamiento e infraestructura, desde antes de su entrega eran visualizadas por un lado, desde la lógica de la necesidad por quienes carecían de vivienda propia; y por otro lado, por la lógica especulativa de quienes detentan el capital, quienes sabían que a partir de la inclusión dentro del plan de desarrollo del perilago se revaloraría económicamente la zona y aumentaría el valor de las viviendas. Esto da muestra de los intereses y disputas de poder que suponen los proyectos de desarrollo económico y territorial como constituyen las represas.

Para finalizar, aludiendo al impacto sobre la calidad de vida de los pobladores en relación al aspecto habitacional se expresaba:

"la calidad de vida me parece que cambió, por ahí el impacto fue fuerte porque eran zonas de características rurales y se transformaron en medio urbanas, medio rurales. Se le dio toda la magnitud rural de lo que se le podía dar dentro de un barrio, los que tenían animales se trasladaron con sus caballos, entonces me parece que en ese sentido la provincia hizo un gran esfuerzo de ponerse a diseñar y pensar cómo darle una mejor calidad de vida sin modificar tanto el hábitat que la gente tenía, porque también es cierto que Potrerillos era lo que era gracias a toda esa gente y eso es innegable y justamente por eso luchamos tanto especialmente las áreas sociales del Municipio y del IPV para que el directorio entendiera esto de la compensación, esto que había que reconocer un porcentaje del valor de sus vivienda; si no, tenían que pagar una cuota altísima y no tenían tanta capacidad de pago y la verdad se los había trasladado sin que ellos lo quisieran hacer, o sea, el fin del traslado era otro" (Coordinadora del equipo social de la Dirección de Vivienda de la Municipalidad de Luján de Cuyo, 03/12/2014).

Como vemos en los relatos, la evaluación social como técnica en relación a la solución habitacional es considerada positiva y un ejemplo de gestión por partes de quienes intervinieron en el proceso desde el Estado. Seguidamente hacemos mención a un 
momento del proceso que es denunciado en los medios de comunicación por las demoras en la entrega de las viviendas, hecho que hacía eco del contexto de crisis económica, social y política del país en que se desarrollaba la relocalización.

\subsubsection{Demoras e ¿imprevistos? Los efectos de la crisis del 2001}

En pleno período de crisis política argentina, en el año 2002, el miedo y el desconcierto por parte de los pobladores volvía a expresarse públicamente ante imprevistos o aspectos no planificados en torno a la relocalización. Mientras el embalse comenzaba a formarse, los pobladores de Villa Potrerillos aún no eran trasladados a sus nuevas casas.

En medio del corralito financiero, la crisis económicas y el virtual default, el barrio no era entregado porque el Gobierno provincial mantenía una deuda con la empresa constructora Laugero-Antares -encargada de la construcción el barrio- que se negaba a entregar las viviendas hasta tanto el ejecutivo saldara el incumplimiento del pago. Al respecto, uno de los directivos de la empresa exponía ante los medios: "Estoy en default, no tengo más dinero para pagar a los obreros y proveedores" (Los Andes, 30/01/2002). Por ello -argumenta al periodismo- no se hacía la interconexión de agua, cloacas y luz del nuevo barrio, tareas que resultaban pendientes e imposibilitaban el traslado de la población. Ante este panorama, una pobladora angustiada expresaba:

"Estamos en ascuas, vivimos en medio de rumores e incertidumbre. Cuando queramos acordar las casas ya no van a ser nuestras" (Ibidem, 30/01/2002).

El miedo estribaba - según argumentan vecinos a los medios- en que la empresa constructora se cobrara con sus viviendas la deuda del gobierno.

Por otro lado, los incumplimientos en los pagos por parte del gobierno se hicieron notar en la paralización de las obra de la nueva ruta 7 y de un acueducto que hacía parte de la obra. En cuanto a la primera, luego de 50 días de inactividad, ante la cancelación de la deuda de la Dirección Nacional de Vialidad (DNV) a la empresa Vialco SA -encargada de la obra- , las máquinas volvieron a funcionar para hacer el trabajo de enripiado de 4,5km del nuevo camino, antes de que se reanude el llenado del embalse y el agua tape la vieja ruta. Este constituía un tramo de emergencia hasta tanto se pudiera realizar el proyecto completo que abarcaba $10 \mathrm{~km}$ de ruta y dos puentes.

En cuanto al nuevo acueducto, para esta fecha, también se reanudó el trabajo frenado por la misma causa (Los Andes, 30/01/2002). La terminación de estas obras, eran esperadas por Cemppsa -el consorcio que construyó la Presa Potrerillos- para avanzar con la limpieza del vaso del embalse (demolición de casas, corte de árboles, etc.). 


\section{La nueva villa de Potrerillos está lista, pero nadie se puede mudar}

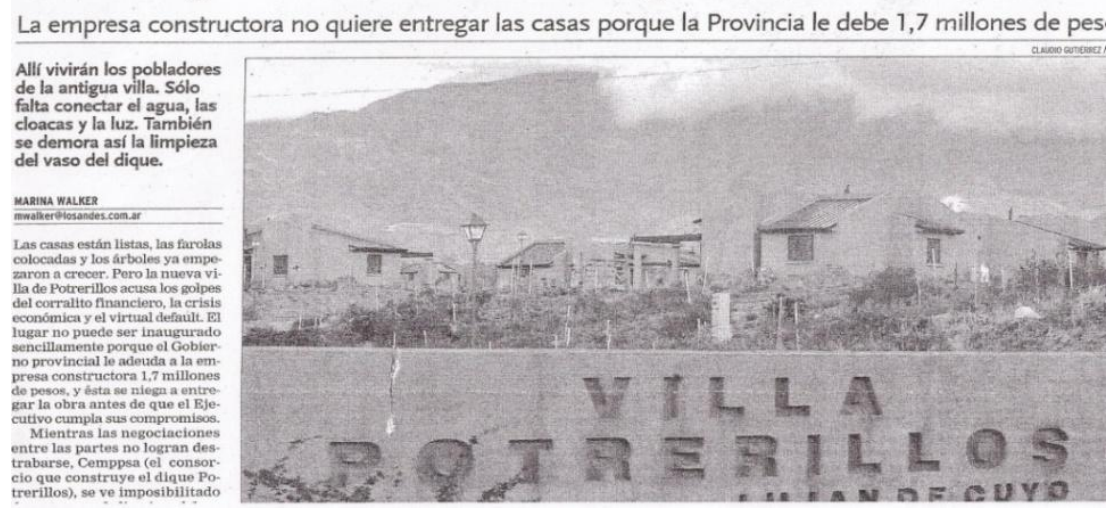

Fuente: Los Andes, 30/02/2002.

Sobre este suceso en particular, a un funcionario entrevistado en el marco de esta tesis se le preguntaba:

E: ¿Hubieron momentos en que se demoraron en el pago? - AM: Terrible, yo me sentía re mal, porque no podía cumplir lo que había prometido, el gran drama de cuando vos tenés un tipo que estás viendo que está construyendo bien, que está metiendo plata, plata, plata, que tiene buenos ingenieros, que tiene buenos obreros, que le estamos exigiendo calidad, qué le decís, -Hay no, hay crisis, De la Rúa está por caer, tenemos el problema que no nos mandan plata, entonces yo hinchaba para que el gobierno nos enviara plata y en especial este porque era el buque insignia, además ellos me exigían a mí que el barrio avanzara pero no me daban la plata" (Presidente del directorio del IPV, 19/12/2014).

Finalmente, el emprendimiento habitacional que comenzó y terminó en un contexto provincial de cortes y piquetes, fue inaugurado el 19 de abril del 2002 por el Gobernador Roberto Iglesias, quien celebró la refundación de la Nueva Villa de Potrerillos a la que se trasladó la población.

Lo visto sobre los efectos habitaciones en Potrerillos alude hasta aquí a la lógica del Estado en torno a la planificación, ejecución y evaluación del proyecto de la relocalización, perspectiva que entra en tensión al considerar las voces y memorias de quienes en el proceso en estudio se vieron afectados. Para profundizar en esto, sobre el momento previo a la mudanza, pasamos ahora a considerar la memoria de estos últimos, lo cual nos permite conocer cómo era vivido y es representado el proceso por los mismos. 
1.1.1.5El antes del traslado desde la memoria de los pobladores

1.1.1.6 Cuando llegó la noticia "no se la creía", "pero ya estaba firmado"

En las entrevistas realizadas a los pobladores sobre el proceso de intervención estatal y los efectos habitacionales, así como sobre las economías de subsistencia y las redes de integración socio-comunitarias de los mismos, es coincidente en los relatos de los entrevistados que al llegar la noticia de la construcción del dique en el lugar donde ellos residían, ésta no era creída por los pobladores debido a los muchos anuncios anteriores finalmente no ejecutados. En palabras de los pobladores:

"Empezó todo con desconfianza de que no iba a ser real la cosa, porque ya venía de tantos años con el proyecto este de hacer el dique, que a la gente -del gobierno- no se la creía. Otra gente -del lugar- decía uh, de acá que llegue el agua hasta acá mira, nos vamos a morir nosotros, los hijos, (...) hasta que empezó la obra y se la empezaron a creer" (Poblador 2, 16/04/2010).

De esta forma, la relocalización de los pobladores no surgió como una necesidad sentida por los mismos y demandada al Estado como sucede en aquellos casos en que los ciudadanos peticionan una mejora de su calidad de vida; por el contrario, en este caso los pobladores no querían mudarse y se resistieron aferrados al sentimiento de arraigo y pertenencia al lugar como podemos leer en el siguiente relato:

"nos organizábamos de boca en boca y decíamos no nos vamos a cambiar, todo el mundo estaba en contra, (...) en un momento estábamos todos unidos en decir no lo vamos a hacer, no queremos que se haga el dique, nosotros muy inmaduros y muy inocentes pensábamos si nosotros decimos que no se haga el dique, no se va a hacer, viste cosas así; pero ya estaba firmado" (Pobladora 1,07/04/2010).

Como vimos en el marco teórico, uno de los requisitos establecidos a la hora de realizar un proyecto de desarrollo de gran envergadura como constituye la construcción de presas y otras obras públicas, es realizar una audiencia pública con la presencia de todos los actores involucrados en el proyecto. Con respecto a la participación de los pobladores afectados en esta instancia, una entrevistada recordaba:

"ellos te invitaban como para cumplir el requisito digamos, para decir invitamos a los pobladores que van a ser trasladados a la audiencia pública, nos ponían las trafic, pero era algo que nosotros no manejábamos y al final de cuentas Lafalla dijo: es una decisión política, el dique se hace y se hace. Hubieron muchos oradores que hablaron en contra" (Pobladora 1, 07/04/2010).

De esta manera, esta instancia constituyó una formalidad sin trascendencia para los pobladores, ya que para ese momento el proyecto "ya estaba cocinado", y no contempló la petición de los pobladores de no ser desalojados. 


\subsubsection{7 "Empezaron a avanzar" y "sistemáticamente nos fueron separando"}

La intervención en la población afectada que debía ser trasladada, como se expuso en el capitulo anterior, se realizó a través de reuniones grupales convocadas por los sectores del Estado provincial involucrados en el proyecto de ordenamiento del perilago, así como por el relevamiento de las condiciones socio-económicas de las familias y sus pertenencias para otorgarles una compensación económica. Estas instancias promovidas por el gobierno son recordadas por los pobladores relocalizados de la siguiente manera:

"las primeras reuniones se hicieron en la casa de los Veamonte ${ }^{18}$, que ahí funcionaba un boliche que es un salón muy grande y en la escuela Negri de abajo -donde funcionaba antes de la construcción de la presa-. Ahí se empezaba a mandar volantes a la gente a las casas, las visitadoras sociales empezaron a ir casa por casa a explicar y bueno, ahí empezaron un montón de problemas.

Después, como no podían manejar mucho el tema se ve que nos pusieron unas psicólogas para que nos trataran y bueno a las psicólogas por supuesto las volvimos locas, por ejemplo me acuerdo de los primeros talleres que hacían, eran unos talleres re tontos digamos porque ellas convocaban a gente de campo, gente que anda a caballo, que está en la montaña, gente que está en otra actividad distinta a lo que hace la gente de la ciudad, en uno de los primeros talleres que hicieron juntaban gente grande, gente de 70 años, (...) dividían en grupo a la gente, ponele de a 10 personas o de 8, a mi me ponían a coordinar ese grupo, otro coordinaba a otro grupo, repartían cartulinas y te daban fibrones, (...) y decían, bueno tenemos que anotar acá en esta cartulina bien grande, a ver, en la amarilla los miedos, en la verde las esperanzas, en la rosada los aciertos, y por ejemplo a mi me decían mis compañeros de mi grupo - no, que se creen estas que van a hacer, que esperanzas, ni que miedos, ni que aciertos, yo no le tengo miedo a estas, que se creen-, o sea el trabajo estaba muy mal encarado.

Después ellos empezaron a avanzar, en las reuniones, en las cosas que nosotros veíamos en el diario, empezaron a venir las camionetas acá, pusieron una oficina en lo que era el correo para eso, empezaron a venir los ingenieros a medir, los que venían a hacerte las encuestas. Hicieron las encuestas casa por casa, ellos venían y te preguntaban cuantos árboles tenés, cuántos hijos tenés, si mandaste a los hijos a la escuela, si no los mandabas, si tenias el baño con inodoro o no, si tenias piso de tierra, si tenias esto, si tenias lo otro, y ahí ellos dedujeron por lo que uno les decía lo que te tenían que dar -como compensación-"(Pobladora 1, 07/04/2010).

En cuanto a las encuestas realizadas por el Estado, otro poblador relataba:

"iban familia por familia a ver cuánto tiempo hacía que vivías, que tenías, en que trabajabas, cómo vivías, qué plantaste, qué no plantaste, qué mejora habías hecho vos, cuánto terreno tenías, cuánta casa era tuya y todo el mundo tubo que demostrar lo que tenía, porque como estaba en negro en realidad el barrio, pero éramos todos de una u otra manera éramos propietarios, yo era uno de los más

${ }^{18}$ Este apellido ha sido modificado a fin de preservar la identidad de los sujetos partícipes del proceso en estudio. 
nuevos, hacía 20 años que estaba acá (...) había gente que vivía desde hacía dos o tres generaciones acá, lo tiene ganado por ley al lugar" (Poblador 2, 16/04/2010).

Aún cuando el Estado justificaba el desalojo tratando de convencer a los afectados de que la relocalización se vería compensada por los beneficios que traería la obra para todo el Gran Mendoza, así como para ellos por el desarrollo económico que la obra generaría en los alrededores del lago, lo cual mejoraría su calidad de vida, la intervención del Estado fue vivida por los pobladores como una invasión a su privacidad, como un atropello al tiempo y esfuerzo dedicado por los mismos a la construcción de su lugar, habitado y elegido entre ríos y montañas. Así también, la intervención fue vivida como una manipulación con efectos sobre la convivencia y organización colectiva de los habitantes afectados. Sobre esto último, se relataba:

"sistemáticamente nos fueron separando. -E: ¿Cómo los fueron separando? MC: Las psicólogas fueron una de las patas más importantes de que nos separaran. Ellas estaban mandadas por el gobierno y tenían que tratar de que la gente hiciera lo que el gobierno decía, y a la gente que se ponía en contra, tenían que tratar de persuadirla para que llegaran a un momento que dijeran -si, voy a hacer lo que el gobierno dice- y nos metían miedo también porque decían que nos íbamos a quedar sin casas" (Pobladora 1, 07/04/2010).

"lo primero que se hizo fue como desunir al pueblo, el gobierno desorganizó, desarmó, desintegró todas las asociaciones que habían, el club, la unión vecinal, hasta mismo la cooperadora de la escuela, no había veracidad en ningún lado, trajeron un grupo de psicólogos para ayudar supuestamente a soportar el desarraigo, y la gente se enojaban entre ellos, se terminó desarmando todo, y después hicieron arreglos independientes, no hubo un grupo sólido para luchar contra el gobierno" (Poblador 2, 16/04/2010).

"Nos tuvieron dos años entre reunión y reunión donde venían los psicólogos, le lavaron la cabeza al pueblo, dale que mejor calidad de vida, mejor casa, mejor esto, mi casa era muy linda, era humilde" (Pobladora 5, 03/09/2010).

Como vemos, a fin de cumplir con los calendarios impuestos por los empresarios encargados de la construcción de la presa, la intervención del Estado sobre la población se centró en la vinculación particular con cada una de las familias afectadas para evaluar el costo de la compensaciones económica a otorgar y exigir el desalojo de forma pacífica. Esta situación, que en cuanto al aspecto habitacional tuvo efectos varios y heterogéneos entre las familias afectadas, a nivel comunitario, como indican los relatos, estimuló la desorganización y desintegración de los espacios colectivos de pertenencia y representación que integraban los lugareños; es decir, impacto las redes de integración socio-comunitarias de los pobladores afectando las relaciones entre los mismos. 
Esto se relaciona con el impacto sobre el componente socio-cultural del "stress multidimensional de relocalización" al que refiere Scudder y Colson (1982), que integra la afectación de: a) la estructura de liderazgo local, b) la red de relaciones sociales en que se inserta cada individuo y cada unidad familiar, c) las pautas de conducta relacionadas con la adaptación al medio ambiente físico y social y d) la "persona" del relocalizado.

Seguidamente se aborda el tema de los acuerdos y desacuerdos sobre el tamaño del terreno así como sobre el tipo, diseño y costo de las nuevas viviendas entre el gobierno provincial y los pobladores afectados por la presa.

\subsubsection{8 "todos queríamos cosas distintas". Acuerdos y desacuerdos}

Como se ha expuesto, la relocalización en estudio no fue elegida y demandada por los pobladores, por tanto el desalojo fue forzado para los mismos. El siguiente recuerdo de una pobladora sobre una persona mayor de la comunidad da cuenta de ello:

"le decían Saturnino mire que hermosa la casita que le vamos a dar. Y él decía: -A mí que me importa la casita, si yo lo que quiero es quedarme acá abajo de este árbol que plante hace 40 años cuando acá era un desierto y no había nada, yo lo único que quiero es sentarme debajo de mis árboles a tomar mate y nada más, a mirar el paisaje. -A su casa la había hecho él con sus manos, sus esfuerzos y su trabajo" (Pobladora 1, 07/04/2010).

Pese a la resistencia de los pobladores, la desocupación del área que comprendía el proyecto de "la presa del desarrollo" era irreversible y por tanto debieron negociar con el gobierno que procedía a efectuar la expropiación. Esta parte del proceso relocalizatorio, que implicó por parte del gobierno, en el marco de la metodología expuesta, un tratamiento puntual con cada grupo familiar, implicó según relatan los pobladores una serie de diferencias entre los mismos que radicaban en las disimiles prácticas y estilos de vida, procedencias, expectativas y proyecciones familiares en relación al imaginado desarrollo del lugar. En palabras de una pobladora:

"es complicado ponerse de acuerdo en una situación de estas porque hay familias que, yo por ejemplo, vine hace 20 años de la ciudad porque a mí me gustaba vivir en el campo y se me dio la oportunidad de comprar aquí, pero hubo gente que vino porque sus abuelos o los padres los trajeron y se instalaron acá, había puesteros, gente que antes había venido de Uspallata, de Puente de Inca, de Tupungato, gente que había vivido distinto, entonces todos queríamos cosas distintas (...) algunos tenían unas pretensiones, otros otras, algunos tenían muchos hijos, otros pocos (Pobladora 1, 07/04/2010). 
De este modo, el caso de estudio expresa, tal como fue expuesto en el marco teórico, una heterogeneidad de situaciones es uno de los factores que caracteriza al fenómeno de las relocalizaciones forzosas.

En relación a estas diversas situaciones, puntualizamos a continuación cómo son recordados y considerados por parte de los pobladores los resultados de la relocalización en términos económicos y sociales. En este sentido, en primer lugar, hacemos referencia a la negociación mantenida entre los mismos y el gobierno sobre el tamaño de los terrenos y el tipo de vivienda construida para la relocalización; y en segundo lugar, consideramos las valoraciones sobre los resultados de la metodología empleada por el IPV sobre los grupos familiares afectados.

\subsection{Los terrenos y el tipo de viviendas}

Como mencionamos en la reconstrucción de los hechos del proceso relocalizatorio, la elección de los terrenos dentro de la zona urbanizada para el reasentamiento, así como el tipo de viviendas fueron dos de los temas que convocaron las reuniones entre los funcionarios del gobierno y los pobladores afectados. Sobre estos aspectos dos pobladores relataban:

"Al principio hacian ver que habían varias opciones de elegir terreno y, después, todo se fue tu, tu, tu, manejando de tal manera el gobierno, primero a todos los agarraban de a grupitos, a estos le decían están estas opciones, a estos tales opciones, repartían distintas versiones y después todo se iba unificando paso a paso, te dabas cuenta ya antes de llegar al final dijiste ah, me metieron en un canal (...) -sin embargo el entrevistado argumenta- el logro fue bastante mejor a lo que nos querían dar, porque uno de los intendentes que había en ese momento acá en Luján, venía con una propuesta de tres hectáreas, hacer dúplex, imaginate que terminamos con un resultado de 60 hectáreas, casas dignas para todos" (Poblador 2, 16/04/2010).

"hubo un acuerdo, porque se empezó el proyecto desde darnos lo mínimo, darnos terrenos de 500 metros, con casas dúplex, hasta que se empezó todos los vecinos, las luchas, las reuniones, eran dos o tres reuniones por semana, un desgaste terrible, hasta que llegamos a obtener lo que hemos obtenido hasta ahora" (Pobladora 1, 07/04/2010).

Pese a lo molesto que, se evidencia, les resultaba a los afectados tener que decidir sobre el diseño de una casa nueva pero no elegida, localizada en el mismo distrito pero no en el lugar de pertenencia, los entrevistados aluden que en relación al terreno para realizar la relocalización en un primer momento se consideraron varias opciones, pero finalmente el 
lugar fue elegido unilateralmente por la DOADU ${ }^{19}$. Por otro lado, en relación a las primeras propuestas habitacionales que se analizaban en las reuniones, producto de la lucha y resistencia, manifiestan que en general resultó beneficioso el acuerdo al que arribaron como grupo con el Estado sobre el tamaño del terreno por hogar y el tipo de vivienda.

Pensando también sobre la solución habitacional para el conjunto de la población afectada, otra pobladora manifestaba:

"para mí fue un trabajo social bien hecho porque las casas fueron iguales para todos, para el que tenía más y para el que tenía menos, a lo mejor la deuda fue más o menos, cada familia tiene su situación particular" (Pobladora 4, 20/05/2010).

En este testimonio, se evidencia que la solución habitacional elaborada por el IPV es entendida por algunos pobladores como una propuesta, que sin dejar de reconocer las heterogéneas situaciones habitacionales y socioeconómicas previas a la instalación de la presa, brindó a todos los desalojados la oportunidad de acceder al mismo tipo de vivienda. Si bien sobre el tamaño de los terrenos y el tipo de viviendas encontramos un acuerdo de parte de los pobladores con los resultados de la negociación realizada con el gobierno, en términos particulares existen discrepancias en cuanto a los valores económicos surgidos de la evaluación de las casas realizada por el IPV para efectuar la compensación económica, sobre este tema se profundizará en el siguiente apartado.

Para finalizar, otro aspecto que generó resistencias entre los pobladores fue el hecho de que el proceso de relocalización fue considerado por personas que no residían en la zona como una oportunidad para acceder a una vivienda y por ello se asentaron en el lugar para ser registrados por el IPV al momento de realizar el relevamiento. Esta situación generó la reacción de los vecinos que residían en el lugar por varias generaciones y eran denominados "colonos". Sobre esto una entrevistada decía:

"esto fue producto de avivadas de gente que fue y usurpó antes algunas casas del ferrocarril, gente que no la habías visto en tu vida, sabiendo la movida que se venía en Potrerillos aprovecharon la oportunidad para acceder a una vivienda (...) a mí no me parece que está bien, me parece que el prioritario es aquel que se quedó en la zona, que de alguna forma u otra trajo un engrandecimiento, ya sea personal o que haya participado en la comunidad permanentemente. A mí me parece que el colono es aquel que se queda permanente, no que va y viene, (...) E: ¿Haces alguna diferenciación entre aquellos que llevan 60, 70 años viviendo aquí y aquellos que llevan 20? -LV: No, hago la diferenciación con aquellos que hace 5 años que están y reclaman derechos que no les corresponden, mi convicción política es: tenés todo el derecho de reclamar,

\footnotetext{
${ }^{19}$ Esta decisión unilateral según aluden miembros de la DOADU fue tomada en consideración a los resultados de los estudios realizados sobre las distintas opciones de terrenos.
} 
siempre y cuando aportes algo, siempre cuando dejes algo en la zona" (Pobladora $6,25 / 10 / 2010)$.

Como podemos ver, el rechazo de algunos relocalizados a la llegada de personas a la zona con el fin de ser incluidos en el nuevo barrio, se fundamenta en el tiempo de residencia y permanencia en el lugar que los hace pertenecer a la categoría de "colono", que serían según los mismos, quienes deberían tener prioridad ante el Estado en relación al resto de los pobladores; que llegan al lugar recientemente buscando oportunidades. Esto da cuenta de la puja por la distribución y apropiación de la tierra que se genera alrededor de las grandes obras de desarrollo, así como del déficit habitacional, que era parte del contexto en que se llevaba a cabo el proceso en estudio.

A continuación, como anticipamos, ahondamos en cómo fueron percibidos y considerados los resultados de la evaluación y compensación económica realizada por el IPV.

\subsection{El reconocimiento económico y social}

Como se ha detallado en el capítulo anterior, dentro de las familias que debían ser relocalizadas existían variadas realidades en cuanto a la cantidad de personas por familia, de hogares por vivienda y de viviendas por terreno. Considerando, por un lado, esta gama de situaciones, así como por otro, la valoración y reconocimiento económico y social realizado por el IPV de las viviendas en que residían los pobladores antes de ser relocalizados, en este apartado se exponen memorias antagónicas.

Vinculado a la valoración económica y social a compensar, algunos entrevistados manifiestan desacuerdo con la resolución del IPV:

"Nosotros -refiere a su familia- llegamos acá en 1964, y fuimos a habitar un lugar chiquito que nos habían prestado, después mi padre construyó la gran casa sobre el terreno del Estado provincial, pero como hay una ley provincial que es la ley veinte añal, nosotros superamos los 20 años de estadía en el lugar, así que prácticamente nos tendría que haber correspondido un título supletorio a través de la sesión de derecho por parte del Estado, cosa que no ocurrió así que las casas que nos dieron por la relocalización las tuvimos que pagar (...) no tendríamos que pagarlas" (Poblador 3, 15/08/2010).

"no reconocieron nada por nuestros lugares, después de demostrar y demostrar que vos estabas ahí, que eras propietario, que la ley te amparaba, todos pensaban en la obra a nivel gobierno y nadie pensaba en la gente. (...) para el gobierno, que era Sancho en ese momento, la gente eran todos usurpadores, (...) vos - alude al IPV- no me pagás lo que yo pido, me la desarmo y me la llevo porque mi casa era un antiguo obrador del ferrocarril que yo había pagado por eso, hicimos un acuerdo con el ferrocarril, yo tenía mi boletita de lo que me había costado la casa, las boletas de la luz de la época, todo a mi nombre" (Poblador 2, 16/04/2010). 
"ellos -alude al gobierno- como que te desvalorizaban la casa de caña y barro" (Pobladora 1, 07/04/2010).

"de acuerdo a la medida de tu familia te daban si quería de 1, 2, 3 dormitorios, depende la cantidad de niños, ojalá vos en tu casa tenías una habitación para vos y una para cada chico, acá te daban una si eran del mismo sexo, una habitación para dos varones y la tuya, dos" (Pobladora 4, 20/05/2010).

Estos relatos expresan la disconformidad de algunos pobladores en cuanto a la valoración y reconocimiento social - tiempo de residencia en el lugar, etc.-, así como económico materiales de la vivienda etc.- realizado por el IPV de sus viviendas autoconstruidas o restauradas, lo cual repercute en el valor que los mismos tienen que pagar para obtener el título de propiedad de la vivienda adjudicada. En este sentido, algunos pobladores consideran que el resultado de la evaluación fue injusto.

Otros, en cambio, manifiestan conformidad en tanto que la propuesta les permitió superar la situación de hacinamiento o precariedad habitacional, brindándoles la oportunidad de obtener la titularidad de la propiedad e independencia familiar. El siguiente testimonio da cuenta de esto:

"En el caso nuestro - de su familia- nosotros vivíamos con mi suegro, eran dos familias, tres casi porque vivía un hermano de mi suegro, entonces nos hicieron una casa a mi suegro, una casa a mi tío y una casa a nosotros. Nosotros la tenemos que pagar porque al vivir con ellos es muy poco el valor nuestro material, mi suegro no, porque era uno de los antiguos, y mi tío no, todo estaba en el mismo predio (...) Yo no estoy desconforme porque en el caso nuestro hubo tres casas. Nosotros teníamos que pagarla, pero ya estamos en nuestro terreno, hagas lo que hagas es tuyo y para tus hijos. No estoy desconforme de las casas que han sido más chicas de las que teníamos pero fueron unas casas muy bien hechas. Ah, y a mi marido le dieron un lote para el corralón" (Pobladora 4, 20/05/2010).

Este relato, da muestra también de aquellos casos de familias cuyas economías de subsistencia dependían de una actividad comercial en el lugar, a quienes el IPV les construyó además de la vivienda, un local comercial, o como en el caso presentado, le adjudicó un terreno para continuar con la actividad. Si bien desde el IPV se contempló una respuesta alternativa a las estrategias económicas de los pobladores comprometidas por la relocalización, como veremos luego, esto no alcanzó en el inmediato y corto plazo para evitar que los afectados se vieran perjudicados por el proceso de ordenamiento territorial. En resumen, dependiendo de las condiciones socio-económicas particulares de cada familia, en relación al aspecto habitacional, algunas evalúan haberse visto perjudicadas por la respuesta del gobierno y otras, por el contrario, consideran haberse beneficiado. 
Quienes habían elegido el lugar por el estilo de vida tranquilo, modesto y rural, el hecho de ser urbanizados les resultó perjudicial; para quienes tenían NBI, la solución habitacional, al considerar las dimensiones del déficit habitacional -precariedad de la vivienda y hacinamiento familiar- (Lentini y Palero, 1997), les proporcionó una oportunidad para mejorar la calidad de vida. En fin, para unos la calidad de vida significaba una cosa y para otros, otra.

Posteriormente, desde la memoria de los relocalizados, se recreará el momento del traslado físico o mudanza de las 70 familias hacia sus nuevas casas que comenzó en el mes de abril del año 2002. Aún cuando la relocalización se realizó a 500m aproximadamente del lugar habitado, considerando que el hecho fue arbitrario, representó un cambio significativo en la vida de los afectados.

\subsubsection{El momento bisagra: "sí o sí te cambiás y listo"}

El traslado físico de la población es el momentos del proceso en estudio que constituye un hecho bisagra entre un antes y un después en la vida de quienes, a causa del desarrollo, debieron dejar sus casas. Una vecina recuerda este momento de la siguiente manera:

"Ponían un camión de vialidad y vos elegías un día para cambiarte y tenías tres viajes o dos viajes de camión y si o si te tenías que cambiar, pasara lo que te pasara vos tenías ese turno, era toda una cosa contra reloj (...) como no te dejaban hasta el último momento cambiarte, no te daban la llave de la casa, te tenías que venir en el momento que ellos te decían (...) no era que vos te podías venir paulatinamente, que te ibas cambiando, no!, sí o sí te cambiás y listo. Veías a la gente cambiándose, los de vialidad que no te cuidaban las cosas, (...) además de perder la casa, perdías un montón de cosas. Inmediatamente vos te ibas y empezaban a pasar las topadoras.

Le pedíamos por favor a los tipos del gobierno que no nos tiraran los hornos de pan porque acá todas las mujeres hacían pan casero porque son todas familias grandes, entonces las mujeres íbamos para allá con la engarilla ${ }^{20}$, con el pan o con la masa, hacíamos el pan, lo metíamos en el horno; en mi casa había quedado una habitación sin tirar porque nosotros estábamos cuidando la estación de ferrocarril, entonces a esa la limpiábamos porque había tierra por todos lados, era como el fin del mundo, la guerra, todo tirado abajo, y yo iba y hacía los alfajores y me los traía y había gente que iban a hacer el pan porque acá arriba no tenían los hornos" (Pobladora 1, 07/04/2010).

De este modo, de prisa y de manera forzada se realizaba la mudanza de los pobladores hacia el nuevo complejo habitacional o nueva Villa Potrerillos. En relación a este

\footnotetext{
${ }^{20}$ Término sinónimo de carretilla.
} 
momento, otro poblador desconforme con el valor económico reconocido por el IPV sobre su vivienda relata:

"me tiraron tantos cientos de pesos para atrás, porque en ese capricho de tirar la casa y traérmela se me fundió la camioneta, porque como ya me había quedado sin trabajo porque mi trabajo estaba allá abajo -vinculado al río-, nunca la pude reparar, la terminé perdiendo por dos mangos" (Poblador 2, 16/04/2010).

Como leemos, la relocalización no solo involucra la pérdida de las viviendas en que residían los pobladores hasta el momento de la construcción de la presa, sino que también afecta la pérdida de otros bienes materiales y el desarrollo de las prácticas domésticas y productivas cotidianas como era la elaboración de alimentos cocinados en hornos de barro para consumo familiar como para su comercialización, y otras fuentes de ingresos económicos, como veremos en el capitulo siguiente. Una de las familias desalojadas luego de tres años de iniciada la relocalización, que tenía un local comercial, narra su recuerdo sobre el día del desalojo:

"nosotros sabíamos que nos iban a desalojar, porque te llega la notificación, (...). Ya fuimos trasladando todo, pero quedaban las maquinarias de la panadería y las heladeras, las cosas del negocio, las vitrinas, esas cosas, y el día de Patrón Santiago -patrono de la Provincia de Mendoza-, el día lunes feriado fue el último día que prendimos el horno, el día miércoles yo llevo el nene a la escuela, y me dice la directora de la escuela -en la televisión están diciendo que a ustedes los desalojan, a ustedes y a otra familia - le digo mire, yo no sé nada y ni el abogado de la familia sabía, entonces llego a la casa y le digo a mi marido (...) Cuando veo el móvil de canal 9 o de canal 7, que pasa por la ruta 7, entonces le digo C llegan los medios, al rato empezamos a ver un auto con una notaria, dos autos de policía, como tres camionetas del gobierno, una máquina topadora y los de EDEMSA, y le dijimos, ¿pero nosotros no teníamos hasta fin de mes? 27 de julio era, y dice sí, lo que pasa es que cuando sale la orden del desalojo que ya tiene su turno no se puede bajar, y a todo esto ya nos estaban cortando la luz (...) vinieron todos los vecino a ayudar (...). Volvieron a conectar la luz y la dejaron hasta el día viernes que mi marido se quedó ahí hasta que se acarreó todo. Se rompe la máquina topadora- creo, entonces lo contratan a mi marido que también tiene una máquina y él fue el que demolió la panadería resumiendo, demolió el horno, las cosas, (...). A nosotros no nos dieron un peso -por la panadería- si no estaban seguros de que nos íbamos de ahi"' (Pobladora 4, 20/05/2010).

En este relato, podemos observar que el recuerdo del desalojo, es construido por la entrevistada en relación a la fecha del último día en que trabajó en la cuadra de su panadería y lo asocia a una fecha pública y religiosa que conmemora al Santo Santiago Apóstol, declarado protector de la Provincia de Mendoza, y día feriado del calendario provincial. Es una fecha referida a su vida privada, pero que toma como referencia para su recuerdo una fecha pública que nada tiene que ver con los fechados alusivos a la obra 
de la presa. Esto hace visible la pluralidad de cronologías o disímiles "vestigios fechados de la memoria" (Pollak, 2006) que ordenan el tiempo vivido de maneras diferentes como constituye el de los actores del proceso en estudio.

En relación al relato, podemos ver también que pese al plazo notificado para desocupar la vivienda, sin previo aviso se adelantó el desalojo. El apresuramiento por desalojar el área también se evidenció en el caso de la última familia relocalizada, cuya casa querían proceder a demoler cuando no se encontraban las personas adultas del hogar. Sobre ésta, una entrevistada que había presenciado el momento relato:

"fueron los últimos que quedaron en esa desolación, que no había un árbol, tenían el agua cortada, la luz cortada, ya habían sacado todo, eran las tres de la tarde, había un camión de vialidad, estaba la gente del IPV y estaba uno de los hijos nada más de $T$ diciéndole que esperaran que llegara la madre, creo que estaba en Luján y el papa creo que estaba trabajando y estaba la policía "te tenés que ir, te tenés que ir" y el "no", obviamente, si la decisión era de los padres, él se tenía que quedar a cuidar hasta el último momento (...) la gente reacciono agresivamente ante la situación porque ellos no se querían ir a vivir a la villa, (...) ya fuera un ranchito, pero era tu lugar, fue jodido y al otro día ya estaba la casa destruida, y al otro día ya no habían ni escombros, fue fuerte, me parece que mucha gente sabía lo que iba a pasar pero no cómo (Pobladora 6, 21/09/2010).

De esta forma, el momento de dejar las viviendas y trasladarse a otra, significó para los pobladores una gran tensión. Sobre este sentir, otra pobladora relataba:

"era algo que vos vivías con eso en la cabeza, preocupante porque llegabas a soñar que llegaba el agua atrás de la casa” (Pobladora 4, 20/05/2010).

Los testimonios expuestos dan cuenta de la naturaleza compulsiva, principal condicionante de los procesos de relocalización -a causa de PGE-. Compulsividad, que en la interpretación de Bartolomé (1985) equivale a decir "sin opción" por parte de los afectados, lo cual hace que el desplazamiento se presente para los mismos como una fuerza exógena y alienante. Seguidamente aludimos a las vivencias de los pobladores una vez relocalizados en las nuevas viviendas.

\subsubsection{En la nueva villa}

Aludiendo al momento inmediato posterior de la mudanza, recurriendo a los registros periodísticos encontramos que algunos pobladores se sentían desahuciados por el desarraigo y otros resignados y esperanzados por el prometido "futuro". Estos sentimientos fueron expresados y quedaron impresos en las páginas de Los Andes del día 20 de abril, un día después de la refundación de la Nueva Villa de Potrerillos: 
"No queremos, pero igual tenemos que mudarnos a la fuerza. Nos prometen que el lugar va a ser muy productivo, pero todavía no vemos nada"

"Es difícil, pero nos vamos a acostumbrar. Es toda una vida que pasamos y construimos la familia. Las casas son muy buenas y en un tiempo todo va a ser mejor"

"Hasta plantamos los árboles y construimos la casa. En Potrerillos no había nada. Ahora empezamos de nuevo, pero todos tenemos esperanza" (12/04/2002).

Años después, al momento de realizar esta investigación, los pobladores relataban y evaluaban los efectos habitacionales de la relocalización de la siguiente manera.

\subsubsection{Las casas nuevas desde adentro}

Indagando en cómo es recordado el después de la mudanza, o sea, la adaptación a las nuevas casas, surgen en las entrevistas aspectos referidos al pago de las viviendas, y de los servicios, así como a los espacios en que se desenvuelve la convivencia familiar y las prácticas cotidianas.

\subsubsection{1 "Quedamos todos con deudas". El costo de la urbanización}

De la totalidad de las familias afectadas, un grupo se rehusó a pagar las viviendas por considerar que no correspondía o no podrían hacerlo luego de ser relocalizados por perder sus fuentes de ingresos. Este grupo mediante un abogado de Derechos humanos le hizo juicio administrativo al gobierno provincial y en estos casos, el gobierno les entregó las viviendas pero no pueden pagar las cuotas de la vivienda todavía y tampoco podrán tener el título traslativo del dominio de la propiedad hasta tanto quienes demandaron al Estado no renuncien al juicio. Sobre esto, una pobladora exponía:

"16 personas -familias- pusimos recurso de amparo, nosotros todavía no pagamos la casa, estaba el Dr. Guevara en aquel tiempo y seguimos acá en la dulce espera, qué es lo que va a pasar, todavía yo no pago mi casa, fui al Instituto de la Vivienda y la quería pagar porque en definitiva eran 40 pesos, sino que yo por miedo al cambio, yo no iba a tener trabajo acá" (Pobladora 5, 03/09/2010).

De esta manera, mediados por el miedo y la incertidumbre, una vez en las nuevas viviendas, un grupo de pobladores se negó a pagar. En el caso de quienes accedieron a pagar, sobre el valor de las viviendas y la posibilidad de abonarlas se manifestaba:

"nos quedamos todos con deuda, pero como iba a ser un crecimiento sociocultural, íbamos a estar insertos de otra manera, una película, nos costaron un montón las casas (...) yo en ese momento no tenía donde irme, entonces firmé el comodato que te dan cuando te dan la llave de la casa bajo un recurso que yo voy a estar 
pagando (...), pero el día que se haga justicia yo quiero mi parte (...) son $\$ 100$ pesos todos los meses, durante treinta años" (Poblador 2, 16/04/2010).

Este relato da muestra que algunos pobladores accedieron a las viviendas de manera obligada por no contar con la posibilidad de otras alternativas, así como esperanzados en el devenir de las promesas del gobierno. Sin embargo, podemos ver, que en el momento de realización de la entrevista el crecimiento sociocultural y la inserción en el proyectado desarrollo aún no eran experimentados por los pobladores. Aludiendo a las implicancias de la urbanización de la nueva villa una vecina relataba:

“...las casas son demasiado caras y lo que se ha valorizado una casa acá en esta Villa no es para un laburador de nosotros que vivíamos en el campo, en nuestras casas, muchas de caña y barro, con gallinero, con una subsistencia de huertas, de pan casero, de pronto estar urbanizados, en estas casas, igualmente las tenemos que pagar" (Pobladora 1, 07/04/2010).

De esta forma, para algunos afectados el costo de las viviendas les resultó elevado, sobre todo para aquellos a quienes desde el punto de vista económico el IPV les reconoció poco en relación al costo de las nuevas viviendas y, por tanto, su deuda fue mayor y/o a más largo plazo.

Otro aspecto mencionado que impactó en el costo de vida de los afectados fue, que al urbanizar la zona, cambiaron los precios de los servicios y económicamente se revalorizó el lugar. En relación a esto se exponía:

"cambiaron todos los costos, viste, renta, el IPV, el agua, la luz, es todo caro, acá no te podes atrasar, allá -señalando el lugar anterior- mal que mal la gente tenía una buena calidad de vida, tenían todos los servicios, hasta teléfono, en la villa nueva no metieron las señales de teléfono y chau, (...) o sea, recurrimos al celular (Poblador 2, 16/04/2010).

De los servicios con que cuenta la nueva villa, los que no fueron instalados cuando se realizó la relocalización y tampoco años después, al momento de realización de la entrevista, fueron el servicio de telefonía domiciliaria -como se cuenta en el relato anterior-, el gas natural, y el derecho a riego. Respecto del derecho a riego, así como al miedo al costo del agua potable utilizada para regar las plantas se manifestaba:

"Y ahora están exigiendo, que hagamos cierre todo verde, nada de medianera, y bueno si, pero con qué agua vamos a regar si no tenemos agua de riego, tenemos agua potable, en cuanto pongan los medidores qué va a pasar, si ahora que ya va a empezar el verano están diciendo que no podemos usar el agua a tal y tal hora porque en la ciudad está faltando y es cierto y que no derrochemos el agua, pero con qué regamos nuestras plantas" (Pobladora 5, 03/09/2010).

Otro relocalizado, manifestaba: 
"Ante donde estábamos viviendo teníamos un terreno que lo regábamos con agua de riego, hoy acá no tenemos agua de riego, el agua de riego riega solamente el arbolado público. Dentro de los terrenos tienen que regar sus plantas con manguera con el agua potable (...) el gobierno antes de construir las casas tendrían que haber visto la viabilidad posible de traer el agua de riego primero para que cada vecino riegue sus frutales y no riegue con agua con cloro que al final de a poco va matando la planta y eso no se tuvo en cuenta (Poblador 3, 15/08/2010).

Este aspecto, vinculado al uso del agua no es menor al momento de evaluar el impacto del Plan de ordenamiento territorial del perilago sobre los pobladores, que antes del desalojo, en parte, basaban su economía de subsistencia en el cultivo de la propia huerta y la plantación de árboles frutales así como en la crianza de animales con los que elaboraban alimentos y conservas. En este sentido, la falta de disponibilidad de agua para riego significó para los pobladores la discontinuidad de ciertas prácticas habituales propias de zona rural. En cuanto al servicio de gas natural así se referían:

\footnotetext{
"está a treinta kilómetros la destilería y ya van a ver -alude al gobierno-, porque el gas solucionaría muchísimo la calidad de vida acá, porque el gas es lo más caro, gastamos a veces en el invierno más plata diaria en calefaccionarnos que en comer, porque hay que estar con la estufa prendida porque el frío es groso (Poblador 2, 16/04/2010).

"acá nos calefaccionarnos con gas y garrafa y con leña en tiempo de invierno y teníamos que salir a buscar leña al campo porque no tenía dinero para comprar leña así que salíamos con mi esposa y mis hijos, ellos era chiquitos, andábamos todos con una carguita de leña, como burros cargueros (...) Hay que cuidar el gas ahora, escasea muy mucho y acá no se consigue" (Poblador 3, 15/08/2010).
}

De este modo, el costo de vida para los pobladores relocalizados se vio acrecentado por el valor de los nuevos servicios vinculados a la urbanización de la zona. Si bien, recurriendo al celular la población suplió la falta de servicios de telefonía fija domiciliaria; la falta de colocación del servicio de gas natural, así como el acceso al agua de riego impactó en las economías de subsistencia y en la calidad de vida de los mismos. A continuación se ahonda en otras prácticas espaciales que hacían parte del estilo de vida de los pobladores y que los mismos debieron re-adaptar al cambiarse de casa.

\subsection{Los espacios de la cotidianidad}

Considerando ahora la percepción de los relocalizados sobre el momento posterior a la mudanza, encontramos en la memoria de los afectados que los espacios de las cocinas así como de las habitaciones, en relación a las casas anteriores, eran considerados 
pequeños y no funcionales a las prácticas y costumbres de algunas familias. Aludiendo al momento de reunión de los miembros de la familia, se narraba:

"nos hicieron unas cocinas como casas de la ciudad y nada que ver, yo he visto mujeres que lloraban porque en las cocinas no les cabía nada, tenemos una mesada que mide, vos la estás viendo, menos de 1 metro y son familias, yo tengo una familia chica, somos 5 personas pero hay familias que son 12, 15 con una mesada de un metro, con una alacena de dos metros (...) en la casa de caña y barro vos tenias una cocina comedor gigante donde ponías un mesón y cabían todos tus nietos y todos tus hijos y vos podías recibirlos a todos los domingos" (Pobladora 1, 07/04/2010).

En este relato se evidencia cómo eran utilizadas las cocinas por la mayoría de las familias en relación a las prácticas habituales que al momento de ser trasladados debieron ser modificadas. Aludiendo a la costumbre de alojar a la familia extensa que venía de visita a la casa de los pobladores, otra pobladora decía:

"en la otra casa re grande venían toda la familia, mi hermanos con la familia, ahora si viene el matrimonio no vienen los hijos porque no hay lugar "(Pobladora 5, 03/09/2010).

Como vemos en los relatos, las viviendas construidas cuyos espacios fueron diseñados siguiendo un modelo urbano les obliga a los pobladores a establecer una nueva relación con los objetos y espacios de uso diario, así como con sus familiares. En cuanto a las habitaciones, que contemplaban el espacio para la colocación del placar, se recordaba:

"hay gente que tenía los roperos de cuando se casaron que no le cabían en el agujero del placar y los del gobierno le decían bueno, tire la pared o venda el ropero y compre uno nuevo, por empezar no teníamos un mango (...) son parejas antiguas que quieren mucho lo que obtuvieron con tanto sacrificio o lo que les regalaron sus padres cuando se casaron y no las quieren romper ni vender" (Pobladora 1, 07/04/2010).

De este modo, el diseño de la vivienda, impactó en la vida diaria de los relocalizados. Este aspecto es recalcado particularmente por las mujeres entrevistadas, encargadas de las tareas domésticas del hogar, quienes vieron reducido su espacio de trabajo y de estar. Indagando luego sobre cómo las casas son percibidas en el momento de las entrevistas, encontramos las siguientes respuestas:

"estas casas son muy altas y son muy frías, son muy bonitas obviamente y están bien hechas, de eso doy fe, porque se han utilizado materiales superiores al código de edificación, (...) esto no se cae así nomas" (Poblador 3, 15/08/2010).

"la casa en sí es hermosa porque es hermosa, a pesar de que es muy chica" (Pobladora 5, 03/09/2010). 


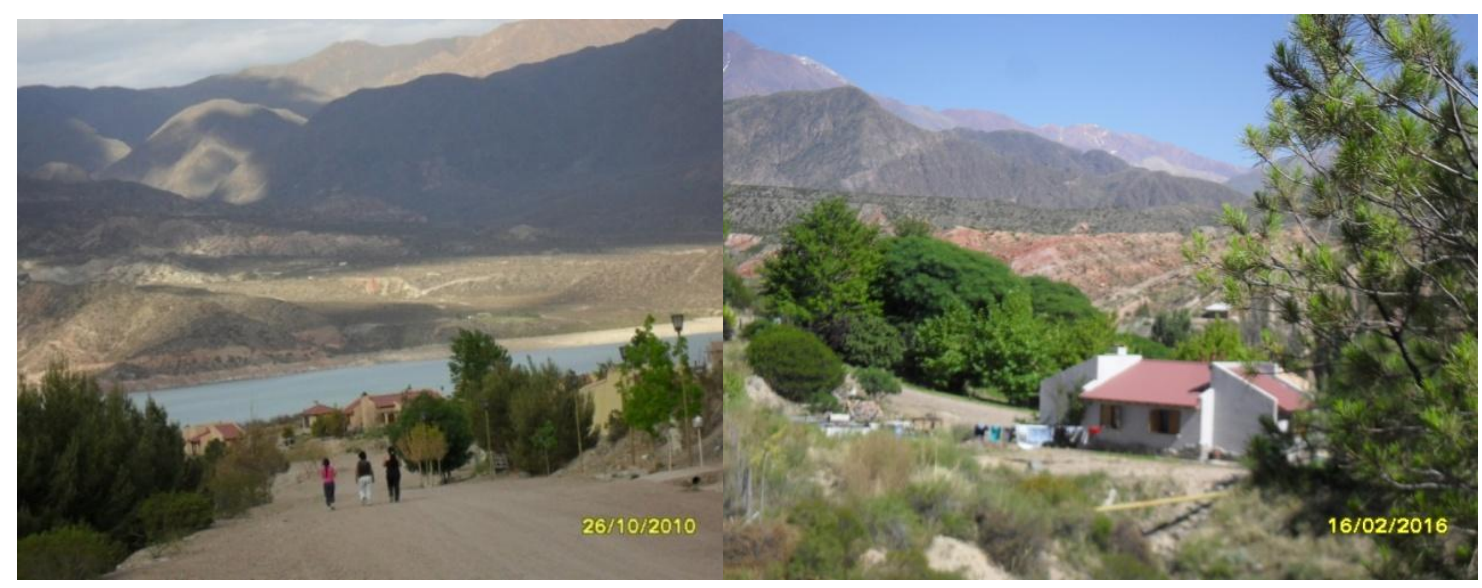

Imagen 18: Desde lo alto del barrio.

Imagen 19: Casa del sector rural. Fotos: Mariana Raffani

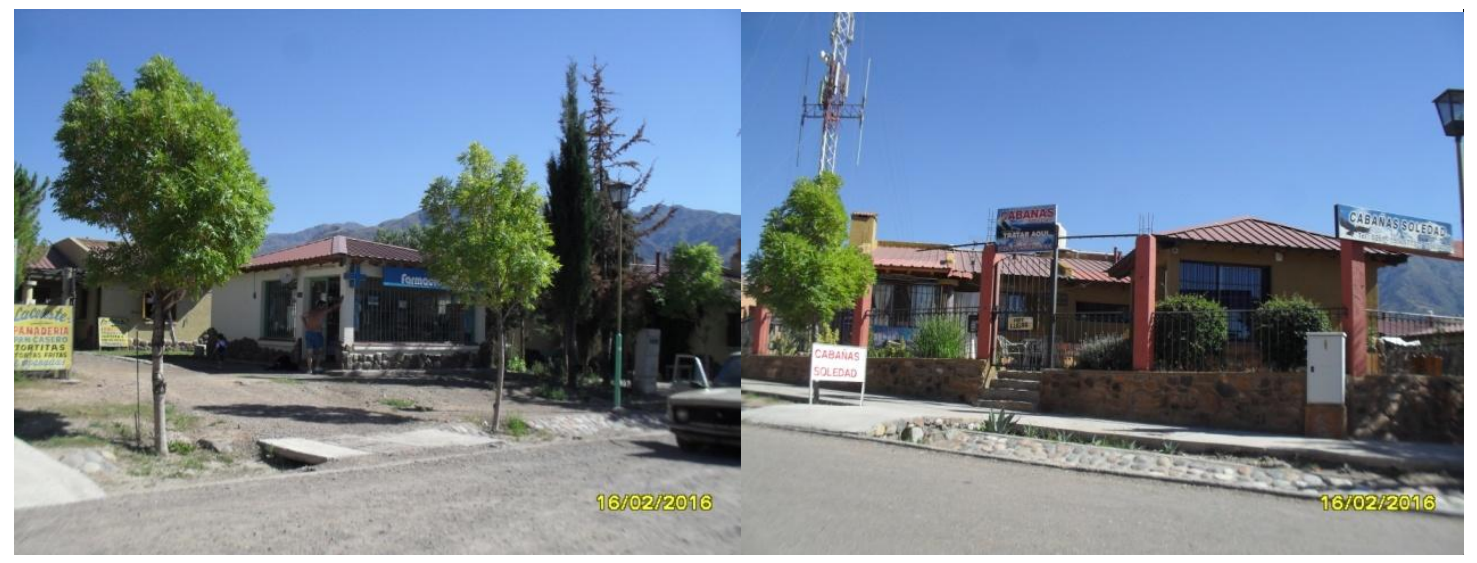

Imagen 20: Local comercial de una vivienda construido por el IPV en el que funciona una farmacia. Imagen 21: Casa agrandada y utilizaba como "cabañas en alquiler". Fotos: Mariana Raffani

Pasados los años, vemos que los pobladores aún cuando todavía encuentran aspectos de las casas que no les convencen en comparación con la casa que habitaban, asumen que las mismas les resultan de su agrado en relación a lo estético como a la calidad de la construcción. Es decir, mientras se observa en los relatos la adaptación de algunos pobladores al nuevo lugar, para otros fue traumante y difícil de soportar. Vemos esto en los siguientes testimonios.

\subsection{Se sintió la muerte}

A modo de cierre de esta sección, hacemos mención a los efectos emocionales que impactaron en el estado anímico y en la salud de la población, que fueron mencionados por la mayoría de los entrevistados. Estos refieren al sentimiento de muerte, pérdida, duelo, desconsuelo y desorientación que significó para los afectados el proceso de 
ordenamiento territorial, y fue agravante o causante de enfermedades; aspectos estos que se incluyen dentro del concepto de "stress multidimensional de relocalización" (Scudder y Colson, 1982) que expresa la tensión en los planos fisiológicos, psicológicos y socioculturales de la población sujeta al traslado compulsivo, aún en aquellas que involucran un mínimo de desplazamiento espacial, o un entorno aparentemente similar al anterior (Bartolomé, 1983b:118).

En palabra de los pobladores:

“(...) en un momento fue terrible, no importaba la casa nueva, extrañábamos el lugar nuestro, porque capaz que si vos decidís hacer el negocio, irte, cambiarte, pero si vos no decidiste, de repente tener que hacerlo es como un shock, no sabes que pasa, por qué te tenés que ir de tu lugar y dejar tus cosas y tus costumbres. No lo superas nunca, hay algunos que se murieron, viejos que en el cambio, en la especulación, el pensar qué harían, si recibe la plata, lo que le estaban proponiendo, si se quedaba acá y las opciones, se murieron (...) yo no estoy en contra de los cambios, lo que pasa es que cuando te tener que cambiar forzadamente, te rompe tu punto de encaje, entonces no sabés si te va a ir bien, temés lo peor. Si vos ya tenés tu covacha te cuesta cambiarla, tenés que tener mucha seguridad económica para que nada te resulte costoso, y bueno justamente no era nuestro caso. Vivíamos en nuestro ranchito, yo vivía en una casita que había restaurado que era un obrador del ferrocarril que tenía como cien años, toda de durmientes, era de cuentito, estábamos re contentos, nos habíamos hecho una casita a nuestro gusto y modo de funcionar, y de repente no la queríamos ni cambiar"' (Poblador 2, 16/04/2010).

"Mi madre ha sufrido mucho, yo no, pero mi madre sí porque desde el vamos que nunca le gustó la casa, ella quería allá que era todo tierra y no se veía para afuera porque era cierre con la manzanita anaranjada, así que las gallinas andaban por todos lados, teníamos $3000 \mathrm{~m}$ de terreno (...) Si, realmente lindo y mi madre nunca se acostumbró a esta casa, es cómoda, o sea, tenés el baño adentro, las comodidades, allá teníamos baño afuera" (Pobladora 5, 03/09/2010).

"Los viejos no pudieron seguir, todos los viejos que tenían sus enfermedades, propias de la vejez, cuando fue todo este problema se le agravaron por el stress y además se murieron muchos más viejos que de costumbre (...) y bueno también psicológicamente nosotros no estábamos bien (...). Antes donde vivíamos era un lugar más apacible, en el campo donde los caminitos te llevaban a la casa de un vecino o de otro, cada uno vivía en medio de un pequeño bosque que rodeaba su casa, que lo había hecho u otro poblador o un abuelo, yo vivía en un bosque que lo había hecho el viejito que me vendió, que había sido un ex jefe del ferrocarril, Don Albertino, después yo seguí poniendo cosas, parquisando, me hice una casa nueva de ladrillos" (Pobladora 1, 07/04/2010).

"Nosotros en síntesis hemos sido perjudicados moral, espiritual, psicológica y económicamente, por qué digo esto, porque yo me críe y jugué en esos patios de aquella vivienda que teníamos junto a mis padres; mi madre se enfermó acá de los nervios, no comía y se debilitó y la atacó un virus, le produjo una meningitis viral y quedó postrada en una cama, de la cama se levantó a la silla de rueda y de la silla 
de rueda hoy está caminando con un andador y a quedado con severos daños neurológicos (...) y mi papá anda enfermo, tiene una hernia umbilical bastante severa y un poco doblado camina" (Poblador 3, 15/08/2010).

"acá hay un antes y un después, tenés el antes de Potrerillos, la zona tranquila, el lugar de vacaciones en el verano, la gente que lo buscaba porque tiene un clima espectacular pero bueno, el dique que es lo que te trae, un cambio, vos tenés que cambiar desde adentro y prepararte, y si crees que no vas a poder cambiar te tenés que ir porque no podes convivir con lo nuevo, es una estructura la que tenés que cambiar, entonces hay gente que eso no lo ve. E: ¿Hay mucha gente que se fue? -LV: No, se murieron, que es distinto -silencio-, hay gente que no lo pudo soportar, ya sea por su edad, ya sea por sus enfermedades, ese silencio se transformó en un ruido, en algo que te machacó mucho la cabeza, es jodido el tema cuando no tenés una preparación o no has tenido una conexión con el exterior -refiere a lugares aledaños a Potrerillos-" (Pobladora 6, 25/10/2010).

"el cambio fue espantoso, en el sentido de que para nosotros fue algo como, viste cuando a una persona se le muere alguien, que estás de un lado y es como se te da vuelta todo, que ya es algo que no lo tenés más, que había que empezar de nuevo, entonces había que arreglar todo, acomodarse" (Pobladora 4, 20/05/2010).

Como vemos en estos relatos, donde se expresa el recuerdo nostálgico de "aquel" lugar elegido, habitado y construido que tuvieron que dejar los afectados, nos muestra que el hecho de no tomar la decisión de mudarse y tener que hacerlo obligadamente, aunque sea en el marco de la ley, perturba cierta estabilidad y organización económica y psíquica de quienes por años se sintieron parte del lugar y sintieron propio el espacio elegido para vivir. En este sentido, quienes se vieron más perjudicados dentro de la población fueron los adultos mayores, los cuales no pudieron o tuvieron dificultades para adaptarse a la vida en el nuevo barrio, donde las casas se encuentran próximas unas de otra y presentaban condiciones y comodidades no habituales para muchos; así como los sectores de menores condiciones socio-educativas y/o económicas.

Este impacto se relaciona, con un paisaje que avasalla costumbres como eran, entre otras, permanecer lejos de la mirada de los vecinos, así como con el gobierno, que llegó a Potrerillos con un plan sobre cómo se debe y tiene que vivir en el lugar, lo cual impone un cambio social que la mayoría de los pobladores no esperaban ni estaban preparados para afrontar. Esto llevó a que muchos se enfermaran, vieran agravadas sus enfermedades o como mencionan los entrevistados- fallecieran, es decir impacto en la mortalidad y morbilidad de la población durante los períodos anterior y posterior a la relocalización.

De este modo, la relocalización implicó efectos sobre las condiciones materiales y económicas de las personas involucradas por el proyecto, así como en los aspectos psicológico y emocional, como fisiológico y socio-cultural, lo cual repercutió en la pérdida 
de la salud física, como de la vida de algunas personas ${ }^{21}$. En este sentido, aludiendo a Bartolomé, el desarraigo masivo y forzoso es interpretado como una "agresión total" tanto (en el sentido biológico) en el plano individual como el social, la cual genera altos niveles de stress sometiendo a duras pruebas las capacidades de adaptación de individuos y comunidades (1985).

Para finalizar, a fin de considerar la magnitud de los efectos sobre los pobladores que experimentan relocalizaciones arbitrarias, mencionamos que estos procesos producen un stress que en la escala de valores, está tercero, después de la muerte de un familiar querido y un divorcio.

\subsubsection{Quienes eligieron irse de Potrerillos}

De la totalidad de hogares cuyas viviendas se encontraban en el lugar elegido para la instalación de la obra, un grupo optó por irse de Potrerillos. Algunas familias lo hicieron previo a la relocalización y eligieron trasladarse a otro distrito o departamento del Gran Mendoza; y otras lo hicieron después de ser relocalizadas y haber cancelado la vivienda. A partir de los testimonios obtenidos, en este apartado ahondamos en cómo fueron y son percibidas estas situaciones por los entrevistados que continuaron residiendo en el lugar.

\subsection{Como alternativa a la relocalización}

Como mencionamos en la reconstrucción del proceso en estudio realizado a partir de documentos oficiales, una de las opciones presentadas por el IPV a los afectados por la obra, era la posibilidad de adquirir una vivienda en otra localidad elegida por los mismos. En cuanto a quienes eligieron esta opción, una pobladora relata que luego de irse del lugar algunos volvieron por no adaptarse o insertarse en la dinámica económica y social del nuevo lugar de residencia. En sus palabras:

"decís Godoy Cruz está cerca de la ciudad, está a 5 minutos del centro, pero los llevaron a vivir a un barrio conflictivo (...) no es lo que querían tampoco, (...) y esa gente quedó en la nada y cuando quiso volver se encontró que no tenía nada y que se tuvo que ir a usurpar un pedazo de terreno y armarse un rancho. (...) te vas a vivir a Godoy Cruz y te encontrás con un lugar totalmente distinto que no sabes ni cómo desarrollarte ahí, que vos lo que sabías hacer en tu pueblo, hacías el pancito, la empanada, salías a la orilla de la ruta, se lo vendías al que pasaba y yo con eso me manejaba, estaba enganchado de la luz, del agua o le pedías a

\footnotetext{
${ }^{21}$ Estos efectos sobre los pobladores afectados por el "proyecto del desarrollo", considerando los estudios de Catullo $(1986,1987)$, también se hicieron visibles en la relocalización de la ciudad de Federación, realizada en abril de 1979.
} 
alguien que te haga un favor, a lo mejor no tenía una garrafa pero me metía un poco a los cerros y sacaba algunas maderas, algún árbol que encontraba caído por ahí y calentaba mi ranchito, en una ciudad no lo podes hacer, en una ciudad donde tenés que vivir enrejado donde no sabes en qué momento te pegan un palo, cosa que acá -refiere a Potrerillos- no lo tenés" (Pobladora 6, 21/09/10).

Como podemos ver en esta interpretación, para quienes tenían escasos recursos económicos y viviendas deficitarias y optaron por una vivienda fuera de Potrerillos, las características del lugar de localización de la nueva vivienda no les resultó beneficioso en términos de calidad de vida, entiéndase por ello en relación a la seguridad, a vivir en un barrio, así como también en relación a las economía de subsistencia e inserción laboral y socio-comunitaria en el nuevo lugar. Este tipo de casos dan cuenta de la dificultad de adaptación de quienes mantenían estrategias de vida en un medio rural y abruptamente se vieron insertos en el medio urbano, donde se despliegan estrategias económicas diversificadas, especializadas y funcionales al sector público como al privado y ejercen hábitos de convivencia propios, como tiempos más acelerados.

Por si esto fuera poco, debido a que este sector de la población había optado por la alternativa propuesta por el IPV de mudarse a una vivienda de otra localidad, más cerca del radio céntrico de Mendoza, cuando decidieron regresar a vivir a Potrerillos no pudieron acceder a una vivienda en el barrio de quienes fueron relocalizados. De esta forma, como se mencionó en el marco teórico, las relocalizaciones rurales afectan no solo las condiciones habitacionales, sino también las economías de subsistencia y las relaciones sociales o redes de integración socio-comunitarias.

Recordando otro caso sobre quienes quisieron volver a Potrerillos y se encontraron sin la posibilidad de acceder a una vivienda construida por el Estado, se expone lo siguiente:

"habían algunas familias que todavía vivían con los hijos o que el hijo se habían ido a trabajar a otro lado y después volvían a su casa. ¿Qué hicieron ellos -el gobierno-? Como eras dos personas viejas y como los hijos estaban casados, agarraron y les dieron una casa de un dormitorio con una cocinita como esta, imagínate, una locura, y así les pasó a varios" (Pobladora 1, 07/04/2010).

Este relato expresa el choque o antagonismo entre la lógica de interpretación del Estado a la hora de evaluar las condiciones económicas y sociales de las familiar afectadas y la lógica de interpretación de las familias considerando sus dinámicas históricas familiares, que como se ha mencionado anteriormente, involucra a la familia extensa o a varios hogares conviviendo en una misma vivienda por tiempos discontinuos, lo cual responde a la búsqueda de oportunidad laborales. En este sentido, algunos pobladores consideraron injusto el hecho de que quienes no se encontraban residiendo en el domicilio al momento 
del relevamiento, en su mayoría familias jóvenes, no hayan sido contados e incluidos en la entrega de viviendas.

\subsection{La emigración de pobladores después de relocalizados}

Otro efecto mencionado en relación al "después de la relocalización" es la venta paulatina de las casas y la emigración de sus habitantes hacia otro lugar de residencia. En cuanto a estos pobladores que decidieron irse de Potrerillos luego de ser relocalizados, un poblador decía:

"hay varias casas canceladas y las han vendido, (...) de las 70 familias que fuimos relocalizados ya se fueron más de 12 familias de acá de la villa y también se murieron algunos titulares, se quedaron los hijos y vendieron; y han comprado casas para tenerlas de fin de semana, o para alquilarlas, el gobierno ha permitido eso, el IPV que dice no es un ente inmobiliario pero ha permitido que se vendan las casas y se siguen vendiendo en la actualidad. Entonces, qué va a llegar a pasar que yo lo estoy avizorando, que se va a descolonizar el lugar porque los colonos están vendiendo y se están yendo" (Poblador 3, 15/08/2010).

La urbanización y relocalización de la nueva Villa Potrerillos genera en varios casos la venta de las viviendas y la emigración de algunos pobladores hacia otros destinos residenciales. Esta dinámica de desplazamiento se completa con la llegada de nuevos habitantes, así como de emprendimientos inmobiliarios y turísticos, situación que se extiende hacia los otros parajes de Potrerillos. El siguiente relato describe esta situación:

"también en el pueblo hay otros lugares que... (...) hay gente que han venido y se han establecido en terrenos fiscales y se están haciendo complejos de cabañas, casas de fin de semana, camping, negocios, o sea que están usufructuando en lo personal los bienes del Estado y nadie toma el toro por las astas ni cartas en el asunto" (Poblador 3, 15/08/2010).

El impacto de la Presa Potrerillos como vimos en los documentos oficiales y los testimonios, transciende el área urbanizada de la relocalización potenciando el crecimiento económico de los parajes aledaños a la nueva villa. En otros términos, el ordenamiento territorial del perilago, aún cuando no se encuentra concluido, propicia un recambio poblacional y promueve la instalación de emprendimientos privados. Esta situación, como se evidencia en el último testimonio, es molesta para algunos fundadores del lugar, pobladores denominados colonos, quienes sienten como una pérdida la emigración de muchos de sus vecinos por años del lugar y una invasión la instalación sin control de los nuevos habitantes e inversionistas. 
En conclusión, la relocalización en estudio es un proceso complejo y conflictivo que involucra a numerosos actores y trasciende ampliamente, como veremos posteriormente, la cuestión habitacional que como se expuso recibió una respuesta o atención por parte del Estado. Paramos ahora a considerar los efectos habitacionales sobre el sector de pobladores de Potrerillos residentes en Avenida Los Cóndores, que no fueron relocalizados y obtuvieron en base al reconocimiento de su historia y memoria la propiedad de sus tierras.

\subsection{De Avenida Los Cóndores: de colonos a propietarios}

Como hemos visto hasta el momento, la población que se localizaba en donde actualmente es el vaso del embalse fue relocalizada, sin embargo el proyecto de ordenamiento territorial como vimos en el capítulo $\mathrm{V}$ abarca a todo el Distrito de Potrerillos y sus valles. En el caso de la población de Avenida Los Cóndores, la intervención del Estado, fue la regularización de la tierra, o sea la adjudicación de los títulos de propiedad. Esta experiencia no consistió solamente en un trámite administrativo, sino que implicó la creación de la Asociación Avenida Los Cóndores por parte de los vecinos y un trabajo de rescate de documentación familiar que avalara la presencia de los pobladores por décadas en la zona y los habilitara a ser tratados por el Estado en término de "colonos" y adquirir derechos en el marco de la Ley provincial 4.711 de colonización. Sobre esta experiencia y la participación de los mismos en el proyecto de ordenamiento territorial la presidenta de la asociación relataba:

"no nos veíamos afectados directamente -refiere a ser relocalizados-, pero sí dentro del plan de ordenamiento estaba el proyecto que se llamaba Desarrollo económico y turístico en Avenida Los Cóndores. A nosotros nos pega desde un costado, nos dicen que de ahí de Avenida Los Cóndores que eran tierras fiscales iban a ser erradicadas las familias porque dentro del desarrollo turístico esa iba a ser la zona comercial y turística, por supuesto eso iba a pasar a manos privadas, nos erradicaban, esos terrenos pasaban al Estado nuevamente e iban a vendérselos a privados para que hicieran su desarrollo, entonces cuando se plantea esa situación la gente se pone muy mal y dicen -no, por qué me van a sacar de un lugar que yo vengo ocupando hace más de 50 o 100 años.

Entonces ahí nos conformamos en asociación, empezamos a averiguar sobre la posibilidad de quedarnos todo el grupo con la tierra (...) y vimos de utilizar la ley de colonización 4.711 que es una ley provincial que únicamente se aplicaba en el sur de la provincia de Mendoza porque de acuerdo a la ley se paga con insumos, es decir con la producción. Empezamos a analizar la ley, pero había que hacerle algunas modificatorias porque nosotros no teníamos producción de tierra, ocupábamos pequeñas parcelas de 500, 1000, 2000 metros pero teníamos la vivienda, con qué lo pagábamos. Entonces hicimos una consulta de abogado y se podían hacer la modificación de un par de artículos que se podían aplicar en la parte noroeste de la provincia que es la zona de Potrerillos. 
El Gobierno de la provincia nos dijeron bueno está bien, ustedes tienen esta propuesta pero van a tener que hacer un trabajo, tienen que certificar fehacientemente que son colonos, ¿y cómo se hacía? Empezar a hacer consulta vecino por vecino, saber cómo y cuándo habían llegado ellos, cómo habían obtenido ese lugar y ahí empieza la parte más bonita de la historia, porque nos encontramos que hay gente que hace 100 años que llegó a la zona y tenían su tierra por legítimo derecho, en qué sentido, fueron y poblaron y tuvieron sus hijos, y sus hijos a sus hijos y así empezamos a encontrar quienes eran los verdaderos colonos de la avenida, así que bueno, descubrimos el primer matrimonio que se asentó en la zona.

E: ¿Quiénes eran? -LV: La familia Jara. Manuel Jara se llamó el primer señor que se casa en el año 1925, 27 más o menos, no recuerdo muy bien, que es el primer matrimonio que se asienta en Cacheuta, ahí existía la oficina de anotaciones de nacimientos (...) porque en aquellas épocas esta fusionado Potrerillos y Cacheuta era un solo lugar (...) esta familia Jara, para nosotros fue un puntal para que la ley de colonización se aplicara porque nos conocía a nosotros y sabían cuando había llegado el resto de la población (...) y a partir de allí empezamos a conocer al resto de las familias, primero Jara, después estaba Vázquez, Sánchez, Quiroga, Ortiz, Vélez. (...) la ley de colonización, nos da la posibilidad de comprar los terrenos que estábamos ocupando (...). El colono si o si tiene que pagar la tierra, pero es un monto muy bajo, es 2 pesos el metro de terreno, es un valor simbólico en realidad, la provincia no te puede vender si no te pone un importe, no te lo puede regalar, si o si lo tenés que adquirir a través de un valor por eso nos pusieron el mínimo" (Presidenta de la Asociación Avenida Los Cóndores, 21/09/2010).

Como se expone, a través de la acción colectiva de conformarse como asociación, este sector de la población dedicado a buscar los comprobantes de los años habitados en el lugar, apelando a la Ley de Colonización logra obtener la titularización de sus tierras a un costo mínimo, simbólico en palabra de la entrevistada.

Si bien el proceso de encuentro con los documentos familiares, que dan cuenta de hechos del pasado, motivaron la reconstrucción cronológica de las familias que fueron arribando al lugar, así como la posibilidad de compartir relatos de vida entre quienes estaban abocados a esta lucha en defensa de sus tierras, la causa que motivaba la búsqueda, que era la intervención del Estado en el marco del plan de ordenamiento territorial, era impuesta y resistida por parte de estos pobladores. La misma entrevistada aludía a los interrogantes y argumentos del cambio que implicaba tener la titularización de las tierras:

"desde la parte de nuestra vecinal costó meternos en la cabeza que a esta tierra la tenés que pagar. -No, pero si yo nunca pagué nada, - Bueno, pero es que hoy tenés que tener esa responsabilidad y esa obligación si te querés quedar y ya vas a dejar de compartir la luz con tu vecino, y lo tenés que hacer porque te da derechos tener una individualidad en tus gastos (...) esas eran las cosas que la gente no estaba acostumbrada, entonces es un cambio, también para tu bolsillo, te tenés que empezar a esmerar, salir a buscar trabajo, generar algo y es muy importante (...) ya dejas de ser un usurpador, mañana cuando tengas el título de la propiedad vas a poder hacer otro tipo de cosas, podés ir y tramitar un crédito en el banco y podes armar tu proyecto, (...) y también está lo otro, -Sí, pero a mí el 
gobierno me choca, viene con todas esas ideas y a mí no me pregunta, a mí no me golpean la puerta y me dicen qué es lo que querés.

El objetivo es tener el título de la propiedad, pagar todos nuestros servicios como corresponde y ya dejar de ser un poblador normal, sino pasar a ser un poblador que puede ambicionar el progreso, es que Potrerillos lo miremos por donde lo miremos, sea cual sea la gestión de gobierno que venga, va a ser un importante ingreso para la provincia, y de nosotros, del pobladores depende qué hacer" (Presidenta de la Asociación Avenida Los Cóndores, 21/09/2010).

Esta estrategia de individualización de los servicios básicos y el reconocimiento de derechos y deberes que implica la titularización de las tierras, es visualizado por la entrevistada como la oportunidad de los pobladores de la Avenida Los Cóndores de insertarse en el desarrollo de la zona capitalizando la inversión pública realizada por el Estado en torno a la presa. Es decir, lo ve como la posibilidad de que los pobladores puedan quedarse en la zona y aprovechar el progreso planificado, teniendo acceso a beneficios, como por ejemplo, la obtención de un préstamo para la inversión en proyectos productivos que los hagan crecer económicamente. En otras palabras, visualiza el escenario de impacto del proyecto en los términos planteados por los planificadores del desarrollo del perilago, que persiguen adaptarse y estar a la altura de la lógica del mercado, pero a diferencia de ellos busca que quienes se beneficien sean en primer lugar quienes formaron el pueblo y aún permanecen allí, ya que entiende que si se deja librado "al azar" este factor, quienes acceden al desarrollo son quienes tienen mayor poder adquisitivo, dejando al margen a los demás.

De esta forma, el plan de ordenamiento territorial del perilago de Potrerillos significó otro acontecer para los pobladores localizados en Avenida Los Cóndores, ya que los mismos, apelando a la Ley 4.711/82 de colonización pudieron obtener mediante la práctica social de asociarse la titularidad de sus propiedades. Se trata de vecinos que lograron comprobar que residían en el lugar desde hace más de 30, 40 y 50 años. En cuanto a este avance, la misma entrevistada en el año 2004 exponía a Los Andes (29/09/2004):

"Pero esto no es un regalo, es una manera de reconocer que habitamos aquí cuando no había nada, ningún servicios y hoy vemos que gran parte del desarrollo de esta zona es gracias a nosotros, a nuestros padres, a nuestros abuelos". 


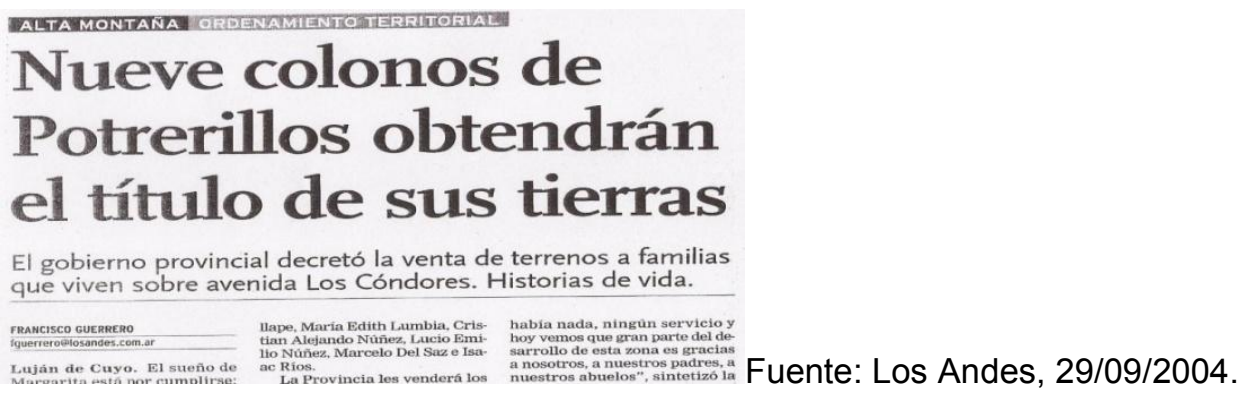

En este apartado hemos abordado los efectos habitacionales y sobre la propiedad de la tierra que el proyecto de desarrollo conllevó sobre los pobladores de Potrerillos. En el siguiente consideramos los efectos sobre las economías de subsistencias de los mismos.

\section{$2 \quad$ Sobre las economías de subsistencia}

\section{1 "estábamos fuera del circuito"}

La desocupación de la zona para la instalación de la presa implicó entre otras cosas el corte y desvío de la Ruta Nacional $N^{\circ} 7$ que dejó desconectadas a las localidades de Cacheuta y Potrerillos, históricamente unidas como vimos en el capítulo III. En lo inmediato, esto llevó a los pobladores de ambos lugares a quedar alejados de la arteria vial que unía la Ciudad de Mendoza con la Ciudad de Santiago de Chile, de la cual dependían las estrategias de subsistencia de la mayoría, vinculadas a la circulación de visitantes y turistas, así como de los trabajadores del transporte de carga. Sumado a esto, en Potrerillos, la obra conllevó además de la relocalización de las viviendas localizadas donde hoy es el vaso del embalse, el de los comercios de alimentos, artesanías, estación de estipendio de combustible y servicios turísticos ubicados al margen de la ruta y en la ribera del Río Mendoza. Sobre los efectos sobre los trabajadores de estos lugares un poblador entrevistado recordaba:

"empezaron a venir un montón de problemas porque al cortar la ruta, había un montón de familias que trabajaban en Cacheuta, el que no era mozo era chofer, otro vendía pan a la orilla de la ruta, cambiaron, otro siguió con el sueldito de nada, de jubilado, de pensionado de dos mangos" (Poblador 2, 16/04/2010).

De este modo, el corte de la ruta implicaba cambios para el sector económicamente activo de ambas localidades, así como también para la población que subsistía con los precarios ingresos provenientes de algún tipo de beneficio de la seguridad social como la jubilación, pensión, etc. el cual era insuficiente considerando el costo que significaba la crisis económica, social y política que se vivía a nivel nacional. 
Si bien en el caso de los relocalizados, el IPV en el terreno adjudicado le construyó locales comercial a los afectados que vivían del comercio para que una vez relocalizados continuaran desempeñando sus prácticas económicas habituales, la población igualmente vio impactadas sus fuentes de ingresos debido a que, a partir del ordenamiento territorial en torno a la obra, la ruta de la cual muchos económicamente dependían quedó ubicada aproximadamente a 400 metros del predio donde se efectuó la relocalización, y por tanto los turista y transportistas ya no pasaban frente a los negocios de los pobladores. Una entrevistada, refiriéndose al conjunto de los afectados, expresaba de la siguiente manera cómo era vivida la situación laboral en este lugar:

"a nosotros jamás el gobierno nos pagó el lucro cesante, o sea que todo el mundo perdió su cadena de laburo con los turistas y acá no venía nadie, porque estábamos fuera del circuito de todos los trabajos, se estaban haciendo todas las rutas, era un tierral por todos lados, los badenes los hicieron demasiado hondos y nadie podía pasar, así, sufrimiento tras sufrimiento, hicieron las rutas y las calles aledañas después que nos cambiaron (...) en vez de haberlo hecho primero y después habernos cambiado. (Pobladora 1, 07/04/2010).

Estos relatos hacen evidente los inconvenientes ocasionados por el Estado a la población de la nueva villa al realizar la construcción de los caminos después de realizar la mudanza de la población, lo cual llevó a que la misma quedara desconectada y, como ellos mismos mencionan, "fuera del circuito" comercial en el que se insertaban sus fuentes de ingresos. Esta falta de previsión de arterias viales alternativas para evitar perjudicar a los pobladores da muestra de que la visión del gobierno sobre el desarrollo del lugar esta puesta en el largo plazo y no contemplaba las necesidades o participación de los pobladores que requerían respuestas inmediatas.

\section{El agua ya borra la vieja ruta a Potrerillos}

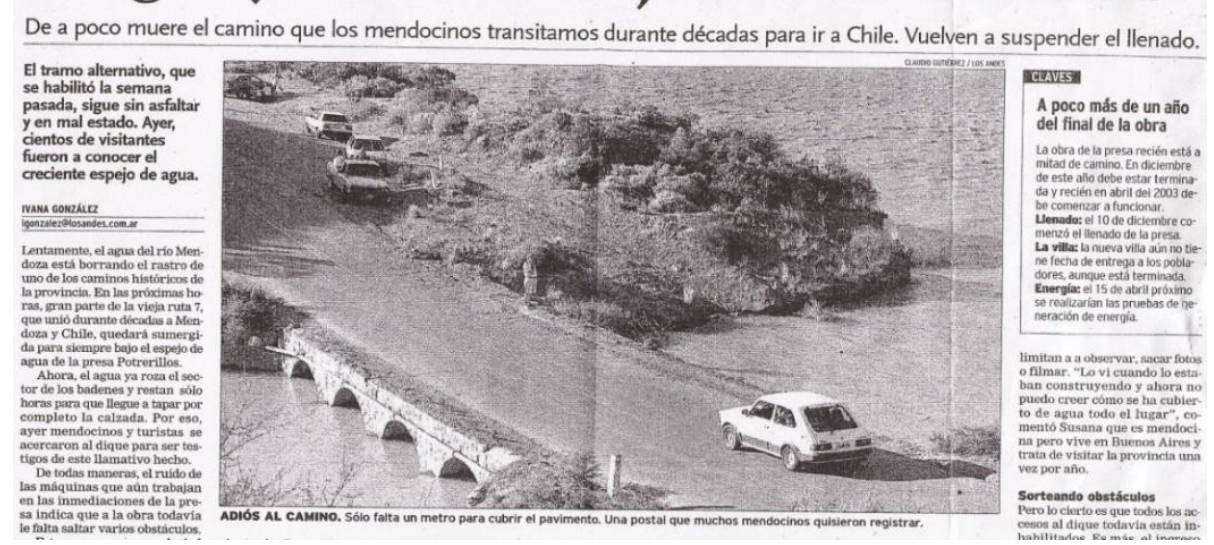

Fuente: Los Andes, 04/03/2002. 


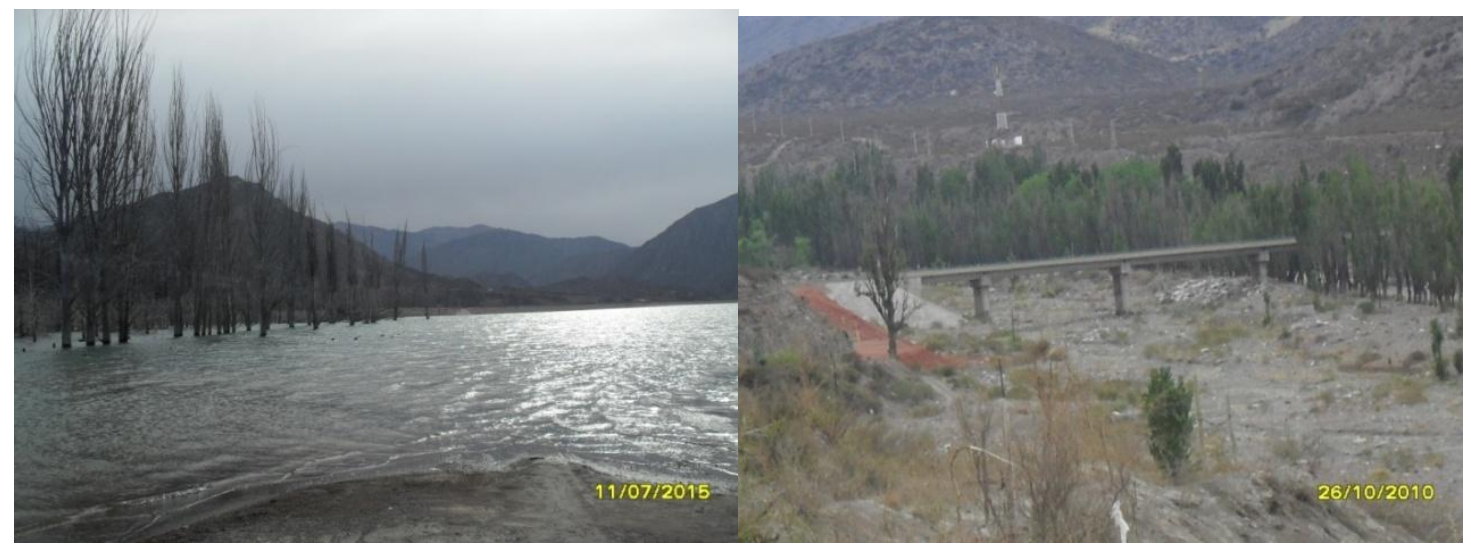

Imagen 22. La ex - Ruta 7 bajo el agua del Río Mendoza.

Imagen 23. La nueva ruta 7 vista desde la nueva Villa Potrerillos. Fotos: Mariana Raffani

En resumen, en Villa Potrerillos además de las viviendas, también fueron relocalizadas las estrategias de subsistencia de los pobladores, proceso que en ningún sentido fue gratuito para los mismos, a quienes les resultó económicamente costosa y emocionalmente dolorosa la readaptación al lugar transformado por el Estado provincial. Así también, al igual que en Cacheuta, debido a la interrupción de la ruta, la población se vio afectada por el consecuente distanciamiento entre ambas localidades que se encontraban físicas y funcionalmente próximas.

\section{2 "muchos cambiaron sus oficios"}

Como se ha expuesto, los cambios territoriales acontecidos en los lugares en estudio, impactaron sobre las estrategias de subsistencia de la población involucrada en el proyecto, lo cual llevó a que muchos perdieran sus trabajos y/o debieran cambiar sus estrategias económicas habituales. Considerando los oficios a los que se dedicaban los pobladores previos a la relocalización como las condiciones socio-económicas de los mismos, presentamos en este apartado los testimonios de varios afectados que manifiestan cómo experimentaron el cambio impuesto por el proyecto.

Para comenzar exponemos el testimonio de una trabajadora independiente que luego de relocalizada aún lo sigue siendo y trabaja en su propio emprendimiento de elaboración de dulces y alfajores que lleva a cabo en el local comercial -construido por el IPV-, al lado del cual ha construido un salón de té para recibir a turistas y visitantes. Así relataba:

"yo hacía artesanías, tenía taller de cerámica, cuero, metales, (...) cuando empezamos con el tema del dique empezamos a tener problemas (...) y ahí empecé a fortalecer la parte de la comida porque me di cuenta que tenía que hacer algo que saliera más rápido, y fue con lo que viví durante un tiempo y bueno 
pero después al final dejé de hacer artesanías, tuve que cambiar y así muchos cambiaron sus oficios.

Cuando nos cambiamos acá, (...) algunas vecinas que nos encontrábamos lloraban de la desesperación porque no teníamos plata, (...) habíamos tocado fondo verdaderamente, al gobierno no le importó". -E: ¿Se juntaban? -MC: Si, a hablar de nuestras penas, a ver cómo podíamos solucionar, después de todos los años que habíamos venido juntándonos para luchar, seguir juntándonos para ver qué hacer, para salir del pozo en el que estábamos metidos, re jodido, muy jodido" (Pobladora 1, 07/04/2010).

Esta pobladora debió readaptar sus estrategias de subsistencia al nuevo contexto, y dejar sus oficios artísticos elegidos para ganarse el sustento económico. El relato nos permite conocer como era sentido por los afectados el cambio y el cansancio con el que se encontraban al momento de ver afectadas sus fuentes de ingresos, después de años de estar en tratativas con el gobierno. Así también, alude a la generación espontánea de las redes sociales de contención que se formaban entre los afectados a fin de ayudarse a superar la situación en la que se encontraban. Reflexionando sobre las implicancias de la relocalización sobre las fuentes laborales, otro poblador, actual trabajador ligado a las empresas náuticas de la zona, exponía:

"yo vivía de mi autosustento, vivíamos ligado al río, a un camping y cerca de las empresas náuticas, entonces a uno le hacía asado, a otro un audiovisual, a otro alquilaba carpas. Tenía como, ya todo armado ahí, de repente pum se cambia todo, acá vamos a hacer una obra pública, ustedes se van, todo cambió (...) en ese momento fue un garrón, que mejor no recordarlo, o sea, y cada vez que recuerdo, recuerdo las cosas bonitas que nos pasaron ahí y es nostálgico (...) yo hacía artesanías, vivíamos así un poco de eso hasta que enganché la parte de fotografía traer acá, (...) gracias a Dios que este cambio de vida y de quedarse sin trabajo y de temores y cosas, no fue que nos espantó del lugar, nosotros con mis hijos nos quedamos acá, cambiamos de laburo, yo estoy relacionado con la náutica ahora..." (Poblador 2, 16/04/2010).

Este relato nos permite ver que el miedo por la inestabilidad económica que significó la instalación de la obra para los pobladores, llevó a muchos a sentir la amenaza de tener que dejar el lugar en busca de nuevas oportunidades. Si bien este poblador, años después agradece el haber resistido las adversidades del contexto y haberse quedado en el lugar, no sucedió así en otros casos en que producto de la crisis de la relocalización, además de la del 2001 que vivía el país, fueron expulsados del lugar en busca de trabajo. Sobre estos últimos un entrevistado recordaba:

"acá había muchas familias que con la crisis del 2001 perdieron muchas cosas, negocios, sus sustentos propios y fruto de la crisis que estaba azotando al país algunos emigraron en aquel entonces en busca de mejoras y en algunos casos la obtuvieron, muy contado con los dedos de las manos, y en otros les fue peor 
porque dejaron sus lugares que habitaron durante años sus antecesores, sus abuelos, sus padres y después cuando volvieron encontraron sus lugares ocupados porque no dejaron a nadie" (Poblador 3, 15/08/2010).

De este modo, la llegada de la obra desestabilizó las prácticas económicas habituales de los pobladores dejándolos desorientados en un territorio en abrupta transformación, que amenaza los esquemas de subsistencia y estrategias adaptativas de la población.

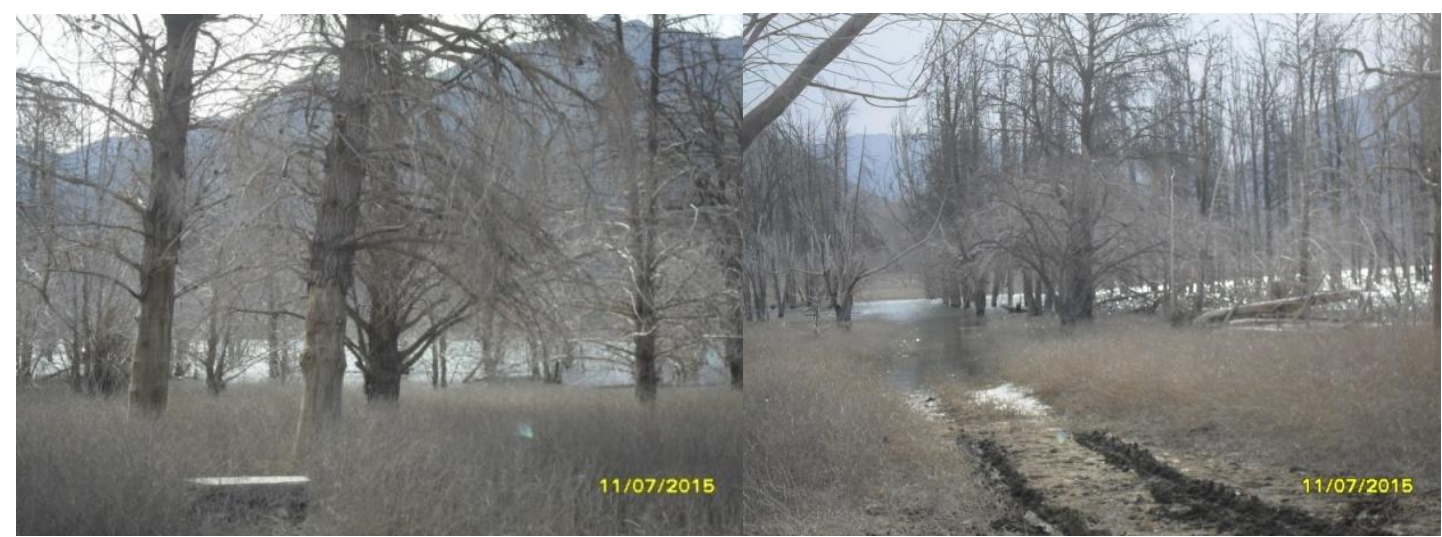

Imagen 24. Cuando el agua baja. Rastros del camping de la UNCuyo,

Imagen 25. Los árboles mueren de pié. Rastros del camping de la UNCuyo, Fotos: Mariana Raffani

En tercer lugar exponemos el testimonio de una pobladora de una familia que desde hacía décadas trabajaba en su propia panadería y pese a las ofertas del gobierno, al ser relocalizados no pudieron continuar con el oficio y emprendimiento familiar, debiendo dedicarse exclusivamente a otro.

"en el caso particular de mi familia se firmó un acta acuerdo donde ellos nos iban a dar los materiales para construir la panadería (...). Antes nos hicieron hacer un proyecto pagado por nuestro bolsillo, tuvimos que pagar al arquitecto para hacer un salón y el horno, o sea lo que entraba en ese salón de material, de mano de obra, todo lo que salía para presentarlo en el Ministerio de Obra Pública (...). A todo esto, el horno no fue tazado como tal, porque era para ellos una construcción de adobe, y bueno presentamos ese proyecto también y quedaba ahí todo latente hasta que una nueva funcionaria nos llama y nos dice que habían decidido darnos la plata para construir la panadería, (...) que no alcanzaba porque vos tenías que pagar los honorarios del abogado, no estaba gratis. E: ¿No les alcanzó para la panadería? -SA: No nos alcanzó para hacer lo que teníamos bien hecho, o sea, primero teníamos que organizarnos porque el cambio fue brusco, viste cuando tenés que resolver algo ya, pero no te da el tiempo, no te dan los costos, (...). Si a vos te construían tu casa de acuerdo a la condición social del grupo familiar, también hubieran visto la situación comercial, y si hubieran construido en el caso nuestro la panadería y después la descontaban, la hubiésemos pagado para seguir con la continuidad del trabajo.

E: ¿Y cómo fue después, estando relocalizados en cuanto al trabajo? -SA: Y la panadería no funcionó mas, nosotros también teníamos un corralón, mi marido tenía un camión, la cargadora entonces vendíamos leña, gas, trabajo de acarreo 
de áridos, ripio, arena, trabajo de fletes y es de lo que vivimos actualmente" (Pobladora 4, 20/05/2010).

Al igual que otros comerciantes localizados sobre la ruta 7 , esta familia vivía de lo que producían y vendían en el lugar así como en los parajes de alta montaña. Como podemos ver en el relato, la negociación entre los afectados y el Estado provincial, hasta el momento de desocupación del espacio requerido por la obra, se producía en un marco de incertidumbre que duró varios años e involucró a funcionarios de distintas gestiones que proponían ofertas diversas. Así también, en el caso expuesto, implicó la contratación particular por parte de los afectados de asesoramiento legal y arquitecto para la confección de un proyecto que fue presentado al Estado para continuar con el emprendimiento familiar. Pese a esto, la respuesta del Estado fue entregarles un monto de dinero para que ellos se edifiquen la panadería, el cual una vez relocalizados no les alcanzó para poder hacerlo y continuar con la actividad realizada por décadas. Reflexionando años después, la entrevistada expresa que hubiese sido justo poder seguir con la fuente de trabajo que tenían, y en este sentido, considera que en lugar de haberles entregado el Estado el dinero para que construyan la panadería, hubiese sido beneficioso que en paralelo a la casa, él mismo la construya y ellos -los relocalizados- pagarla al igual que como lo hacen con las viviendas, lo cual, según argumenta, hubiese evitado que se frene el ritmo de trabajo. En el caso de esta familia, que no es el de la mayoría de las involucradas, previo a la relocalización también poseía otro negocio el cual pasó a constituir su única estrategia de subsistencia, por ello no quedaron sin trabajo.

Por último, exponemos el testimonio de un poblador relocalizado quien, luego de conseguir empleo en relación de dependencia en la empresa constructora de la obra, una vez ésta terminada, quedó por varios años desempleado -entiéndase en relación de dependencia- hasta su incorporación en la Delegación municipal de Villa Potrerillos. En el caso de esta familia, al igual que en otros, actualmente sus estrategias de subsistencias dependen de las instituciones del Estado que se ubican en la zona como la mencionada o las escuelas. Situando su experiencia en el contexto nacional el entrevistado narraba:

"en la caída del gobierno de De La Rúa yo no tenía trabajo en relación de dependencia, tenía trabajo en lo nuestro -señala conservas-, eso lo hace ella señala a su esposa-, lo hacía con mi mamá allá abajo -el lugar de residencia previo a la relocalización-, y nosotros -refiere a los hombres de la casacuidábamos los frutales, regábamos, podábamos, sembrábamos, cuidábamos los animales, no necesitábamos mirar los clasificados a ver si encontrábamos trabajo ni buscar en los avisos que ponen en los comercios, oficinas, etc., ni los llamados de la radio, de la televisión. Nosotros producíamos y de ello consumíamos y recaudábamos a través de nuestras ventas y teníamos todo los impuestos al día, 
(...). Si necesitábamos curarnos, íbamos al centro de Salud, pedíamos la receta y lo comprábamos con nuestro dinero, no le pedíamos que nos dieran medicamentos (...) allá abajo -el anterior lugar de residencia- teníamos miles de frascos, de dulces, jaleas y mermeladas, escabeches y conservas, licores, todo artesanal (...) teníamos 1.200 plantas entre frutales e hibridas, duraznos de siete clases, peras de tres, dos clases de cerezas, guindas, uvas blanca, negra, moscatel y huevo de gallo, habían algunas nueces, avellanas, almendras, níspero, damascos, teníamos un lugar donde sembrábamos el orégano y lo cosechábamos, lo secábamos y lo vendíamos; comprábamos en Maipú aceitunas y las preparábamos nosotros; teníamos hongos, secábamos los hongos. Teníamos huerta, sembrábamos toda clase de verduras, sandías, melones, (...) distintos clases de zapallo del año, del tronco, calabaza, italiano, corianito, etc. sembrábamos también maíz, choclos, zanahoria, frutillas, frambuesas, y perdimos todo lo que habíamos sembrado y nos quedamos sin nada y muy triste porque de tenerlo todo tuvimos que vender los vehículos, yo no tenía trabajo, no tenía ocupación y cada día era peor (...). E: ¿Aparte tenían panadería? AJ: Si, teníamos la panadería dentro de la casa.

Teníamos tres vehículos, con uno de ellos hicimos reparto para la zona de El Salto, Las Chacritas, El Carmelo, el Alto Manantial, etc. y vendíamos también comidas preparadas: carne a la masa, empanadas, comidas típicas, sándwich de jamón crudo y pan casero porque criábamos cerdo, carneábamos, elaborábamos nuestros propios productos, panceta, huesito para los locros, costillares de cerdo aliñado, jamones, bondiola, chorizos, morcilla, costeletas de cerdo, lo teníamos todo controlado por veterinario; también teníamos vacas, sacábamos la leche, se hacía queso, manteca, dulce de leche y consumíamos la leche de los animales nuestros los vacunos, también de cabras, teníamos cabras, ovejas, gallinas, recogíamos los huevos todos los días y era todo sano, teníamos de todo y si nos dolía el estómago nos curábamos con hierbas medicinales, acá hay muchas" (Poblador 3, 15/08/2010).

En este último caso, la economía de subsistencia de la familia antes de ser relocalizada se basaba no sólo en la comercialización de productos sino también en la elaboración de los mismos a partir de la plantación de frutales y cultivo de huerta, así como de la crianza de animales para la venta y autoconsumo. Al ser desalojados y tener que trasladarse, en este caso no sólo vieron afectadas sus fuentes de ingresos por el desvío de la ruta sino también su soberanía alimentaria, sufriendo la pérdida de las plantaciones, y demás bienes que tuvieron que vender para subsistir durante el tiempo en que los adultos de la familia quedaron desempleados. Esta situación llevó al entrevistado como a otras personas del lugar a solicitar trabajo en relación de dependencia y efectuar prácticas no acostumbradas como buscar empleo en los clasificados de los diarios o ir a "golpear puertas o tocar timbres" como manifiesta. En este sentido, el poblador diferencia el trabajo en relación de dependencia del trabajo realizado por las mujeres de la casa como la producción de conservas que fue lo que les permitió en parte generar ingresos monetarios 
durante el tiempo de su desempleo. Esta diferenciación nos permite avistar la división de trabajo al interior del hogar vinculada a la condición de género.

Para finalizar, en el caso de quienes optaron por realizar trabajo en relación de dependencia, después de la empresa constructora de la obra fue la Municipalidad de Luján de Cuyo en primer lugar y después las escuelas quienes incorporaron laboralmente a los pobladores desocupados. Sobre esto, el mismo poblador relataba:

"Yo estuve casi cuatro años sin poder conseguir trabajo, porque la construcción del embalse si trajo una mano de obra, yo trabajé para el consorcio, pero una vez que se fue la empresa, (...) acá los únicos que se están portando bien en este lugar es la municipalidad porque ha venido y nos ha dado trabajo, hoy tiene 64, 65 empleados, tiene una secretaria administrativa, un delegado municipal, un delegado ambiental, hay tres capataces, son de acá de Potrerillos, la mayoría son hijos de colonos, colonos y nietos de colonos y el mínimo, un $1 \%$ no es de acá" (Poblador 3, 15/08/2010).

A partir de los testimonios expuesto, vemos en general, que dependiendo las condiciones socio-económicas de los pobladores éstos fueron diversamente afectados en sus fuentes de ingresos, así como diversas fueron las alternativas contempladas por los mismos a la hora de readaptar las estrategias de subsistencia al nuevo contexto. De esta forma, la relocalización implica o acarrea a un cambio social y económico acelerado que somete a duras pruebas la capacidad adaptativa de los afectados (Bartolomé: 1985; 9).

Avistamos así mismo, que más allá de las diferencias entre las familiares lo que resultó común a todas en relación a este aspecto fue la falta de acompañamiento o apoyo del Estado luego de la inauguración del barrio, o de la denominada por el gobierno refundación de Villa Potrerillos, realizada en abril del 2002, que llevó a los pobladores a realizar una serie de acciones colectivas en busca de presencia y respuestas del Estado en relación a las nuevas necesidades que presentaban. Sobre éstas ahondamos seguidamente.

\section{3 "Queremos una participación activa"}

Considerando los espacios de representación definidos por Lefebvre en el marco teórico como los espacios de los habitantes vividos como práctica social, aludimos en este apartado a las manifestaciones que se gestaron en el Consejo de Potrerillos, organización integrada por la población involucrada por el proyecto, que en las calles y a través de los medios de comunicación hicieron públicos sus reclamos, demandas y denuncias en busca de respuestas del Estado.

Concluido el traslado de la población, a razón del inexistente inmediato "impacto positivo alto" que se anunciaba en la Declaración de Impacto Ambiental para la zona en estudio, y 
la necesidad de ser parte del desarrollo del área que hasta el momento no existía, los habitantes de Villa Potrerillos, Valle del Sol, El Salto y Las Vegas se agruparon y elaboraron un petitorio que presentaron a la Comisión de Derechos y Garantías del Senado, a la Cámara de Diputados y a la DPV de la provincia el 2 de octubre de 2002. Entre los temas expuestos en el documento, se aludía a la mantención de las fuentes de trabajo, la relocalización de los emprendimientos en lugares estratégicos de acuerdo a la nueva traza de caminos, la titularización de las tierras para quienes no fueron relocalizados y la mantención de las entidades culturales y recreativas como el club social y deportivo, y la posta tradicionalista de Potrerillos. Así también se peticionaba agua de riego para cada lote, la promoción de espacios artesanales, comerciales y culturales, la disposición de uno o varios terrenos para la construcción de viviendas para las familias jóvenes de la zona y la provisión de un terreno de 5ha para emprendimientos turísticos de los pobladores que integrarían en una Cooperativa de Provisión de Servicios Turísticos "Potrerillos". A esto se suma la solicitud de un micro-hospital para el distrito y la creación de un comedor comunitario para los niños de la nueva villa. Esta demanda se fundamentaba en la situación que vivían los pobladores, que un representante del grupo expresaba en los medios:

"Los vecinos estamos ajenos al desarrollo que se está generando en torno al dique. Queremos una participación activa, no una simple solución a nuestro problema habitacional" (UNO, 03/10/2002).

Esta preocupación se correspondía con el desentendimiento del gobierno -una vez entregadas las viviendas- de las nuevas necesidades de la población y la no continuación de las obras planeadas para el perilago. En ese momento, la actividad turística era inexistente en tanto no se encontraban terminados los accesos hacia el lago y hacia la nueva villa, mucho menos existían servicios de recolección de residuos, sanitarios públicos, etc. y el arbolado no superaba el metro de altura en la nueva zona residencial. Esta ausencia, fue utilizada por personas particulares que cobraban un "peaje" por dejar a visitantes acercarse al agua -argumentando que pasaban por su propiedad-, así también por quienes en nombre de entidades benéficas pedían colaboración por el estacionamiento de vehículos (UNO, 15/08/2002). 


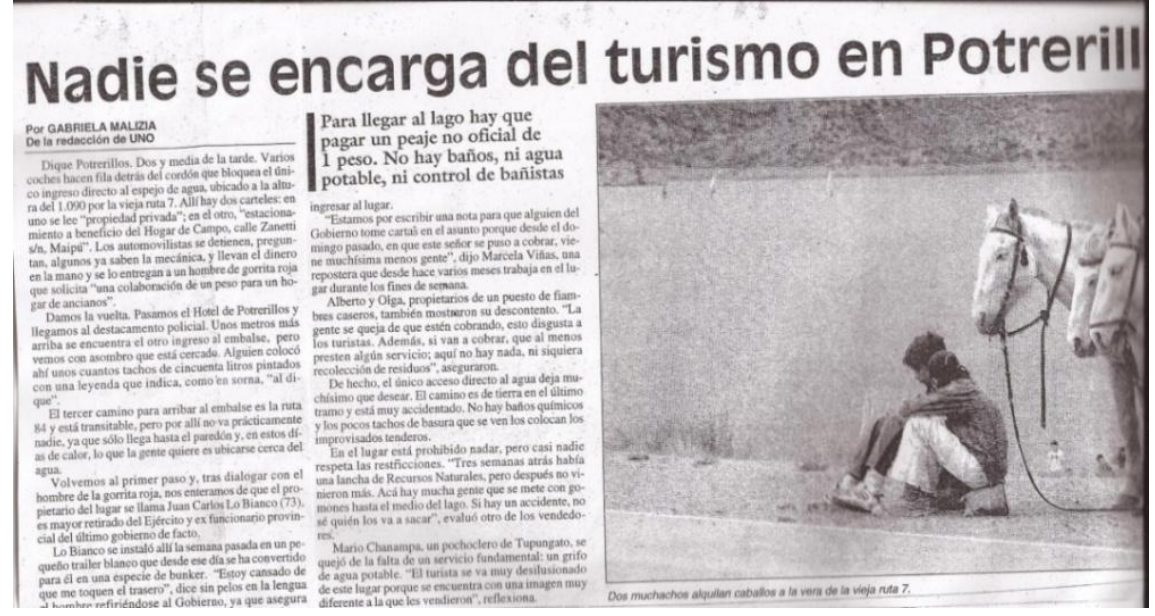

Fuente: UNO, 15/10/2002.

\section{Vecinos piden participar en el diseño de Potrerillos Por GABRIELA MALIZIA
De la redacción de UNO \\ Un grupo de 70 pobladores del Valle Po- trenillos se dirigieron ayer ala Legishitura para
reclamar el lugar que les prometió el Gobier- nnen la nlanificación urbana veconómica que}

Fuente: UNO, 3/10/2002

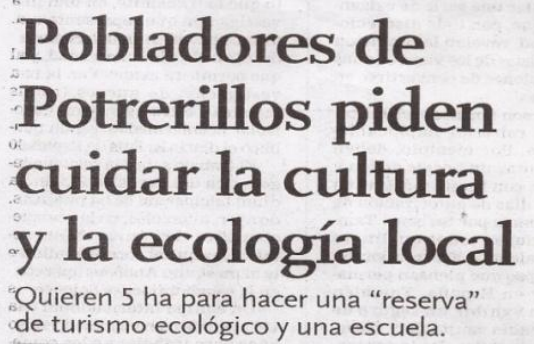

Fuente: Los Andes, 3/10/2002.

En el año 2003 nuevos reclamos se hacen eco en las páginas de los diarios. Un grupo de vecinos que viven de la única estación de combustible de Potrerillos reclamaban ante el temor de que la nueva habilitación del desvío del camino hacia el corredor internacional los dejase aislados. Este pedido se fundamentaba en la incomunicación del gobierno para con los afectados en relación a las obras que se iban realizando en el lugar, lo cual perjudicaba sus fuentes de sustento diario. El detonante, en esta ocasión, fue un corte de la Ruta 7 de 5 horas realizado por la DPV a la altura del Río Blanco sin previo aviso a los pobladores (UNO, 07/02/2003). En términos de los vecinos:

"Nos dejaron incomunicados. Nunca tuvieron la gentileza de avisarnos que iban a cortar la ruta y la gente de Vialidad nos dijo que a partir del lunes la iban a cortar al todo para habilitar el nuevo desvío. A nosotros el gobierno no nos ha informado"

\section{Temor en Potrerillos porque dicen que los dejarán aislados}

Por CLAUDIA PAGLIARULO cpagliaruloediariouno.net.ar

Un grupo de once pobladores de Potreri-

los que viven de la clientela de la única es-

de guerra ante el temor de que la próxima
Vialidad cortó por unas horas la ruta 7 para conectar el

nuevo desvío a Chile. Desde

el lunes, el corte sería total

Fuente: UNO, 07/02/2003. 
Como podemos ver, la falta de comunicación de parte del gobierno con los vecinos se hace notar en el después de la relocalización; este hecho, impulsa una vez más a los pobladores nucleados en el Consejo Comunitario del Valle de Potrerillos (representantes de más de 100 familias) a exponer públicamente sus demandas y propuesta del petitorio, denominado "Plan Popular Estratégico" frente a diputados de las comisiones de Obras Públicas, Ambiente, Urbanismo y Vivienda el día 13 de Mayo. En esta reunión, ante la presencia de los medios de comunicación y las autoridades los pobladores denunciaban:

"nos sacaron de nuestro hábitat natural y nos depositaron en un barrio donde ni siquiera tenemos derecho a riego y donde los que viajan o vienen de paseo no acceden fácilmente".

"nos dejaron sin empleo y ahora encima nos exigen que paguemos un crédito hipotecario. ¿Pero cómo podemos afrontar cuotas de un préstamo si ni siquiera tenemos para comer?"

"Mi nuevo local quedaría a 400 metros de la ruta internacional. Ningún camión va a desviarse para arreglar una rueda. Vamos a quedar sin trabajo como todos acá. Será que desde el Ejecutivo pretenden transformarnos en futuros beneficiarios de los planes sociales" (UNO, 14/05/2003).

\section{Pataleo vecinal en Potrerillos}
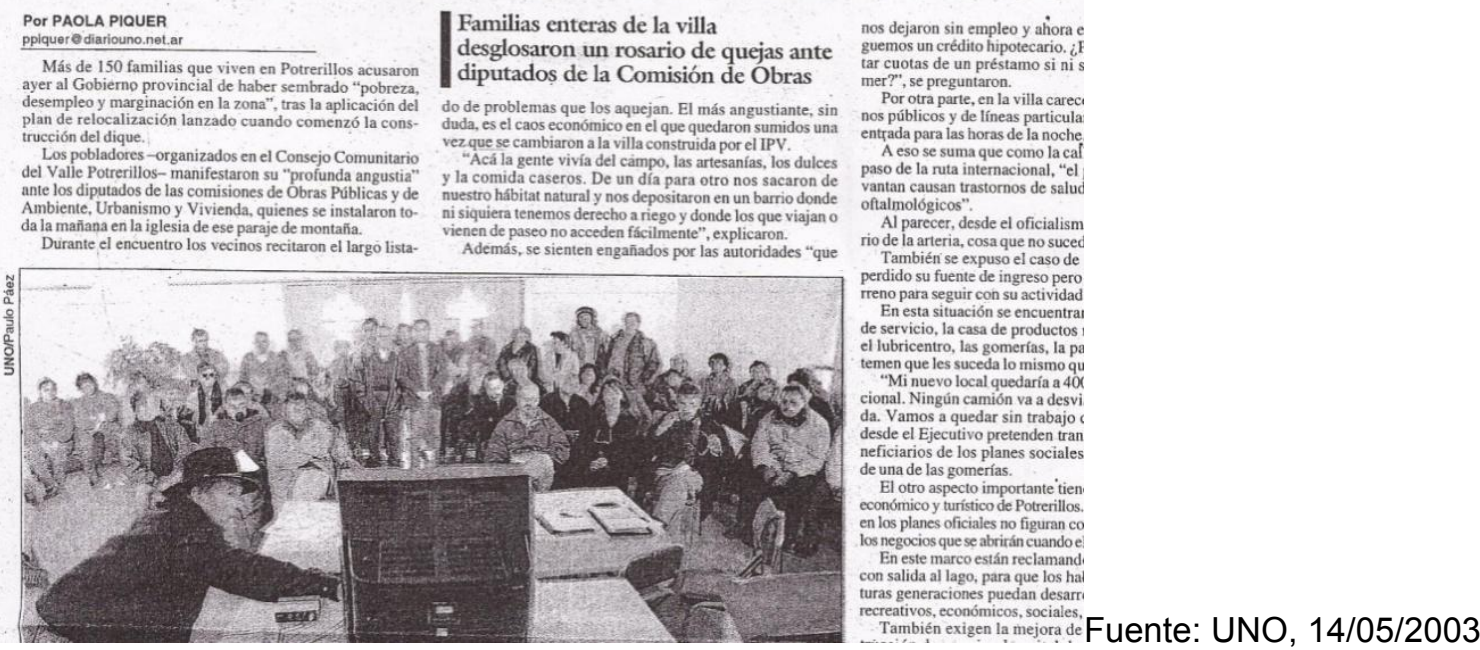

De este modo, los vecinos acusaban públicamente al gobierno de sembrar "pobreza, desempleo y marginación" tras la aplicación del plan de ordenamiento territorial en torno a la obra. El encabezado de esta nota, revela así mismo en el lenguaje, la posición frente al conflicto expresado, lo cual da muestra de cómo los medios de comunicación ejerciendo el efecto de hegemonía que describe Angenot (1998) en algunos momentos del proceso 
hacen su aporte en la tarea de despolitizar las estrategias colectivas de los pobladores afectados, haciendo aparecer sus demandas como "caprichos".

En este contexto, en que el gobierno no prioriza las necesidades de la población afectada, y donde por otro lado existían demoras en el llenado del embalse por dudas sobre la seguridad de la obra, lo cual llevó a la realización de nuevos estudios por la necesidad de construcción de un terraplén, en el verano del 2003 como del 2004 aún no llegaba el esperado desarrollo turístico al lugar.

En enero del 2004, debido a que el desvío de la ruta internacional $\mathrm{N}^{\circ} 7$ pasaba por el barrio nuevo cuyas calles son de tierra, una nueva protesta de vecinos se hicieron sentir en las calles de Potrerillos (Los Andes, 22/02/2004). Esta vez exigiendo que les asfalten el ingreso a la villa. Una representante de las familias relocalizadas, ante funcionarios de la DPV que se encontraban en el lugar trabajando exponía que por el constante contacto con el polvillo que levantaban los vehículos gran cantidad de niños y grandes padecían alergias, así mismo denunciaba:

"Pareciera que estuvieran haciendo todo para que nos cansemos y nos vayamos a vivir a otra parte"

"Hace dos años que estamos fuera del circuito comercial que teníamos antes. ¿Qué futuro podemos esperar?"

"Lo peor de todo es que ahora, en la hermosa villa tenemos casos de desnutrición, porque no nos dejan tener huertas o animales de granja. Antes nadie padecía hambre porque siempre uno tenía animales y verduras, pero ahora estamos solos, aislados".

De esta forma, podemos ver en los reclamos de los pobladores el sentimiento de hartazgo por la falta de respuestas del gobierno, la desesperación por la afectación de las estrategias de subsistencia y la necesidad de tener una participación activa o decisiva en la planificación del desarrollo. Estas denuncias, demandas y propuestas realizadas por los pobladores a través de los medios son una prueba más de los efectos inmediatos de la obra en el distrito de Potrerillos. 


\section{Potrerillos tampoco se podrá disfrutar el próximo verano}

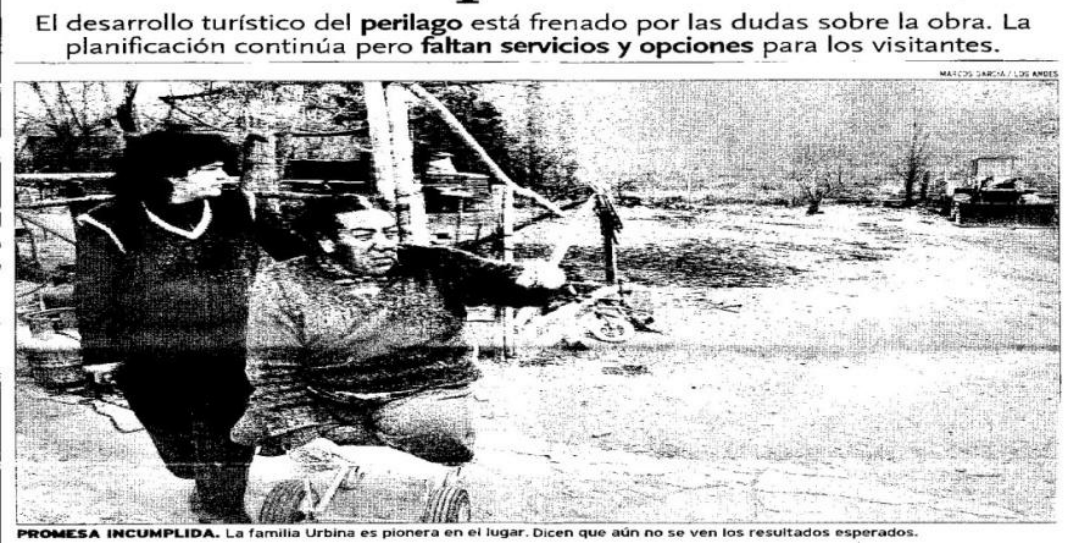

Fuente: Los Andes, 29/06/2003.

Mientras tanto, por otro lado, en los medios de comunicación también se expresaban los intereses que la obra despertaba en actores privados así como de los municipios involucrados. Sobre esto ahondamos posteriormente.

\section{4 "Detrás del perilago"}

Una vez inaugurada la obra, la creación del Ente Administrador del Perilago ${ }^{22}$-organismo en el cual podrían tener voz los afectados y del cual dependería la sustentabilidad del desarrollo en el lugar- era tema de debate entre funcionarios de distintos sectores del gobierno así como entre actores privados, los cuales representaban intereses irreconciliables que derivaron en conflictos políticos y legales.

Por una parte, existían problemas entre el municipio de Luján de Cuyo que demandaba al Gobierno de Mendoza y el consorcio privado CEMPPSA el cobro de tasas y aforos municipales no tributados por la construcción de la presa; así como la presentación de la

\footnotetext{
${ }^{22}$ Organismo que se piensa autárquico que tendrá la facultad de vender y concesionar los terrenos que conforman el perilago, formado con representación del Poder Ejecutivo de la provincia -el cual será siempre su presidente-, el Departamento General de Irrigación, la Municipalidad de Las Heras y la Municipalidad de Luján de Cuyo, además de la participación de una Gerencia, formada por cinco directores titulares y suplentes; un Consejo Técnico Consultivo, formado por representantes de organismos públicos (EPRE, EPAS, DPV, las direcciones de Ordenamiento Ambiental y Desarrollo Urbano, de Saneamiento y Control Ambiental, de Administración de Contratos y Obras Públicas, de Recursos Renovables, de Hidraúlica, de Patrimonio Histórico y Cultural y de Vías y Medios de Transporte, el Instituto Nacional del Agua y el Ambiente, el CRICYT y equipos técnicos municipales) y un Consejo de Participación Comunitaria, formado por las uniones vecinales aledañas a Potrerillos, entidades profesionales y académicas, centros de estudios empresariales, ambientalistas, entre otros.
} 
documentación técnica de la obra, el pago de seis millones de metros cúbicos de ripio usados en la construcción que fueron extraídos de las canteras del departamento y el pago de patentes por las diversas explotaciones comerciales que realizó la empresa en el funcionamiento de las pequeñas usinas hidroeléctricas, sumado al cobro de las multas por el tiempo de demora en la presentación de lo solicitado. Esta disputa se remonta a 1998 cuando el entonces gobernador Arturo Lafalla, mediante la Ley 1.321 estipuló que la empresa que llevaría adelante la obra estaría eximida de tributar los impuestos provinciales referentes a la construcción de la presa (UNO, 22/08/2002), lo cual no incluye los impuestos y permisos de la Municipalidad de Luján de Cuyo.

Así también, el interés por las tierras del perilago, se manifestaba de parte de los Municipios de Godoy Cruz que manifiesta tener derecho a participar en las decisiones del ente administrador aduciendo que los límites de sus departamentos podrían llegar hasta el área en cuestión y Capital que solicita la construcción de un acceso directo por el piedemonte al área del embalse. En el primer de los casos se trataba de delimitaciones territoriales que requerían una previa definición a la creación de la autoridad de aplicación y en el segundo de un proyecto altamente cuestionado por su impacto ambiental (Los Andes, 25/03/2007).

Por otro lado, se sucedieron conflictos derivados de la función del organismo, que además de colaborar en la preservación de la calidad del bien hídrico que constituye la fuente principal del agua potable y riego del oasis norte de la provincia, y conservar el patrimonio paisajístico y cultural del lugar, es lograr el desarrollo urbanístico, recreativo, deportivo y turístico del perilago. En cuanto a este último objetivo, la disputa surgía a raíz de las 3.000 hectáreas que tiene el perilago, de las cuales 1.700 son tierras fiscales que el organismo dispondría para la venta a emprendedores inmobiliarios, así como para la concesiones a clubes y camping. Este punto generó controversias en varias direcciones: surgieron conflictos entre actores privados que se oponían a ser expropiados por parte del Estado denunciando que éste después pretendía vender las tierras nuevamente al sector privado, lo cual es ilegal; así como entre privados que aducían tener títulos de propiedad de las tierras superpuestos o que compraron terrenos en los alrededores del lago sin luego poder escriturarlos por problemas entre los viejos dueños de la tierra así como por la falta de definición por parte del Estado del sector a expropiar a fin de realizar el tramo vial pendiente de conexión entre las localidades de Cacheuta y Potrerillos. Estos litigios se presentaban en un contexto en la tierra del área y de sus alrededores se sobrevaluación desmesurada por parte del mercado inmobiliario, que especulaba dando lugar a una puja 
de intereses por las márgenes del embalse que prometía la posibilidad de grandes negocios (Ibidem, 2007).

En este marco de divergencias, la creación del Ente Administrador el Perilago, del cual depende el uso y gestión de las tierras, así como las decisiones sobre el manejo y distribución del agua en el perilago fue aprobado por la Cámara de Diputados en el año 2005. Quienes defendían el proyecto argumentaban referido al organismo:

"Es necesario que tenga autonomía para lograr que las cosas salgan de manera rápida. Hoy hay varios Ministerios que tienen que ver con Potrerillos y es necesario que haya un organismo que se dedique de manera exclusiva, la urgencia es para desarrollar el plan estratégico" (Gustavo Morgani, Subsecretario de Ambiente). (Los Andes, 18/08/2005).

Por otro lado, los diputados opositores planteaban a los medios:

"La Ley en general es buena, pero no se puede permitir que se vendan terrenos del Estado sin la aprobación de la Legislatura. Así lo dice el artículo 99 de la Constitución" (Roberto Blanco, Diputado Justicialista, opositor del proyecto). (Los Andes, 18/08/2005).

Finalmente el proyecto pasó a la Cámara de Senadores y ahí quedó archivado hasta el día de la fecha, por lo tanto aún el perilago no cuenta con autoridad de aplicación que establezca ciertas condiciones para permitir el desarrollo proyectado como una planificación de los terrenos, la creación de una red de distribución de agua potable, otra de cloacas y servicios que posibiliten urbanizar sin poner en riesgo la calidad del agua del reservorio que alimenta al oasis norte de la provincia.

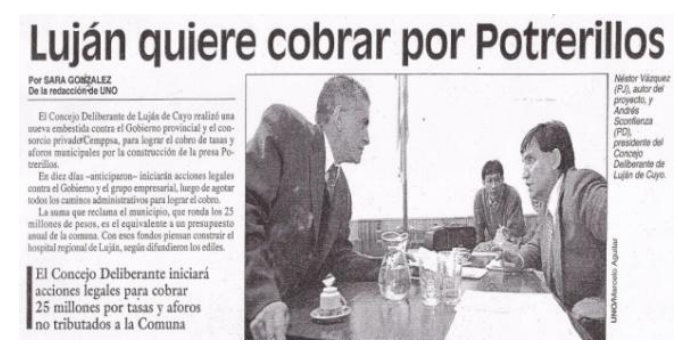

Fuente: UNO, 22/09/2002

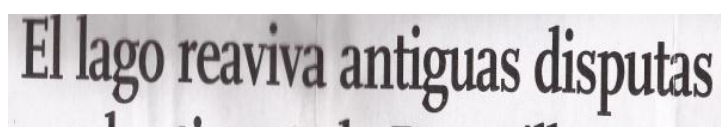
por las tierras de Potrerillos

Varias familias dicen ser las dueñas de
los terrenos aledaños al embalse. La cotización de la zona creció muchísimo.

Fuente: Los Andes, 19/04/2002

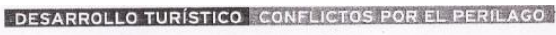 \\ La venta de terrenos traba la creación del Ente de Potrerillos \\ Quieren que cada operación se haga con acuerdo de la Legislatura. Godoy Cruz también pide participación.}




\section{Debaten la ley para regular el negocio costero de Potrerillos}

Se crearía un Ente de Administración del Perilago que vendería, concesionaría tierras y decidiría hectáreas que están en litigio, según el proyecto que analizará mañana Diputados
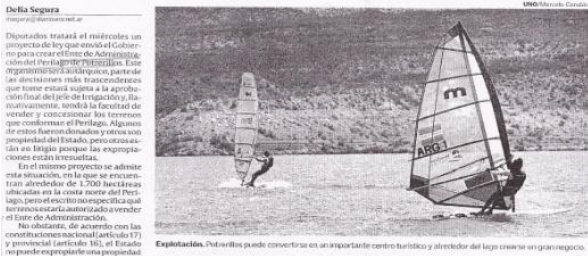

Fuente: UNO, 16/08/2005

\section{Detrás de la pelea por el perilago de Potrerillos hay un negocio millonario}

El Ente, cuya creación debate la Legislatura, tendría a su cargo 1.700 hectáreas. Podría vender y concesionar tierras por más de 100 millones. Intereses privados.

Fuente: Los Andes, 25/03/2007

\section{Potrerillos: todos quieren la costa, pero por ahora es zona prohibida}

El Gobierno emplazó y está desalojando a quienes han hecho construcciones no autorizadas. También ha recibido numerosas ofertas de empresas que buscan hacer negocios en la zona. Lo que será la nueva villa.

Fuente: Los Andes, 28/06/2008

De esta forma, el lugar estratégico del perilago, provoca grandes crisis y aflora competencias e intereses de distintos sectores del Estado, así como de particulares y empresas que había invertido en la zona. En este marco de disputas de poder que genera el territorio, la diversidad de conflictos encontrados, así como la falta de definiciones de límites territoriales y competencias jurisdiccionales de los sectores del Estado involucrados, hacen del perilago un "espacio social" inmanejable que ni siquiera cuenta con una autoridad de administración. Por tanto, en el mismo aún no se materializa el desarrollo planeado por el Estado y esperado por los pobladores.

2.5 "fue un proyecto que quedó truncado". Por los funcionarios

Volviendo a las consecuencias de la obra sobre la economía de subsistencia de los pobladores, en el presente apartado se expone el recuerdo sobre lo acontecido y la evaluación del proceso por parte de los representantes del gobierno que cumplieron funciones en el marco del plan de ordenamiento del perilago. Haciendo referencia a la intención de continuar trabajando en el lugar, una vez entregadas las viviendas y trasladada la población, intención que no llegó a concretarse, quienes hacían parte de los sectores del Estado avocados al trabajo con la población exponían:

"fue un proyecto que quedó truncado porque yo lo presenté para continuar trabajando, porque como en todos lados, se terminan los contratos, si bien no había necesidad de que lo continuara el mismo equipo de personas, lo podía hacer 
otro. Se hizo todo un trabajo de relevamiento antes de la relocalización para saber todos los proyectos económicos productivos que tenía la gente, se trabajó con el Ministerio de economía para ver que subsidios, que ayuda podían tener para poder arrancar en el otro lugar, o apoyar lo que venían haciendo y todo eso fue un proceso que llevo unos meses y desde el momento que se produjo la relocalización se cortó, no siguió el equipo de trabajo y se cortó la acción que venían haciendo. La gente tenía muchas intensiones de hacer cosas nuevas para el turismo, querían hacer algo con las truchas, había proyectos de sembrar hierbas naturales, como 10 familias estaban enganchadas en proyectos productivos pero eso no llegó al momento de la ejecución" (Trabajadora Social. Miembro del equipo de intervención de la Municipalidad de Luján de Cuyo, 10/12/2014).

"se hizo una presentación del proyecto acá en el mismo instituto -IPV-, por parte del mismo equipo social, no nos lo aprobaron (...) yo creo que no se financió ninguno porque no cumplían los requisitos. -E: ¿Quiénes no cumplían los requisitos? -LT: Los proponentes de los proyectos -los pobladores-, porque a lo mejor la actividad que desarrollaban con anterioridad era mucho más informal que lo que solicitaban para el financiamiento de este tipo de proyectos. -E: ¿Y qué solicitaban por ejemplo? -LT: Y la regularidad, estar inscriptos, bueno, lo que nosotros buscábamos con la intervención nuestra era la flexibilización de todo eso. Las líneas que existía en ese momento de crisis absoluta te imaginarás que eran rígidas" (Trabajadora social. Coordinadora del equipo social del IPV que intervino en la relocalización, 26/09/2011)

De este modo, se relevaron las propuestas productivas de las familias relocalizadas y se prometió asesoramiento y acompañamiento por parte del Estado provincial para que los afectados puedan reinsertarse en la dinámica del mercado local como ellos habían propuesto a través de una cooperativa de servicios turísticos, sin embargo una vez reasentada la población, el Estado dejó de prestar servicios. Esta no continuidad, como se relata se debió a la escisión de los contratos de los técnicos, profesionales y/políticos avocados al proyecto, así como a la falta de un recurso económico y humanos destinado exclusivamente para ello. En este sentido, pese a las necesidades y reclamos de la gente, así como a la intensión y trabajo hacia dentro de las instituciones de algunos miembros de los equipos sociales para continuar asistiendo a la población, la intervención del Estado se limitó a realizar el desalojo y reasentar en un nuevo lugar a la población con el fin de desocupar el predio requerido por la obra. Esto se afirma en las entrevistas realizadas:

"nosotros terminamos las viviendas, se entrego la obra y bueno si en el caso de verificar algún trabajo o que pudiera haber algún tipo de reclamo por parte de la gente, no hubo ningún problema al afecto así que no volvimos mas" (Diseñador del proyecto urbanístico de la Villa Potrerillos y de las viviendas. Coordinador de la Dirección de Obra, 11/12/2014).

"nuestra intervención llega hasta la entrega y el contacto posterior para el relevamiento pos ocupacional y todo lo que tiene que ver con los controles de pago de cuotas, con esas cosas pero nada más" (Trabajadora social. 
Coordinadora del equipo social de la Dirección de Vivienda de la Municipalidad de Luján de Cuyo que intervino en la relocalización, 03/12/2014).

"se comprometieron en un sin número de cosas y nunca cumplieron porque ellos prometieron que íbamos a avanzar, que el desarrollo integral del perilago iba a ser muy benéfico para instalarse con algún comercio, que iba a haber líneas de créditos blandos, subsidios y nunca llegaron, ni micro-emprendimiento, ni desarrollo local, ni desarrollo sustentable, absolutamente nada, fue todo una mentira" (Presidente de la Asociación de Fomento de Potrerillos, 06/04/2011).

De esta forma, en un contexto de crisis por las consecuencias de la relocalización así como por el período de recesión económica que aquejaba al país, los pobladores lejos de la asistencia del gobierno debieron hacer frente solos a las nuevas necesidades surgidas por la instalación del "proyecto de desarrollo".

En un sentido más amplio, vinculado al desarrollo del área, trabado por la falta de una autoridad de aplicación, la directora del plan de ordenamiento territorial explicaba:

"E: ¿No contaban con leyes? -NG: Exactamente, el marco legal como para decir (...) tenemos disponible tanto metros cúbicos de agua y uno se lo puede dar para el perilago, una cosa así, entonces en realidad existe la planta de tratamiento de agua potable ahí en la avenida Los Cóndores, que por la capacidad que tiene puede surtir de agua potable para todo el perilago, pero hasta ahora eso está frenado porque nunca el DGI ha definido qué cantidad de agua le corresponde al perilago, y de hecho parte de la base que los derechos de agua del río Mendoza están todos vendidos y que no existe derecho de agua para..., esa es una de las limitantes que hay para el desarrollo del perilago, es una cuestión de negociación porque ellos con el respaldo legal que tienen en este momento es verdad tienen vendido en la parte media y baja los 75 hectokilos por segundo que arrastra el río, pero para poder aumentar esa capacidad hemos hecho el embalse, eso nunca se dijo, qué capacidad se aumentaba, eso son metros cúbicos que uno los podría poner como derecho de riego y ahí podríamos utilizar una parte importante para el perilago. Por el momento hay algunos emprendimientos pero se surten de aguas subterráneas porque no está regulada, pero tienen que hacer el pozo, tienen que compartirlo, es decir hay una serie de problemas que los inversores no pueden hacerlo porque es muy caro, los inversores que va a poner cabañas o un hotel no se va a gastar el capital en buscar el agua, hacer el pozo, comprar el motor, compartirlo con los demás gratuitamente, no puede ser, todo eso esta trabando el desarrollo del lugar, es la forma en que se ha instrumentado" (Directora del Plan de ordenamiento territorial y desarrollo turístico del perilago, 23/03/2015).

Como podemos ver, el desarrollo proyectado del perilago que promete mucha potencialidad económica para la provincial no se evidencia en el lugar debido a la postergación de la aprobación de un marco legal que permita hacer una distribución racional del agua a lo largo de toda la cuenca del río Mendoza, en la cual se incluye el área de estudio; así como que plantee las competencias de los sectores del Estado involucrados como la provincia y los Municipios de Luján de Cuyo y Las Heras. La 
entrevistada argumenta así mismo que donde se evidencia el crecimiento de inversiones a partir de la instalación de la obra, es en los parajes El Salto, Manantiales, Las Vegas, Valle del Sol, Piedras Blancas, Los Zorzales, etc. del distrito. Sobre ello decía:

"Después del 2004 el crecimiento se dio en las villas altas, allí donde había agua no muy buena pero están los arroyos. Nosotros hicimos un relevamiento para el municipio de Luján en el año 2003, 2004 y en un verano aumentaron 400 viviendas allá arriba, sabes lo que es eso, es una barbaridad, sin control, sin cloacas, sin que haya una visión integrada de qué tipo de materiales pueden usar para construir, de cuáles no, hubo experiencias de cabañas que no tenían bien los techos y en el primer zonda se los llevó todos" (Directora del Plan de ordenamiento territorial y desarrollo turístico del perilago, 23/03/2015).

De esta forma, si bien se registra un crecimiento en construcciones en los parajes, también se reconoce la falta regulación en el marco de las leyes de protección ambiental así como en materia de construcción. En este sentido, podemos ver que el área circundante al denominado perilago también carece de la atención e inversión del Estado en obras de infraestructuras y legislaciones pertinentes.

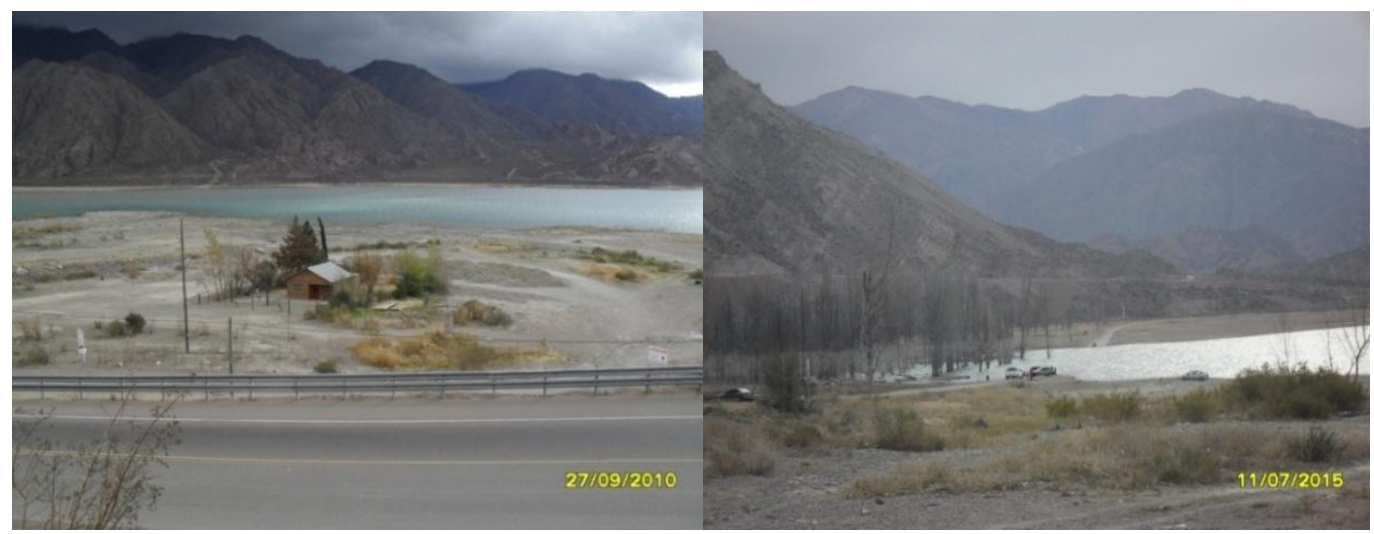

Imagen 26. Una de las pocas casas del perilago que no fue relocalizada.

Imagen 27. El perilago sin forestar y sin servicios. Fotos: Mariana Raffani

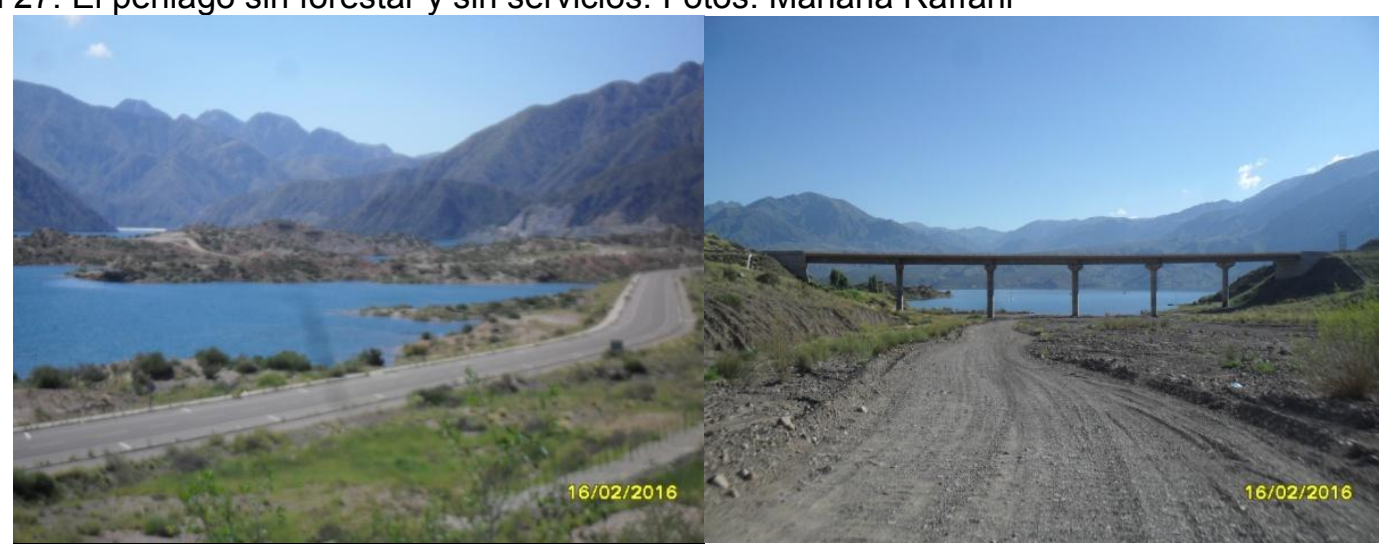

Imagen 28 y 29. Los dos primeros tramos de la Ruta 82 que uniría a Cacheuta y Potrerillos. Fotos: Mariana Raffani. 


\section{Sobre los espacios colectivos de integración}

Finalmente, aludimos a los espacios de la comunidad donde los pobladores compartían prácticas sociales que se vieron afectados por el proceso de relocalización. Ellos son el Club Social y Deportivo Potrerillos, la Posta tradicionalista, el edificio de la vieja estación del Ferrocarril Trasandino; así como la escuela Carlos Negri -que fue traslada a la nueva villa- y la Iglesia Católica -donde celebraban fiestas y realizaban actividades-, la cual si bien cuenta con un terreno en el barrio, al día de la fecha no se ha construido.

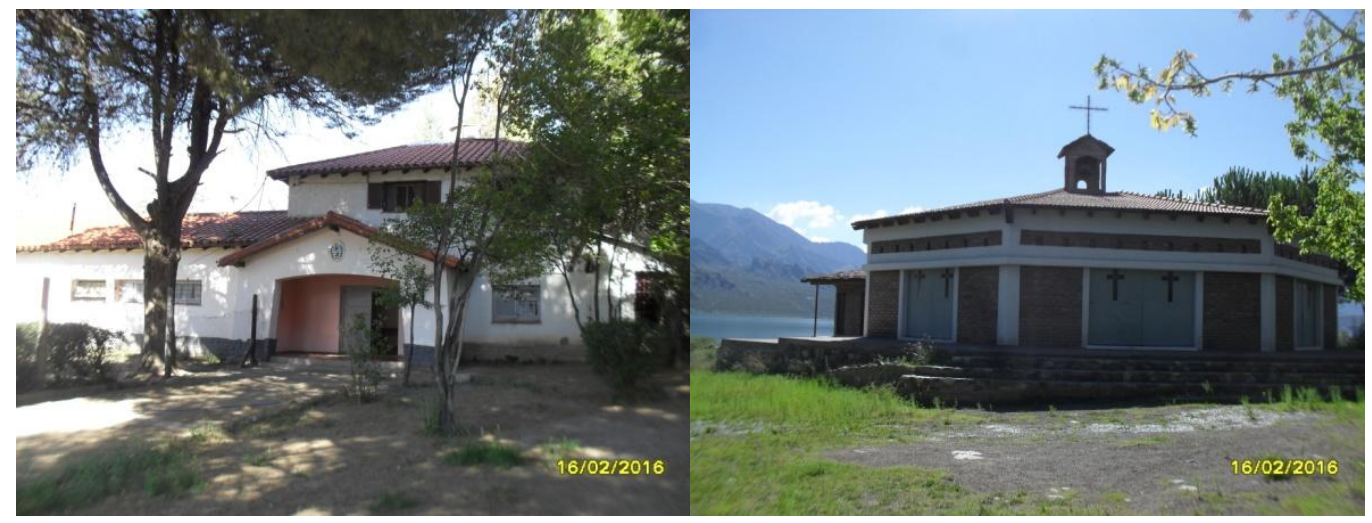

Imagen 30. La vieja escuela primaria de Potrerillos donde actualmente funciona un Centro de capacitación para el trabajo.

Imagen 31. La Iglesia Santa Teresa de Los Andes que no fue relocalizada. Fotos: Mariana Raffani

En cuanto a la Posta tradicionalista, donde se realizaban actividades relacionadas con caballos, no recuperó su lugar en el nuevo pueblo y la misma dejó de funcionar. Sobre ello se decía:

"a la posta, que era donde se reunían los gauchos nunca le dieron nada, que era el lugar más amplio, los que más terreno tenían eran los de la Asociación Gaucha de Potrerillos que era una que estaba enfrente del automóvil club, esos se quedaron sin terreno y eso si realmente es una manera de destruir las costumbres, entonces es una cuestión jodida porque ahí está el núcleo de las costumbres ancestrales de la gente de acá" (Presidenta de la Biblioteca Popular Armando Tejada Gómez, 09/04/2011).

Por otro lado, el Club Social y Deportivo Potrerillos, recibió un terreno en el que continúa realizando sus actividades, pero sigue a la espera de un lugar en el perilago para realizar actividades acuáticas. Sobre este se exponía:

"ellos si tenían un espacio que ahora está todo bajo el agua, unas cuantas hectáreas donde se desarrollaban, los chicos jugaban a la pelota, participaban en campeonatos sociales, tenían una conexión bastante interesante los jóvenes de Potrerillos con las otras poblaciones cercas, Luján, y eso ayudó a que nuestro jóvenes que hoy tienen 30, 40 años supieran que Potrerillos no era sólo Potrerillos, sino que cruzando la montaña te podías encontrar una ciudad, o sea te podías 
relacionar con otra gente, $(. .$.$) hoy están reclamando una porción o una salida al$ perilago para poder tener actividades de recreaciones con todo lo que se hace deportivamente en el perilago, pero acá no hay una decisión política institucional que diga bueno, el polideportivo es para los niños de Potrerillos lo vamos a hacer, esta la tierra" (Presidenta de la Asociación Avenida Los Cóndores, 21/09/2010).

De este modo, esta institución, tan significativa para el intercambio e integración de los jóvenes, espera la posibilidad de tener un acceso al perilago para aprovechar las ventajas que ofrece la obra en beneficio de los niños y jóvenes de la localidad.

Por último, en relación a la Estación del Ferrocarril, desde hacía 11 años antes del desalojo había sido salvada del desmantelamiento por Marta Carmona y Claudio Moyano que la convirtieron en la Biblioteca Popular "Armando Tejada Gómez", así como en el albergue del teatro "El tren", de un museo arqueológico y de una feria de artesanías. Este edificio fue desarmado identificando cada una de sus piedras y piezas (dinteles, ventanas, tímpanos, esquinas) y trasladado a la nueva casa del matrimonio, quienes quedaron a su cuidado hasta tanto la misma se pudiera reconstruir y dar valor patrimonial. Este fue uno de los espacios más lamentados por los miembros de la comunidad, como por los mendocinos en general que lo frecuentaban como lugar histórico de referencia.

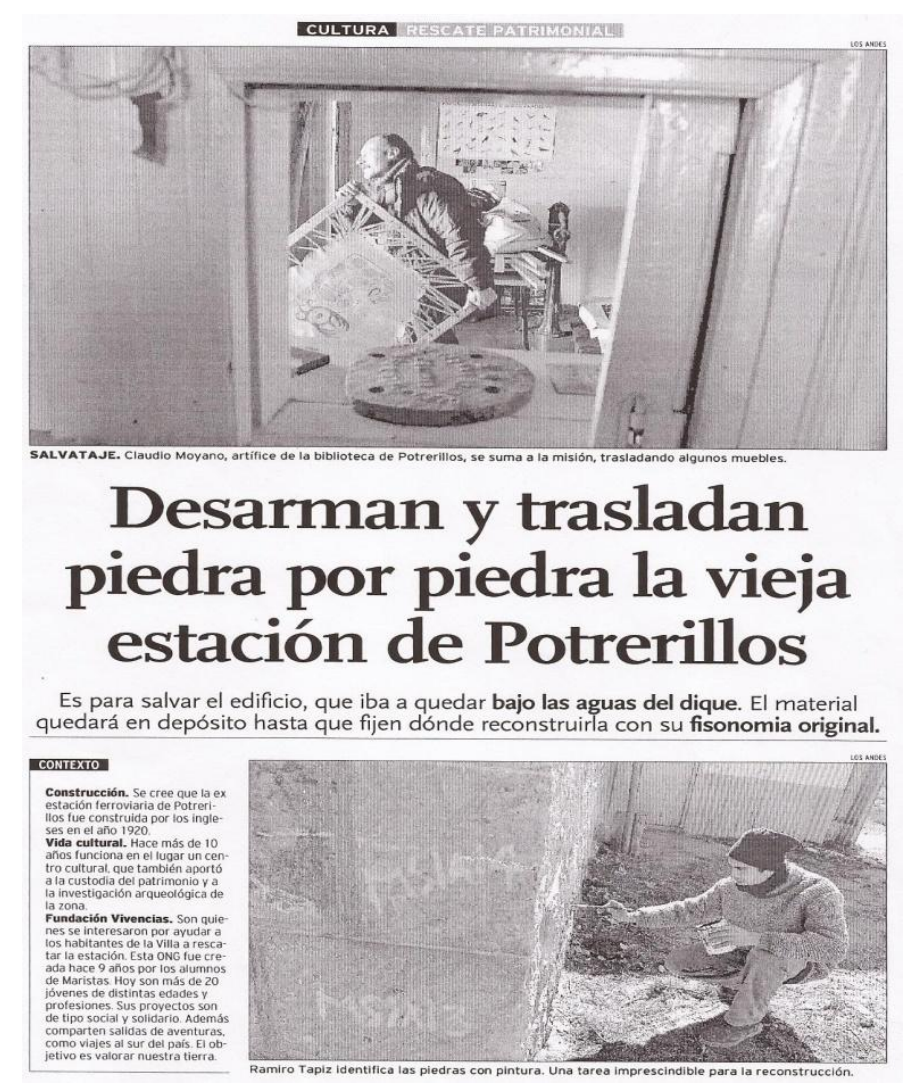

Fuente: Los Andes, 10/07/2002. 
El material de la biblioteca fue trasladado a un edificio construido en el nuevo barrio destinado a la Delegación municipal de Potrerillos, donde continúa funcionando pese a los numerosos pedidos de los vecinos al gobierno para que reconstruya la biblioteca en un lote asignado para ello, dentro del nuevo barrio. De este modo, el proceso en estudio tuvo su impacto en los espacios comunes de encuentro, recreación y formación de los pobladores y, en la mayoría de los casos, sus representantes aún siguen reclamando tierra y recursos para continuar brindando servicios a la comunidad o mejorar su calidad.

Por su parte, el Estado se dedicó a construir una escuela en el nuevo barrio donde funciona el nivel primario y secundario de escolaridad, así como un terciario y un Centro Integrador Comunitario (CIC) provisto de salones de usos múltiples y consultorios para que se traslade el Centro de Salud $N^{\circ} 34$ que atiende a la comunidad. Estos espacios pararon a ser utilizados por la población para reuniones vecinales como para la realización de eventos sociales. Así mismo, el edificio de la sede municipal para el distrito.

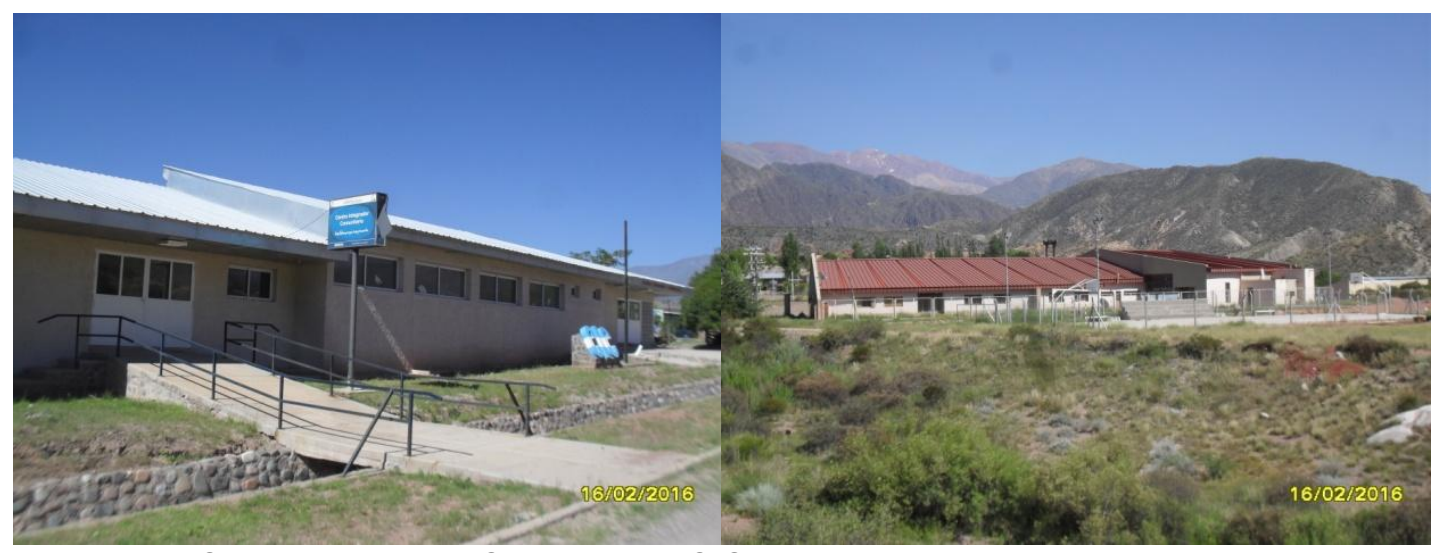

Imagen 32. Centro Integrador Comunitario (CIC).

Imagen 33. Actual Escuela Carlos Negri ubicada en el barrio donde funciona el nivel primario, secundario y terciario de educación. Fotos: Mariana Raffani

Para finalizar, hacemos referencia al cementerio, espacio que no fue afectado y alrededor del cual se planeó y edificó la relocalización; evitando el Estado, de esta manera, sumar más efectos perjudiciales a la comunidad ${ }^{23}$. Este espacio en sí mismo constituye un lugar de memoria, puesto que es el único lugar de conmemoración que perdura de la antigua villa.

Seguidamente, abordamos en los efectos sobre el lugar y la población de Cacheuta para finalmente poder establecer relaciones en las consideraciones finales.

\footnotetext{
${ }^{23}$ Ver ubicación del cementerio en mapa del barrio anexado al final de este trabajo.
} 


\section{CAPITULO VII \\ LOS EFECTOS EN CACHEUTA Y SUS POBLADORES}

En el caso de Cacheuta, los pobladores no fueron oficialmente relocalizados, sin embargo, a partir del ordenamiento territorial realizado por el Estado provincial en torno a la presa, el lugar quedó localizado en un nuevo contexto geográfico - funcional, en el que a causa del corte y desvío de la Ruta nacional $\mathrm{N}^{\circ} 7$ se vieron afectadas las estrategias de subsistencia, como la accesibilidad de los pobladores a los servicios de salud y educación.

Así también, a partir de la instalación de la obra, el lugar fue escenario de una dinámica espontánea de crecimiento de la población y ocupación del territorio sin intervención estatal, proceso que pasamos a narrar, aludiendo al relato de habitantes y funcionarios, como a fuentes periodísticas y fotográficas.

\section{Sobre el lugar de antes: "era más tranquilo (...) había turismo de paso"}

A partir de la instalación de la obra, en Cacheuta se puede ver un impacto socio-territorial diverso del que se presenta en Potrerillos. Para poder dimensionar el impacto comenzamos con el relato de una pobladora de 65 años nacida en el lugar, cuyo padre llegó al mismo como trabajador del ferrocarril. Ella decía:

"Éramos pocas familias, contadas con los dedos, los autos que pasaban por la ruta internacional, paraban, compraban pero no se quedaban. Había una carnicería, una verdulería, una librería, un club. Mi papá tenía un bar donde tomaban algo los pasajeros que paraban en la estación del tren y después se iban. Teníamos la escuela primaria que fue donada por la señora Victoria Aguirre junto a otras casitas que tenía la escuela. Así se llamaba la escuela, "Victoria Aguirre" hasta que fue cerrada en el año 85 por los pocos alumnos que tenía, entonces mandamos a los niños a la escuela de Potrerillos. Casi todos acá trabajaban en el Hotel de Cacheuta, en el más grande, en el primero -antes del aluvión- y recuerdo que nosotros, los del pueblo íbamos a ver cuando venía alguien al hotel, tenía una araña -lámpara colgante- gigante, era muy bonito" (Pobladora 7, 02/02/2016).

De este modo, Cacheuta era un paraje compuesto por una población pequeña, cuyas estrategias de subsistencia dependían de la actividad del ferrocarril -cuando este funcionaba- como de la presencia del Hotel Cacheuta en el que se empleaban. Así mismo, asociado al tránsito vehicular de la Ruta 7 , de turistas y de transportistas de carga internacional parte de la población se dedicaba a la venta de productos sobre esta arteria vial. En relación a esto último, otra pobladora nacida y criada en el lugar, agregaba: 
"Era más tranquilo, había turismo de paso, el turismo no estaba desparramado como ahora, íbamos a la escuela primaria y al centro de salud en Potrerillos. No era un polo turístico como ahora" (Pobladora 8, 02/02/2016).

Haciendo una comparación con el momento actual del paraje, en el que profundizaremos posteriormente, la entrevistada alude a que la vida de aquel lugar de antes era pacífica y aunque debían trasladase diariamente alrededor de $12 \mathrm{~km}$ para asistir a la escuela o cuando lo necesitaban al centro de salud de Potrerillos, vivían tranquilos y con estas necesidades cubiertas.

En el lugar, aludiendo a las mismas, había el Club social y deportivo Cacheuta en el que realizaban actividades recreativas y deportivas, una pensión-bar y el cementerio, así como un comercio de carnicería, verdulería y librería del que se proveían los pobladores durante el año; y en los meses de verano se vendían regionales destinados a turistas.

Pasando ahora a nuestro tema de estudio, en relación al momento de la llegada de la noticia de la construcción de la presa hidroeléctrica, se relataba:

"Cuando llegó la noticia el pueblo tenía mucho miedo de que el paredón se rompa porque este -alude a Cacheuta- es el primer pueblito abajo del dique" (Pobladora $8,02 / 02 / 2016)$.

De esta forma, al igual que en Potrerillos la presencia de la noticia sobre la construcción de la obra, en sus comienzos y a lo largo de su ejecución, se vivía con miedo e incertidumbre por parte de los pobladores afectados, aspectos que refieren al "stress multidimensional de relocalización" (Scudder y Colson, 1982). A continuación, pasamos a narrar lo sucedido a partir de la instalación de la presa.

\section{El impacto del corte y desvío de la ruta 7}

Como se ha mencionado, el corte y desvío de la Ruta 7, obra que hacía parte del plan de ordenamiento territorial del perilago, generó efectos sobre las economías de subsistencia de los pobladores de los distritos de Cacheuta y Potrerillos. En el caso de Cacheuta, la localidad quedó desconectada y aislada del circuito turístico-comercial que integraba junto a otros parajes de montaña que se sucedian a lo largo de la ruta con destino al país de Chile. De esta forma, el lugar dejó de ser un paraje de "paso obligado" de turistas y trabajadores del transporte de carga internacional quedando ubicado -desde la ciudad de Mendoza- como destino final de la Ruta provincial 82.

El corte de la ruta generó que el arribo de personas al lugar comenzara a disminuir, lo cual afectó las estrategias de venta de los pobladores así como produjo el aislamiento de 
los mismos de los servicios de salud y educación que recibían en la localidad de Potrerillos. Es decir, con la llegada de la obra, de situarse aproximadamente a $12 \mathrm{~km}$ de distancia de éstos servicios, pasaron a tener que trasladarse $30 \mathrm{~km}$ para poder recibirlos en el distrito cabecera del Departamento de Luján de Cuyo.

De esta forma, quedaron localizados a más de $70 \mathrm{~km}$ de Villa Potrerillos, lugar al que los pobladores concurrían a participar de actividades de integración social como fiestas o campeonatos de fútbol que se realizaban entre los clubes deportivos de los lugares. A partir de esta interacción, es que más de una familia se compone de pobladores procedentes de ambos parajes y con la llegada de la obra quedaron físicamente alejadas. Este cambio territorial afectó las estrategias de subsistencia no solo de los pobladores de Cacheuta, sino también de los distritos de Las Compuertas y Blanco Encalada, también localizados sobre la ex ruta internacional.

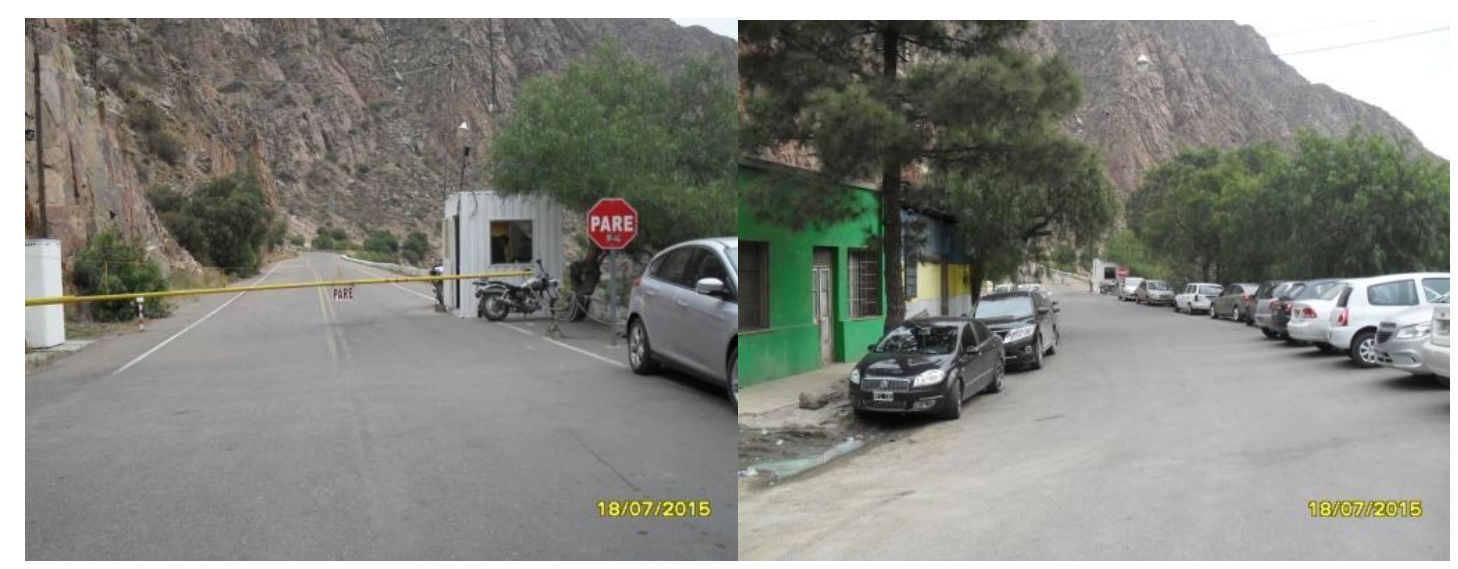

Imagen 34 y 35 . Hasta donde llega la Ruta provincial $\mathrm{N}^{\circ} 82$, ex Ruta nacional $\mathrm{N}^{\circ} 7$. Fotos: Mariana Raffani.

Debido al acrecentamiento de las distancias hacia los centros proveedores de servicios públicos y privados, en relación al aumento del costo de los traslados, una pobladora de Cacheuta recordaba:

"Por un tiempo, casi dos año, la empresa CEMPPSA nos entregó pases gratis de colectivos a todos los habitantes de Cacheuta porque se nos encarecía ir a Luján" (Pobladora 8, 02/02/2016).

Así también, haciendo referencia a los planes de mitigación implementados por el Estado sobre esta población, la misma entrevistada exponía:

"Desde el área de comercio del gobierno, se dejó de cobrar impuestos" (Pobladora 8, 02/02/2016). 
De esta forma, el pago de los boletos por un tiempo por parte de la empresa constructora, así como el permiso de parte del gobierno para que los pobladores que poseían negocios reduzcan sus gastos al no pagar impuestos fueron los paliativos brindados por parte de los responsables de la obra a los afectados de Cacheuta. Podemos ver así, lo limitado y circunstancial de la respuesta estatal para esta localidad y sus habitantes que vieron afectadas sus fuentes de ingresos por el corte del tránsito vehicular.

A continuación ahondamos en las acciones colectivas realizadas por los pobladores que se hicieron públicas en los medios de comunicación a fin de exponer sus necesidades y solicitar la presencia del Estado.

\section{1 "estamos marginados" y "esperando desde hace años"}

A razón del incumplimiento por parte del Estado de la habilitación de la arteria vial alternativa "para no afectar la conexión entre Cacheuta y Potrerillos" anunciada en 1998 en la Declaración de Impacto Ambiental, en el año 2003 vecinos de la localidad exponían de la siguiente manera las consecuencias del corte de la ruta sobre sus economías:

"Estamos marginados desde que la ruta a alta montaña y a Chile ya no pasa por aquí, debido a la construcción del dique Potrerillos. Entre semana casi no circulan autos y apenas hay un poco de movimiento los domingos, por lo que las ventas de servicios menores (pan, leña, etc.), comidas, combustibles y artesanías están en su mínima expresión".

"Hace 5 años que nos prometen una solución pero el puente nunca se hace" (Los Andes, 18/05/2003).

\section{Dos distritos aislados tras la construcción del dique Potrerillos}

Los pobladores de Las Compuertas y Cacheuta piden un puente para poder salir a la ruta internacional. La zona tiene cada vez menos movimiento.

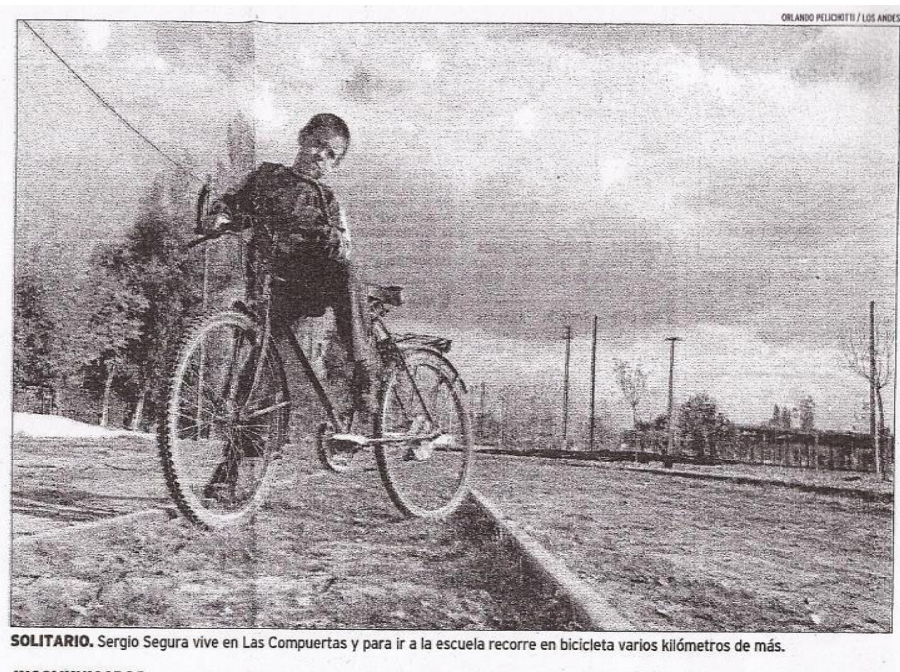

Fuente: Los Andes, 18/05/2003. 
De esta manera se manifestaba el descontento de la población afectada, que a través de los años continuaron reclamos en los medios locales de comunicación a la espera de la construcción del nuevo tramo de la Ruta provincial 82 que uniría a ambos lugares.

En el año 2005 aludiendo a la promesa, los pobladores reclamaban nuevamente:

"Es lo que estamos esperando desde hace años. Con la presa para nosotros se cortó todo. Esperamos que esto traiga nuevamente a los turistas. En este tiempo hemos aprendido a salir adelante"

"Antes a este lugar venían miles de personas todo el año. Ahora sólo los fines de semana de verano viene gente, tenemos muchas esperanza en el camino" (Los Andes, 27/08/2005).

El entusiasmo por la llegada de la esperada obra, se manifiesta también entre los habitantes de Las Compuertas y Blanco Encalada, distritos también afectados por el corte de la ruta. Una vez más, tras 12 años de espera los vecinos realizaron lo que denominaron un "corte simbólico" sobre Ruta 7, a la altura de la cárcel Alma Fuerte, solicitando que se finalice con la pavimentación de los metros que faltan para que concluyan con el proyecto definitivamente. En esta oportunidad, los vecinos denunciaban:

"Lo que pedimos es que el Estado se haga cargo porque es su obligación (...). "Esta protesta no significa que estemos en contra del gobierno, sino a favor del progreso. Si por ejemplo ocurre un accidente grave en la ruta y hay que trasladar a la persona la demora es muchísima. Con la obra la ambulancia podría llegar más rápido y tal vez le podés salvar la vida a una persona" (Poblador de la zona).

"Esta situación nos perjudica a todos, estamos estancados y no tenemos nada cerca. A los chicos los tenemos que mandar a la escuela de la villa (Potrerillos) y encima sólo tenemos una línea de micro con pocas frecuencias (Presidente de la Unión Vecinal Puente Colgante Cacheuta).

"Queremos una solución, ya que la comunicación de las rutas está prevista desde que se inauguró el dique (en 2001). En invierno, cuando las temperaturas son muy bajas, se congela el desvío del túnel. Quedamos varados y hay que esperar que venga Vialidad y lo limpie (...). A veces se producen embotellamientos y los policías de tránsito no pueden controlar las enormes colas de autos que se generan" (Integrante de la Asociación Aires de Montaña). (Los Andes, 22/04/2012).

De este modo los vecinos reclamaban por la falta de accesibilidad a los servicios de salud y educación, así como por las condiciones de trabajo, que sería posible revertir a través de la culminación de la artería de conexión entre las localidades, así como por la mantención en buen estado del camino que utilizan para llegar a la ciudad de Mendoza o al distrito cabecera de Luján de Cuyo. 
MANIFESTACIÓN

\section{Otro reclamo en Cacheuta}

para que terminen la

\section{ruta del lago}

Vecinos se manifestaron ayer pidiendo que se completen los 400 metros que faltan para unir el distrito con Potrerillos. La obra lleva más de una década y, pese a

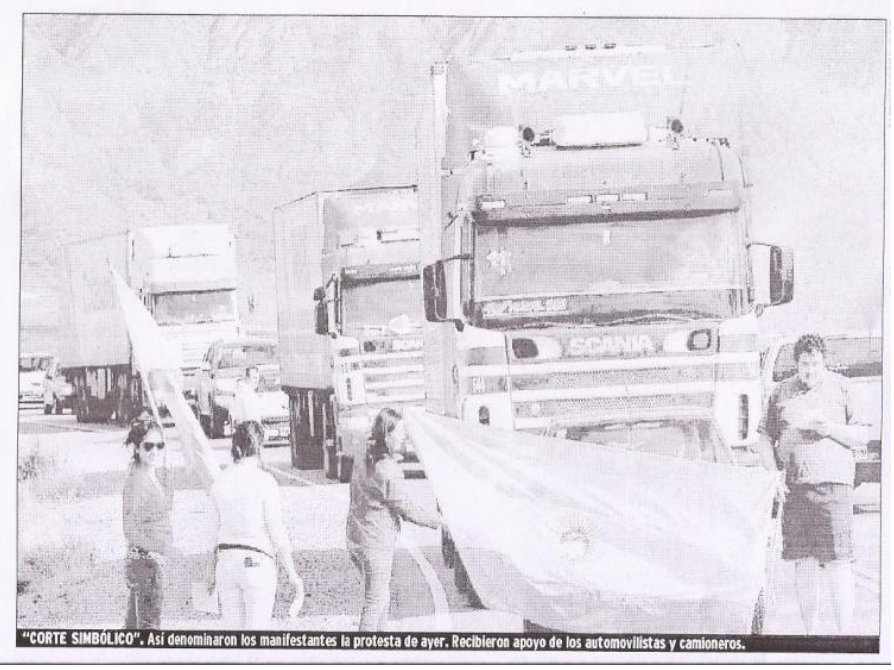

Fuente: Los Andes, 22/04/2012

A través de los años, se sucedían estos reclamos y demandas de los pobladores, así como el Estado provincial continuaba prometiendo una y otra vez la reapertura del túnel. Sobre esto nos centramos a continuación.

\subsection{Promesas}

Mientras la población reclama entre otras cosas por la pérdida de sus fuentes de trabajo, el gobierno priorizaba la terminación de la ruta 7 que unía las ciudades de Mendoza y Santiago de Chile; y en el 2005 se anunciaba la construcción del camino que circunda una parte del espejo de agua, o sea los dos primeros tramos de la ruta 82 que en un futuro cuando decidan realizar el tercer tramo- volvería a conectar a Cacheuta y Potrerillos (Los Andes, 27/08/2005).

Este tercer y último tramo de carretera conlleva la explotación de una montaña para la realización de un túnel. Sobre esto, durante tres períodos gubernamentales, desde el inicio de la obra, se sucedieron anuncios sobre su concreción pero constituyeron promesas incumplidas. En el 2006, la ruta del perilago fue licitada por el gobierno de Julio Cobos y pagada por el Banco Interamericano de Desarrollo (BID), pero en el 2008 uno de sus tramos quedó paralizado. Luego Celso Jaque, en el 2010 aseguró que concretarían la obra, pero en nada se avanzó (Los Andes, 27/11/2010). Finalmente en el gobierno de Francisco Pérez, en un contexto de campaña política, el 6 de marzo de 2015 nuevamente se anunció la ejecución de la obra y se encarteló con la noticia el lugar de Cacheuta, prometiendo la finalización de la misma para el próximo mandato de gobierno. 


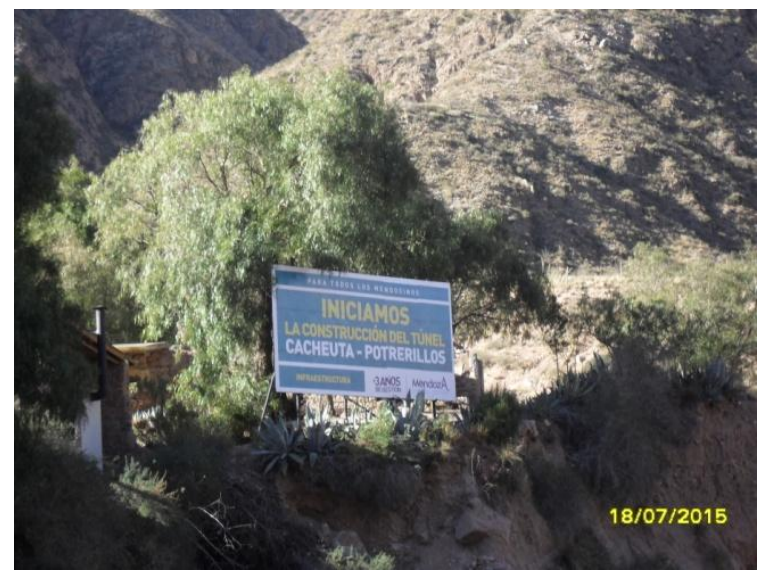

Imagen 36. Cartel colocado por el gobierno en Cacheuta que anuncia el inicio de la construcción del túnel. Foto: Mariana Raffani

Sobre esta promesa, al momento de esta investigación una pobladora exponía:

"La ruta 82 quedó en la nada, a pesar de que el gobierno ha puesto carteles eso no es real, está evaluando si lo va hacer o no porque acá no hay plata -refiere al Gobierno de la provincia-. Tal vez se reconstruya la ruta 82 para llegar a Cacheuta pero no la del túnel" (Pobladora 8, 02/02/2016).

En resumen, el tercer tramo de la ruta que uniría a Cacheuta y Potrerillos sigue siendo esperado, ya que ningún mandatario, independientemente de su color político, concluyó la obra prometida en 1998 en la Declaración de Impacto Ambiental. Debido a la situación financiera de la provincia se cree que tampoco se pueda concluir en el período del gobierno en curso de Alfredo Cornejo. Sumado de estos efectos producidos por el corte y desvío de la Ruta 7, la construcción de la presa generó en la localidad otros impactos socio- territoriales. Sobre estos ahondamos en el próximo apartado.

\section{El crecimiento de la población y la ocupación del territorio}

3.1 Alrededor de los rieles: tierra, techo y trabajo

El fenómeno de la obra, como PGE que se caracteriza por el gigantismo, el aislamiento y la temporariedad como define Lins Ribeiro (1987) significó, aludiendo a los testimonios, una gran fuente de trabajo temporario para muchas personas del lugar así como para personas procedentes de otros lugares que durante la construcción residían en los obradores que había construido CEMPPSA para los trabajadores, ubicados a pocos kilómetros del paraje de Cacheuta.

Este hecho de atracción de mano de obra, propició el comienzo de una nueva dinámica de poblamiento del lugar, ya que parte de quienes procedían de otros destinos eligieron 
quedarse y empezar a construir sus viviendas, en algunos casos utilizando materiales como durmientes y rieles del ferrocarril que habían sido sacados del vaso del embalse, apilados y abandonados en el lugar por el Estado. De este modo, motivado por la necesidad de trabajo y vivienda, comenzó a formarse un asentamiento espontáneo sobre tierras fiscales pertenecientes al ferrocarril.

Por otro lado, motivados por la lógica del mercado, este lugar rodeado de montañas fue visto como una oportunidad con fines comerciales e inmobiliarios por parte de particulares y empresas -algunos procedentes de otras provincias- que sobre la ribera del Río Mendoza fueron construyendo emprendimientos turísticos y recreativos como clubes y camping, complejo de cabañas, restaurantes, pub, minimarket y negocios de ventas de artesanías, además de playas de estacionamiento para vehículos. De esta forma, con la llegada de familias y negociantes de otros lugares creció la población de Cacheuta llegando a sumar entre 250 y 300 personas aproximadamente, según manifiesta una pobladora, que no cuentan con la instalación de redes de agua, luz y cloacas. Sobre la instalación de los nuevos habitantes y emprendimientos, una pobladora que vive en el lugar desde mucho tiempo antes de la llegada de la obra relataba:

"La invasión de produce por la fuerza, avasallar es la palabra" (Pobladora 7, 02/02/2016).

Con esta frase, la misma alude al atropello que sienten los antiguos pobladores ante la llegada descontrolada de los nuevos, lo cual es vivido como una invasión y, pese al crecimiento turístico, un deterioro del lugar. De este aspecto se pude deducir, que esta población -como la de Potrerillos- a partir de la instalación de la obra ve afectada sus redes y espacios de integración social.

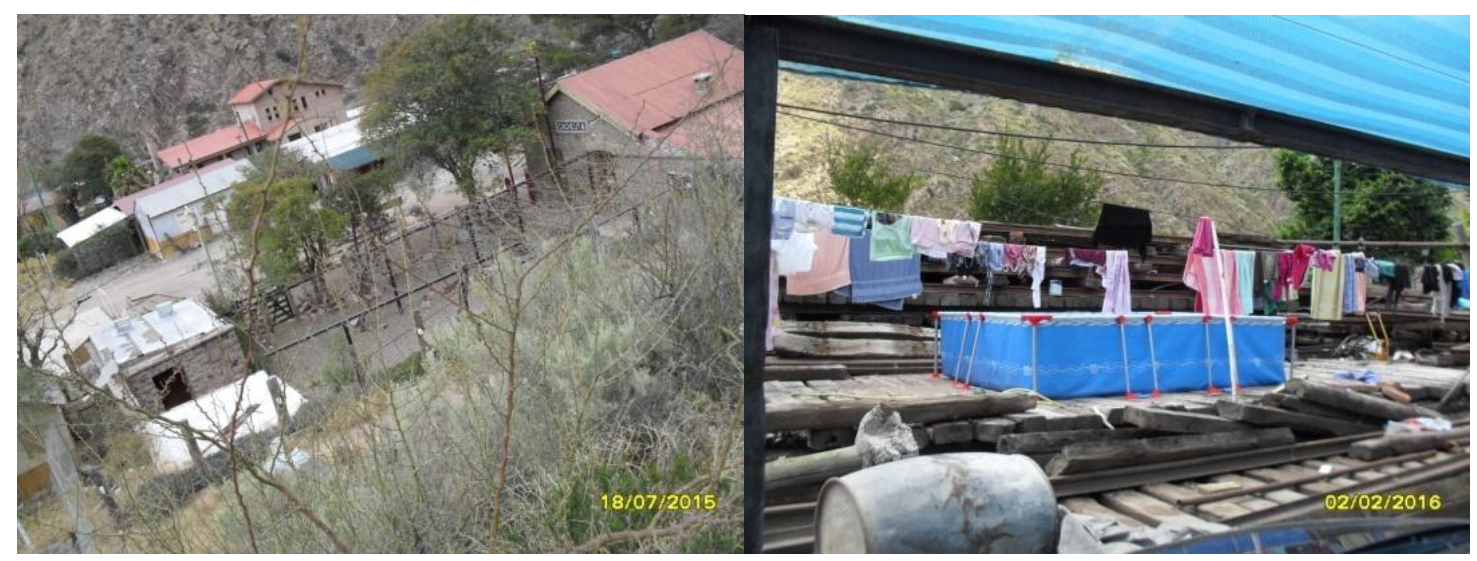

Imagen 37. Construcción de viviendas alrededor de los edificios de la ex - Estación del ferrocarril. Imagen 38. Patio de una vivienda sobre rieles y durmientes. Fotos: Mariana Raffani 

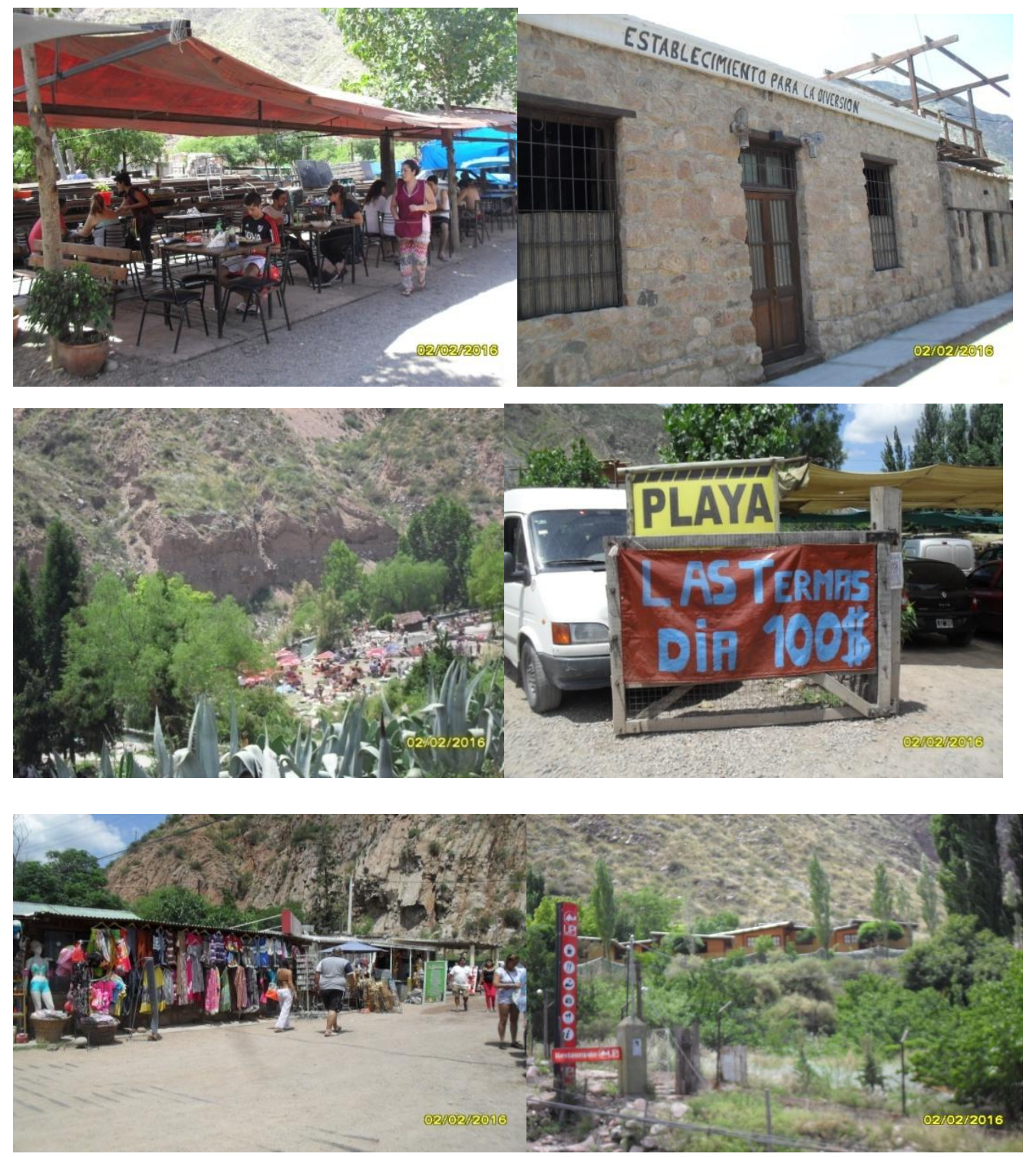

Imagen 39, 40, 41, 42, 43, 44. Emprendimientos turísticos: restaurante y pub, alojamientos, camping, playas de estacionamiento, comercios. Fotos: Mariana Raffani

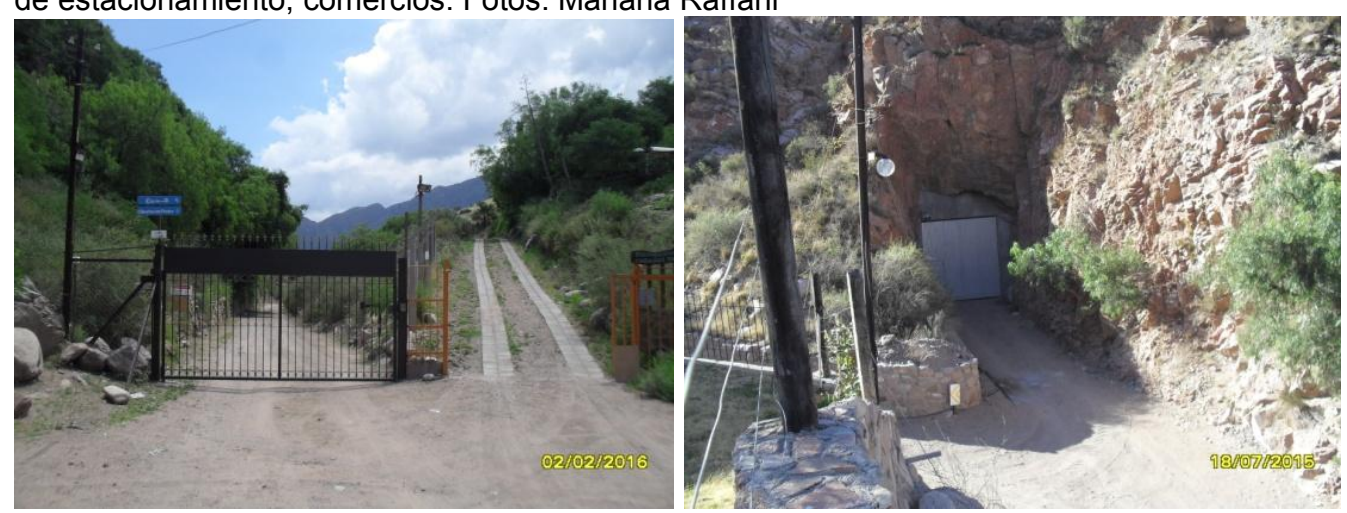

Imagen 45. Cierre del camino por donde circulaba el tren, hoy entrada de un establecimiento privado. Imagen 46. Cierre del túnel del tren, al que se podía visitar caminando, hoy territorio de emprendimiento privado. Fotos: Mariana Raffani 
De esta forma, unos motivados por la necesidad de vivienda y trabajo, y otros por la lógica del mercado fueron generando un asentamiento y, como expone una entrevistada, un turismo desordenado estimulado por la especulación sobre el desarrollo que el proyecto en los papeles y en los medios prometía; dinámica de crecimiento que no fue acompañada por la presencia estatal por tanto se sucedieron hechos que atentan contra la seguridad y garantía de derechos, así como de obligaciones de antiguos y nuevos pobladores. Sobre esto ahondamos a continuación.

\subsection{Sobre los espacios públicos de la localidad}

Hay una serie de aspectos, vinculados a los espacios y/o instituciones públicas que constituyen negligencias y omisiones de parte del Estado para con el lugar y la población de Cacheuta, lo cual da cuenta de los límites del proyecto de desarrollo, que no previó el impacto socio-territorial en esta localidad.

\subsubsection{La in-comunicación}

El primer problema mencionado a la hora de realizar las entrevistas fue el vinculado a la comunicación vía telefonía celular, ya que en la zona no cuenta con señal que le permita a los pobladores estar comunicados. Este problema de incomunicación radica también en la ausencia de teléfonos públicos en buen estado, así como de telefonía fija en la posta sanitaria, única institución oficial destinada a la población.

\subsubsection{La escuela y el cementerio: ex - espacios públicos}

Aludimos a la carencia de escuelas primaria y secundaria que tiene el lugar, lo cual lleva a que los niños, adolescentes y jóvenes que quieren estudiar deban trasladarse $30 \mathrm{~km}$ hasta el distrito cabecera del Departamento de Luján de Cuyo o un poco menos, hasta la escuela de Blanco Encalada en el caso de estudiantes de nivel primario. Esta situación se agrava porque el edificio de la escuela "Victoria Aguirre" y casitas aledañas que habían sido donadas por la persona que lleva el nombre, perteneciente al Gobierno de Mendoza fue entregado por el Honorable Consejo Administrativo de Enseñanza Pública y por el Intendente de Las Heras en el año 2001 a un emprendedor privado para la realización de un complejo de cabañas, salón de eventos, canchas deportivas y pileta destinado a recibir contingentes y particulares. Es decir, la escuela que se había cerrado por la poca cantidad de niños no puede ser reabierta ahora que la población creció porque pertenece a manos 
privadas. De esto se deduce que el Estado para garantizar el derecho a la educación de la población debería instalar como mínimo aulas satélites en el lugar, o en su defecto expropiar este lugar para el bien común de la comunidad.

Las siguientes fotos muestran la ex escuela y casitas aledañas que hacía parte de la misma, así como las placas ubicadas en el mástil que dan cuenta de su fundación en el año 1917, y del apoyo y agradecimiento a la misma de parte de padres de la cooperadora, del Club deportivo de Cacheuta y de los ex -alumnos de la escuela durante su funcionamiento por más de 50 años.

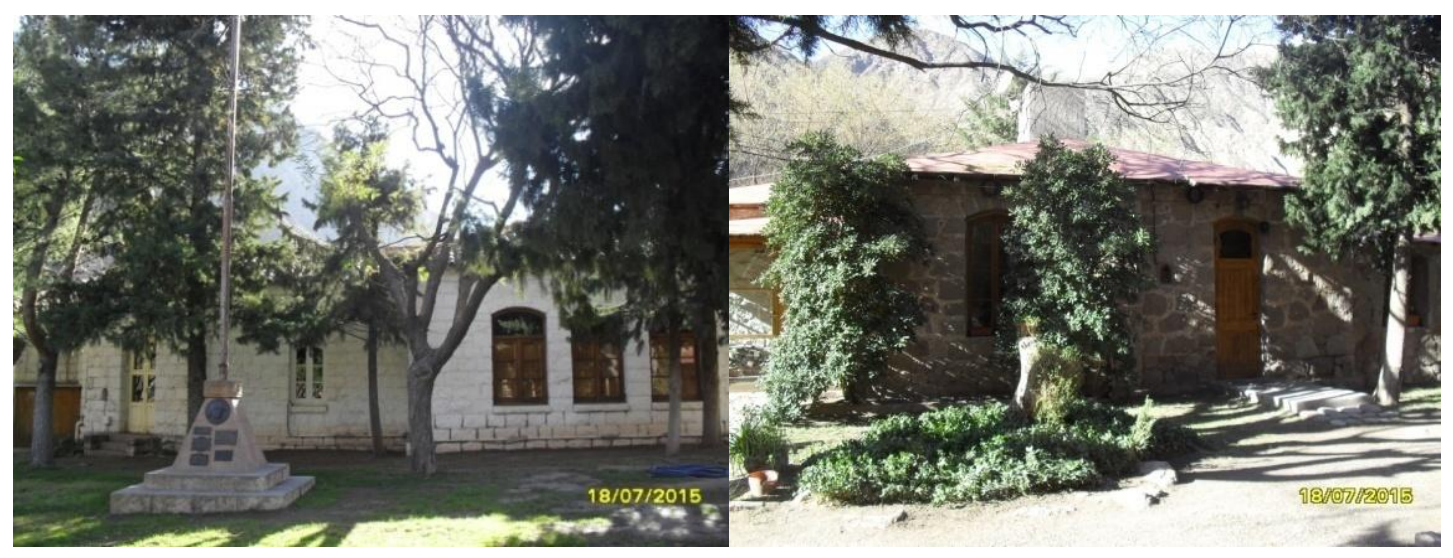

Imagen 47 y 48 . Ex escuela pública “Victoria Aguirre”. Fotos: Mariana Raffani
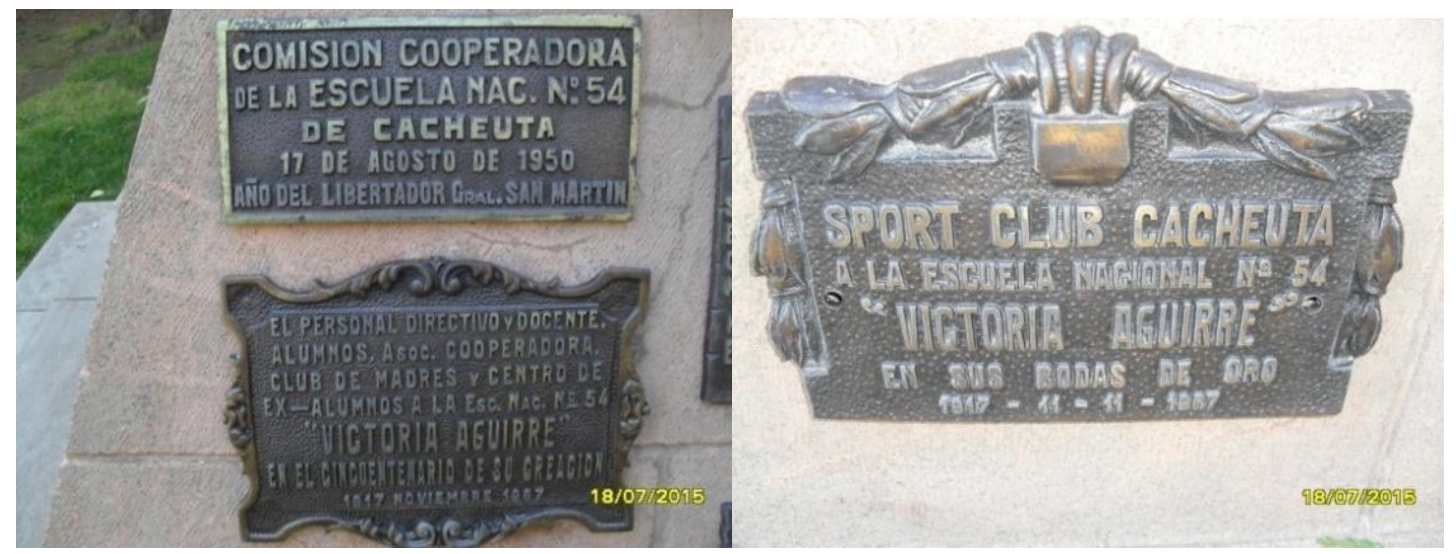

Imagen 49 y 50 . Sobre el mástil de la escuela 1. Fotos: Mariana Raffani

Así también en el mástil de la escuela se ubican las placas de agradecimiento del grupo emprendedor a los funcionarios públicos que les cedieron el establecimiento en el año 2001. Las exponemos a continuación. 


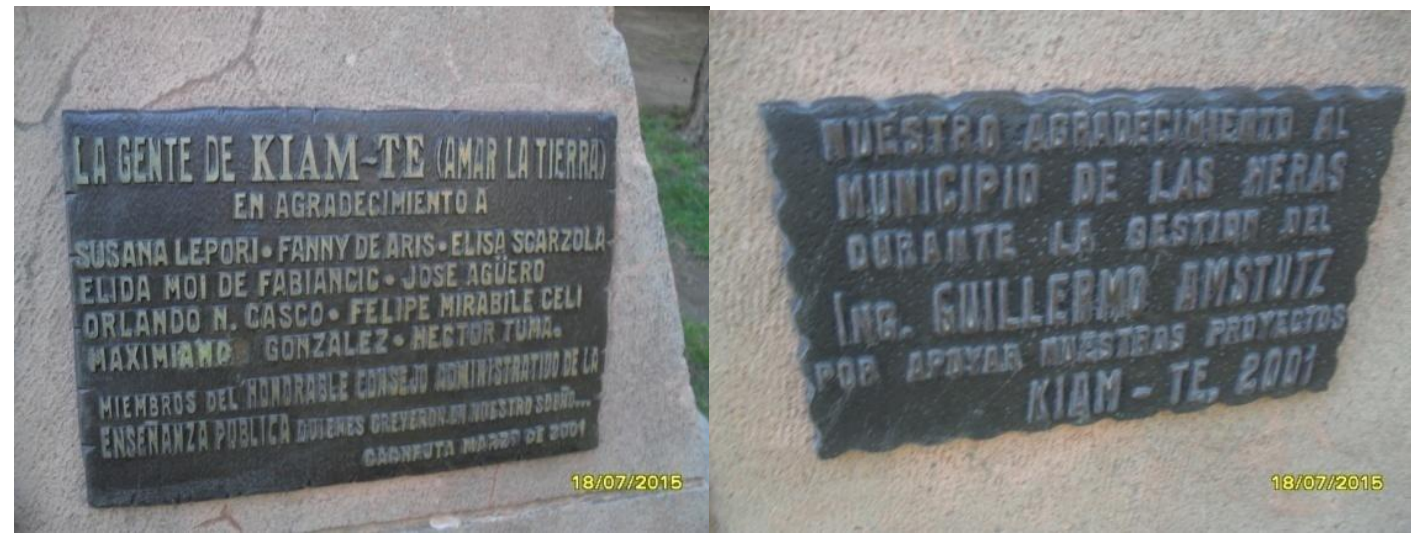

Imagen 51 y 52 . Sobre el mástil de la escuela 2. Fotos: Mariana Raffani

Otro espacio público afectado por el complejo mencionado es el cementerio del lugar, al cual no se puede libremente acceder porque ha quedado localizado dentro del cierre perimetral del mismo emprendimiento privado. Sobre esto una pobladora manifestaba:

"Al cementerio no se puede pasar si no lo autoriza el señor. No podemos ir a prender una vela o ponerle flores a nuestros familiares. Para pasar tenemos que sacar la chapa, decir que venimos del Ministerio de Salud" (Pobladora, enfermera de la Posta sanitaria, 02/02/2016).

Claramente, la pérdida de la entrada al cementerio afecta un lugar de memoria, al decir de Nora (1984) donde se "cristaliza y refugia la memoria" de los antiguos pobladores de la comunidad, al tiempo que les permite unir el presente con el pasado reciente y más lejano. De esta forma, los lugares públicos de la comunidad dejaron de serlo, pasando a formar parte de propiedades privadas.

\subsubsection{Por acción de los vecinos: la posta de salud, la plaza y el playón}

Debido al corte de la ruta, luego de quedar imposibilitados de acceder al centro de salud localizado en Potrerillos, fruto del esfuerzo de vecinos que conformaron la asociación sin fines de lucro "Aires de Montaña" lograron que el gobierno les construyera en el lugar el edificio para la posta sanitaria que desde antes de la llegada de la obra existía en el lugar. Sobre esta se contaba:

"La posta comenzó en 1996 en mi casa, después se trasladó a EDEMSA y finalmente a este edificio" (Pobladora y enfermera de la Posta sanitaria, 02/02/2016).

Actualmente funciona dos veces a la semana en horario de mañana y presta servicios de atención primaria. Es decir, que en caso de necesitar servicios de mayor complejidad los 
pobladores deben trasladarse hacia los centros de atención de Luján de Cuyo, así como en el caso de necesitar alguna medicación porque el lugar no cuenta con farmacia.

Por acción de los vecinos Cacheuta también cuenta con juegos de esparcimiento y un playón de cemento para realizar actividades deportivas. Sobre esto se comentaba:

"Con el esfuerzo de la asociación construimos un playoncito para los niños, pero acá no hay profes que vengan a dar clases, muchos no han terminado la primaria, ni la secundaria" (Integrante de la Asociación Aires de Montaña).

De este modo, ante la ausencia del Estado, los antiguos pobladores son quienes accionan alternativas para los niños y jóvenes. A continuación exponemos fotos que complementan este relato.

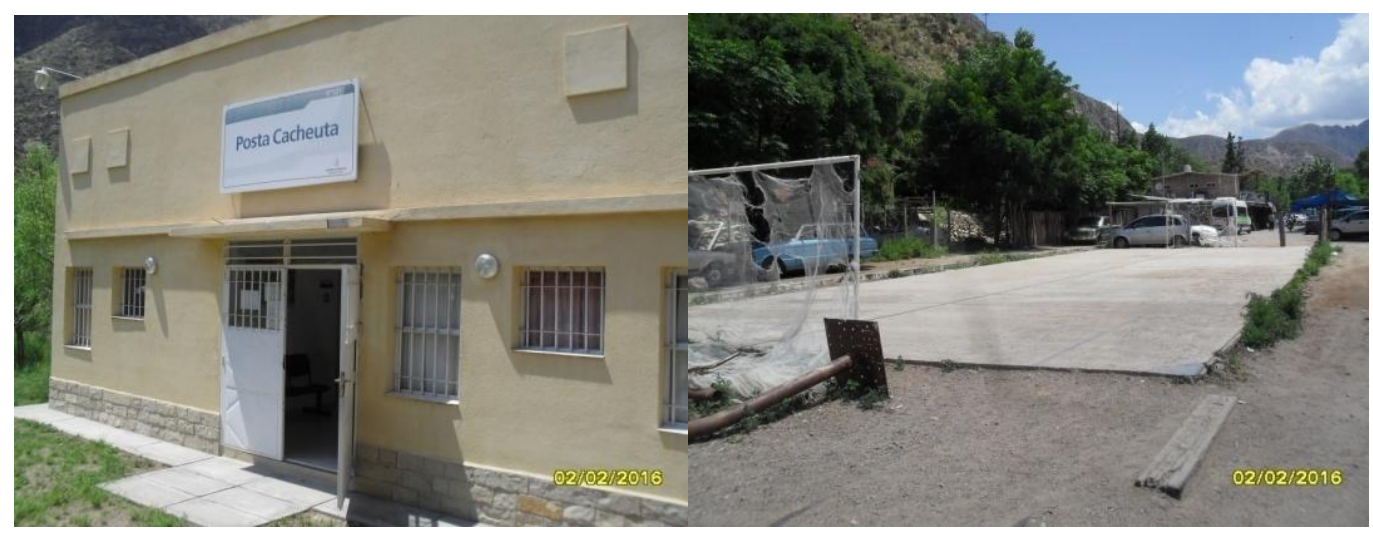

Imagen 53. La posta sanitaria abierta una mañana de Martes.

Imagen 54.El playón deportivo sobre las vías del ferrocarril. Fotos: Mariana Raffani

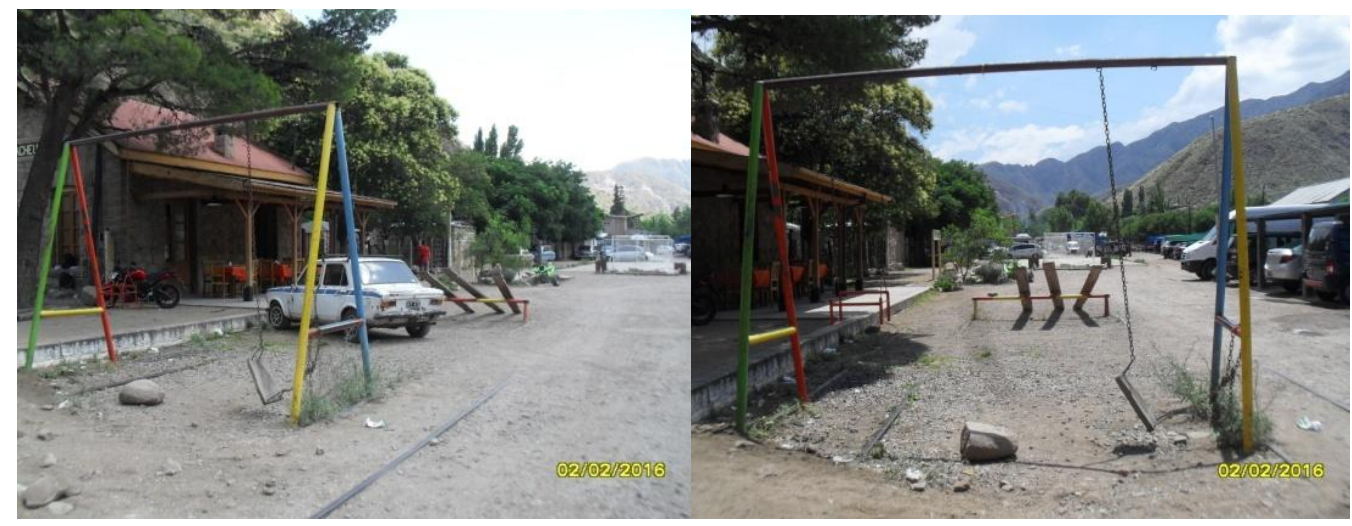

Imagen 55 y 56. Los juegos de esparcimiento para niños, al lado del tránsito vehicular. Fotos: Mariana Raffani

En función de lo expuesto y como las imágenes muestran, podemos ver que el servicio de la posta de salud es insuficiente considerando que presta servicios solo dos medios días de la semana, y que los juegos se encuentran rotos y ubicados al costado del paso vehicular, sobre el espacio de las vías del ferrocarril, único lugar no utilizado para el 
asentamiento de viviendas y/o emprendimientos; así también vemos como que el playón de cemento no cuenta con baldosas como tienen las canchas deportivas. De ello deriva, que sobre estos tres puntos mencionados, el Estado debería aportar recursos materiales y humanos para que la población cuente con equipamiento adecuado y acorde a la cantidad y necesidades de la población, dentro de las que se encuentran la prevención y promoción de la salud, ligadas al deporte, la recreación y la formación.

Para finalizar este aparatado sobre las acciones de los vecinos, ante la pregunta sobre cómo visualizan el futuro del lugar, las pobladoras entrevistadas respondieron:

"laburando como una hormiga el trabajo comunitario" (Pobladora, enfermera de la Posta sanitaria, 02/02/2016).

"si continuamos con la ausencia gubernamental va a ser remar en el barro, no es solamente la ausencia acá, es la ausencia en general" (Pobladora, integrante de la Asociación "Aires de Montaña”02/02/2016).

De esta forma, si bien las entrevistadas dan ejemplo de la lucha cotidiana que ejercen en defensa de los derechos de la población, la presencia irremplazable del Estado en el lugar es un anhelo de las mismas.

\subsubsection{Inexistentes}

En este apartado incluimos la falta de espacios culturales y formativos de la comunidad como una biblioteca popular y un salón de usos múltiples, ya que no existe lugar cerrado comunitario para la reunión de los vecinos.

Así también, aludimos a la carencia de sanitarios públicos como de accesos a la ribera del río gratuitos destinados a los pobladores así como a los visitantes y turistas que actualmente no pueden acercarse al río porque la ribera ha sido cercada por los emprendedores privados. El libre acceso existente es empinado, por el cual no pueden acceder personas con dificultades para caminar y es, además, un espacio elegido para el derroche de residuos. De este modo, el acceso a la margen del río queda reservado para quienes alquilan cabañas o entran al camping o club, es decir para quienes pagan.

Por último, hacemos mención al inexistente mantenimiento y control de la ex -ruta internacional, en la cual a la altura de la localidad, algunos pobladores cobran a turistas y visitantes el estacionamiento sobre la banquina. Estas infracciones como otras no son controladas ni reguladas por el Estado dando lugar a la presencia de negocios ilegales. 


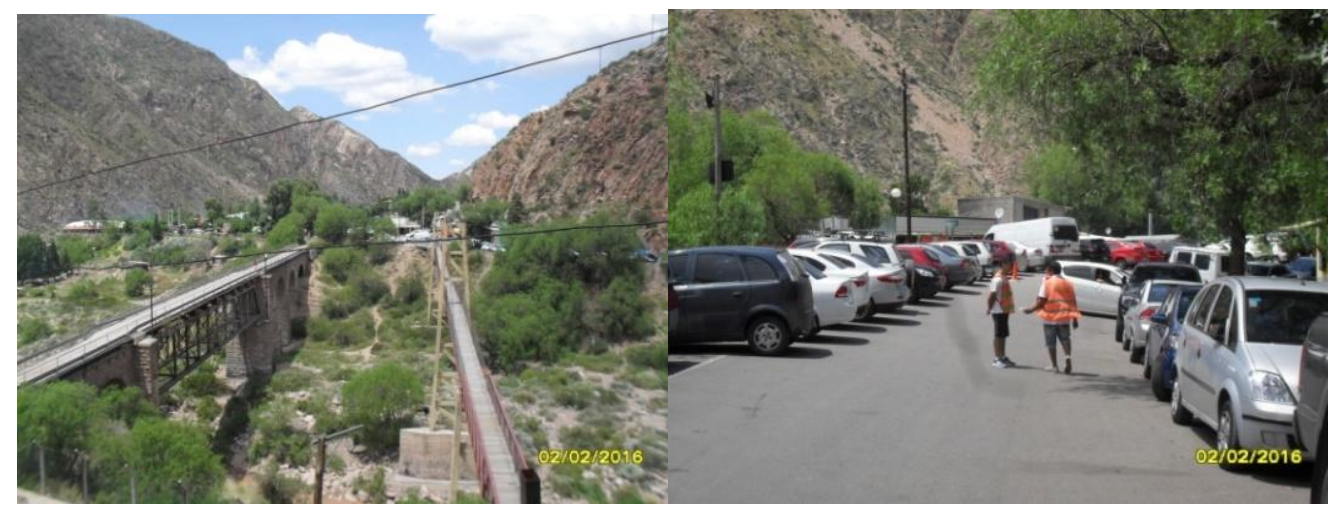

Imagen 57. Vista de la bajada al río de acceso público.

Imagen 58. Estacionamiento privado en la banquina de la Ruta $N^{\circ} 82$. Fotos: Mariana Raffani.

En síntesis, en todos los aspectos detallados la constante es la ausencia del Estado, llámese municipio de Las Heras, de Luján de Cuyo, Estado provincial o Estado nacional. Sobre esta ausencia se le pregunto a pobladoras por qué creían que el Estado no se hace cargo de prestar servicios en el lugar y sus respuestas fueron las siguientes:

"Somos una comunidad tan pequeña que no hay voto que mueva al gobierno" (Pobladora 8, 02/02/2016).

"No tenían -alude al Estado- visión de futuro de ver lo que iba a crecer Cacheuta, de planificar en infraestructura" (Pobladora 7, 02/02/2016).

La desatención del Estado según menciona una entrevistada, radica en que la cantidad de personas de la localidad no es representativa desde el punto de vista electoral, por ello la inversión pública no resulta de interés por parte de los gobernantes de turno. Por otro lado, otra entrevistada arguye a que el Estado no previó el impacto que la obra podría generar en el lugar. Para finalizar, incorporamos el testimonio de los funcionarios, lo cual nos permiten conocer su evaluación del impacto del proyecto sobre el lugar.

\section{3 "Cacheuta prácticamente ha tenido todo el impacto negativo"}

En cuanto a la localidad de Cacheuta, la directora del plan de ordenamiento manifestaba que ésta no se encuentra incluida en el proyecto de desarrollo del gobierno sobre el área del perilago. Así mismo, que desde tiempo antes de la construcción de la presa, existen problemas jurisdiccionales sobre el lugar derivados de la falta de definición del límite físico y político entre los departamentos de Las Heras y Luján de Cuyo. En palabras de la funcionaria:

"Cacheuta no está integrado en el proyecto del perilago de Potrerillos porque está enfrente del paredón, aguas debajo del dique (...) el perímetro de ordenamiento territorial terminaba en la pared del dique, entonces Cacheuta prácticamente ha tenido todo el impacto negativo porque no se lo planifico, porque atrajo inversiones 
que están mal ubicadas, es espantoso, vos no podes estar cobrando establecimiento en una ruta internacional, hay cosas que no funcionan y a eso no lo aborda ni Las Heras ni Luján porque los dos tienen competencia y ninguno tiene competencia porque no está definido el límite, porque en realidad creen que el límite es el río (...). Es muy conflictivo, entonces eso ha provocado que esa zona prácticamente esté totalmente desarticulada, las instalaciones son pésimas, se está deteriorando la ruta 82 porque nadie la atiende y se han empezado a desarticular las instalaciones que ya estaban, entonces es una zona como que se va envejeciendo y es una zona con gran potencial porque eso da al dique y es hermosa, (...) es una villa miseria, la gente se ha acercado porque hay trabajo pero no ha sido capaz de construir casas, provocada por esa inestabilidad e incertidumbre entre los municipios y el estado provincial" (Directora del Plan de ordenamiento territorial y desarrollo turístico del perilago, 23/03/2015).

De este modo, ningún sector del Estado se hace cargo de la localidad en términos de planificación e integración de los pobladores al desarrollo territorial y económico local, lo cual genera desde antes de la obra y aún más después, el deterioro del lugar, la ocupación y urbanización informal de las tierras, la construcción de viviendas precarias y la falta de provisión de servicios básicos para los pobladores. Esta situación no solo pone en riesgo la calidad de vida de los mismos, sino también la calidad del agua que se consume en el oasis norte de la provincia.

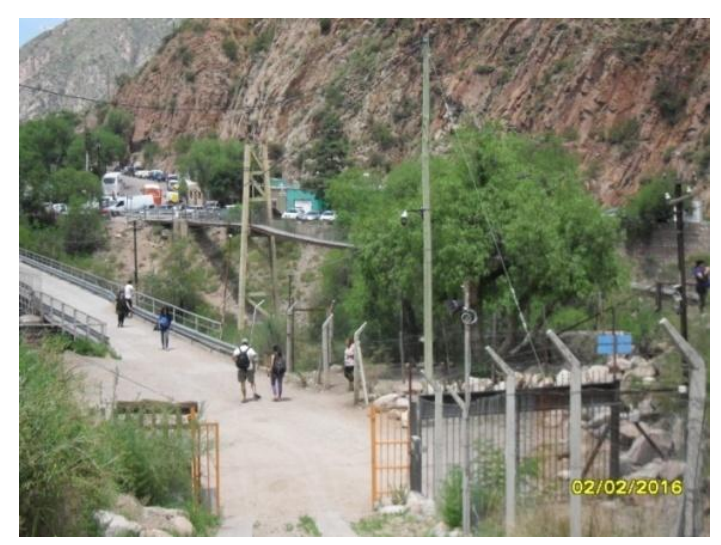

Imagen 59. De un lado y del otro del puente colgante. Cacheuta de Las Heras y Cacheuta de Luján. Foto: Mariana Raffani.

De este modo, se muestra la coexistencia de lógicas, tiempos, proyecciones y costosbeneficios diferenciales entre los actores partes de los procesos socio-territoriales en estudio. En otras palabras, se entiende que "En nombre de criterios de racionalidad económica se justifica que los "beneficios" ocasionados por el "progreso" de estas obras no se trasladen a la población más afectada" (Radovich, 2005:114). 


\section{REFLEXION FINAL: PARA NO CONCLUIR}

Con el propósito de contribuir, a partir del estudio de un caso, a la reflexión sobre los efectos de las políticas de desarrollo que, persiguiendo modelos/diseños globales, se emplazan en lugares concretos habitados, vemos que en el contexto de la fase neoliberal del capitalismo de la década del 90 y primeros años del siglo XIX, el impacto socioterritorial del proyecto de la Presa Potrerillos sobre las poblaciones de Cacheuta y Potrerillos manifiesta efectos diversos. Esto se debe a que Potrerillos fue incluido en el Plan de ordenamiento territorial y desarrollo turístico del perilago, elaborado por el Estado provincial; en cambio, Cacheuta, no fue incorporada en éste ni en ningún otro plan. De esto deriva, que los efectos analizados sobre los pobladores en uno y otro lugar se corresponden con acciones y/u omisiones del Estado promotor de la obra.

En el caso de Cacheuta, a causa del desvío de la Ruta nacional $\mathrm{N}^{\circ} 7$, obra incluida en el mencionado plan, los pobladores quedaron aislados del circuito turístico y económico de montaña que esta vía propiciaba entre las ciudades de Mendoza y Santiago de Chile, viendo afectadas sus economías de subsistencia, así como las prestaciones de salud y educación que recibían en la localidad de Potrerillos. Situación que los obliga a trasladase $30 \mathrm{~km}$ al distrito cabecera del departamento de Luján de Cuyo para recibir estos servicios. Así mismo, el proyecto de desarrollo incitó en la localidad un circuito migratorio propio. Un sector de quienes fueron empleados en la construcción de la presa, una vez que el emprendimiento terminó, movilizados por la necesidad de trabajo y vivienda se localizaron en la zona. Quienes también eligieron el lugar, pero en este caso especulando desde la lógica del mercado, fueron comerciantes y emprendedores inmobiliarios que construyeron cabañas de alojamientos, restaurantes, camping, playas de estacionamientos, etc. destinadas a turistas. De esta forma, comenzó a formarse un asentamiento espontáneo sobre las tierras del ex ferrocarril trasandino y la ribera del río Mendoza.

Esta dinámica de poblamiento y ocupación del territorio da lugar a una serie de acontecimientos que atentan contra los derechos y obligaciones del Estado, los empresarios, los pobladores, así como de los visitantes. Entre ellos podemos mencionar

que los lugares públicos de la comunidad, tales como la escuela y el cementerio, dejaron de serlo pasando a formar parte de una propiedad privada; el servicio de atención de la salud que brinda la posta sanitaria es insuficiente; los espacios de esparcimiento y recreación se encuentran en mal estado y mal localizados; así también se carece de espacios comunitarios de usos múltiples, de paseos y sanitarios públicos, como de redes 
de cloacas, agua, etc. De este modo, a causa de la instalación de la obra, en Cacheuta se manifiestan efectos habitacionales y sobre la propiedad de la tierra, sobre las economías de subsistencia y las redes de integración social de los pobladores; así como sobre los espacios públicos y el patrimonio cultural y de la memoria del lugar.

En resumen, aun cuando la localidad se encuentra registrada en los estudios oficiales dentro del 'área de mayor impacto del proyecto para la población local', por parte del gobierno provincial, así como de los departamentales de Luján de Cuyo y Las Heras, aquella no fue incluida en un plan de urbanización que pudo incluir inversiones públicas en equipamiento e infraestructura, regule las inversiones privadas e integre a la localidad al desarrollo territorial, económico y social local.

En relación a los impactos negativos de alcance local y temporarios anunciados en la Declaración de Impacto Ambiental en 1998, que se atenuarían previéndose obras alternativas para no afectar la comunicación entre Cacheuta y Potrerillos, éstas nunca fueron realizadas pese a los reiterados reclamos de pobladores y sucesivas promesas oficiales. En su lugar, las medidas de mitigación por los perjuicios ocasionados a los pobladores se limitaron a paliativos, por el lapso de un tiempo, a la entrega de boletos de transporte por parte de la empresa constructora y al no cobro de impuestos por parte del gobierno a los comerciantes perjudicados.

De este modo, aun cuando a partir de la obra se evidencia un crecimiento poblacional y numerosos emprendimientos turísticos en Cacheuta, a 15 años de la inauguración de la misma, debido a la ausencia y negligencia estatal, esto no se ha traducido en un desarrollo económico y social del lugar.

Por otro lado, en el caso de Potrerillos, área incluida en el Plan de ordenamiento territorial y desarrollo turístico del perilago, existe una variedad de efectos habitacionales y sobre la tenencia de la tierra dependiendo de la zona de residencia de los pobladores: quienes residían donde se instaló la obra, fueron relocalizados; parte de esta población emigró del lugar antes, así como después de ser relocalizados. Quienes residían en Av. Los Cóndores -zona aledaña al perilago- obtuvieron el título de sus tierras; y en los parajes altos de Potrerillos se produjo un crecimiento poblacional, así como de inversiones inmobiliarias y turísticas.

En cuanto a la relocalización, partiendo de que no surgió de una necesidad sentida y demandada al Estado sino que, por el contrario, los pobladores se resistieron al desalojo, los sectores encargados del gobierno, como ellos manifiestan, realizaron un trabajo con la intención de encantar y convencer a los afectados con la nueva vivienda y evitar que los 
mismos manifiesten públicamente el rechazo a la decisión arbitraria de tener que trasladarse. En este marco de tensión, la gestión de la solución habitacional es recordada y evaluada por los funcionarios entrevistados, como una intervención innovadora desde el punto de vista social, en cuanto a la metodología de relevamiento y compensación económica que propició la puesta en valor económico de lo tangible como de lo intangible de las familias afectadas, para luego descontarlo del valor de la casa adjudicada. Desde el punto de vista técnico, como una obra emblemática en la historia del IPV que implicó una construcción sobre un terreno irregular y de viviendas adecuadas a la zona de montaña, con un costo económico superior a las casas construidas en general por el IPV. Aun cuando esta intervención constituye un antecedente en materia de desalojo y relocalización a causa de proyectos de desarrollo en la provincia, la misma es también definida por los entrevistados en términos de "el mal menor" que el Estado les pudo haber causado a los habitantes desalojados.

Por otro lado, considerando el testimonio de los relocalizados sobre la solución habitacional, podemos decir que, dependiendo de las heterogéneas situaciones socioeconómicas previas de los pobladores, existen discrepancias sobre los valores económicos surgidos de la evaluación de las casas para efectuar la compensación económica, lo cual repercute en la deuda que los pobladores no tenían planeada y tienen que pagar para obtener el título de la vivienda. En este sentido, las familias de menores recursos fueron quienes adquirieron una deuda mayor que las de mayor poder adquisitivo, quienes cubrieron en mayor medida o en su totalidad el costo de las nuevas casas.

Así mismo, en relación a la calidad de vida, quienes habían elegido el lugar por el estilo de vida tranquilo y rural, el hecho de pasar a vivir a un lugar urbanizado, en espacios reducidos y próximos de otras casas, sin agua de riego para la plantación de frutales y huerta, como se mencionaba, les resultó perjudicial; y quienes tenían NBI manifiestan que la solución habitacional les permitió superar la situación de hacinamiento y/o precariedad habitacional, brindándoles la oportunidad de obtener la titularidad de la propiedad e independencia familiar, y por tanto de mejorar la calidad de vida. En la heterogeneidad de la población para unos la calidad de vida significaba una cosa y para otros, otra; así como también se imponía la concepción del gobierno, que en el marco de los parámetros de la construcción sismo resistente y del modelo estético de viviendas que proponía, de acuerdo a la "imagen" de desarrollo que buscaba, menospreciaba las viviendas de adobe o mixtas que los pobladores habían construido conforme a sus gustos, tradiciones, y 
modo de funcionar. De este modo, vemos lo subjetivo del término, que responde a distintas valoraciones por parte de los actores del proceso.

Pese a estas diferencias, según los testimonios de los pobladores, se considera que en la negociación entre el Estado y los afectados existió un acuerdo en relación al tamaño de los terrenos y el tipo de viviendas que finalmente se construyeron, así como en que se brindó a todos los relocalizados la oportunidad de acceder al mismo tipo de vivienda, o sea que, en este sentido, la solución habitacional constituyó un intento de nivelar hacia arriba.

De la población a relocalizar, quienes optaron por una vivienda fuera de Potrerillos, con la intención de acercarse a los centros urbanos, según manifestaron, no todos pudieron adaptarse a las características de los nuevos lugares y decidieron volver a vivir en Potrerillos, pero ya no pudieron acceder a una vivienda en el barrio de quienes fueron relocalizados. En estos casos, el haberse ido del lugar les resultó perjudicial, debido a lo cual, en la actualidad siguen demandando al IPV por la adjudicación de nuevos lotes y la construcción de viviendas.

La urbanización de la nueva villa también impacto en el lugar en otros sentidos. En relación a los relocalizados, significó el aumento del costo de vida por el precio de los nuevos servicios. Esta revalorización del lugar, sumado a la pérdida de trabajo de muchos pobladores -a causa de la obra-, generó en varios casos la venta de las viviendas o la puesta en alquiler y la emigración de los pobladores. Este desplazamiento poblacional se completa con la llegada de nuevos habitantes y/o emprendedores inmobiliarios y turísticos, dinámica que se extiende hacia los parajes altos de Potrerillos, donde el crecimiento se realiza fuera de un marco legal de regulación. En otros términos, el ordenamiento territorial del perilago, aún cuando no se encuentra concluido, propicia un recambio poblacional y promueve en el lugar la instalación de capitales privados, situación que es molesta para algunos fundadores del lugar, denominados colonos, quienes sienten como pérdida la emigración de sus vecinos y como invasión la instalación sin control de los nuevos habitantes e inversionistas.

Finalmente, respecto de los pobladores de Avenida Los Cóndores, apelando a la Ley 4.711/82 de colonización obtuvieron, mediante la práctica de asociarse, el registro de sus propiedades. Se trata de vecinos que lograron comprobar que residían en el lugar desde hacía más de 30, 40 y 50 años y con ello lograron el reconocimiento de derechos y deberes que conlleva la titularización de las tierras. Este proceso, significó para los mismos la posibilidad de quedarse en la zona, así como la oportunidad -a través de la 
posibilidad de acceder a créditos- de insertarse en el desarrollo planificado del lugar a partir de la inversión en proyectos productivos.

Volviendo a los efectos del proceso relocalizatorio, que superan ampliamente el aspecto habitacional, en relación a las economías de subsistencia, si bien desde el IPV, en aquellos casos en que se trataba de familias que dependían de la actividad comercial, les construyó un local en el nuevo barrio o les adjudicó un terreno para la continuidad laboral, estas medidas no alcanzaron -en el inmediato y corto plazo- para evitar que se vieran perjudicados. Debido, por un lado, a que muchos -al igual que en Cacheuta- dependían del tránsito de la Ruta Nacional $\mathrm{N}^{\circ} 7$, arteria que fue desviada, quedando situada a $400 \mathrm{~m}$ aproximadamente del nuevo barrio, al que no ingresaban turistas y visitantes; y por otro lado, a que el Estado no contempló en su planificación programas de acción específicos elaborados en base a estudios de factibilidad social, tampoco el presupuesto en recursos humanos y económicos, como los tiempos necesarios para su ejecución, con el fin de acompañar, asesorar y capacitar a los afectados para la generación de emprendimientos productivos, y/o la cooperativa de servicios turísticos por ellos propuesta.

Como resultado, dependiendo de las condiciones socio-económicas de cada familia, éstas fueron diversamente afectadas, así como disímiles fueron las alternativas contempladas a la hora de readaptar las estrategias de subsistencia en el contexto de inestabilidad y crisis económica e institucional que a nivel nacional se vivía. Esto generó que muchos dejaran el lugar en busca de oportunidades laborales; también fue el motivo de denuncias y demandas públicas de los pobladores solicitando participación en el desarrollo.

En resumen, en relación a las formas de mitigación de los efectos del proyecto, se cumplió con la solución habitacional para quienes fueron relocalizados y la regularización de la tenencia de la tierra para quienes residían en Av. Los cóndores, pero no con los programas de reinserción social y económica en la zona. Esta situación es aprovechada por las empresas que se instalan, benefician de la inversión pública realizada y emplean poca gente del lugar, lo cual deriva en que las ganancias no sean para el lugareño.

De esta forma, el proceso en estudio, que duró varios años de negociaciones, conflictos y resistencias, significó un período material y emocionalmente costoso a nivel individual, familiar y comunitario para los afectados ya que la relocalización, aún cuando se realizó a $500 \mathrm{~m}$ aproximadamente del lugar habitado, implicó la pérdida de las viviendas y otros bienes materiales, como el desarrollo de prácticas domésticas y productivas, siendo vivido por muchos como un desarraigo. Así mismo, estimuló la desorganización de la comunidad y la desintegración de los espacios colectivos de pertenencia de los habitantes; los 
cuales, espontáneamente formaban nuevas redes sociales a fin de contenerse y ayudarse a superar la situación. Estas rupturas, como la reorganización de la comunidad y de la dinámica familiar, según relatan, perjudicaron sobre todo a los adultos mayores.

En función de lo expuesto, se afirman las hipótesis planteadas al inicio de este trabajo, que postulan que los proyectos de inversión y desarrollo, en el marco de la globalización neoliberal, son productores de desplazamiento de poblaciones, y como producciones sectoriales, generan ordenamientos socio-territoriales no democráticos y excluyentes. Así mismo, en relación al caso de estudio, el desarrollo promovido por el Estado provincial para el área circundante a la obra, a partir de la definición de los usos del suelo, propicia la concentración económica y genera desalojos y relocalizaciones, así como la desatención de los sectores afectados.

En este sentido, también se afirman las hipótesis derivadas, que postulan: a) que el Estado provincial a la vez que promueve la integración de una red de capitales privados en las zonas de mayor impacto de la obra, desintegra las redes locales de integración social y económica de los pobladores; b) que la relocalización arbitraria propicia un contexto vulnerable a la manifestación de posteriores migraciones de los afectados; c) que los grupos de escasos recursos socio-económicos son los más expuestos a los efectos negativos del proyecto; y d) que la participación de los afectados en la co-creación de la perspectiva del desarrollo y en su planificación disminuye los efectos negativos evitables de las obras. En relación a esta última, se establece la afirmación en función de que esta co-creación de la perspectiva del desarrollo entre el Estado, los pobladores y demás actores del proceso no existió y por tanto acontecieron los efectos presentados.

Para finalizar, considerando que ubicar temporalmente a las memorias significa aludir en palabras de Jelin al "espacio de la experiencia en el presente" (Jelin, 2002: 13), nos referimos al contexto de realización de esta investigación en que las mismas son evocadas y vemos que se enmarcan dentro de un proceso de ordenamiento territorial, que a 15 años de iniciado, se encuentra frenado por la postergada creación de una autoridad de administración del perilago.

Esto se debe, a disputas por el territorio -entre sectores del Estado, particulares y empresas que han realizado inversiones en la zona-, al igual que a conflictos en torno a la distribución del agua a lo largo de la cuenca del río Mendoza y deriva tanto, en la ausencia de inversiones públicas en obras de infraestructuras y la creación de leyes apropiadas, como en la falta de una instancia formal de participación de los pobladores. 
En decir, a razón de la falta de múltiples definiciones y debates sobre lo público y lo privado, no existe el desarrollo sustentable del que se habla en el proyecto.

En este contexto, las memorias sobre el proceso en estudio, de parte de los pobladores afectados de ambos lugares se asocian a efectos perjudiciales sobre las personas, la comunidad y los lugares, a necesidades insatisfechas, denuncias y demandas surgidas a partir de la intervención estatal, así como a promesas no cumplidas por parte del Estado. En el caso de los funcionarios, se vinculan a resaltar la "gran" obra hidroeléctrica y los méritos de la intervención en el caso de la relocalización, así como al desentendimiento y desatención del impacto de la presa en la localidad de Cacheuta. De esta forma, las memorias de los diversos actores colectivos del proceso hacen evidente una disociación en la planificación del ordenamiento territorial, que piensa la obra sin visibilizar el impacto que pueda tener para las zonas aledañas en término de contenidos y costos sociales. Así también, entre la concepción del desarrollo que expresa y la ejecución del proyecto que realiza. Es decir, manifiestan que el proyecto no concilia, desde sus comienzos, los intereses políticos y económicos con los intereses de los afectados.

En este marco, incorporar en la reconstrucción de los procesos en estudio el relato de la "minoría afectadas", como constituye el caso de los pobladores relocalizados de Villa Potrerillos o aislados de Cacheuta, hace visible la heterogeneidad de actores que son afectados de manera diferente por este tipo de proyectos. En este sentido, resulta pertinente aludir al concepto de "memorias en disputa", esgrimido por Pollak (2006), que resalta la importancia de las "memorias subterráneas" que en nuestro caso serían las de los afectados, que se oponen a la "memoria oficial", que recalca la magnificencia de la obra y considera los efectos sobre los pobladores como un costo colateral del proyecto.

De esta forma, en un contexto de transformaciones socio-territoriales, que en nombre del desarrollo constituye silenciosamente la materialidad de un modelo-sistema injusto supeditado al rumbo del mercado de suelos como a las rentas del capital-, este trabajo nos permiten reflexionar y poner en debate los mecanismos de la intervención estatal realizada sobre las poblaciones afectadas, las consecuencias e implicancias de este tipo de proyecto y el rol del Estado como garante de derechos.

En otros términos, entendemos que la "recuperación del pasado y su utilización subsiguiente" son dos momentos diferentes, que pueden ser leídos de "manera literal o de manera ejemplar" (Todorov, 2000, p.30). En el primer caso, el suceso es preservado en su literalidad, persistiendo con sus causas y consecuencias, así como en las personas vinculadas, sin conducir más allá de sí mismo. En el segundo caso, sin negar la propia 
singularidad del suceso, una vez recuperado, el recuerdo es utilizado como manifestación de una categoría más general, el cual sirve para comprender nuevas situaciones, con otros agentes. En este último caso, el recuerdo se abre a la analogía y relación con otros hechos, es decir, entra en la esfera pública, se constituye en palabra de Todorov (2000) en un "exemplum" del cual se puede extraer una lección (p.31). De este modo, el pasado, basado en semejanzas, se convierte en principio de acción con vistas en el presente, o sea que se vincula al deseo así como a la demanda social de justicia, reconocimiento, etc. En base a estas consideraciones, este trabajo pretende constituir una forma de reminiscencia en su sentido ejemplar, es decir busca aportar al estudio y debate público sobre los efectos del proyecto global partiendo de un caso particular, que guarda similitud con muchos otros casos que se manifiestan a lo largo y ancho del planeta, tanto en el presente, como en el pasado reciente y más lejano como continuidad.

A modo de cierre, y en la búsqueda del planteo y materialidad de un desarrollo diferente, se propone que la reflexión sobre este tipo proyectos de carácter público, se puede iniciar preguntándonos desde el nivel local, en vista a una planificación colectiva: ¿Qué direccionalidad o perspectiva debería tener a fin de involucrar a todos los sectores sociales y nivelar las disparidades existentes entre los mismos? ¿Quiénes deberían planificar y en qué instancias se debería ejecutar tal planificación? ¿Cómo y quiénes deberían evaluarlo, regularlo, reverlo? ¿En qué períodos? En fin, la propuesta invita al quiebre de la reproducción lineal e históricamente incontrolada del sistema injusto, que impone tiempos y reglamentos por medio de las instituciones a fin de justificar, en el marco de la legalidad, prácticas arbitrarias, que acrecientan los capitales de pocos.

En este sentido, se plantea la necesidad de un desarrollo que contemple la escala humana a decir de Mac Neef, Elizalde y Hopenhayn (1986), desde una mirada integral, considerando lo cotidiano, cercano y propio a fin de superar la disociación que se produce al intentar reproducir un modelo ajeno y reducido a lo económico, que manifiesta efectos perjudiciales. Por el contrario, en un marco de participación social y construcción colectiva de conceptos, políticas y prácticas, creemos que la inversión realizada en proyectos de carácter público, deberían presentarse como una oportunidad de superación de ciertas condiciones de las poblaciones involucradas. 


\section{BIBLIOGRAFÍA}

Acordinaro, N. (2009) Desde Luján. Una mirada a los sucesos mendocinos. Biblioteca Municipal Juan Bautistas Alberdi. Municipalidad de Luján de Cuyo. Mendoza.

Arendt, H. (2006) Los Orígenes del Totalitarismo. Alianza Editorial. Madrid.

Arpini, A. (2005) Espacio público, conflictividad y participación. Reflexiones desde América Latina. Guaymallén: Qellqasqa.

Brachetta, M.; Bragoni, B.; Mellado, V. y Pelagatti, O. (2012) Te contamos una historia de Mendoza (de la conquista a nuestros días). Colección Ida y Vuelta. EDIUNC. Universidad Nacional de Cuyo.

Balazote A., Catullo, M.R. y Radovich, J. C. -Org.- (2001) "Introducción” En: Antropología y grandes proyectos en el Mercosur. La Plata: Editorial Minerva.

Balazote A. y Radovich, J. C. (2003) "Grandes represas hidroeléctricas: efectos sociales sobre poblaciones Mapuches en la Región del Comahue, Argentina”. En: Sílvio Coelho dos Santos e Aneliese Nacke -OrgHidrelétricas e povos indígenas. Florianópolis: Letras Contemporáneas.

Barabás, A. y Bartolomé, L. (1992) Antropología y Relocalizaciones. En Reacomodos y construcción de presas; Alteridades, Año 2, Núm.4, Universidad Autónoma Metropolitana, Iztapalapa.

Barone, M. y Fernández, R. (2006). "Relocalización de Poblaciones en Proyectos Hidroeléctricos: Retos y desafíos en el nuevo escenario regional". Ponencia presentada en el IV Congreso Argentino de Presas y Aprovechamientos Hidroeléctricos. Organizado por el Comité Argentino de Presas del 15 al 19 de agosto en Posadas, Misiones. Disponible en: http://www.cadp.org.ar/congresostemastrabajos.php?temaid=8\&anio=2006

Bartolomé, L. (1983b) "El papel de los programas de acción en los procesos de relocalización compulsiva de población". En Revista Interamericana de Planificación, vol.XVII, No 68, p. 115-131.

-(1984a) "Aspectos sociales de la relocalización de la población afectada por la construcción de grandes represas". En Suarez F. Efectos sociales de las grandes represas en América Latina. Montevideo. Fundación Cultura Universitaria para CIDES (OEA)-ILPES (ONU). PP.115-144.

-(1985) "Estrategias adaptativas de los pobres urbanos: el efecto "entrópico" de la relocalización compulsiva". En Bartolomé (coord.) Relocalizados: Antropología Social de las Poblaciones Desplazadas". Ediciones del IDES, Buenos Aires, No3, p.25-48.

-(1989) traducción de: CERNEA, Michael M. (1980): Involuntary Resettlement in Development Projects: Policy Guide-lines in World Bank-Financed Projects, World Bank Technical Paper No 80, Washington. Traducido al español por Leopoldo J. Bartolomé (1989).

-(2001) Combatiendo a Leviatan. La Articulación y Difusión de los Movimientos de Oposición a los Proyectos de Desarrollo Hidroeléctricos en Brasil (1985-91). En Balazote A., Catullo, M.R. y Radovich, J. C. Org.- Antropología y grandes proyectos en el Mercosur. La Plata: Editorial Minerva. Pp. 15-56.

Basualdo, E. (2001). Sistema político y modelo de acumulación en la Argentina. Bernal, Universidad Nacional de Quilmes-FLACSO-IDEP.

Betancur J. (2009) "El segundo saqueo de América Latina: implicaciones para la planeación urbana". En Brand, P. La Ciudad Latinoamericana en el Siglo XXI: globalización, neoliberalismo, planeación. Editor Peter Charles Brand. Medellín: Universidad Nacional de Colombia, Escuela de Planeación Urbano- Regional. ISBN: 978-958-728-018-0 Pp. 83-119.

Brand, P. (2009) "La globalización neoliberal y la planeación urbana: perspectivas para América Latina". En Brand, P. La Ciudad Latinoamericana en el Siglo XXI: globalización, neoliberalismo, planeación. Editor Peter Charles Brand. Medellín: Universidad Nacional de Colombia, Escuela de Planeación Urbano- Regional. ISBN: 978-958-728-018-0 Pp 7-34.

Brunstein, F. - Laurelli, E.- Rofman, A. - Vidal, A. -Comp.- (1989) Grandes inversiones públicas y espacio regional. Experiencias en América Latina. Ediciones CEUR.

Castells M. (2006) La era de la Información. Economía, sociedad y cultura. La sociedad red. Vol I. Siglo XXI Editores. Buenos Aires. 
Catullo, M. R. (1986) "Relocalizaciones compulsivas de población. Estudio de un caso: ciudad Nueva Federación (Entre Ríos)”, en: Runa, Nueva Serie, № XVI, p.137-156.

-(1987) "Identidad comunitaria e identidad barrial en un proceso de relocalización compulsiva de población (Ciudad Nueva Federación, Entre Ríos)". En Proceso de contacto interetnico. Buenos Aires: Ediciones Bermejo.

- (1998/1999) "Proyectos de gran escala en el marco del Mercosur. Clases sociales, intereses sectoriales y brokers en procesos de relocalización". En Cuadernos del Instituto Nacional de Antropología y Pensamiento Latinoamericano N¹8. Buenos Aires. Pp. 69-90.

- (2001) "Poder y Niveles de Decisión en Proyecto de Gran Escala". En: Antropología y grandes proyectos en el Mercosur. La Plata: Editorial Minerva.

- (2001a): "Centralismo, poder regional y participación: la ciudad de Federación; Entre Ríos, Argentina". En: Reis, M.J. y Bloemer, N. (Org), Populações Locais, Projetos de Desenvolvimento e Questões Sócio-ambientais, Editora de la Universidad Federal de Santa Catarina y Editorial Futura, Florianópolis, p. 167-196.

- (2002) "Estudios de Impactos Sociales en el Mercosur. Procesos relocalizatorios, nuevos espacios urbanos y reconstrucción de redes de relaciones sociales", en: Revista de Antropología Social, No 15-16, p. 49-69.

- (2006). Ciudades Relocalizadas: una mirada desde la Antropología Social. Buenos Aires: Biblos.

Catullo, M. R. y Rosato, V. (2015) "Cementerios Británicos: las tumbas británicas en Federación y en Colonia Mandisoví, Entre Ríos", XI Congreso Argentino de Antropología Social 'Edgardo Garbulsky”'. Perspectivas críticas en Antropología Social. Construcciones teóricas y prácticas desde América Latina, Universidad Nacional del Litoral, Rosario, 23 al 26 de julio.

Clark, D. - Fox, J. - Treakle, K. (2005) Derecho a exigir respuestas: Reclamos de la sociedad civil ante el Panel de Inspección del Banco Mundial. Buenos Aires, Siglo XXI Editores Argentina.

COMISIÓN MUNDIAL DE REPRESAS (2000) Represas y Desarrollo: Un Nuevo Marco para la Toma de Decisiones - Una Síntesis de la Comisión Mundial de Represas. Noviembre del 2000.

CONSEJO NACIONAL DE LA VIVIENDA Nº (2002) "Relocalización de la tradicional Villa de Potrerillos". Equipo Social de Gerencia de Evaluación. Gerencia de Planificación Estratégica.

Coronil, F. (2005) "Naturaleza del poscolonialismo: del eurocentrismo al globocentrismo". En La Lander, E. (Comp.) La colonialidad del saber: eurocentrismo y ciencias sociales. Perspectivas latinoamericanas. Buenos Aires: CLACSO.

Cuevas Marín, P. (2005) "Colonialidad y memoria: a propósito del cuerpo y del lugar". En Guaca N². Segundo semestre. Lima.

Declaración de Curitiba. Afirmando el derecho a la vida y a la cultura de las poblaciones afectadas por las represas. Aprobada en el "Primer Encuentro Internacional de Afectados por Represas". Curitiva, Brasil, 14 de marzo 1997.

De Matos, C. (2009). "Modernización capitalista y revolución urbana en América Latina: cinco tendencias genéricas". En Brand, P. La Ciudad Latinoamericana en el Siglo XXI: globalización, neoliberalismo, planeación. Editor Peter Charles Brand. Medellín: Universidad Nacional de Colombia, Escuela de Planeación Urbano-Regional. ISBN: 978-958-728-018-0 Pp.37-82

De Sousa Santos, B. (2009). El fin de los descubrimientos imperiales. En Una Epistemología del Sur: La reinvención del conocimiento y la emancipación social. (pp. 213-224). México: Siglo XXI - CLACSO.

Díaz, E. (2007). Entre la tecnociencia y el deseo. La construcción de una epistemología ampliada. Buenos Aires: Biblos.

Duarte, G; Frotscher, M y Laverdi, R. (comp.) (2011) Desplazamientos en Argentina y Brasil. Aproximaciones en el presente desde la historia oral. Red Latinoamericana de Historia Oral. Buenos Aires: IMAGO MUNDI.

Dussel, E. (2005). Europa, modernidad y eurocentrismo. En Lander, E. (Comp). La colonialidad del saber: eurocentrismo y ciencias sociales. Perspectivas latinoamericanas. (pp. 41-53). Buenos Aires: CLACSO. 
Escobar, A. (1996). La invención del Tercer Mundo. Construcción y deconstrucción del desarrollo. Bogotá: Norma.

- (2005) El lugar de la naturaleza o la naturaleza del lugar: globalización o postdesarrollo? En Lander E. (comp) La colonialidad del saber: eurocentrismo y ciencias sociales. Perspectivas latinoamericanas. Buenos Aires: CLACSO.

Etchemendy, S. (2001). "Construir coaliciones reformistas: la política de las compensaciones en el camino argentino hacia la liberalización económica". En Desarrollo Económico, 160.

Francione, M. - Poggiese, H. A. (1996) Relocalización de la Comunidad Indígena Pilquiniyeu del Limay. Articulación institucional y participación de nuevos asentamientos para la población mapuche de la Provincia de Río Negro, alcanzada por la represa Piedra del Águila. Viedma/Buenos Aires. FLACSO.

Ferrarotti, F. (1990). La historia y lo cotidiano. (1 ${ }^{\mathrm{a}}$ ed. $2^{\mathrm{a}}$ reimp.) Buenos Aires: Centro Editor de América Latina.

-(2007) "Las historias de vida como método". En: Convergencia. Revista de Ciencias Sociales. UAEM, México. Núm 44, mayo-agosto 2007, pp. 15-40.

Fundación PROTEGER. Disponible en: http://www.proteger.org.ar/

Gago, A. (1995). El espacio regional como escenario de los procesos de globalización. La región de Cuyo en los noventa. Estudios Regionales N43, PP 117-149.

- (1999). Rupturas y conflictos en la historia económica de Mendoza. Acumulación, instituciones, relaciones sociales y poder. Argentina: Publicaciones CEIR Mendoza. ZETA Editores.

Geertz, C. (1995). "La ideología como sistema cultural". En: La interpretación de las culturas. Gedisa, Barcelona.

Gellert, P. K., \& Lynch, B. D. (2003). Mega-projects as displacements. International Social Science Journal, 55(175), 15-25. ISSJ 175rUNESCO2003. Published by Blackwell Publishing Ltd., 9600 Garsington Road, Oxford OX42DQ,UKand 350 Main Street, Malden,MA02148, USA

Ginestar, A. (2001) Pautas para identificar, formular y evaluar proyectos. Buenos Aires: Asociación Argentina de Evaluación. Programa Interamericano sobre Proyectos de la Secretaría General de la Organización de los Estados Americanos OEA. CICAP-Uruguay Centro Interamericano de Cooperación y Capacitación.

GOBIERNO DE MENDOZA. Ministerio de Ambiente y Obras Públicas. Presa Potrerillos. Síntesis de la Manifestación General de Impacto Ambiental. Sistema de Información Pública (En cumplimiento de la Ley 5.961 Art.33; Decreto 2.109/94 Art. 19²). Los Andes. 13 de diciembre de 1998.

GOBIERNO DE MENDOZA. Ministerio de Ambiente y Obras Públicas. Dirección de Ordenamiento Ambiental y Desarrollo Urbano. Proyecto Potrerillos. Plan de Ordenamiento y Gestión territorial. Proyecto de desarrollo turístico y recreativo Aprovechamiento Integral del Río Mendoza. Primer Informe. Mendoza. Noviembre, 2000.

GOBIERNO DE MENDOZA. Ministerio de Ambiente y Obras Públicas. Decreto №1825 con fecha 31 de agosto del 2000.

GOBIERNO DE MENDOZA. Ministerio de Ambiente y Obras Públicas. Resolución N¹046 del IPV con fecha 20 de septiembre del 2001.

GOBIERNO DE MENDOZA. Instituto Provincial de la Vivienda. Resolución $N^{\circ} 499$ del 16 de julio de 2002.

GOBIERNO DE MENDOZA. Ministerio de Turismo y Cultura. Cultura x Mendoza. Plan Estratégico 2005-2010. Recuperado el 13 de mayo de 2013 de http://www.cultura.mendoza.gov.ar/archivos/legislacion/plancultural.pdf

Gray de Cerdán, N. (2000) Propuesta general de ordenamiento del uso del suelo. 1ra Parte: La Nueva Ciudad Cabezera - El proceso de relocalización. En GOBIERNO DE MENDOZA. Ministerio de Ambiente y Obras Públicas. Dirección de Ordenamiento Ambiental y Desarrollo Urbano. Proyecto Potrerillos. Plan de Ordenamiento y Gestión territorial. Proyecto de desarrollo turístico y recreativo Aprovechamiento Integral del Río Mendoza. Primer Informe. Mendoza. Noviembre, 2000. 
-(2003) Villa Potrerillos, una nueva ciudad creada por proceso de relocalización de población. Centro de Estrategias Territoriales para MERCOSUR (CETEM). Dpto. Geografía. Facultad de Filosofía y Letras. U. N. Cuyo. En Noticias y Comentarios. Estudios Geográficos, LXIV, 251, 2003.

-(2005). Repensando el Gran Mendoza. Estrategias de desarrollo urbano. Argentina, Mendoza: Editorial de la Universidad Nacional de Cuyo.

Grosso, V. y Raffani, M. (2013) "Territorios de progreso y territorios de escasez. La apropiación y distribución del agua en la cuenca del río Mendoza, Argentina”. En Revista HUELLAS. №17. Publicación del Instituto de Geografía. Facultad de Ciencias Humanas. UNLPam. Miño y Dávila Editores.

Gudiño de Muñoz, M. (2002). "Impacto de la obra "Presa Potrerillos" en los habitantes de la villa y su entorno inmediato". En Proyección N²/2002 Centro de Investigación y Formación para el Ordenamiento Territorial (CIFOT). FFyL. UNCuyo.

Gudiño, M. E., D’Inca M. V., Reyes Paecke, S. \& Rivas, M. (2005). Estrategias de integración y transformaciones metropolitanas. Mendoza: EDIUNC.

Halbwachs, M. (2004). La memoria colectiva, Zaragoza: Universidad de Zaragoza.

- (2002). Los marcos sociales de la memoria. Universidad de Concepción-Universidad de VenezuelaANTHROPOS

Jelin, E. (2003). Monumentos, memoriales y marcas territoriales. Madrid: Siglo XXI. - (2001). Los trabajos de la memoria. Madrid: Siglo XXI.

Jofré, J. L. (s/f). Obras sanitarias mendoza: de Empresa privada a pública. En Plataforma de Información para políticas públicas. Disponible en: www.politicaspublicas.uncu.edu.ar

Lacoste, P. (1998). "El proyecto del dique Potrerillos". En Grandes Obras de Mendoza. Aportes para el estudio de la Historia de la Ingeniería y el Turismo con especial referencia al Corredor Andino. Serie Humanidades y Ciencias Sociales NN5. Diario Uno. Mendoza.

-(2000) El Ferrocarril Trasandino. 1872-1984. Un siglo de ideas, política y transporte en el sur de América. Santiago: Editorial Universitaria.

Lafalla, A. (2010). Utopía y realidad. Testimonio de un gobernador (1995-1999). Mendoza: EDIUNC.

Lefebvre, H. (1974/2000) La production de l'espace. 4ª edición. Anthropos.

Lentini, M. (2008). Transformaciones de la cuestión social habitacional: principales enfoques y perspectivas. El caso de Argentina en el contexto latinoamericano. En Economía, sociedad y territorio, vol. VIII, núm. 27, mayo-agosto, 2008 pp.661-692 El colegio Mexiquense, A.C. México. En Redalyc Sistema de Información Científicos. Red de Revistas Científicas de América Latina, el Caribe, España y Portugal. www.redalyc.org - (2009). "El estudio de caso/s como estrategia de enseñanza-aprendizaje y de investigación: su potencialidad para abordar la complejidad desde perspectivas interdisciplinarias". Ponencia presentada en el XV Encuentro de la Red ULACAV (Red latinoamericana de Cátedras Universitarias de Vivienda). Organizado por la Facultad de Arquitectura-Universidad Nacional del Nordeste del 9 al 11 de set. en Resistencia, Chaco.

Lentini, M. y Palero, D. (1997a) "El hacinamiento: la dimensión no visible del déficit habitacional”. En Boletín INVI N³2. Chile, Agosto. Volumen 12, pp 23-32.

- (1997b) "Hacinamiento y vida familiar: la necesidad de independencia habitacional". En Boletín INVI $N^{\circ}$ 32. Chile, Noviembre. Volumen 12, pp 111-117.

Lins Ribeiro, G. (1987). “¿Cuánto más grande mejor? Proyectos de gran escala: una forma de producción vinculada a la expansión de sistemas económicos”. En Desarrollo Económico. Vol.27, №105, Abril-Junio. IDES, Buenos Aires.

Mac Neef, M., Elizalde, A. y Hopenhayn, M. (1986). Desarrollo a escala humana, Development dialogue, número especial. Fundación Dag Hammarskjold, Uppsala, Suecia.

Mairal Buil, G. (1996) "Recordar para sobrevivir o la memoria colectiva en acción". Revista de Antropología Social, $n^{\circ}$. Servicio de Publicaciones, UCM. Pp: 65-82. -(1993) "Perder el Pueblo. Antropología aplicada y Política Hidráulica". Revista de Antropología Social, $n^{\circ}$ 2. Madrid: Editorial Complutense. Pp: 185-237. 
Marre, M.; Díaz Araujo, E.; Barbosa, M. C.; Mohando, A.; Faro, B.; Reta, J.; Medalla, A. (2007) Proy. Aspectos críticos de la organización político institucional y de la administración del servicio de agua potable en Mendoza. Cód. 06/F-180. Informe final. Proyectos bienales 2005-2007. UNCuyo. Mímeo.

Marx, K. 1946. El Capital, Crítica de la Economía Política. Tomo I: Fondo de Cultura Económica. México.

Maza, J. I. (1990). “Departamento de Luján”. En Toponimia, tradiciones y leyendas mendocinas. Fundación Banco de Boston. Argentina.

Mignolo, W. (Comp.). (2001). Introducción. En Capitalismo y geopolítica del conocimiento. El eurocentrismo y la filosofía de la liberación en el debate intelectual contemporáneo. (pp. 9-53) Buenos Aires: Del signo.

- (2002) Colonialidad global, capitalismo y hegemonía epistémica. En Walsh, C., Schiwy, F. y Castro-Gómez, S. (Eds). Indisciplinar las ciencias sociales. Geopolíticas del conocimiento y colonialidad del poder. Perspectivas desde lo andino. (pp. 215-244) Quito: Universidad Andina Simón Bolívar. ABYA-YALA. - (2003). Historias locales/diseños globales. Colonialidad, conocimientos subalternos y pensamiento fronterizo. Madrid: AKAL.

Mignolo W. y Tlostanova M. (s.f.). Habitar los dos lados de la frontera/teorizar en el cuerpo de esa experiencia. Revista Ixchel.org. Asociación de Literatura Comparada en América Central y el Caribe. ISSN: 1659-391X. Disponible en: http://www.revistaixchel.org/volumen-i/teoria-literaria/47.

Montaña, E; Torres, L; Abraham, E; Torres, E; Pastor, G. (2005). "Los espacios invisibles. Subordinación, marginalidad y exclusión de los territorios no irrigados en las tierras secas de Mendoza, Argentina" en Revista Región y sociedad. Vol. XVII, N³2. 2005. pp 1-32.

Morgani, R. y Raffani, M. (2012) “Mendoza y los orígenes de la ciudad neoliberal” En: Tiempo y Espacio 28. Universidad del Bio Bio: Chillán, Chile. Pp.55-75. Disponible en: http://www.ubiobio.cl/miweb/web2012.php?id_pagina=6462

Müller, A. (2012). "Hacia un nuevo paradigma: el necesario regreso de la planificación energética". V Jornadas de Economía Crítica. La crisis global como crisis del pensamiento económico. 23, 24 y 25 de agosto de 2012. FCE. UBA.

NACIONES UNIDAS (2007). Aplicación de la Resolución 60/251 de La Asamblea General, de 15 de marzo de 2006, titulada "Consejo de Derechos Humanos". Informe Del Relator Especial sobre una vivienda adecuada, como parte del derecho a un nivel de vida adecuado, Miloon Kothari. Disponible en: http://www.onuhabitat.org/index.php?option=com docman\&task=cat view\&gid=79\&ltemid=70

Nora, P (1984) Introducciones a Les Lieux de Mémoire. París: Gallimard. Traducción en español.

Novaro, M. (2006). Historia de la Argentina Contemporánea. De Perón a Kirchner. Buenos Aires, Ednasa. Cap. 7 a 12.

Nuñez, A (2009). De la alienación, al derecho a la ciudad. Una Lectura (posible) sobre Henri Lefebvre. Revista THEOMAI Estudios sobre Sociedad y Desarrollo. Numero 20, segundo semestre 2009. Disponible en: http://www.revista-theomai.unq.edu.ar/numero20/ArtNunez.pdf

Ostuni, J. (2011). La dinámica espacial del desarrollo del Gran Mendoza, particularmente de su núcleo. Editorial de la Facultad de Filosofía y Letras de la Universidad Nacional de Cuyo.

Oslender, U. (2002) "Espacio, lugar y movimientos sociales: hacia una "espacialidad de resistencia". En Scripta Nova. Revista electrónica de geografía y ciencias sociales. Universidad de Barcelona, 2002, Vol. VI, No 115.

Pastoriza, E. (2011) La conquista de las vacaciones. Breve historia del turismo en Argentina. Buenos Aires: edhasa.

Perez, G.; Muglia, N y Rossi S. (2000) Compensación del patrimonio comprometido por el llenado del lagoembalse. En GOBIERNO DE MENDOZA. Ministerio de Ambiente y Obras Públicas. Dirección de Ordenamiento Ambiental y Desarrollo Urbano. Proyecto Potrerillos. Plan de Ordenamiento y Gestión territorial. Proyecto de desarrollo turístico y recreativo Aprovechamiento Integral del Río Mendoza. Primer Informe. Mendoza. Noviembre, 2000. 
Pintos, P. (2005). La espacialidad de la resistencia social: entre la visibilidad en las calles y la acción en el territorio. Notas sobre la espacialidad piquetera en la Argentina reciente. En Reflexiones geográficas. № 11. Abril de 2005. Agrupación de Docentes Interuniversitarios de Geografía.

Polanyi, K. (1992) La Gran transformación. Los orígenes políticos y económicos de nuestro tiempo. Fondo de Cultura Económica. México.

Pollak, M. (2006). Memoria, olvido, silencio. La producción social de identidades frente a situaciones límite. La Plata: Al Margen.

PRESIDENCIA DE LA NACIÓN. Instituto Nacional de Estadística y Censos INDEC, Censo 2010. Disponible en: (http://www.censo2010.indec.gov.ar/preliminares/cuadro_mendoza.asp).

PROGRAMA DE LAS NACIONES UNIDAS PARA EL DESARROLLO UNDP (2000), "Derechos que facultan a las personas para combatir la pobreza”. Madrid. Barcelona. México: Ediciones Mundi-Prensa.

PROVINCIA DE MENDOZA (1938). 3 años de gobierno. Guillermo Cano. Febrero 1935-1938. D’Accurzio: Mendoza.

Radovich, J. C. (2005). "Ideología de grandes proyectos en la Región Comahue, Argentina”, en: Disputas territoriales y conflictos interétnicos en Brasil y Argentina. Córdoba: Ferreyra Editor.

Raffani, M. (2013) "El desalojo y relocalización en el proyecto de inversión y desarrollo de la Presa Potrerillos de Mendoza, Argentina”. En Revista Cuaderno Urbanos. Espacio, cultura y sociedad 14. Nobuko/EUDENE. Editorial de la Universidad Nacional del Nordeste. Junio 2013.

RED DE OBSERVATORIOS DE CUYO. Informe Anual. Perspectivas 2012. Diagnóstico 2011. Recuperado el 08 de mayo de 2013 de http://www.observatoriosdecuyo.com/categorias/index/documentos-de-la-red-deobservatorios-de-cuyo

Rehnfeldt, M. (2003) "Las tinieblas envuelven la Tierra. La construcción de la Hidroeléctrica Yacyretá y la relocalización de los indígenas Mbyá Guaraní del Mbaepú”. En: Sílvio Coelho dos Santos e Aneliese Nacke Org- Hidrelétricas e povos indígenas. Florianópolis: Letras Contemporáneas.

Roig, A. (2008). El pensamiento latinoamericano y su aventura. (pp. 131-162). Buenos Aires: El Andariego.

Sassen, S. (2007). Una Sociología de la globalización. Discusiones / Katz. Buenos Aires: Katz.

Scudder, T. Y Colson, E (1982). "From Welfare to Development: a Conceptual Framework for the Analysis of Dislocated People". In Involuntary Migration and Resettlement. The Problems and Responses of Dislocated People, (A Hansen y A. Oliver-Smith, comps.) Boulder, Colorado: Westview-Press.

Svampa, M. (2004) "Fragmentación espacial y procesos de integración social hacia arriba: socialización, sociabilidad y ciudadanía". Espiral, setiembre-diciembre año/vol. XI, número 031. Universidad de Guadalajara. México. Pp. 55-84.

Therburg, A; Fasciolo, G; Comellas, E; Zuloaga, J. Y Gudiño, M.E. (2004). Marco estratégico para la provincia de Mendoza. Diagnóstico físico- ambiental. UNCu. Mendoza.

Todorov, T. (2000) Los abusos de la memoria. Paidós. Barcelona.

Trapé, A.; Botteon, C.; Lara, M. I. \& Serio, M. (2011) Pobreza y Distribución del Ingreso en Mendoza (19802010). Proyecto de investigación científica y técnica orientado (PICTO). Facultad de Ciencias Económicas. UNCuyo.

Valles M. (1999) Técnicas cualitativas de investigación social. Reflexión metodológica y práctica profesional. Madrid: Síntesis.

Vasilachis De Gialdino, I. (2008). "Los fundamentos epistemológicos de la investigación cualitativa". En Cohen, N. y Piovani, J. I. (comp.) La metodología de la investigación en debate. (pp. 197-218). La Plata: Universidad Nacional de La Plata. 
Villegas de Lillo, B. (2002) Todo cambia. Potrerillos también y tiene su historia. En Proyección N²/2002 Centro de Investigación y Formación para el Ordenamiento Territorial (CIFOT). FFyL. UNCuyo.

\section{Material audiovisual}

"el cuarto oscuro: 6mm3" (2005) Director: Tomás Ochoa.

"Construcción de una ciudad" (2007) Director y Productor: Néstor Frenkel.

\section{Fuentes periodísticas}

Los Andes, 26-8-1984 "Pasado y futuro de un lugar privilegiado. Termas de Cacheuta". Sección Dominial. Pp. 4 y 5. Los Andes, 06-04-1997 "Sin la venta de EMSE no hay construcción de Potrerillos". Los Andes, 20-05-1997 "El senado aprobó la privatización de EMSE". Los Andes, 29-05-1997 "Privatizarán EMSE". Los Andes, 19-03-1997 "Privatización de EMSE y ejecución de Potrerillos". Los Andes, 22-10-1997 "Al fin, anunciaron la construcción de Potrerillos". Los Andes, 5-12-1997 "Acuerdo para construir la presa de Potrerillos". Los Andes, 30-12-1997 "La legislatura votó a favor del dique Potrerillos". Los Andes, 12-06-1998 "El consorcio ganador aseguró que hoy pagará los U\$S 150 millones". Los Andes, 13-06-1998 "Pagó el adjudicatario y se le transfirió OSM". Los Andes, 24-06-1998 "Dan por EDEMSA U\$S 237 millones".

Los Andes, 28- 07-1998 "Potrerillos dejará sin casa a 150 familias". Los Andes, 27-04-1999 "Después de casi un siglo el dique potrerillos es una realidad". Los Andes, 07-05-1999 "El pueblo de Potrerillos quiere seguir viviendo junto a su río". Los Andes, 08-07-1999 "Elaborarán un proyecto de relocalización. En 90 días deciden el destino de la villa de Potrerillos".

Los Andes, 02-08-1999 "Diputados defienden a vecinos de Potrerillos".

Los Andes, 25-11-2001 "Vecinos del dique temen mudarse".

Los Andes, 11-12-2001 "La obra del siglo. Acto de inauguración".

Los Andes, 30-01-2002 "La nueva villa de Potrerillos está lista pero nadie se puede mudar". Los Andes, 04-03-2002 "El agua ya borra la vieja ruta a Potrerillos". Los Andes, 19-04-2002 "El agua reaviva antiguas disputas por las tierras de Potrerillos". Los Andes, 10-07-2002 "Desarman y trasladan piedra por piedra la vieja estación de Potrerillos". Los Andes, 22-09-2002 "Luján quiere cobrar por Potrerillos".

Los Andes, 03-10-2002 "Pobladores de Potrerillos piden cuidar la cultura local".

Los Andes, 18-05-2003 "Dos distritos aislados tras la construcción del dique Potrerillos"

Los Andes, 29-06-2003 "Potrerillos tampoco se podrá disfrutar el próximo verano". Los Andes, 29-09-2004 "Nueve colonos de Potrerillos obtendrán el título de sus tierras". Los Andes, 27-08-2005 "Una ruta bordeará el lago y unirá otra vez a Cacheuta y Potrerillos". Los Andes, 18-08-2005 "La venta de terrenos traba la creación del Ente de Potrerillos". Los Andes, 25-03-2007 "Detrás de la pelea por el perilago de Potrerillos hay un negocio millonario". Los Andes, 28-06-2008 "Potrerillos: todos quieren la costa pero por ahora es zona prohibida". Los Andes, 27-11-2010 "Promesas en Potrerillos: ruta del perilago, petit hotel y balneario" Los Andes, 22-04-2012 "Otro reclamo en Cacheuta para que terminen la ruta del lago".

UNO, 31-12-1997 "Potrerillos quedó para 1998".

UNO, 29-12-1998 "Potrerillos empieza a ser realidad".

UNO, 19-09-2001 "Buscan inversores para Potrerillos".

UNO, 07-02-2002 "Temor en Potrerillos porque dicen que los dejarán aislados".

UNO, 03-10-2002 "Vecinos piden participar en el diseño de Potrerillos".

UNO, 15-10-2002 "Nadie se encarga del turismo en Potrerillos".

UNO, 14-05-2003 "Pataleo vecinal en Potrerillo".

UNO, 16-08-2005 "Debaten la ley para regular el negocio costero de Potrerillos". 


\section{ANEXOS}

Especial Potrent

DIQUE POTRERILLOS

DATOS TECNICOS*

\begin{tabular}{|c|c|}
\hline Superficie del perilago y tierras fiscales adyacentes & 3.350 ha. \\
\hline Niveles del embalse & $\begin{array}{l}\text { Cota máxima de operación (vertedero): } 1.377,30 \text { m.s.m. } \\
\text { Cota de mínima operación: } 1.340 \text { m.s.m } \\
\text { Cota máxima extraordinaria: } 1381,70 \text { m.s.m }\end{array}$ \\
\hline Superficie del embalse & $\begin{array}{l}\text { En cota mínima de operación: } 555 \text { ha. } \\
\text { En cota máxima extraordinaria: } 1.474 \text { ha. }\end{array}$ \\
\hline Volúmen del embalse & En cota máxima normal: $420 \mathrm{Hm}^{3}$ \\
\hline Caracteristicas de la presa & $\begin{array}{l}\text { Alto: } 114 \text { metros } \\
\text { Largo } 470 \text { metros } \\
\text { Tipo: de material suelto con núcleo seco } \\
\text { Vertedero: tipo Morning Glory }\end{array}$ \\
\hline Profundidad & Máxima: 107 metros \\
\hline Dimensiones del embalse & $\begin{array}{l}\text { Ancho máximo: } 3 \mathrm{~km} \text {. } \\
\text { Largo máximo: } 12 \mathrm{~km} \text {. }\end{array}$ \\
\hline Fluctuación del nivel de embalse & $37,30 \mathrm{~m}$. (entre cotas máxima y minima de operación) \\
\hline Superficie máxima de banda árida & $\begin{array}{l}919 \text { ha. (entre cotas máxima extraordinaria y mínima de } \\
\text { operación) }\end{array}$ \\
\hline Fecha de inicio de llenado & Diciembre de 2.001 (previsto) \\
\hline Tiempo de llenado & 4 años (estimación, según caudales) \\
\hline Actividad económica dominante & Servicios turísticos locales, administración pública \\
\hline $\begin{array}{l}\text { Aptitud de usos } \\
\text { (superficies) }\end{array}$ & $\begin{array}{l}\text { Área Urbana: } 418,02 \text { ha. } \\
\text { Área turístico- recreativa: } 412,42 \text { ha. } \\
\text { Área complementaria: } 73,89 \text { ha. } \\
\text { Área de restricción especial: } 2.137,35 \text { ha. } \\
\text { Total Área Zonificada: } 3.041,68 \text { ha. }\end{array}$ \\
\hline
\end{tabular}

* Fuente: Ministerio de Medio Ambiente y Obras Públicas, Subsecretaría de Medio Ambiente, Dirección de Ordenamiento Ambiental y Desarrollo Urbano Gobierno de Mendoza

Fuente: Ministerio de Ambiente y Obras Públicas, Secretaría de Medio Ambiente, Dirección de Ordenamiento Ambiental y Desarrollo Urbano. Gobierno de Mendoza. 

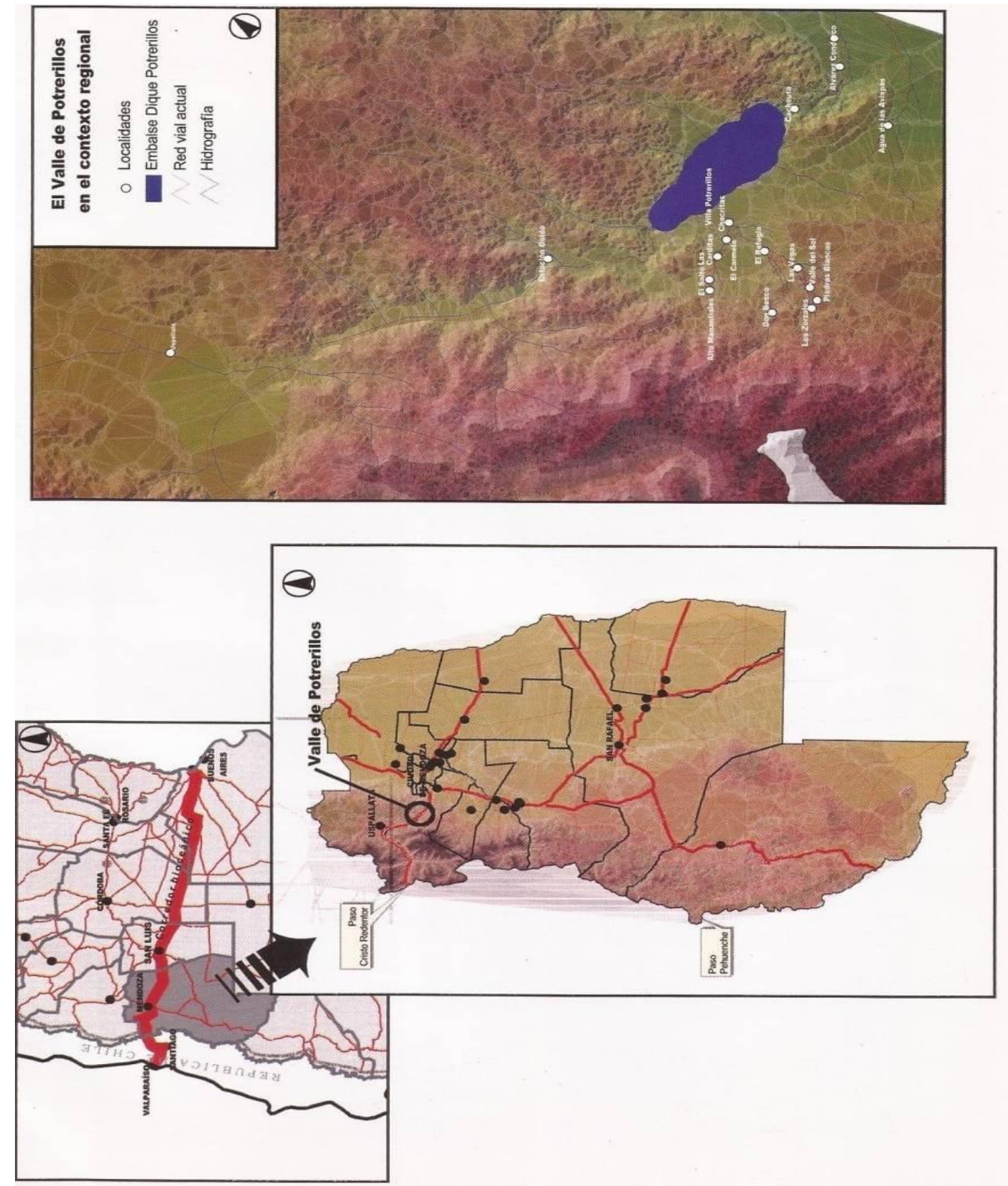

Fuente: Cartografías elaboradas por el CIFOT. En Proyección `2 - 2002. 


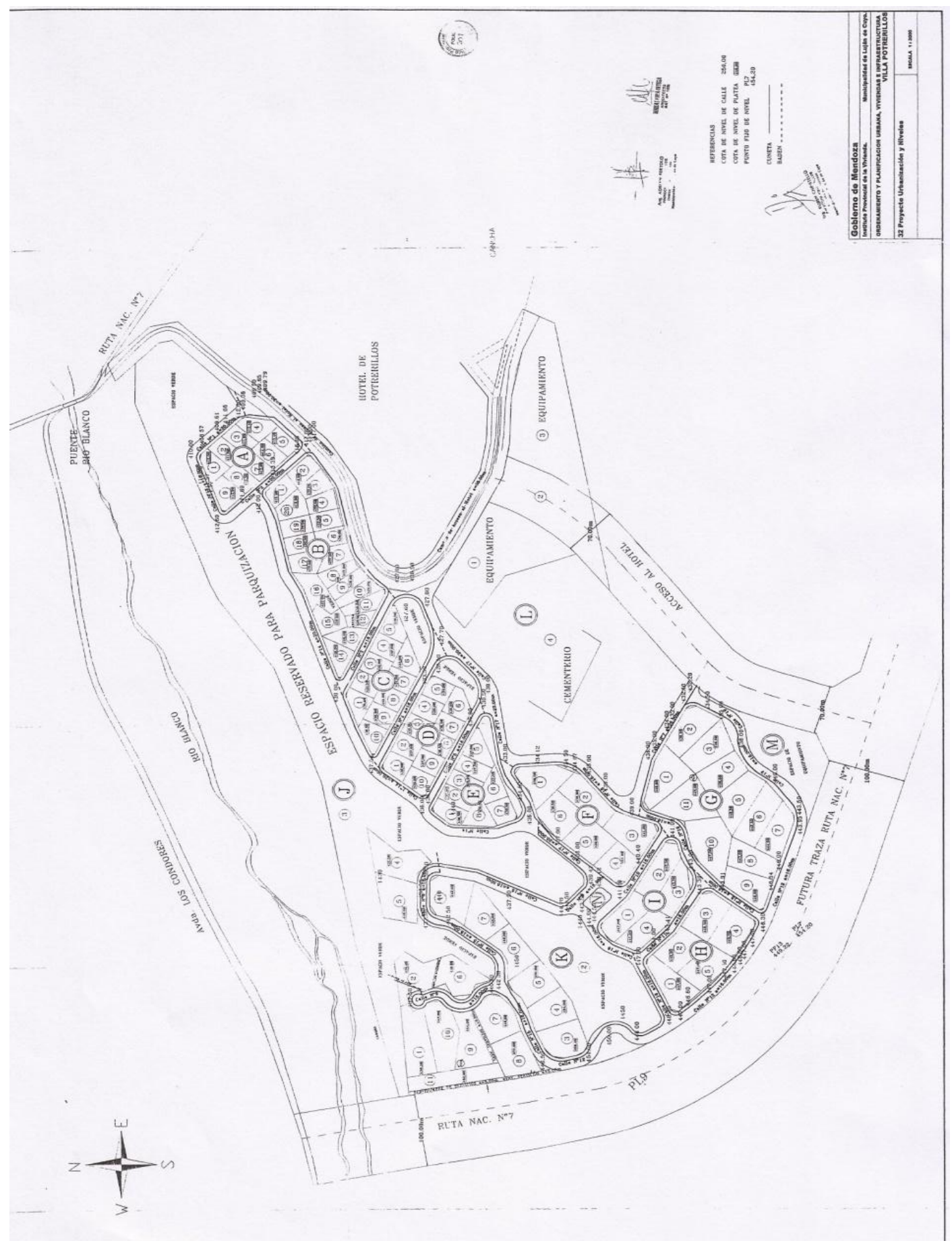

Fuente: Ordenamiento y planificación urbana, viviendas e infraestructura Villa Potrerillos. Instituto Provincial de la Vivienda - Municipalidad de Luján de Cuyo. Gobierno de Mendoza. Archivo del IPV. Gobierno de Mendoza. 


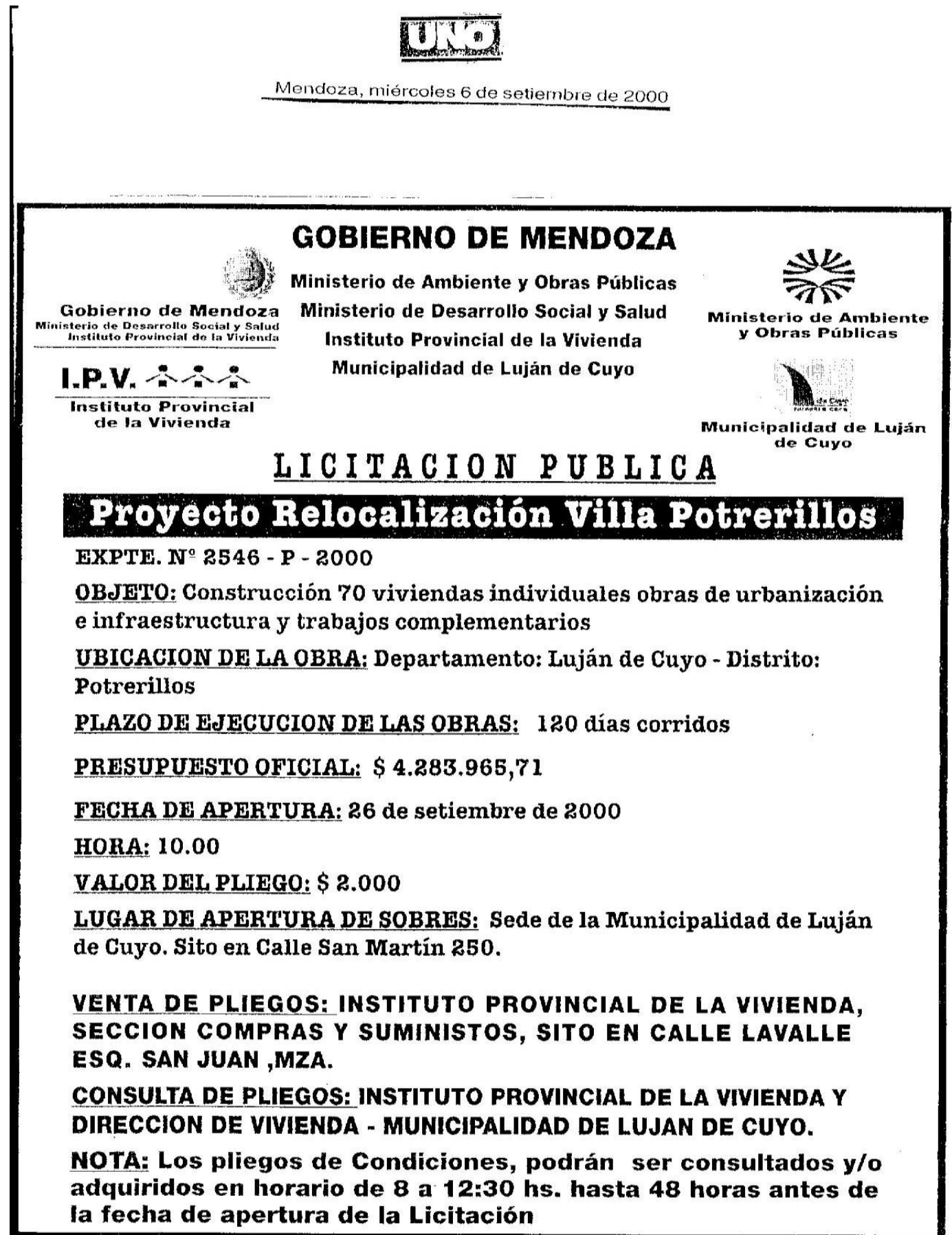

Fuente: UNO, 06/09/2000. 